Supporting Information

\title{
Visible Light Enhanced Cobalt-Catalyzed Hydrogenation: Switchable Catalysis Enabled by Divergence Between Thermal and Photochemical Pathways
}

Lauren Mendelsohn, Connor S. MacNeil, Lei Tian, Yoonsu Park, Gregory D. Scholes, and Paul J. Chirik*

Department of Chemistry, Frick Laboratory

Princeton University, Princeton, NJ 08544, USA

pchirik@princeton.edu

\section{Table of Contents}

$\begin{array}{ll}\text { I. General Considerations } & \text { S2 }\end{array}$

II. General Catalytic Hydrogenation Procedures and Products S6

$\begin{array}{ll}\text { III. Spectrometric Data } & \text { S16 }\end{array}$

IV. Measurement of Quantum Yield $\quad$ S19

$\begin{array}{ll}\text { V. Specific Experimental Details } & \text { S23 }\end{array}$

VI. Transient Absorption Spectroscopic Data $\quad$ S35

$\begin{array}{ll}\text { VII. Computational Analyses } & \text { S40 }\end{array}$

VIII. Coordinates and Energies of Optimized Geometries S41

IX. Spectroscopic Data $\quad$ S51

$\begin{array}{lrr}\text { X. References } & \text { S154 }\end{array}$ 


\section{General Considerations}

All air- and moisture-sensitive manipulations were carried out using vacuum line, Schlenk and cannula techniques or in an MBraun inert atmosphere (nitrogen) dry box unless otherwise noted. All glassware was stored in a pre-heated oven prior to use. The solvents used for airand moisture-sensitive manipulations were dried and deoxygenated using literature procedures. ${ }^{1}$ Celite was dried at $180{ }^{\circ} \mathrm{C}$ under vacuum for 3 days prior to use. Deuterated solvents for NMR spectroscopy were distilled from sodium metal under an atmosphere of argon and stored over $4 \AA$ molecular sieves. $(R, R)^{\mathrm{iPr}}{ }^{\mathrm{D}} \mathrm{DuPhos} \mathrm{Co}(\mathrm{CO})_{2} \mathrm{H}, \mathbf{1}$, and $[(R, R)$ $\left.{ }^{\text {iPrDuPhosCo}}(\mathrm{CO})\left(\mu^{2}-\mathrm{CO}\right)\right]_{2}$, 2, were prepared according to literature procedures. ${ }^{2,3}(R, R)$ ${ }^{\mathrm{iPr}}$ DuPhos was purchased from Strem Chemicals and used as received.

All olefins, unless otherwise noted, were purchased from Sigma Aldrich and used without further purification. All olefins that are liquids at room temperature were placed over activated 4 A molecular sieves in a thick-walled vessel. On a high vacuum line, the olefin was subjected to 3 freeze-pump-thaw cycles. The olefin was left to dry over the sieves overnight in the vessel. The next day, the olefin was subjected to several more freeze-pump-thaw cycles until there was no deflection of the line vacuum. All olefins that are solids at room temperature were dried in a vacuum adapted round-bottom flask on the high vacuum line overnight.

${ }^{1} \mathrm{H}$ NMR spectra were recorded on either Bruker AVANCE 400 or 500 spectrophotometers operating at $399.80 \mathrm{MHz}$, and $500.46 \mathrm{MHz}$, respectively. ${ }^{2} \mathrm{H}$ NMR spectra were recorded on a Bruker AVANCE 400 spectrometer operating at $61.42 \mathrm{MHz} .{ }^{13} \mathrm{C}$ NMR spectra were recorded on either Bruker AVANCE 300 or 500 spectrometers operating at $100.54 \mathrm{MHz}$ and $125.85 \mathrm{MHz}$, respectively. ${ }^{31} \mathrm{P}$ NMR spectra were acquired on either Bruker 400 or 500 AVANCE spectrometers operating at $161.84 \mathrm{MHz}$ or $202.40 \mathrm{MHz}$, respectively. All ${ }^{1} \mathrm{H}$ and ${ }^{13} \mathrm{C}$ NMR chemical shifts are reported in ppm relative to $\mathrm{SiMe}_{4}$ using the ${ }^{1} \mathrm{H}$ (benzene- $d_{6}: 7.16 \mathrm{ppm}$ ) and ${ }^{13} \mathrm{C}$ (benzene- $d_{6}$ : $128.06 \mathrm{ppm}$ ) chemical shifts of the solvent as a standard. ${ }^{1} \mathrm{H}$ NMR data for diamagnetic compounds are reported as follows: chemical shift, multiplicity $(s=$ singlet, $d=$ 
doublet, $\mathrm{t}=$ triplet, $\mathrm{q}=$ quartet, $\mathrm{p}=$ pentet, $\mathrm{br}=$ broad, $\mathrm{m}=$ multiplet, app $=$ apparent, obsc $=$ obscured), coupling constants $(\mathrm{Hz})$, integration, assignment. ${ }^{1} \mathrm{H}$ NMR data for paramagnetic compounds are reported as follows: chemical shift, integration, peak width at half height $(\mathrm{Hz})$. ${ }^{13} \mathrm{C}$ NMR data for diamagnetic compounds are reported as follows: chemical shift, number of protons attached to carbon (e.g. $\mathrm{CH}_{2}$ ), assignment.

Absorption spectra were recorded on a Cary 60 UV-Vis spectrometer (Agilent Technologies, Santa Clara, California). Absorption measurements were done using a $2 \mathrm{~mm}$ cuvette fitted with a J. Young valve and sealed with a Teflon cap prepared in a $\mathrm{N}_{2}$-filling glove box, for which the maximum absorbance in the visible region of the solution was never above $0.5 \mathrm{OD}$. The emission spectra of LEDs were measured using a visible-nearlR optical fiber in conjunction with an Ocean Optics USB4000 miniature spectrometer. The excited-state lifetime of 1 was determined using femtosecond transient absorption spectroscopy. A $1 \mathrm{kHz}$ regeneratively amplified Ti:Sapphire laser (Coherent Libra, Santa Clara, California) with a commercial optical parametric amplifier (OPerA Solo, Vilnius, Lithuania) and commercial transient absorption spectrometer (Ultrafast Systems Helios, Sarasota, Florida) were used with a detailed setup description reported previously. ${ }^{4}$ In brief, the output pulse of the Ti:Sapphire laser Coherent Libra, centered at $800 \mathrm{~nm}$ with a duration of ca. $45 \mathrm{fs}$ and pulse power of $4 \mathrm{~W}$, is split with a 90 $10(\mathrm{r}-\mathrm{t})$ beamsplitter to generate the pump and probe. The reflected portion of the output $800 \mathrm{~nm}$ is directed into the commercial optical parametric amplifier OperA Solo to generate light at 400 $\mathrm{nm}$ and $420 \mathrm{~nm}$. Both the ouput of the OperA Solo and transmitted portion of the output $800 \mathrm{~nm}$ are directed into a commercial transient absorption spectrometer Helios. The pump pulse is chopped at $500 \mathrm{~Hz}$ with its polarization controlled by a broadband $\lambda / 2$ waveplate and then focused into the sample position. The remaining $800 \mathrm{~nm}$ is mechanically delayed and then focused into a $2 \mathrm{~mm}$ thick translating $\mathrm{CaF}_{2}$ crystal to generate a white light continuum from 325 $\mathrm{nm}$ to $800 \mathrm{~nm}$ with its intensity and polarization controlled by a combination of $\lambda / 2$ waveplate and polarizer. After filtering the remaining fundamental light, the continuum is tuned to overlap 
with pump pulse and focused into the sample position and eventually enters a CCD camera for detection. All experiments on this setup were done at magic angle ${ }^{5}$ to avoid reorientation effects of the samples on nanosecond timescale. The samples were prepared in a $2 \mathrm{~mm} \mathrm{~J}$-Young cuvette for which the absorbance at pump wavelength was below 0.4 OD. Pre and post scan absorption measurements were performed to make sure the photodegradation was minimal during the measurement. No severe degradation was found for all measured samples. The resultant data were background subtracted by subtracting the averaged transient absorption spectra before time zero. The excited-state lifetime was then determined by global analysis using single exponential fittings.

GC-MS analyses were performed using an Agilent5975 MSD. The temperature program used was as follows: $40{ }^{\circ} \mathrm{C}$, isothermal $3 \mathrm{~min} ; 15^{\circ} \mathrm{C} / \mathrm{min}$ to $225^{\circ} \mathrm{C}$, isothermal $10 \mathrm{~min}$. Chiral GC analysis is explained where used. Chiral GC analyses were performed using a Shimadzu GC-2010 gas chromatograph equipped with a Shimadzu AOC-20s autosampler and a Shimadzu beta-dex capillary column $(30.0 \mathrm{~m} \times 0.25 \mathrm{~mm})$. The instrument was set to an injection volume of $1.0 \mu \mathrm{L}$, an inlet split ratio of $10.0: 1$, and an inlet temperature of $250{ }^{\circ} \mathrm{C}$. UHP-grade S3 helium was used as a carrier gas with a column flow of $1.00 \mathrm{~mL} / \mathrm{min}$ and a total flow of 14.0 $\mathrm{mL} / \mathrm{min}$ at $97 \mathrm{kPa}$. The temperature program for chiral GC analysis of methyl 2acetamidoacrylate (MAA) hydrogenation products was as follows: $90{ }^{\circ} \mathrm{C}$, isothermal 75 minutes; $22^{\circ} \mathrm{C} / \mathrm{min}$ to $200^{\circ} \mathrm{C}$, isothermal $6 \mathrm{~min}$.

All computational calculations were carried out with Gaussian09 quantum chemical package. ${ }^{6}$ Geometry optimizations of transition metal complexes were performed with wB97XD functional and the cc-pVDZ basis set. ${ }^{7-9}$ Cobalt and phosphorus atoms were represented using the def2-TZVP basis set. ${ }^{10-12}$ UltraFine grid was used for the integrals. For those structures having various conformations, the most stable conformer was searched and utilized. Vibrational frequency calculations and frontier molecular orbital analysis were carried out at the same level of theory as the geometry optimizations. Single point energy calculations were further performed 
with cc-pVTZ basis set and def2-TZVP for cobalt and phosphorus atoms. Solvation calculations were carried out at the same level of theory as the single point calculations by employing conductor-like PCM ( $\mathrm{CPCM}$ ) model with the dielectric constants of $\varepsilon=2.2706$ for benzene..$^{13,14}$ 


\section{General Catalytic Hydrogenation Procedures and Products}

General Procedure: In a nitrogen-filled glovebox, a scintillation vial was charged with unsaturated substrate $(0.30 \mathrm{mmol}), 1(0.008 \mathrm{~g}, 0.015 \mathrm{mmol})$, mesitylene $(0.030 \mathrm{~mL}, 0.021$ $\mathrm{mmol}$ ) (internal standard), and benzene- $d_{6}(3.0 \mathrm{~mL})$. This solution was divided in three $(1 \mathrm{~mL}$ each) and transferred into three thick-walled glass vessels equipped with magnetic stir bars. On a high-vacuum line, the solutions were frozen in liquid nitrogen and the headspace was removed from each vessel. The vessels were then backfilled with $4 \mathrm{~atm}$ of $\mathrm{H}_{2}$ gas. The reaction mixtures were thawed, and the dark reaction was wrapped in aluminum foil. The dark reaction was stirred at room temperature while wrapped in aluminum foil for $18 \mathrm{~h}$. The thermal reaction was stirred under minimal ambient light in an oil bath at $100{ }^{\circ} \mathrm{C}$ for $18 \mathrm{~h}$. The photochemical reaction was stirred at room temperature (solution temperature was about $35{ }^{\circ} \mathrm{C}$ in front of the LED lamps as measured by a thermometer) and irradiated with two blue Kessil ${ }^{\mathrm{TM}} \mathrm{H}-150$ blue lamps (30 W) for $18 \mathrm{~h}$. The set up was cooled by two small fans (Holmed HNF0410A). After 18 hours, the vessels were put back on the high-vacuum line, the solutions were frozen, and the headspaces were removed. The vessels were then shipped back into the nitrogen-filled glovebox, where the solutions were transferred into J-young NMR tubes and analyzed via ${ }^{1} \mathrm{H}$ and ${ }^{31} \mathrm{P}$ NMR, in addition to GC-MS if the NMR results were unclear. Unisolated yields were calculated based on ${ }^{1} \mathrm{H}$ NMR integrations. If necessary, purification of the mixture by filtration through a silica plug using benzene- $d_{6}$ furnished the saturated product.

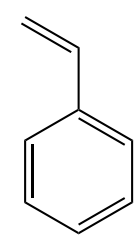


Styrene (3a): The title compound was purchased from Sigma Aldrich and dried according to the general procedure for olefin preparation. The spectral data collected matched those previously reported.<smiles>CCc1ccccc1</smiles>

Ethyl benzene: Hydrogenation of styrene by the general procedure yielded ethyl benzene as follows: $20 \%$ (dark), $>99 \%$ (thermal), $>99 \%$ (light) unisolated yields. The spectral data collected matched those previously reported.<smiles>C=C(C)c1ccccc1</smiles>

$\alpha$-Methyl styrene (3b): The title compound was purchased from Sigma Aldrich and dried according to the general procedure for olefin preparations. The spectral data collected matched those previously reported.<smiles>CC(C)c1ccccc1</smiles>

Isopropyl benzene: Hydrogenation of $\alpha$-methyl styrene by the general procedure yielded isopropyl benzene as follows: $<0.5 \%$ (dark), $37 \%$ (thermal), $>99 \%$ (light) unisolated yields. The spectral data collected matched those previously reported.<smiles>C=C(c1ccccc1)c1ccccc1</smiles> 
1,1-Diphenyl ethylene (3c): The title compound was purchased from Sigma Aldrich and dried according to the general procedure for olefin preparations. The spectral data collected matched those previously reported.<smiles>CC(c1ccccc1)c1ccccc1</smiles>

1,1-Diphenyl ethane: Hydrogenation of 1,1-diphenyl ethylene by the general procedure yielded 1,1-diphenyl ethane as follows: $<0.5 \%$ (dark), $38 \%$ (thermal), $>99 \%$ (light) unisolated yields. The spectral data collected matched those previously reported.<smiles>C(=C/c1ccccc1)\c1ccccc1</smiles>

Trans-stilbene (3d): The title compound was purchased from Sigma Aldrich and dried according to the general procedure for olefin preparations. The spectral data collected matched those previously reported.<smiles>c1ccc(CCc2ccccc2)cc1</smiles>

1,2-Diphenyl ethane: Hydrogenation of trans-stilbene by the general procedure yielded isopropyl benzene as follows: $<0.5 \%$ (dark), $<2 \%$ (thermal), $\%$ (light) unisolated yields. The spectral data collected matched those previously reported. 
<smiles>C#Cc1ccccc1</smiles>

Phenyl acetylene (3e): The title compound was purchased from Sigma Aldrich and dried according to the general procedure for olefin preparations. The spectral data collected matched those previously reported.

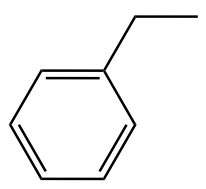

Ethyl benzene: Hydrogenation of phenyl acetylene by the general procedure yielded ethyl benzene as follows: $<0.5 \%$ (dark), $>99 \%$ (thermal), $>99 \%$ (light) unisolated yields. The spectral data collected matched those previously reported.<smiles>C(#Cc1ccccc1)c1ccccc1</smiles>

Diphenyl acetylene (3f): The title compound was purchased from Sigma Aldrich and dried according to the general procedure for olefin preparations. The spectral data collected matched those previously reported.

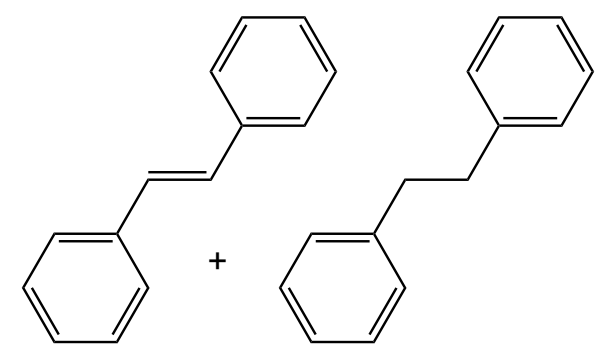

Styrene + ethyl benzene: Hydrogenation of diphenyl acetylene by the general procedure yielded mixtures of trans-stilbene and 1,2-diphenyl ethane as follows: $<0.5 \%$ conversion (dark), 
$68 \%$ trans-stilbene $+32 \%$ 1,2-diphenyl ethane (thermal), 27\% trans-stilbene $+73 \%$ 1,2-diphenyl ethane (light) unisolated yields. The spectral data collected matched those previously reported.

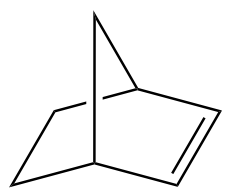

Norbornene (3g): The title compound was purchased from Sigma Aldrich and dried according to the general procedure for olefin preparations. The spectral data collected matched those previously reported.

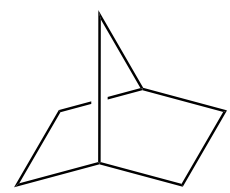

Norbornane: Hydrogenation of norbornene by the general procedure yielded norbornane as follows: $<0.5 \%$ conversion (dark), $>99 \%$ (thermal), $>99 \%$ (light) unisolated yields. The spectral data collected matched those previously reported.<smiles>C1=CCCCC1</smiles>

Cyclohexene (3h): The title compound was purchased from Sigma Aldrich and dried according to the general procedure for olefin preparations. The spectral data collected matched those previously reported.<smiles>C1CCCCC1</smiles>

Cyclohexane: Hydrogenation of cyclohexene by the general procedure yielded cyclohexane as follows: $<0.5 \%$ conversion (dark), $<0.5 \%$ (thermal), $75 \%$ (light) unisolated yields. The spectral data collected matched those previously reported. 
Cyclopentene (3i): The title compound was purchased from Sigma Aldrich and dried according to the general procedure for olefin preparations. The spectral data collected matched those previously reported.<smiles>C1CCCC1</smiles>

Cyclopentane: Hydrogenation of cyclopentene by the general procedure yielded cyclopentane as follows: $<0.5 \%$ conversion (dark), $<0.5 \%$ (thermal), $>99 \%$ (light) unisolated yields. The spectral data collected matched those previously reported.<smiles>C=C1CCC(C(C)(C)C)CC1</smiles>

4-Tert-butyl-methylene cyclohexane (3j): The title compound was purchased from Sigma Aldrich and dried according to the general procedure for olefin preparations. The spectral data collected matched those previously reported.<smiles>CC(C)(C)[C@H]1CC[C@H](C)CC1</smiles>

$(1 s, 4 s)-1-($ Tert-butyl)-4-methylcyclohexane) + ((1r,4r)-1-(tert-butyl)-4-methylcyclohexane): Hydrogenation of 4-tert-butyl-methylene cyclohexane by the general procedure yielded mixtures of (1s,4s)-1-(tert-butyl)-4-methylcyclohexane) and ((1r,4r)-1-(tert-butyl)-4-methylcyclohexane) as follows: $<0.5 \%$ conversion (dark), $<0.5 \%$ (thermal), $>99 \%$ (light) unisolated yields. The spectral data collected matched those previously reported.<smiles>C/C=C(/C)CC</smiles> 
3-Methylpent-2-ene (3k): The title compound was purchased from Sigma Aldrich and dried according to the general procedure for olefin preparations. The spectral data collected matched those previously reported.<smiles>CCC(C)CC</smiles>

3-Methylpentane: Hydrogenation of 3-methylpent-2-ene by the general procedure yielded 3methylpentane as follows: $<0.5 \%$ conversion (dark), $<0.5 \%$ (thermal), $80 \%$ (light) unisolated yields. The spectral data collected matched those previously reported.

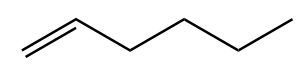

1-Hexene (3I): The title compound was purchased from Sigma Aldrich and dried according to the general procedure for olefin preparations. The spectral data collected matched those previously reported.<smiles>CCCCCC</smiles>

Hexane: Hydrogenation of 1-hexene by the general procedure yielded hexane as follows: $<0.5 \%$ conversion (dark), $54 \%$ hydrogenation $+43 \%$ isomerization (thermal), $>99 \%$ hydrogenation (light) unisolated yields. The spectral data collected matched those previously reported.<smiles>C1=COCCC1</smiles>

3,4-Dihydropyran (3m): The title compound was purchased from Sigma Aldrich and dried according to the general procedure for olefin preparations. The spectral data collected matched those previously reported.<smiles>C1CCOCC1</smiles> 
Tetrahydropyran: Hydrogenation of 3,4-dihydropyran by the general procedure yielded tetrahydropyran as follows: $3 \%$ conversion (dark), $9 \%$ (thermal), $>99 \%$ (light) unisolated yields. The spectral data collected matched those previously reported.<smiles>C=C(C)NC(=O)OC</smiles>

Methyl 2-acetamidoacrylate (MAA, 3n): The title compound was purchased from Sigma Aldrich and dried according to the general procedure for olefin preparations. The spectral data collected matched those previously reported.<smiles>CC(=O)NC(C)C(C)=O</smiles>

Methyl acetylalaninate: Hydrogenation of methyl 2-acetamidoacrylate by the general procedure yielded methyl acetylalaninate as follows: $<0.5 \%$ conversion (dark), $>99 \%$ (thermal), $>99 \%$ (light) unisolated yields. The spectral data collected matched those previously reported.<smiles>C=C(C)C(C)=O</smiles>

Dimethyl 2-methylenemalonate (3o): The title compound was purchased from Sigma Aldrich and dried according to the general procedure for olefin preparations. The spectral data collected matched those previously reported.<smiles>COC(C)C(C)C(C)=O</smiles>

Dimethyl 2-methylmalonate: Hydrogenation of dimethyl 2-methylenemalonate by the general procedure yielded dimethyl 2-methylmalonate as follows: $60 \%$ conversion (dark), $>99 \%$ (thermal), $>99 \%$ (light) unisolated yields. The spectral data collected matched those previously reported. 
<smiles>CCOC(=O)/C=C(\C)c1ccccc1</smiles>

Ethyl (E)-3-phenylbut-2-enoate (3p): The title compound was purchased from Sigma Aldrich and dried according to the general procedure for olefin preparations. The spectral data collected matched those previously reported.<smiles>CCOC(=O)CC(C)c1ccccc1</smiles>

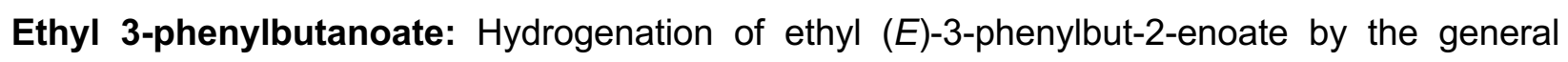
procedure yielded ethyl 3-phenylbutanoate as follows: <0.5\% conversion (dark), $26 \%$ (thermal), $>99 \%$ (light) unisolated yields. The spectral data collected matched those previously reported.<smiles>c1ccc2nc3ccccc3cc2c1</smiles>

Acridine (3q): The title compound was purchased from Sigma Aldrich and dried according to the general procedure for olefin preparations. The spectral data collected matched those previously reported.<smiles>C1=CC2Nc3ccccc3C(C3c4ccccc4NC4C=CC=CC43)C2C=C1</smiles>

9,10-Dihydroacridine + Octahydro-9,9'-biacridine: Hydrogenation of acridine by the general procedure yielded 9,10-dihydroacridine and octahydro-9,9'-biacridine as follows: $<0.5 \%$ conversion (dark), $20 \%+22 \%$ (thermal), $<0.5 \%+25 \%$ (light) unisolated yields. The dimer was 
insoluble in benzene- $d_{6}$, thus the precipitate was dissolved and identified in trifluoroacetic acid$d_{1}$. The spectral data collected matched those previously reported.<smiles>CC(C=O)c1ccccc1</smiles>

2-Phenylpropanal (3r): The title compound was purchased from Sigma Aldrich and dried according to the general procedure for olefin preparations. The spectral data collected matched those previously reported.<smiles>CC(O)C(C)c1ccccc1</smiles>

2-Phenylpropanol: Hydrogenation of 2-phenylpropanal by the general procedure yielded 2phenylpropanol as follows: $<0.5 \%$ conversion (dark), $<0.5 \%$ (thermal), $>99 \%$ (light) unisolated yields. The spectral data collected matched those previously reported. 


\section{Spectrometric Data}

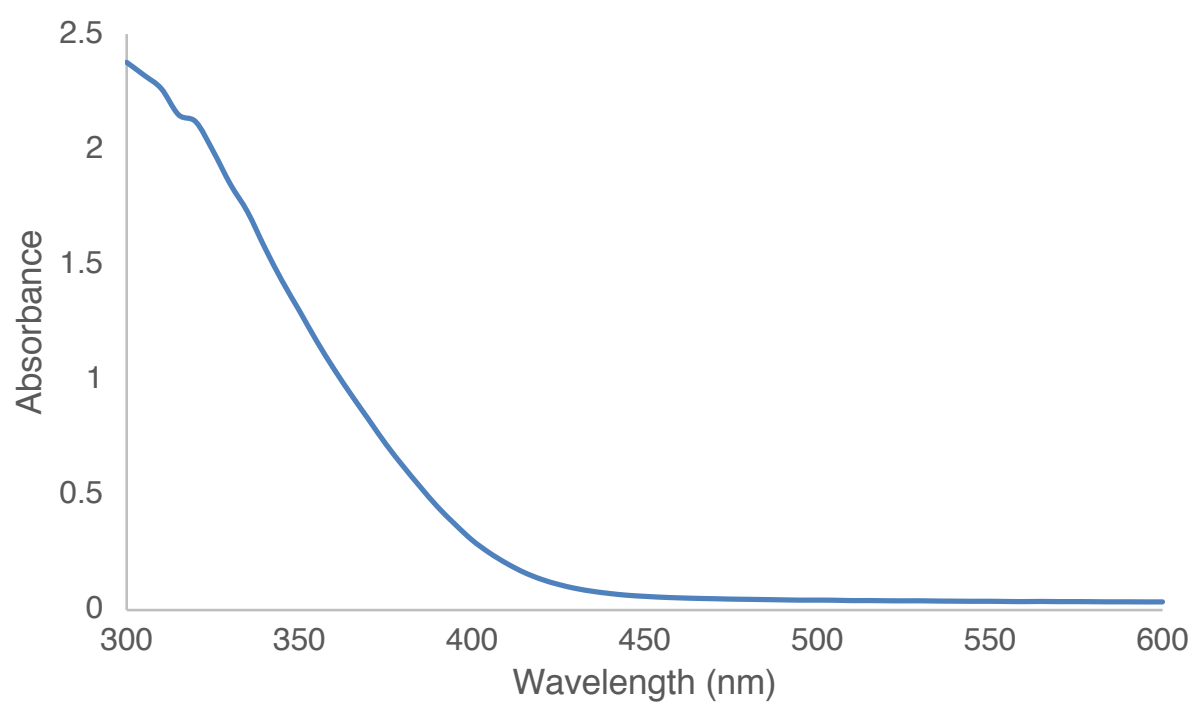

Figure S1. UV-visible absorption spectrum of 1 in toluene. 


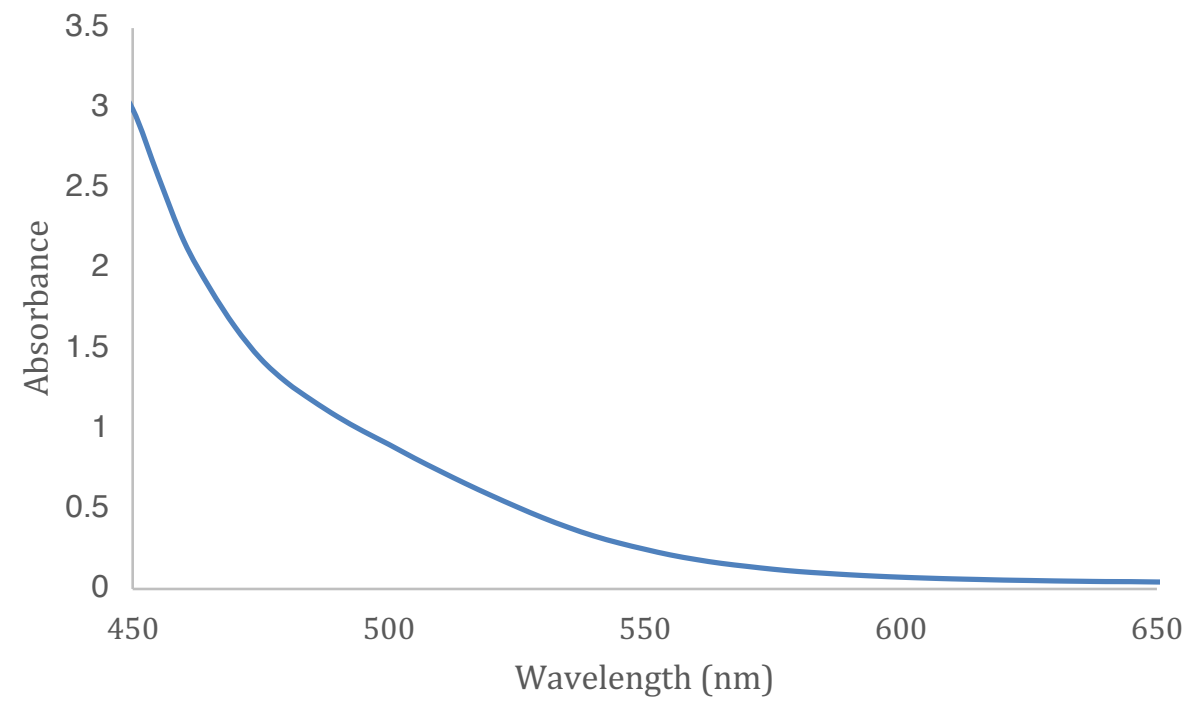

Figure S2. UV-visible absorption spectrum of $\mathbf{2}$ in toluene. 


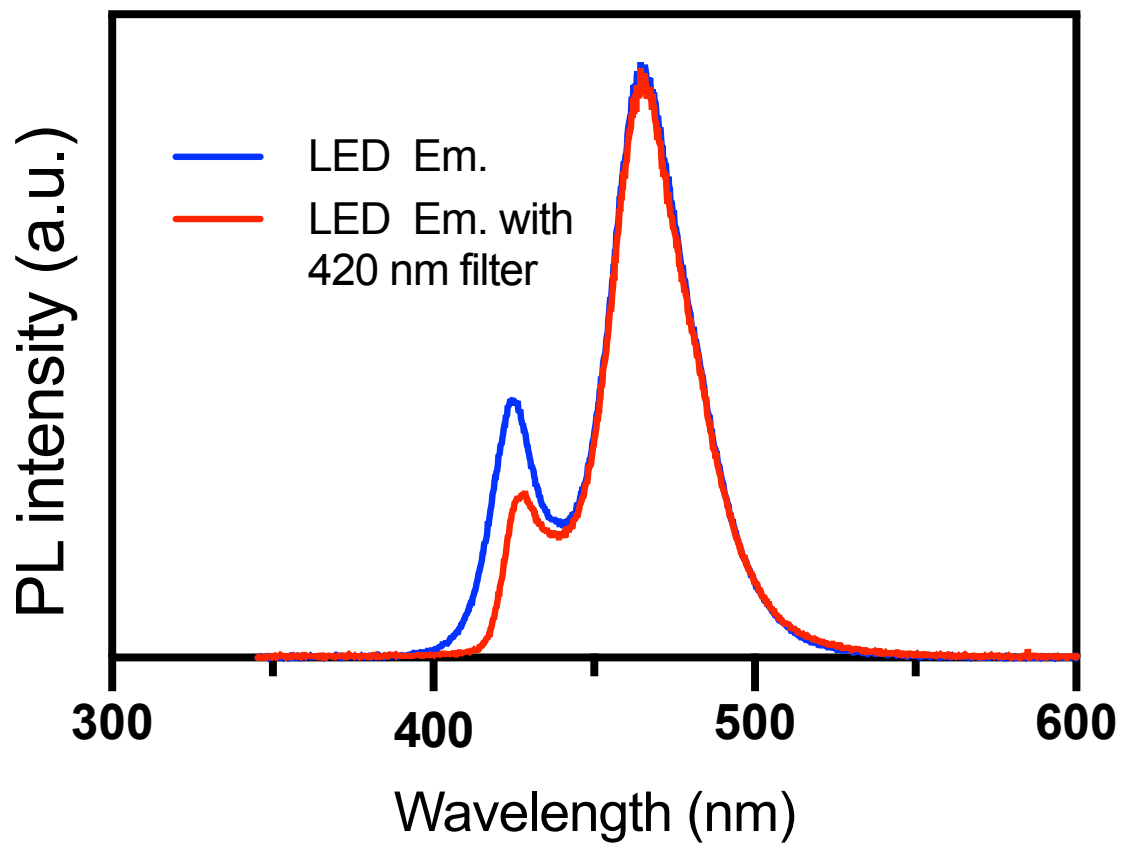

Figure S3. Normalized emission spectra of Kessil LED lamp (blue) and the LED lamp equipped with $420 \mathrm{~nm}$ long-pass filter (red). 


\section{Measurement of Quantum Yield}

Photon flux measurement. A modified procedure was used based on the literature. ${ }^{15}$ Potassium ferrioxalate $\left(\mathrm{K}_{3} \mathrm{Fe}\left(\mathrm{C}_{2} \mathrm{O}_{4}\right)_{3} \cdot 3 \mathrm{H}_{2} \mathrm{O}\right)$ was used without further purification. A blue Kessil H-150 lamp (30 W, $\lambda_{\max }=465 \mathrm{~nm}$, Figure S3) was used to ensure quantum yield of potassium ferrioxalate decomposition is almost 1.0. Two stock solutions were prepared as follows. Solution A: In a $25 \mathrm{~mL}$ volumetric flask, $1.8 \mathrm{~g}$ potassium ferrioxalate was dissolved in $1.2 \mathrm{~mL} 1 \mathrm{M} \mathrm{H}_{2} \mathrm{SO}_{4}$ and further diluted with $\mathrm{H}_{2} \mathrm{O}(c[\mathrm{Fe}]=$ $0.15 \mathrm{M})$. Solution B: $6.6 \mathrm{~g}$ of sodium acetate was dissolved in $60 \mathrm{~mL} 0.5 \mathrm{M} \mathrm{H}_{2} \mathrm{SO}_{4} .547$ mg of 1,10-phenanthroline (phen) was added to this solution. Both solutions were stored in the dark. To the $25 \mathrm{~mL}$ Strass-type flask used for photoreduction was added $1.50 \mathrm{~mL}$ of solution A. While stirring, the solution was irradiated using the blue Kessil lamp fitted with a $420 \mathrm{~nm}$ long-pass filter at room temperature. After a certain amount of time $(t)$, irradiation was halted and $2.50 \mathrm{~mL}$ of developer solution B was added immediately. The resulting solution was left in the dark for 1 hour. $160 \mu \mathrm{L}$ of the solution was then diluted to $5.0 \mathrm{~mL}$ using a volumetric flask, transferred to a cuvette in the dark, and the electronic absorption spectrum was obtained (Figure S4). The absorbance at $510 \mathrm{~nm}$ $\left(\mathrm{Fe}(\right.$ phen $) 3^{2+}$ complex, $\left.\varepsilon=11100 \mathrm{M}^{-1} \mathrm{~cm}^{-1}\right)$ was measured at $\mathrm{t}=6.0 \mathrm{~s}, 10.6 \mathrm{~s}, 15.5 \mathrm{~s}$, and 20.4 s. 


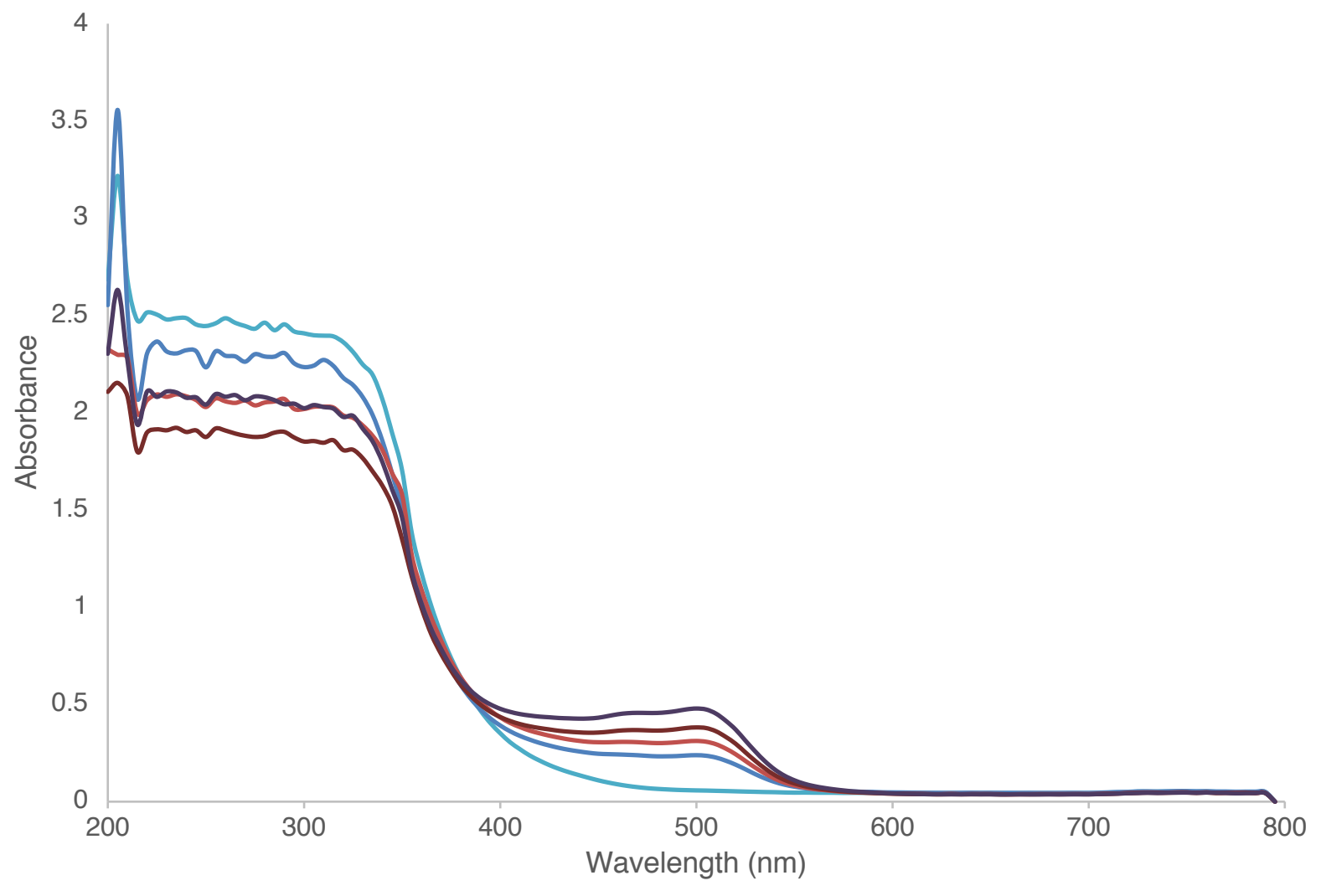

$-0 \mathrm{~s}-6.0 \mathrm{~s}-10.6 \mathrm{~s}-15.5 \mathrm{~s}-20.4 \mathrm{~s}$

Figure S4. Electronic absorption spectra of $\mathrm{Fe}(\text { phen })_{3}{ }^{2+}$ for photon flux measurement. Table S1. Photon flux measurement (data for Figure S5)

\begin{tabular}{l|l|l|l|l|l}
\hline $\mathrm{t}(\mathrm{s})$ & 0 & 6.0 & 10.6 & 15.5 & 20.4 \\
\hline $\mathrm{A}(510 \mathrm{~nm})$ & 0.0576 & 0.206 & 0.312 & .381 & .478 \\
\hline$c\left(\mathrm{Fe}^{2+}\right.$, cuvette, $\left.\mu \mathrm{M}\right)$ & 5.19 & 18.5 & 28.1 & 34.3 & 43.0 \\
\hline $\begin{array}{l}n\left(\mathrm{Fe}^{2+}, \mu \mathrm{mol}, \text { flask }\right)=c\left(\mathrm{Fe}^{2+},\right. \\
\text { cuvette, } \mu \mathrm{M}) \times(5.00 \mathrm{~mL} / 0.160 \\
\mathrm{mL})\end{array}$ & 0.648 & 2.31 & 3.51 & 4.29 & 5.38 \\
$\times(1.50 \mathrm{~mL}+2.50 \mathrm{~mL}) \times 10^{-3}$ (eq. \\
$\mathrm{S} 1)$
\end{tabular}




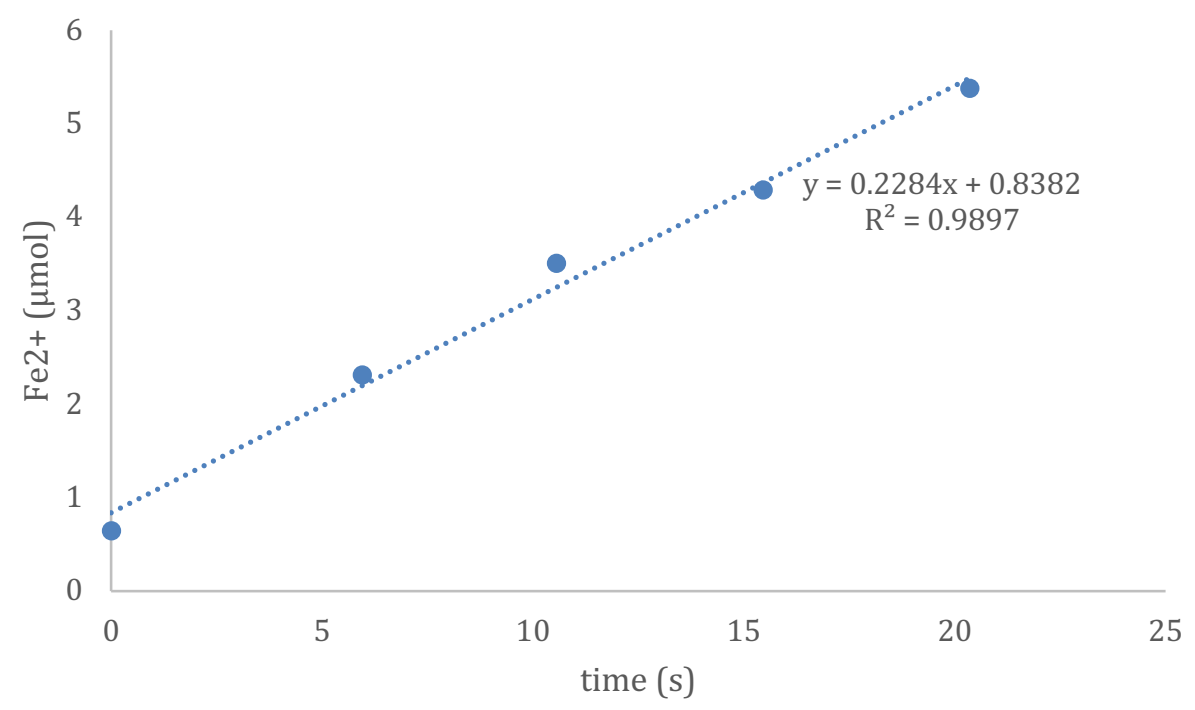

Figure S5. Time course for photodecomposition of ferrioxalate (data for Table S1).

Photon flux can be then calculated using eq. S2:

$$
\begin{aligned}
& \text { photon flux }=\frac{\mathrm{n}\left(\mathrm{Fe}^{2+}, \mathrm{mol}\right)}{\Phi \cdot \mathrm{t} \cdot \mathrm{f}} \quad \text { (eq. S2) } \\
& =\frac{0.228 \times 10^{-6}}{1.1 \times 0.97}=2.1 \times 10^{-7} \text { Einstein } \mathrm{s}^{-1}
\end{aligned}
$$

where $n\left(\mathrm{Fe}^{2+}, \mathrm{mol}\right) / \mathrm{t}$ is the slope of the above time course measurement (Figure S5). $\Phi$ is the quantum yield for the ferrioxalate actinometer, $\Phi_{450 \mathrm{~nm}} \sim 1.1^{16}$ and $f \sim 0.97$ at 450 nm. ${ }^{17}$

Reaction quantum yield calculation. Reaction quantum yield was estimated by using the measured photon flux under our reaction setup and equation S3.

$$
\Phi_{\mathrm{rxn}}=\frac{\text { mol product }}{\text { photon flux } \cdot \mathrm{t} \cdot \mathrm{f}} \quad \text { (eq. S3) }
$$

The $f$ value of approximately 1 was calculated from the absorbance $(0.300)$ of a benzene solution of 1 at the same concentration as in reaction at $440 \mathrm{~nm}$ using equation S4.

$$
f=\log _{10}{ }^{-1}(A)-1 \quad \text { (eq. S4) }
$$


The same reaction vessel as was used for measurement of photon flux was charged with styrene $(0.092 \mathrm{~mL}, 0.80 \mathrm{mmol}), 1(0.001 \mathrm{mg}, 0.002 \mathrm{mmol}, 0.2 \%$ catalyst loading) and benzene- $d_{6}(1.0 \mathrm{~mL})$. On a high vacuum line, the solution was frozen and the headspace removed. The vessel was then backfilled with 4 atm of $\mathrm{H}_{2}$. The solution was irradiated by the blue Kessil LED lamp with the $420 \mathrm{~nm}$ longpass filter for 4 minutes. The catalyst was then removed by a silica plug using benzene- $d_{6}$ and the formation of ethyl benzene was calculated by ${ }^{1} \mathrm{H}$ NMR to be $10.6 \%$ yield. Consequently, the reaction quantum yield can be calculated as follows:

$$
\Phi_{\mathrm{rxn}}=\frac{2.7 \times 10^{-6} \mathrm{~mol}}{2.1 \times 10^{-7} \text { Einstein } \mathrm{s}^{-1} \cdot(60 \mathrm{~s} \times 30) \cdot 1}=0.17 \text { (eq. S5) }
$$

A number of factors likely limit the quantum efficiency: 1 ) an assumption of $f=1$ in our reaction conditions could underestimate the quantum efficiency. 2) it is difficult to determine how many photons are actively involved in the product forming process. For example, later hydrogenation steps could also be driven by the excited $\mathbf{1}$. 


\section{Experimental Details}

Time-course monitoring of $\alpha$-methyl styrene hydrogenation. In a nitrogen-filled glovebox, a scintillation vial was charged with $\alpha$-methyl styrene $(0.026 \mu \mathrm{L}, 0.20 \mathrm{mmol})$, $1\left(0.003 \mathrm{~g}, 0.006 \mathrm{mmol}, 3 \%\right.$ catalyst loading), and benzene- $d_{6}(1.2 \mathrm{~mL})$. The solution was transferred in equal portions to two J-Young NMR tubes. On a high vacuum line, the solutions were frozen and the headspaces were removed. The tubes were then backfilled with $4 \mathrm{~atm}$ of $\mathrm{H}_{2}$. The solutions were kept frozen with ice water, and thawed just before taking a ${ }^{1} \mathrm{H}$ NMR spectrum of each sample and re-frozen following acquisition. In five minute intervals, one sample was placed in front of two blue Kessil LED lamps while the other was heated in a $100{ }^{\circ} \mathrm{C}$ oil bath. Following the five minute time interval, the solutions were frozen, ${ }^{1} \mathrm{H}$ NMR spectra were taken, and the solutions were frozen again. This process was repeated at 5 minute time intervals until the total reaction time with blue light/heating was 45 minutes. Integration of ${ }^{1} \mathrm{H}$ NMR spectra were used to generate the relative rate plots based on the concentrations of $\alpha$-methyl styrene and isopropyl benzene in solution.

Generation of $\left[(\mathrm{P}-\mathrm{P}) \mathrm{Co}(\mathrm{CO})\left(\boldsymbol{\mu}^{2}-\mathrm{CO}\right)\right]_{2}$. In a nitrogen-filled glovebox, a scintillation vial was charged with $\mathrm{Co}_{2}(\mathrm{CO})_{8}(0.020 \mathrm{~g}, 0.058 \mathrm{mmol})$ and bis(phosphine) $(0.12 \mathrm{mmol}, 2$ equiv.), and THF (2.0 mL). The resulting solution was stirred at room temperature for 2 hours, after which the solution was filtered through celite and the solvent was removed in vacuo to reveal a crude solid which was used directly in reaction.

Hydrogenation of styrene with $\left[(\mathrm{P}-\mathrm{P}) \mathrm{Co}(\mathrm{CO})\left(\mu^{2}-\mathrm{CO}\right)\right]_{2}$ complexes. In a nitrogen-filled glovebox, a scintillation vial was charged with styrene $(0.012 \mathrm{~mL}, 0.10 \mathrm{mmol}),[(\mathrm{P}-$ $\left.\mathrm{P}) \mathrm{Co}(\mathrm{CO})\left(\mu^{2}-\mathrm{CO}\right)\right]_{2}(0.005 \mathrm{mmol}, 2.5 \mathrm{~mol} \%)$, mesitylene $(0.010 \mathrm{~mL}, 0.072 \mathrm{mmol})$ and 
benzene- $d_{6}(2.0 \mathrm{~mL})$. The solution was transferred into a thick-walled vessel equipped with a stir bar and removed from the glovebox. On a high vacuum line, the solution was frozen and the headspace was removed. The vessel was then backfilled with 4 atm of $\mathrm{H}_{2}$. The vessel was irradiated by two blue Kessil LED lamps for 18 hours with stirring at ambient temperature. After 18 hours, the sample was brought back into the glovebox where the sample was transferred into a J-Young NMR tube and analyzed by ${ }^{1} \mathrm{H}$ NMR spectroscopy.

Control reaction of styrene with $\mathrm{Co}_{2}(\mathrm{CO})_{8}$. In a nitrogen-filled glovebox, a scintillation vial was charged with styrene $(0.011 \mathrm{~mL}, 0.10 \mathrm{mmol}), \mathrm{Co}_{2}(\mathrm{CO})_{8}(0.003 \mathrm{~g}, 0.009 \mathrm{mmol}, 9$ mol\%), and benzene- $d_{6}(1.0 \mathrm{~mL})$. The solution was transferred into a thick-walled vessel equipped with a stir bar and removed from the glovebox. On a high vacuum line, the solution was frozen and the headspace was removed. The vessel was then backfilled with 4 atm of $\mathrm{H}_{2}$. The vessel was irradiated by two blue Kessil LED lamps for 18 hours with stirring at ambient temperature. After 18 hours, the sample was brought back into the glovebox where the sample was transferred into a J-Young NMR tube and analyzed by ${ }^{1} \mathrm{H}$ NMR spectroscopy.

Reaction of 1 with TEMPO radical. In a nitrogen filled glovebox, a scintillation vial was charged with $1(0.021 \mathrm{~g}, 0.039 \mathrm{mmol})$, TEMPO radical $(0.010 \mathrm{~g}, 0.064 \mathrm{mmol}, 1.6$ equiv.), and benzene- $d_{6}(1.0 \mathrm{~mL})$. The solution was transferred to a J-Young NMR tube and allowed to react for 10 minutes. ${ }^{1} \mathrm{H}$ and ${ }^{31} \mathrm{P}$ NMR spectra were taken, revealing full conversion of 1 to 2 and the formation of TEMPO-H. The sample was put on a high vacuum line, where the solution was frozen and the headspace was removed. The tube 
was then backfilled with 4 atm of $\mathrm{H}_{2}$. After 10 hours, ${ }^{1} \mathrm{H}$ and ${ }^{31} \mathrm{P}$ NMR spectra were taken, revealing regeneration of 1 .

Catalytic hydrogenation of 2,4,6-tert-butyl-phenoxy radical. In a nitrogen filled glovebox, a scintillation vial was charged with 2,4,6-tert-butyl-phenoxy radical $(0.015 \mathrm{~g}$, $0.057 \mathrm{mmol}), 1(0.003 \mathrm{~g}, 0.005 \mathrm{mmol}, 10 \mathrm{~mol} \%)$, mesitylene (0.010 g, $0.072 \mathrm{mmol})$, and benzene- $d_{6}(1.0 \mathrm{~mL})$. The solution was transferred to a J-Young NMR tube and transferred to a high vacuum line, where the solution was frozen and the headspace removed. The tube was then back-filled with $4 \mathrm{~atm}$ of $\mathrm{H}_{2} .{ }^{1} \mathrm{H}$ NMR spectroscopy after 48 hours revealed the formation of 2,4,6-tert-butylphenol in approximately $90 \%$ yield.

Hydrogenation of $\alpha$-cyclopropyl styrene. $\alpha$-Cyclopropyl styrene was synthesized according to literature procedures. ${ }^{18}$ In a nitrogen filled glovebox, a scintillation vial was charged with $\alpha$-cyclopropyl styrene $(0.020 \mathrm{mg}, 0.20 \mathrm{mmol}), 1(0.005 \mathrm{~g}, 0.010 \mathrm{mmol})$, mesitylene $(0.020 \mathrm{~mL}, 0.14 \mathrm{mmol})$, and benzene- $d_{6}(1.0 \mathrm{~mL})$. The solution was split in two and transferred into two thick-walled vessels equipped with stir bars. The vessels were removed from the glovebox and moved to a high vacuum line where the solutions were frozen and the headspaces removed. The vessels were then backfilled with $4 \mathrm{~atm}$ of $\mathrm{H}_{2}$. The light reaction was stirred under irradiation by two blue Kessil LED lamps (standard blue light set-up) for 18 hours. The thermal reaction was stirred under minimal light for 18 hours while heating in a $100^{\circ} \mathrm{C}$ oil bath. After 18 hours, the vessels were put back on the high vacuum line, where the solutions were frozen and the headspaces removed. The vessels were then thawed and shipped back into the glovebox. The solutions were transferred to sealed NMR tubes and identities and yields of various products were determined by ${ }^{1} \mathrm{H}$ NMR and GC-MS spectroscopy. 
Hydrogenation of vinyl cyclopropane: Vinyl cyclopropane was synthesized by an adapted literature procedure, as follows, and characterized by the literature. ${ }^{19}$ Methyl triphenyl phosphonium bromide $(25.5 \mathrm{~g}, 71.2 \mathrm{mmol})$ was suspended in $25 \mathrm{~mL}$ of toluene in a thick-walled vessel, to which sodium $t$-amylate $(8.23 \mathrm{~g}, 74.7 \mathrm{mmol})$ in $20 \mathrm{~mL}$ toluene was added. The resulting solution was stirred at room temperature for 30 minutes, after which cyclopropyl aldehyde $(2.5 \mathrm{~g}, 29.7 \mathrm{mmol})$ in $5 \mathrm{~mL}$ toluene was added. The vessel was sealed and the solution was refluxed under vacuum for 2 hours. The solution was then cooled to room temperature. On a Schlenk line, the highly volatile product was vacuum transferred out of solution and into a second flask containing molecular sieves to dry. The product was found to be mostly clean, with slight traces of toluene. After following typical olefin drying procedures, the vinyl cyclopropane product was hydrogenated as follows. In a nitrogen-filled glovebox, a scintillation vial was charged with vinyl cyclopropane $(0.011 \mathrm{~g}, 0.002 \mathrm{mmol}), 1(0.005 \mathrm{~g}, 0.010 \mathrm{mmol})$, and benzene$d_{6}(2.0 \mathrm{~mL})$. The solution was split in two and transferred to two thick-walled vessels equipped with stir bars. The vessels were removed from the glovebox and put on a high vacuum line, where the solutions were frozen and the headspaces removed. The vessels were then back-filled with $4 \mathrm{~atm}$ of $\mathrm{H}_{2}$. One vessel was heated to $100{ }^{\circ} \mathrm{C}$ under minimal ambient light, while the other was irradiated under standard blue light conditions for 18 hours. After this time, the solutions were put back on the high vacuum line where the headspaces were removed. Inside of the glovebox, the solutions were transferred to J-Young NMR tubes, and analyzed by ${ }^{1} \mathrm{H}$ NMR spectroscopy. 
Hydrogenation of 4-tert-butylmethylenecyclohexene. In a nitrogen filled glovebox, a scintillation vial was charged with 4-tert-butylmethylenecyclohexene $(0.045 \mathrm{~g}, 0.30$ $\mathrm{mmol}), 1(0.008 \mathrm{~g}, 0.015 \mathrm{mmol})$, mesitylene $(0.030 \mathrm{~mL}, 0.22 \mathrm{mmol})$, and benzene- $d_{6}$ (3.0 mL). The solution was split in three and transferred into three thick-walled vessels equipped with stir bars. The vessels were removed from the glovebox and moved to a high vacuum line where the solutions were frozen and the headspaces removed. The vessels were then backfilled with 4 atm of $\mathrm{H}_{2}$. The dark reaction was wrapped in tin-foil and stirred at room temperature for 18 hours. The light reaction was stirred under irradiation by two blue Kessil LED lamps (standard blue light set-up) for 18 hours. The thermal reaction was stirred under minimal light for 18 hours while heating in a $100{ }^{\circ} \mathrm{C}$ oil bath. After 18 hours, the vessels were put back onto the high vacuum line, where the solutions were frozen and the headspaces removed. The vessels were then thawed and shipped back into the glovebox. The solutions were transferred to sealed NMR tubes and yields of various products were quantitated by ${ }^{1} \mathrm{H}$ and quantitative $-{ }^{13} \mathrm{C}$ NMR spectroscopy.

Hydrogenation of MAA. In a nitrogen-filled glovebox, a scintillation vial was charged with MAA (0.035 mg, $0.30 \mathrm{mmol}), 2(0.008 \mathrm{mg}, 0.0075 \mathrm{mmol}, 2.5 \mathrm{~mol} \%)$, mesitylene $(0.030 \mathrm{~mL}, 0.22 \mathrm{mmol})$, and benzene- $d_{6}(3.0 \mathrm{~mL})$. The solution was split into three portions and transferred to three thick-walled vessels equipped with stir bars. The vessels were removed from the glovebox and transferred to a high vacuum line where the solutions were frozen and the headspaces were removed. The vessels were then backfilled with 4 atm of $\mathrm{H}_{2}$. The dark reaction was wrapped in tin-foil and stirred at room temperature for 18 hours. The light reaction was stirred under irradiation by two blue 
Kessil LED lamps (standard blue light set-up) for 18 hours. The thermal reaction was stirred under minimal light for 18 hours while heating in a $100{ }^{\circ} \mathrm{C}$ oil bath. After 18 hours, the vessels were put back onto the high vacuum line, where the solutions were frozen and the headspaces removed. The vessels were then thawed and shipped back into the glovebox. The solutions were transferred to sealed NMR tubes and yields of various products were quantitated by ${ }^{1} \mathrm{H}$ NMR spectroscopy and chiral gas chromatography.

Thermal styrene deuteration under $\mathrm{CO}$. In a nitrogen-filled glovebox, a scintillation vial was charged with 1-D $(0.010 \mathrm{~g}, 0.019 \mathrm{mmol})$, styrene $(0.012 \mathrm{~mL}, 0.10 \mathrm{mmol}, 5$ equiv.), and $\mathrm{C}_{6} \mathrm{H}_{6}(0.6 \mathrm{~mL})$. The solution was transferred to a J-Young NMR tube and removed from the glovebox. On a high vacuum line the solution was frozen and the headspace was removed. The tube was then backfilled with $1 \mathrm{~atm}$ of $\mathrm{CO}$. The tube was then heated for 5 hours at $75{ }^{\circ} \mathrm{C}$, at which point the sample as analyzed by ${ }^{2} \mathrm{H}$ NMR spectroscopy.

Photochemical styrene deuteration. In a nitrogen-filled glovebox, a scintillation vial was charged with 1-D (0.010 g, $0.019 \mathrm{mmol})$, styrene $(0.012 \mathrm{~mL}, 0.10 \mathrm{mmol}, 5$ equiv.), and $\mathrm{C}_{6} \mathrm{H}_{6}(0.6 \mathrm{~mL})$. The solution was transferred to a J-Young NMR tube and removed from the glovebox. The sample was irradiated by two blue Kessil LED lamps (standard blue light set-up) for 3 hours, at which point the sample was analyzed by ${ }^{2} \mathrm{H}$ NMR spectroscopy.

${ }^{13} \mathrm{CO}$ exchange experiments. In a nitrogen-filled glovebox, a scintillation vial was charged with $1(0.008 \mathrm{~g}, 0.0075 \mathrm{mmol})$ and benzene- $d_{6}(1.0 \mathrm{~mL})$. The solution was transferred to a J-Young NMR tube and ${ }^{1} \mathrm{H}$ and ${ }^{13} \mathrm{C}$ NMR spectra were recorded. The 
tube was then placed on a high vacuum line where the solution was frozen and the headspace removed. The tube was then backfilled with $0.2 \mathrm{~atm}$ of ${ }^{13} \mathrm{CO}$ gas. The tubes were kept frozen and thawed just before placing in an NMR spectrometer. Several ${ }^{13} \mathrm{C}$ NMR spectra were taken in succession, showing immediate formation of ( $\left.{ }^{\mathrm{iPr} D u P h o s}\right) \mathrm{Co}\left({ }^{13} \mathrm{CO}\right)_{2} \mathrm{H}$ which did not increase over time.

Decomposition of 1 under blue light. In a nitrogen-filled glovebox, a scintillation vial was charged with $1(0.015 \mathrm{~g}, 0.028 \mathrm{mmol})$ and benzene- $d_{6}(1.0 \mathrm{~mL}) .{ }^{1} \mathrm{H}$ and ${ }^{31} \mathrm{P}$ NMR spectra were recorded. The sample was then irradiated by two blue Kessil LED lamps for 2 hours (standard blue light set-up), at which point ${ }^{1} \mathrm{H}$ and ${ }^{31} \mathrm{P}$ NMR spectra were recorded. Repetition of this experiment under a green Kessil ${ }^{\mathrm{TM}}(525 \mathrm{~nm})$ LEDs showed no conversion by ${ }^{1} \mathrm{H}$ and ${ }^{31} \mathrm{P}$ NMR after 3 hours.

Wavelength Dependence of the Photodecomposition of 1. In a nitrogen-filled glovebox, a scintillation vial was charged with $1(0.008 \mathrm{~g}, 0.0075 \mathrm{mmol})$ and benzene- $d_{6}$ $(1.0 \mathrm{~mL})$. The solution was transferred to a J. Young NMR tube and ${ }^{1} \mathrm{H}$ and ${ }^{31} \mathrm{P}$ NMR spectra were recorded. The solution was then irradiated with a green Kessil LED lamp $\left(\lambda_{\max }=525 \mathrm{~nm}\right)$ for one hour, after which ${ }^{1} \mathrm{H}$ and ${ }^{31} \mathrm{P}$ NMR spectra were recorded. Next, the solution was irradiated with a blue Kessil LED lamp fitted with a $475 \mathrm{~nm}$ bandpass filter for one hour, after which ${ }^{1} \mathrm{H}$ and ${ }^{31} \mathrm{P}$ NMR spectra were recorded. Then the solution was irradiated with a blue Kessil LED lamp fitted with a $420 \mathrm{~nm}$ bandpass filter for one hour, after which ${ }^{1} \mathrm{H}$ and ${ }^{31} \mathrm{P}$ NMR spectra were recorded. Finally, the solution was irradiated with a naked blue Kessil LED lamp for one hour and ${ }^{1} \mathrm{H}$ and ${ }^{31} \mathrm{P}$ NMR spectra were recorded. 
Bis(phosphine) exchange experiments. In a nitrogen-filled glovebox, a scintillation vial was charged with $1(0.010 \mathrm{~g}, 0.015 \mathrm{mmol}),(S, S)-{ }^{\mathrm{Me}}$ DuPhos $(11 \mathrm{mg}, 0.036 \mathrm{mmol})$ and benzene- $d_{6}(1.0 \mathrm{~mL}) .{ }^{1} \mathrm{H}$ and ${ }^{31} \mathrm{P}$ NMR spectra was recorded. The same was then irradiated by two blue Kessil LED lamps for 6 hours (standard blue light set-up), at which point ${ }^{1} \mathrm{H}$ and ${ }^{31} \mathrm{P}$ NMR spectra were recorded, revealing nearly full conversion to $\left[(S, S)-\left({ }^{\text {Me}} \text { DuPhos }\right) \mathrm{Co}(\mathrm{CO})\left(\mu^{2}-\mathrm{CO}\right)\right]_{2}$ and $(R, R)^{\text {iPr}}$ DuPhos. Repetition of this experiment under 1 atm of $\mathrm{CO}$ revealed approximately $5 \%$ conversion to $[(S, S)$ ( ${ }^{M e}$ DuPhos $\left.) \mathrm{Co}(\mathrm{CO})\left(\mu^{2}-\mathrm{CO}\right)\right]_{2}$ and $2 \%$ conversion to 2 . Repetition of this experiment again under 4 atm of $\mathrm{H}_{2}$ revealed approximately $30 \%$ conversion to $[(S, S)$ (MeDuPhos) $\left.\mathrm{Co}(\mathrm{CO})\left(\mu^{2}-\mathrm{CO}\right)\right]_{2}$ and $7 \%$ conversion to $(\mathrm{S}, S)-\left({ }^{\mathrm{Me}}\right.$ DuPhos) $\mathrm{Co}(\mathrm{CO})_{2} \mathrm{H}$.

Light/dark reaction monitoring of $\alpha$-Methyl styrene hydrogenation. In a nitrogenfilled glovebox, a scintillation vial was charged with $\alpha$-methyl styrene $(0.026 \mathrm{~mL}, 0.20$ mmol), $1\left(0.003 \mathrm{mg}, 0.006 \mathrm{mmol}, 3 \%\right.$ catalyst loading), and benzene- $d_{6}(1.0 \mathrm{~mL})$. The solution was transferred into a J-Young NMR tube. On a high vacuum line, the solution was frozen and the headspace removed. The tube was then back-filled with 4 atm of $\mathrm{H}_{2}$. A ${ }^{1} \mathrm{H}$ NMR was taken. The tube was then irradiated using a blue Kessil LED lamp for 15 minutes, followed by another ${ }^{1} \mathrm{H}$ NMR. The solution was allowed to sit for a set period of time under dark, room temperature conditions and then another ${ }^{1} \mathrm{H}$ NMR was taken. This on/off process was repeated for several cycles. ${ }^{1} \mathrm{H}$ NMR integrations were used to determine the amount of product formation at each timepoint (Figure S6). 


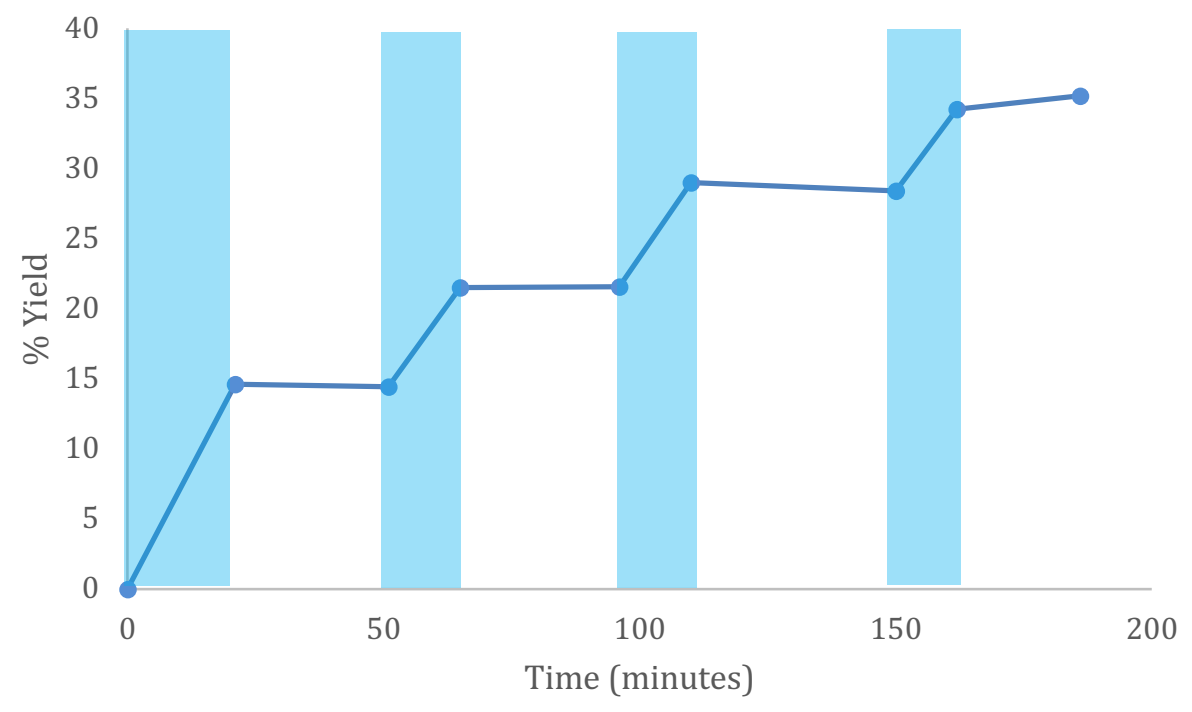

Figure S6. On-off experiment for the hydrogenation of $\alpha$-methyl styrene by 1 . Blue bars indicate time when the light was on, white sections indicate time when the light was off.

Time-course monitoring of MAA hydrogenation. In a nitrogen-filled glovebox, a scintillation vial was charged with MAA $(0.023 \mathrm{~g}, 0.20 \mathrm{mmol}), 1(0.003 \mathrm{~g}, 0.006 \mathrm{mmol}$, $3 \%$ catalyst loading), and benzene- $d_{6}(1.6 \mathrm{~mL})$. The solution was transferred in equal portions to two J-Young NMR tubes. On a high vacuum line, the solutions were frozen and the headspaces were removed. The tubes were then backfilled with 4 atm of $\mathrm{H}_{2}$. The solutions were kept frozen with ice water, and thawed just before taking a ${ }^{1} \mathrm{H}$ NMR spectrum of each sample and re-frozen following acquisition. In five minute intervals, one sample was placed in front of two blue Kessil LED lamps while the other was heated in a $100{ }^{\circ} \mathrm{C}$ oil bath. Following the five minute time interval, the solutions were frozen, ${ }^{1} \mathrm{H}$ NMR spectra were taken, and the solutions were frozen again. This process was repeated at 5 minute time intervals until the total reaction time with blue light/heating was 40 minutes. ${ }^{1} \mathrm{H}$ NMR spectra integrations were used to generate the 
relative rate plots based on the concentrations of MAA and methyl acetylalaninate in solution.

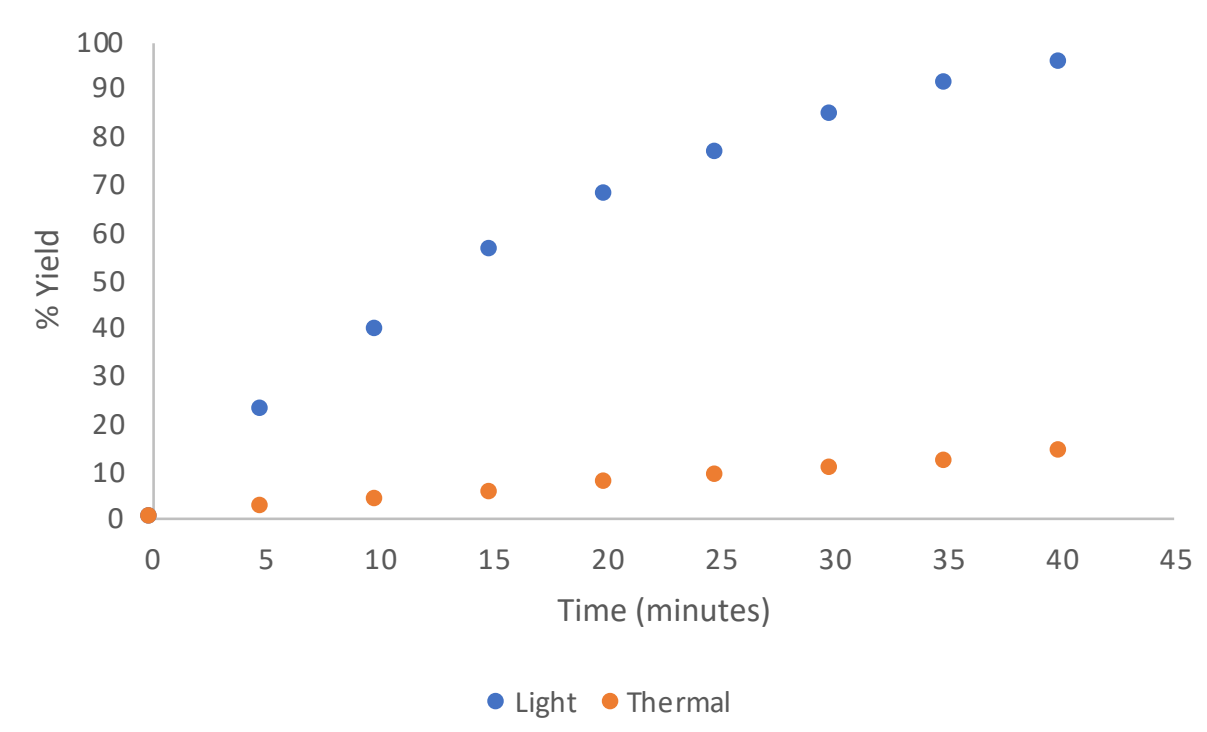

Figure S7. Time course monitoring of the hydrogenation of MAA under blue light (35 ${ }^{\circ} \mathrm{C}$, blue) and thermal $\left(100{ }^{\circ} \mathrm{C}\right.$, orange) conditions.

Time-course monitoring of 4-tert-butyl-4-methylenecyclohexane hydrogenation. In a nitrogen-filled glovebox, a scintillation vial was charged with 4-tert-butyl-4methylenecyclohexane $(0.030 \mathrm{~g}, 0.20 \mathrm{mmol}), 1(0.003 \mathrm{~g}, 0.006 \mathrm{mmol}, 3 \%$ catalyst loading), and benzene- $d_{6}(1.6 \mathrm{~mL})$. The solution was transferred in equal portions to two J-Young NMR tubes. On a high vacuum line, the solutions were frozen and the headspaces were removed. The tubes were then backfilled with 4 atm of $\mathrm{H}_{2}$. The solutions were kept frozen with ice water, and thawed just before taking a ${ }^{1} \mathrm{H}$ NMR spectrum of each sample and re-frozen following acquisition. In five minute intervals, one sample was placed in front of two blue Kessil LED lamps while the other was heated in a $100{ }^{\circ} \mathrm{C}$ oil bath. Following the five minute time interval, the solutions were frozen, ${ }^{1} \mathrm{H}$ NMR spectra were taken, and the solutions were frozen again. This process 
was repeated at 5 minute time intervals until the total reaction time with blue light/heating was 40 minutes. ${ }^{1} \mathrm{H}$ NMR spectra integrations were used to generate the relative rate plots based on the concentrations of 4-tert-butyl-4-methylenecyclohexane and 1-tert-butyl-4-methylcyclohexane in solution.

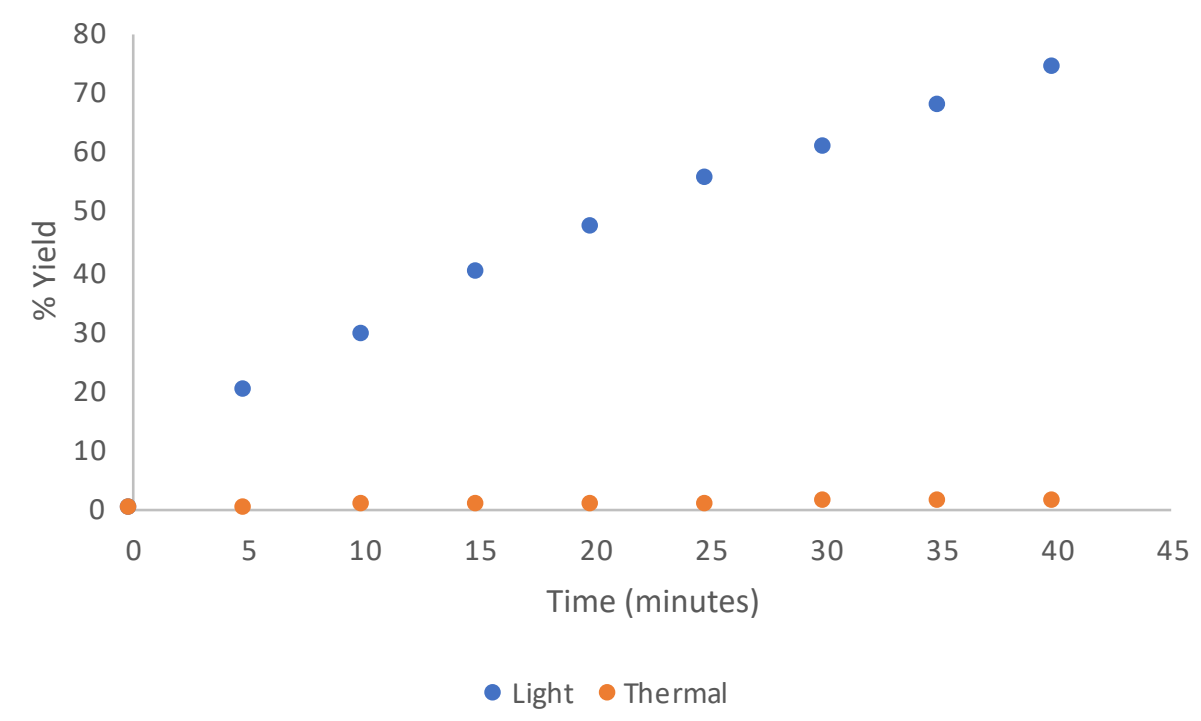

Figure S8. Time course monitoring for the hydrogenation of 4-tert-butyl-4methylenecyclohexane under blue light $\left(35^{\circ} \mathrm{C}\right.$, blue $)$ and thermal $\left(100^{\circ} \mathrm{C}\right.$, orange) conditions.

UV/blue light comparison reaction. In a nitrogen-filled glovebox, a scintillation vial was charged with MAA (0.014 g, $0.012 \mathrm{mmol}), 1(0.002 \mathrm{~g}, 0.004 \mathrm{mmol}, 3.3 \mathrm{~mol} \%)$, and $2 \mathrm{~mL}$ of a pentane/THF (2:1) mixture. The solution was split in two and one half was transferred to a standard thick-walled vessel, while the other was transferred to a thick wall vessel made of quartz glass. The two solutions were transferred to a high vacuum line, where the solutions were frozen and the headspaces were removed. The vessels were then backfilled with 4 atm of $\mathrm{H}_{2}$. The standard vessel was irradiated under standard blue light conditions (2 blue Kessil LED lamps, cooled with fans) for exactly 7 minutes, while the quartz vessel was irradiated in a Rayonet UV box cooled with circulating water for 7 minutes. Following irradiation, both tubes had their headspaces 
removed on the high vacuum line and were transferred into the glovebox, where the solvent was removed under vacuum. The non-volatile residues were taken up with benzene- $d_{6}$ and transferred to NMR tubes. ${ }^{1} \mathrm{H}$ NMR spectroscopy was used to determine reaction progress. 


\section{Transient Absorption Spectroscopic Data}
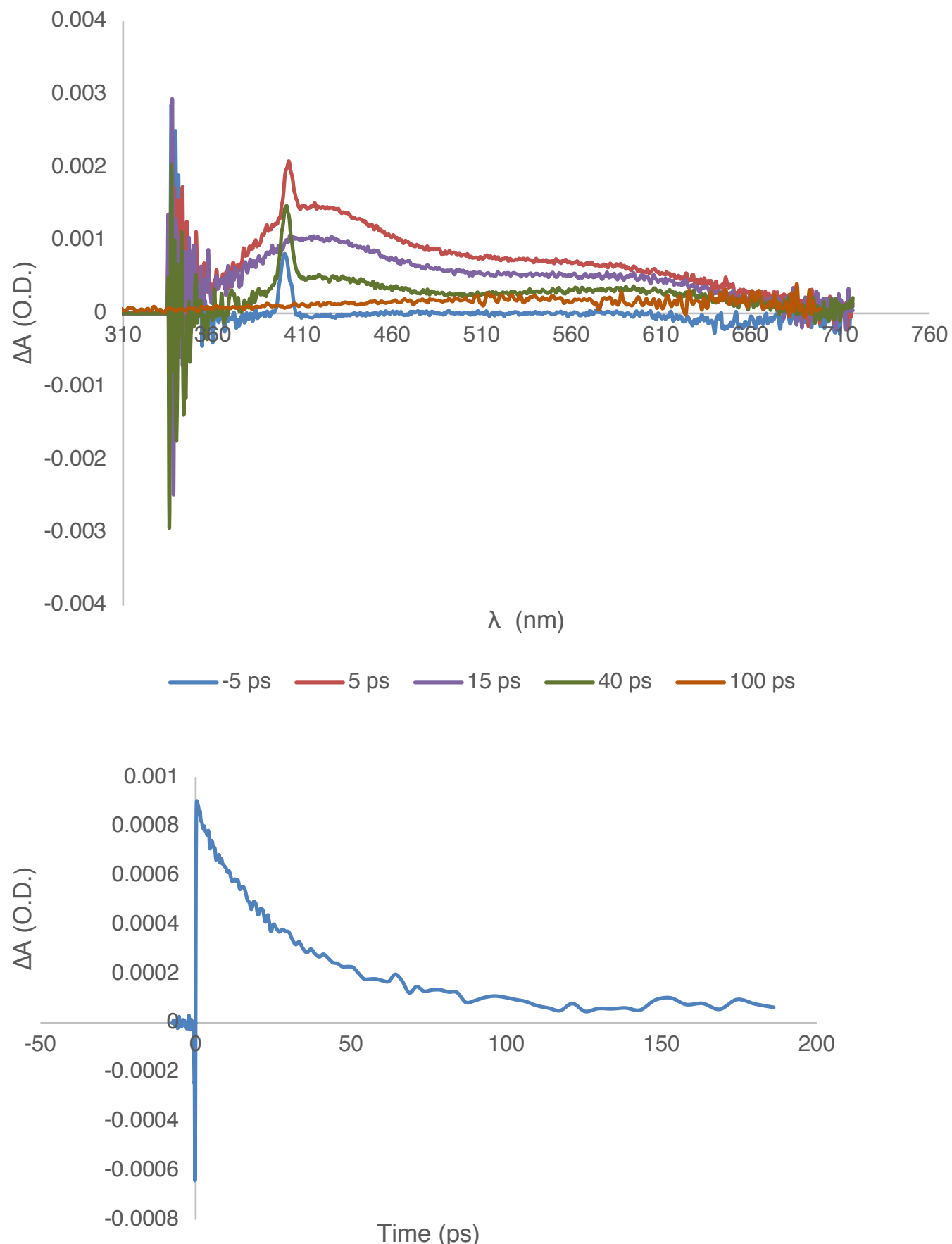

Figure S9. (top) Selected femtosecond transient absorption spectra of 1 in toluene (3.3 mM, $298 \mathrm{~K}, \mathrm{THF}, \lambda$ pump $=400 \mathrm{~nm}$, Ppump $=500 \mu \mathrm{W})$. Fitting of this data using global analysis generated an excited state lifetime value of $37 \mathrm{ps}$. (bottom) Kinetic trace showing the singlet exponential decay of the spectral peak at $480 \mathrm{~nm}$. 

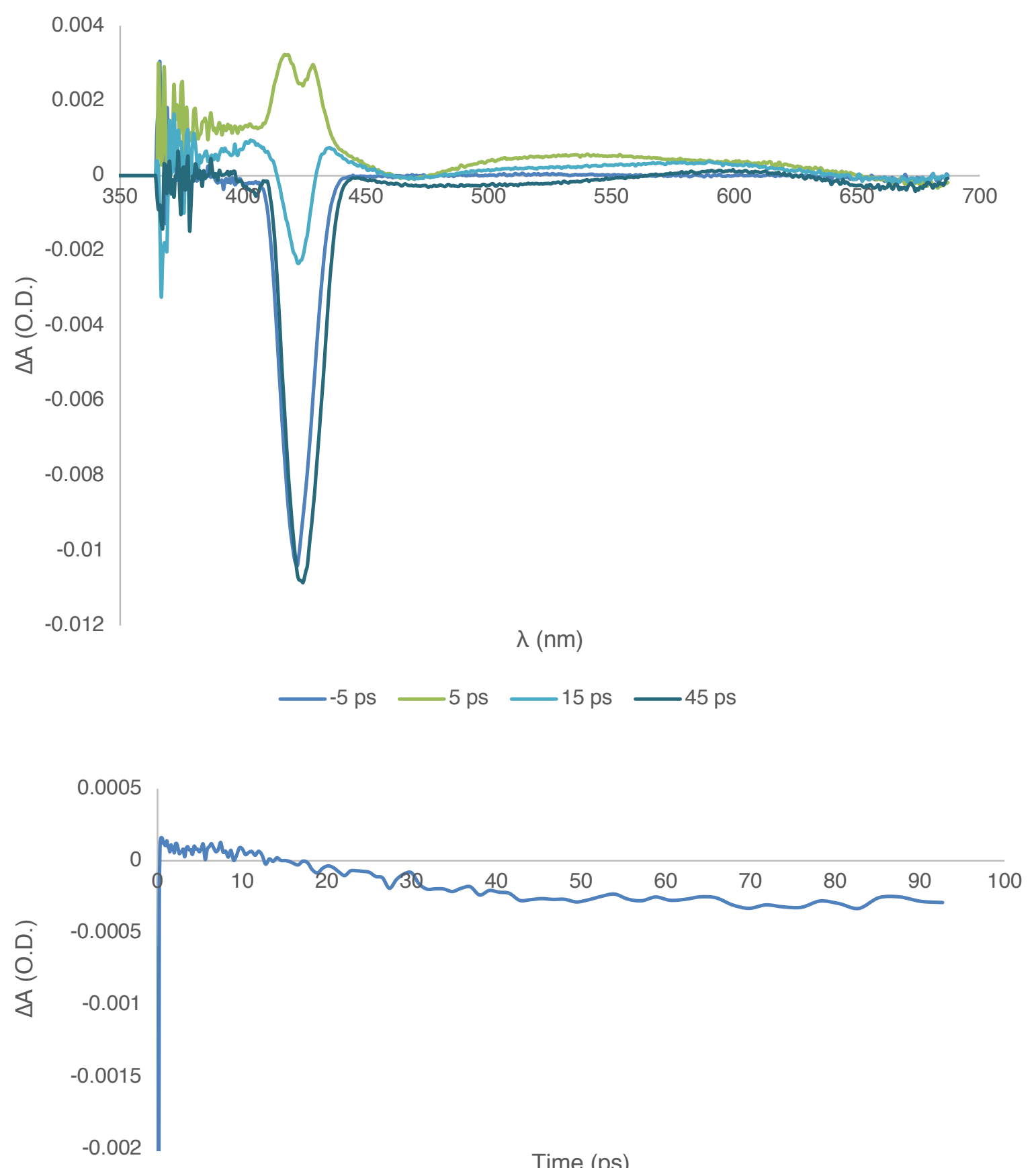

Figure S10. (top) Selected femtosecond transient absorption spectra of 1 in THF (3.3 mM, 298 $\mathrm{K}$, THF, $\lambda$ pump $=420 \mathrm{~nm}$, Ppump $=500 \mu \mathrm{W}$ ). Fitting of this data using global analysis generated an excited state lifetime value of 22.8 ps. (bottom) Kinetic trace showing the singlet exponential decay of the spectral peak at $480 \mathrm{~nm}$. 

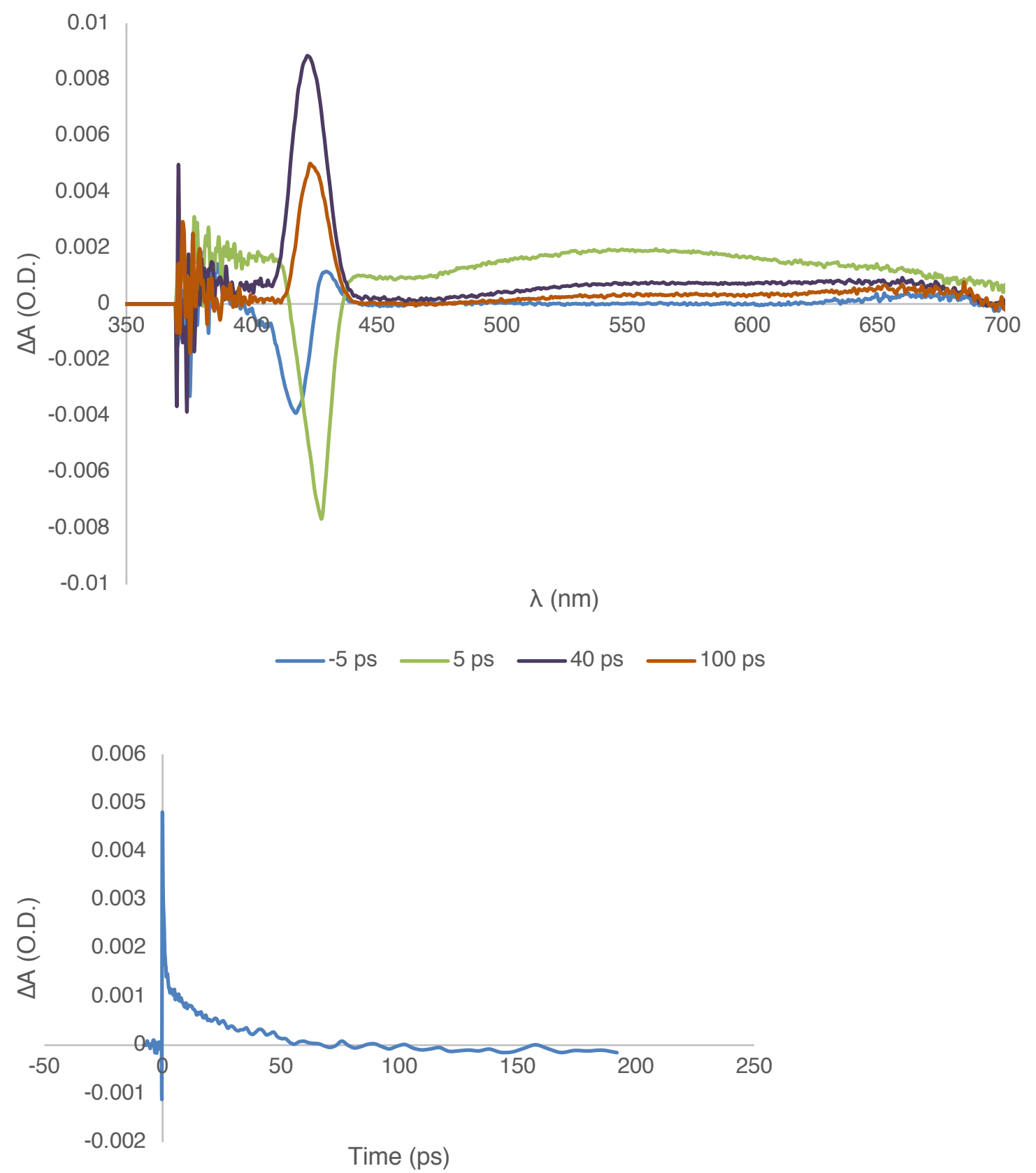

Figure S11. (top) Selected femtosecond transient absorption spectra of 1 in toluene $(3.3 \mathrm{mM}$, $298 \mathrm{~K}, \mathrm{THF}, \lambda$ pump $=420 \mathrm{~nm}$, Ppump $=500 \mu \mathrm{W}$ ) with $200 \mu \mathrm{L}$ of styrene. Fitting of this data using global analysis generated an excited state lifetime value of 26.5 ps. (bottom) Kinetic trace showing the singlet exponential decay of the spectral peak at $480 \mathrm{~nm}$. 

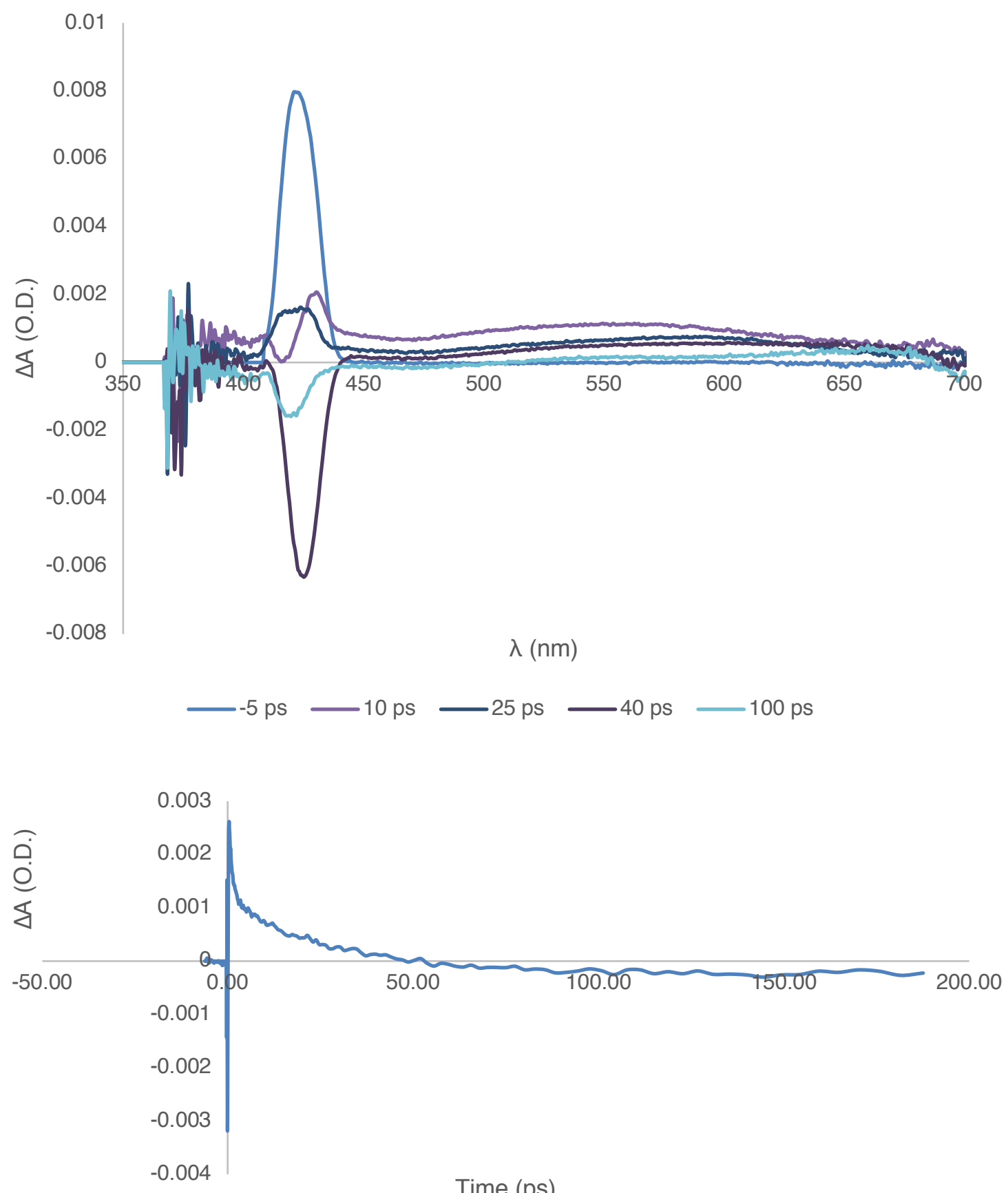

Time (ps)

Figure S12. (top) Selected femtosecond transient absorption spectra of 1 in toluene $(3.3 \mathrm{mM}$, $298 \mathrm{~K}, \mathrm{THF}, \lambda$ pump $=420 \mathrm{~nm}$, Ppump $=500 \mu \mathrm{W}$ ) with $200 \mu \mathrm{L}$ of cyclopentene. Fitting of this data using global analysis generated an excited state lifetime value of 24.3 ps. (bottom) Kinetic trace showing the singlet exponential decay of the spectral peak at $480 \mathrm{~nm}$. 

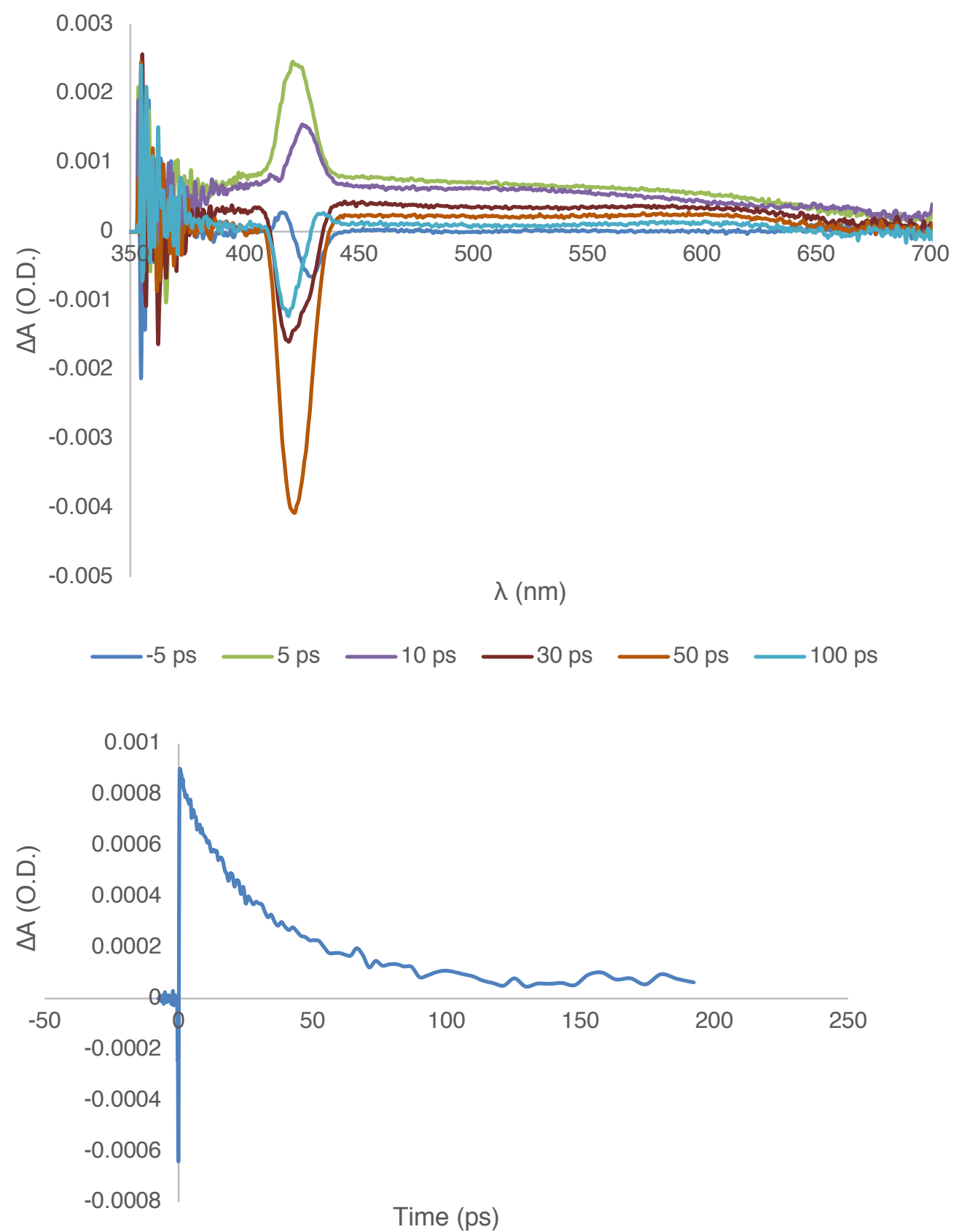

Figure S13. (top) Selected femtosecond transient absorption spectra of 1 in toluene (3.3 $\mathrm{mM}$, $298 \mathrm{~K}, \mathrm{THF}, \lambda$ pump $=420 \mathrm{~nm}$, Ppump $=500 \mu \mathrm{W}$ ) under $1 \mathrm{~atm}$ of CO. Fitting of this data using global analysis generated an excited state lifetime value of 29.1 ps. (bottom) Kinetic trace showing the singlet exponential decay of the spectral peak at $480 \mathrm{~nm}$. 


\section{Computational Analyses}

Isodesmic reaction scheme for DFT-based evaluation of $\mathrm{M}-\mathrm{H}$ bond dissociation free energies (M-H BDFEs). Thermodynamic properties of metal-hydride complexes could be effectively estimated by employing thermochemical cycles and isodesmic schemes of chemically related compounds. ${ }^{20}$ The systematic cancellation of errors and reliable energetics were obtained by DFT-based calculations in various systems. ${ }^{21-25}$ In order to achieve best estimation, reference systems that BDFEs were experimentally measured and tabulated were carefully chosen based on chemical similarity with the system of interest.

Table S2. Calculated BDFE of ( $\left.{ }^{\mathrm{iPr} D u P h o s}\right) \mathrm{Co}(\mathrm{CO})_{2} \mathrm{H}$ (1).

\begin{tabular}{|c|c|}
\hline $\begin{array}{c}\left({ }^{\mathrm{PPr} D u P h o s}\right) \mathrm{Co}(\mathrm{CO})_{2} \mathrm{H}+ \\
\left.\left({ }^{(\mathrm{Pr}} \mathrm{DuPhos}\right) \mathrm{Co}(\mathrm{CO})_{2} \bullet+(\mathrm{CO})_{4} \mathrm{Co}-\mathrm{H}\right)_{4} \mathrm{Co} \bullet \\
(\mathrm{CO})_{4} \mathrm{Co}-\mathrm{H} \stackrel{\mathrm{H}}{\rightleftarrows}(\mathrm{CO})_{4} \mathrm{Co} \bullet+\mathrm{H} \bullet\end{array}$ & 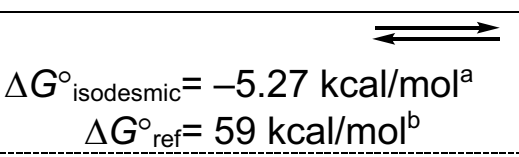 \\
\hline 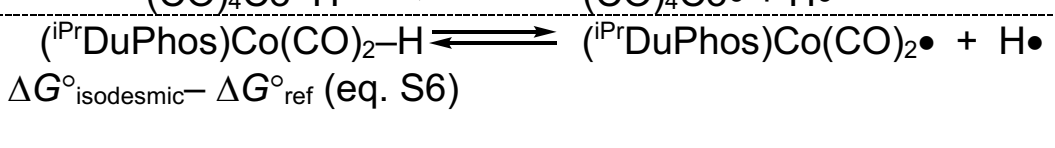 & $\Delta G^{\circ}{ }_{B D F E}(\mathbf{1})=$ \\
\hline
\end{tabular}

$(\mathrm{Co}, \mathrm{P})\}$ level of theory. ${ }^{\mathrm{b}}$ Retrieved from ref. ${ }^{26,27}$ 


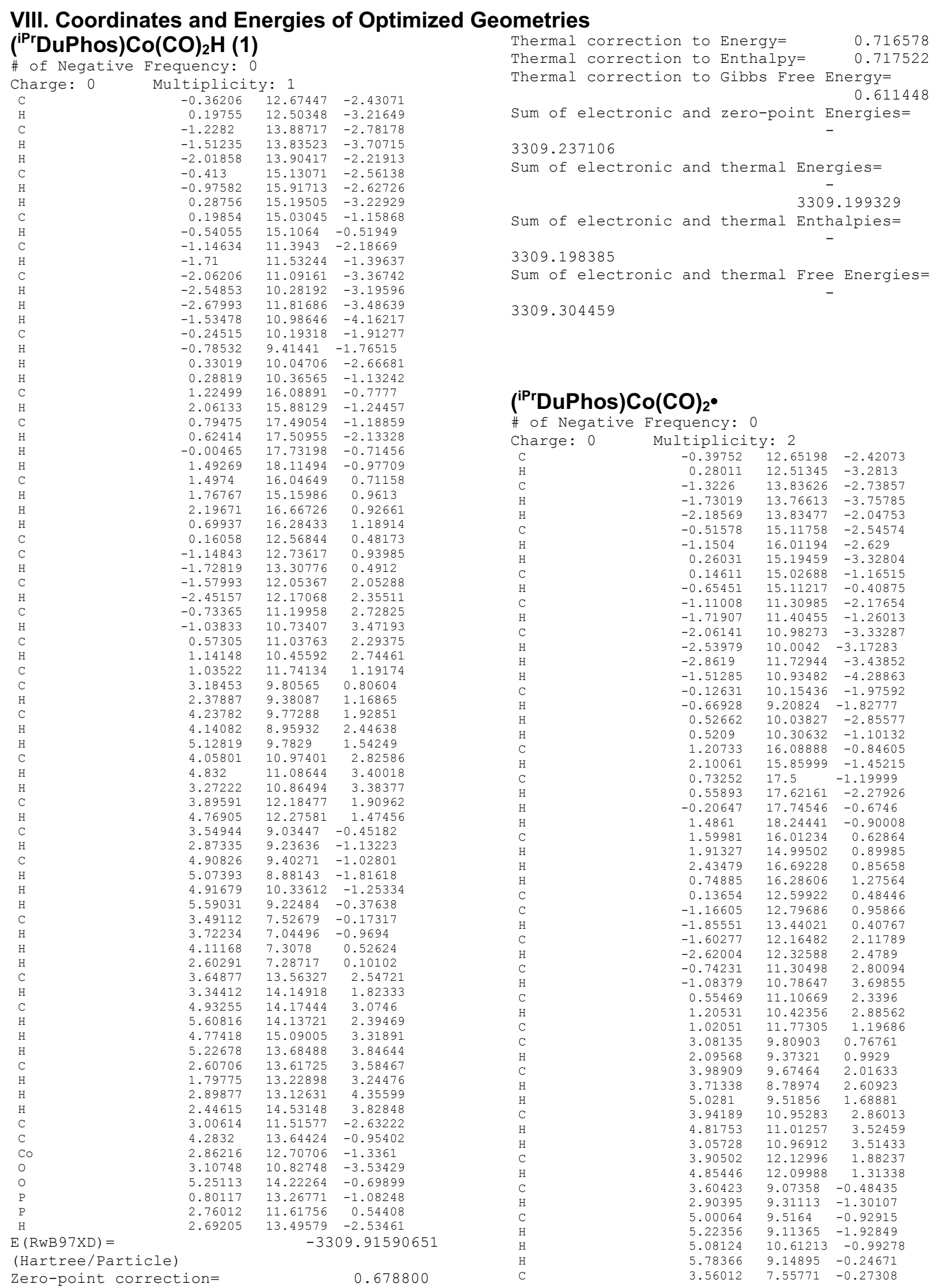




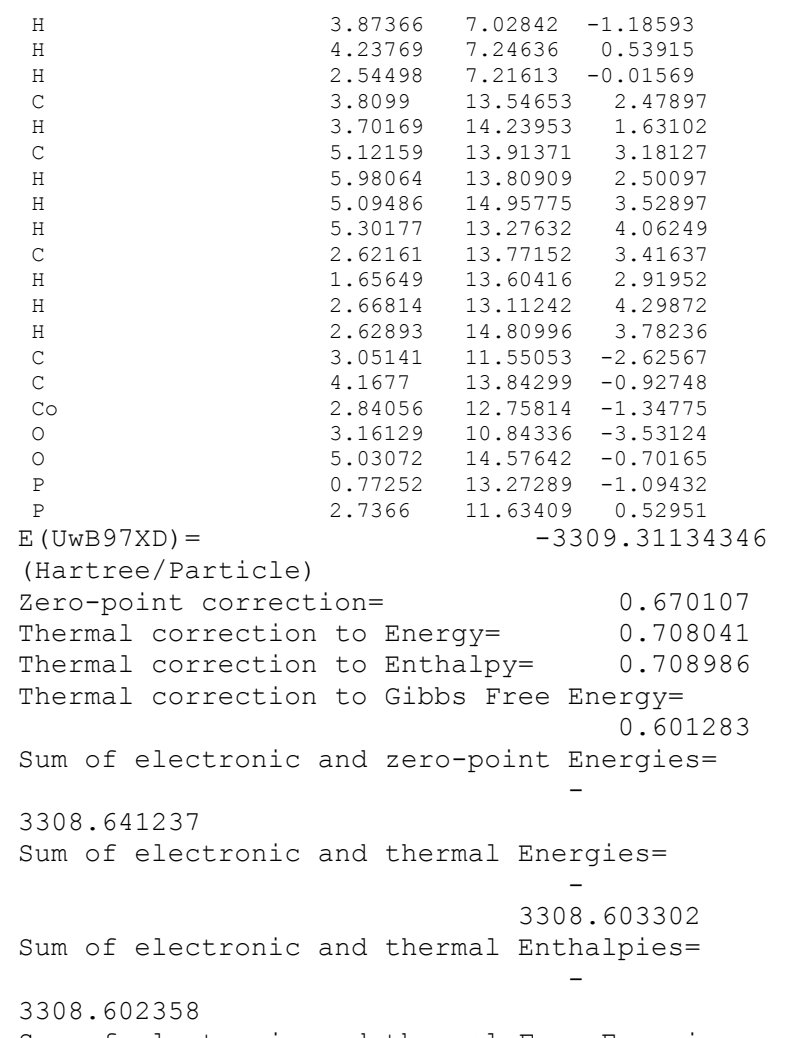

Sum of electronic and thermal Free Energies=

3308.710060

\section{$\mathrm{Co}(\mathrm{CO})_{4} \mathrm{H}$}

\# of Negative Frequency: 0

Charge: $0 \quad$ Multiplicity: 1

$\begin{array}{llll}\text { C } & 3.1156 & 11.38934 & -2.64273 \\ \text { C } & 4.05821 & 13.88974 & -0.26529 \\ \text { Co } & 2.73227 & 12.65705 & -1.23189 \\ O & 3.1076 & 10.71217 & -3.8481 \\ \text { O } & 5.11397 & 14.50824 & 0.48895 \\ \text { C } & 1.14901 & 13.25744 & -0.28756 \\ O & 0.16359 & 13.50205 & 0.23635 \\ \text { C } & 3.3055 & 11.20115 & -0.05556 \\ \text { O } & 3.57509 & 10.32459 & 0.65748 \\ \text { H } & & & 0.3557\end{array}$

$\begin{array}{llll}\mathrm{H} & 2.59588 & 13.78635 & -2.35579\end{array}$

$\mathrm{E}(\mathrm{RwB} 97 \mathrm{XD})=$
(Hartree/Particle)

$-1836.42651357$

Zero-point correction= $\quad 0.041293$

Thermal correction to Energy $=\quad 0.051362$

Thermal correction to Enthalpy $=0.052307$

Thermal correction to Gibbs Free Energy=

Sum of electronic and zero-point Energies=

1836.624636

Sum of electronic and thermal Energies=
1836.614567

Sum of electronic and thermal Enthalpies=

1836.613622

Sum of electronic and thermal Free Energies=

1836.661534

\section{$\mathrm{Co}(\mathrm{CO})_{4^{\circ}}$}

\# of Negative Frequency: 0

Charge: 0 Multiplicity: 2

$\begin{array}{llll}\text { C } & 3.1156 & 11.38934 & -2.64273\end{array}$

$\begin{array}{llll}\mathrm{C} & 4.05821 & 13.88974 & -0.26529\end{array}$

Co $2.73227 \quad 12.65705-1.23189$

$\begin{array}{llll}0 & 3.1076 & 10.71217 & -3.8481\end{array}$

$\begin{array}{llll}0 & 5.11397 & 14.50824 & 0.48895\end{array}$

$\begin{array}{llll}\mathrm{C} & 1.14901 & 13.25744 & -0.28756\end{array}$

$\begin{array}{llrr}0 & 3.3055 & 11.20115 & -0.05556 \\ 0 & 3.57509 & 10.32459 & 0.65748\end{array}$

$\mathrm{E}(\mathrm{RwB} 97 \mathrm{XD})=\quad-1835.85030606$

(Hartree/Particle)

Zero-point correction $=\quad 0.031824$

Thermal correction to Energy= $\quad 0.042196$

Thermal correction to Enthalpy= 0.043140

Thermal correction to Gibbs Free Energy=

0.006418

Sum of electronic and zero-point Energies=

1836.036545

Sum of electronic and thermal Energies=

1836.026173

Sum of electronic and thermal Enthalpies=

1836.025229

Sum of electronic and thermal Free Energies=

1836.074788

\section{$\mathrm{H} \bullet$}

Charge: 0 Multiplicity: 2

$\mathrm{H} \quad 0.000000000 \quad 0.000000000 \quad 0.000000000$

$\mathrm{E}(\mathrm{ZPE})=$

0.000000

$E($ Thermal $)=$

0.001416

$\mathrm{E}(\mathrm{SCF})=$

$\mathrm{DE}(\mathrm{MP} 2)=$

$\mathrm{DE}(\mathrm{CBS})=$

$\mathrm{DE}(\mathrm{MP} 34)=$

$\mathrm{DE}(\mathrm{CCSD})=$

$\mathrm{DE}(\operatorname{Int})=$

$\mathrm{DE}($ Empirical $)=$

$-0.499818$

0.000000

0.000000

0.000000

0.000000

0.000000

0.000000

$\mathrm{CBS}-\mathrm{QB} 3 \quad\left(\begin{array}{ll}0 & \mathrm{~K}\end{array}\right)=$

CBS-QB3 Energy=

CBS-QB3 Enthalpy=

CBS-QB3 Free Energy=

$-0.499818$

$-0.498402$

$-0.497457$

$-0.510472$ 
Time dependent DFT computed excited states of 1-calculated with wB97XD/\{cc-pVTZ, def2$\operatorname{TZVP}(\mathrm{Co}, \mathrm{P})\}$ level of theory.

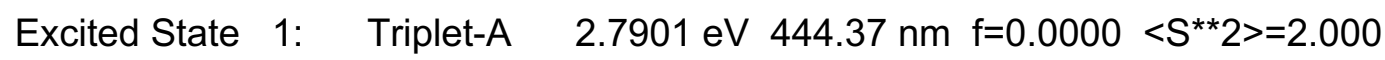

$$
\begin{array}{ll}
142(\mathrm{HOMO}-1) \rightarrow 146(\mathrm{LUMO}+2) & -0.40194 \\
143(\mathrm{HOMO}) \rightarrow 146(\text { LUMO }+2) & 0.50693 \\
143(\mathrm{HOMO}) \rightarrow 147(\text { LUMO }+3) & 0.11052
\end{array}
$$

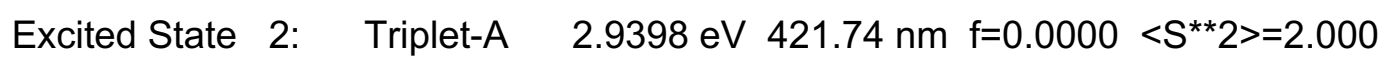
$136(\mathrm{HOMO}-7) \rightarrow 146(\mathrm{LUMO}+2) \quad-0.14336$

142(HOMO-1) ->146(LUMO+2) 0.50014

143(HOMO) ->146(LUMO+2) $\quad 0.40116$

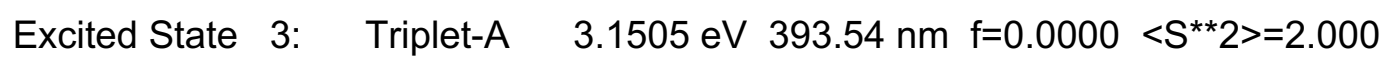
142(HOMO-1) ->147(LUMO+3) 0.14493

142(HOMO-1) ->148(LUMO+4) $\quad-0.11693$

142(HOMO-1) ->150(LUMO+6) $\quad 0.15676$

143(HOMO) ->147(LUMO+3) $\quad 0.48242$

143(HOMO) ->149(LUMO+5) $\quad 0.24768$

143(HOMO) ->150(LUMO+6) $\quad-0.14586$

143(HOMO) $->154($ LUMO+10) $\quad-0.12998$

Excited State 4: $\quad$ Singlet-A $\quad 3.5021 \mathrm{eV} \quad 354.02 \mathrm{~nm} \mathrm{f}=0.0019<\mathrm{S}^{* *} 2>=0.000$ $\begin{array}{ll}\text { 142(HOMO-1) ->146(LUMO+2) } & -0.30690 \\ \text { 143(HOMO) ->146(LUMO+2) } & 0.58196\end{array}$

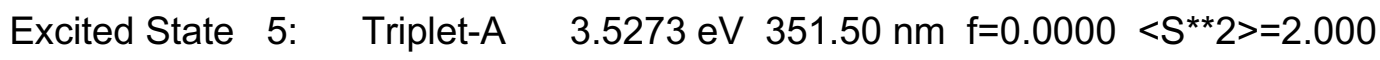
137(HOMO-6) ->146(LUMO+2) $\quad-0.19364$

138(HOMO-5) ->146(LUMO+2) $\quad-0.12089$ 


$$
\begin{array}{ll}
\text { 140(HOMO-3) ->146(LUMO+2) } & 0.11725 \\
\text { 141(HOMO-2) ->146(LUMO+2) } & 0.52036 \\
\text { 142(HOMO-1) ->147(LUMO+3) } & 0.16544
\end{array}
$$

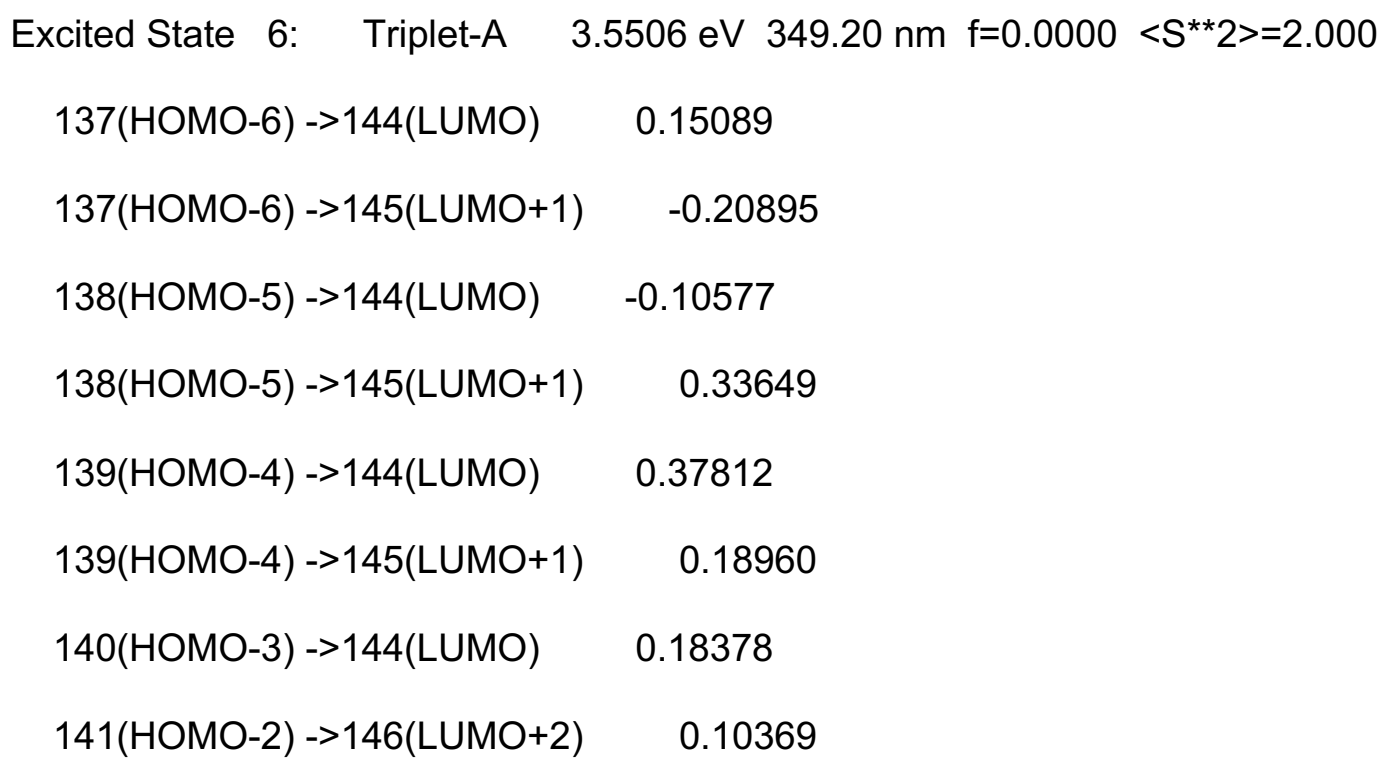

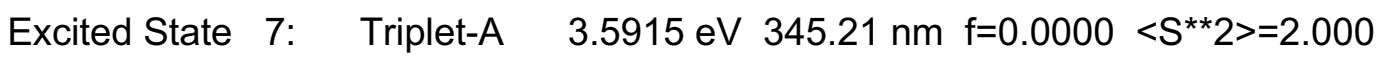

$$
\begin{array}{ll}
\text { 138(HOMO-5) ->146(LUMO+2) } & 0.10041 \\
\text { 141(HOMO-2) ->146(LUMO+2) } & -0.20985 \\
\text { 142(HOMO-1) ->146(LUMO+2) } & -0.10813 \\
\text { 142(HOMO-1) ->147(LUMO+3) } & 0.43139 \\
\text { 142(HOMO-1) ->148(LUMO+4) } & -0.21254 \\
\text { 142(HOMO-1) ->150(LUMO+6) } & 0.17292 \\
\text { 142(HOMO-1) ->154(LUMO+10 } & -0.12020 \\
\text { 143(HOMO) ->148(LUMO+4) } & -0.16367 \\
\text { 143(HOMO) ->149(LUMO+5) } & -0.15975 \\
143(\mathrm{HOMO})->150(\text { LUMO+6) } & 0.15266
\end{array}
$$




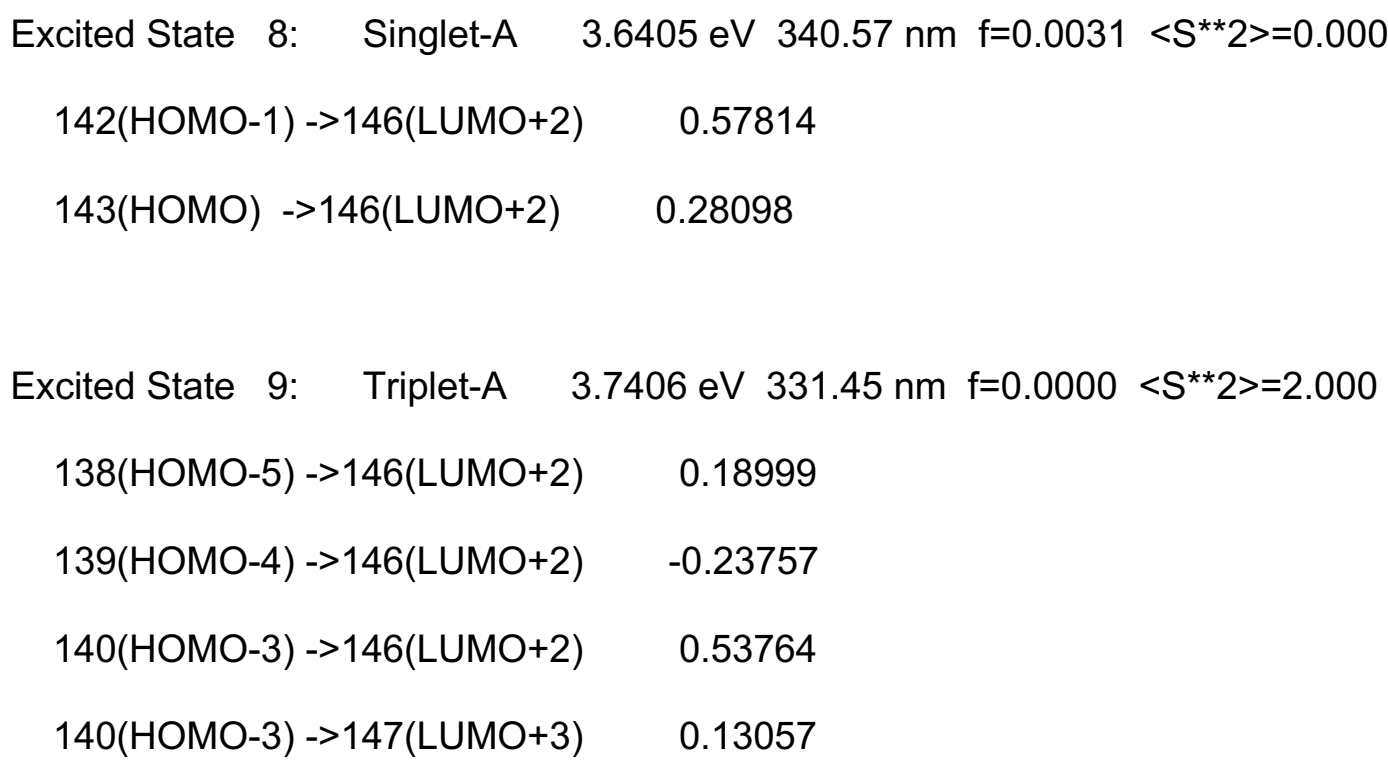

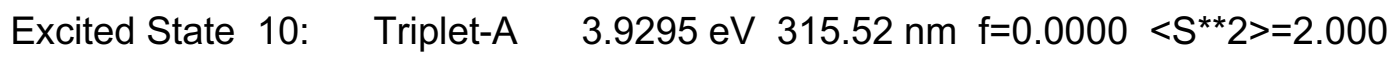
142(HOMO-1) ->144(LUMO) 0.16018

142(HOMO-1) ->145(LUMO+1) $\quad-0.25171$

142(HOMO-1) ->149(LUMO+5) 0.17545

142(HOMO-1) ->150(LUMO+6) - $\quad-0.21448$

143(HOMO) $->144($ LUMO) $\quad-0.15608$

143(HOMO) ->145(LUMO+1) 0.26865

143(HOMO) $->147($ LUMO+3) $\quad 0.30561$

143(HOMO) $->150($ LUMO+6) $\quad 0.23208$

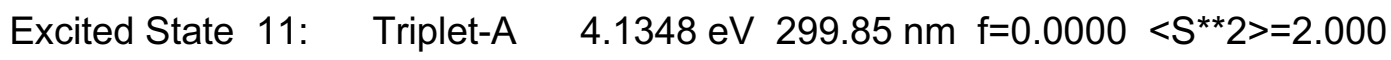
142(HOMO-1) ->145(LUMO+1) 0.12727
142(HOMO-1) ->150(LUMO+6) 0.14556
143(HOMO) $->144($ LUMO) $\quad-0.29366$
143(HOMO) ->148(LUMO+4) 0.50730
143(HOMO) ->149(LUMO+5) - -0.17673 
143(HOMO) ->150(LUMO+6) 0.16297

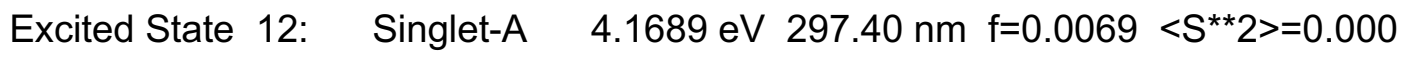

$$
\begin{array}{ll}
\text { 137(LUMO-6) ->146(LUMO+2) } & -0.22441 \\
\text { 138(LUMO-5) ->146(LUMO+2) } & -0.16441 \\
\text { 141(LUMO-2) ->146(LUMO+2) } & 0.56207
\end{array}
$$

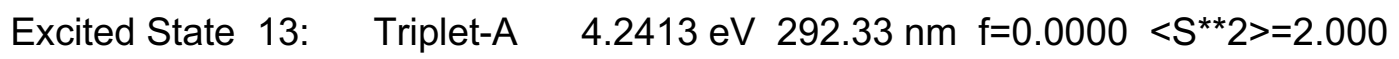
142(HOMO-1) ->144(LUMO) $\quad-0.19577$

142(HOMO-1) ->145(LUMO+1) 0.18509

142(HOMO-1) ->147(LUMO+3) $\quad-0.29771$

142(HOMO-1) ->149(LUMO+5) $\quad-0.23025$

142(HOMO-1) ->150(LUMO+6) 0.16746

142(HOMO-1) ->154(LUMO+10) 0.10062

143(HOMO) ->145(LUMO+1) 0.30844

143(HOMO) ->147(LUMO+3) 0.11843

143(HOMO) ->148(LUMO+4) - -0.22956

143(HOMO) ->150(LUMO+6) 0.17812

Excited State 14: Singlet-A $4.2958 \mathrm{eV} 288.62 \mathrm{~nm} \mathrm{f}=0.0022<\mathrm{S}^{\star *} 2>=0.000$
140(HOMO-3) ->146(LUMO+2) $\quad-0.15780$
141(HOMO-2) ->146(LUMO+2 0.10297
143(HOMO) ->144(LUMO) 0.56665
143(HOMO) ->148(LUMO+4) - $\quad-0.15908$
143(HOMO) ->149(LUMO+5) 0.12564
143(HOMO) ->150(LUMO+6) - 


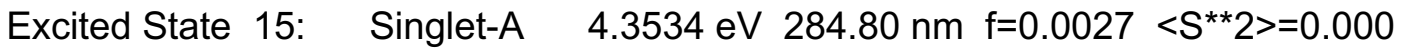

$$
\begin{aligned}
& \text { 138(HOMO-5) ->146(LUMO+2) } 0.15385 \\
& \text { 139(HOMO-4) ->146(LUMO+2) - -0.19575 } \\
& \text { 140(HOMO-3) ->146(LUMO+2) } \quad 0.46577 \\
& \text { 140(HOMO-3) ->147(LUMO+3) } 0.14216 \\
& \text { 142(HOMO-1) ->144(LUMO) } \quad-0.12121 \\
& \text { 142(HOMO-1) ->147(LUMO+3) - } \\
& \text { 143(HOMO) ->144(LUMO) } 0.23419 \\
& \text { 143(HOMO) ->145(LUMO+1) } 0.16312
\end{aligned}
$$

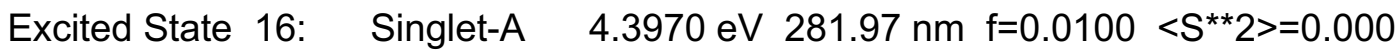

$$
\begin{array}{lc}
\text { 140(HOMO-3) ->146(LUMO+2) } & -0.22133 \\
\text { 142(HOMO-1) ->144(LUMO) } & -0.13848 \\
\text { 142(HOMO-1) ->147(LUMO+3) } & -0.20218 \\
\text { 143(HOMO) ->145(LUMO+1) } & 0.46955 \\
\text { 143(HOMO) ->147(LUMO+3) } & 0.21277 \\
\text { 143(HOMO) ->148(LUMO+4) } & -0.10013 \\
\text { 143(HOMO) ->150(LUMO+6) } & 0.16430
\end{array}
$$

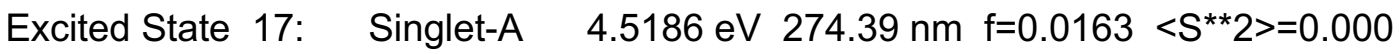
142(HOMO-1) ->144(LUMO) 0.26798 


$$
\begin{array}{ll}
\text { 143(HOMO) ->148(LUMO+4) } & 0.26789 \\
\text { 143(HOMO) ->149(LUMO+5) } & -0.11976
\end{array}
$$
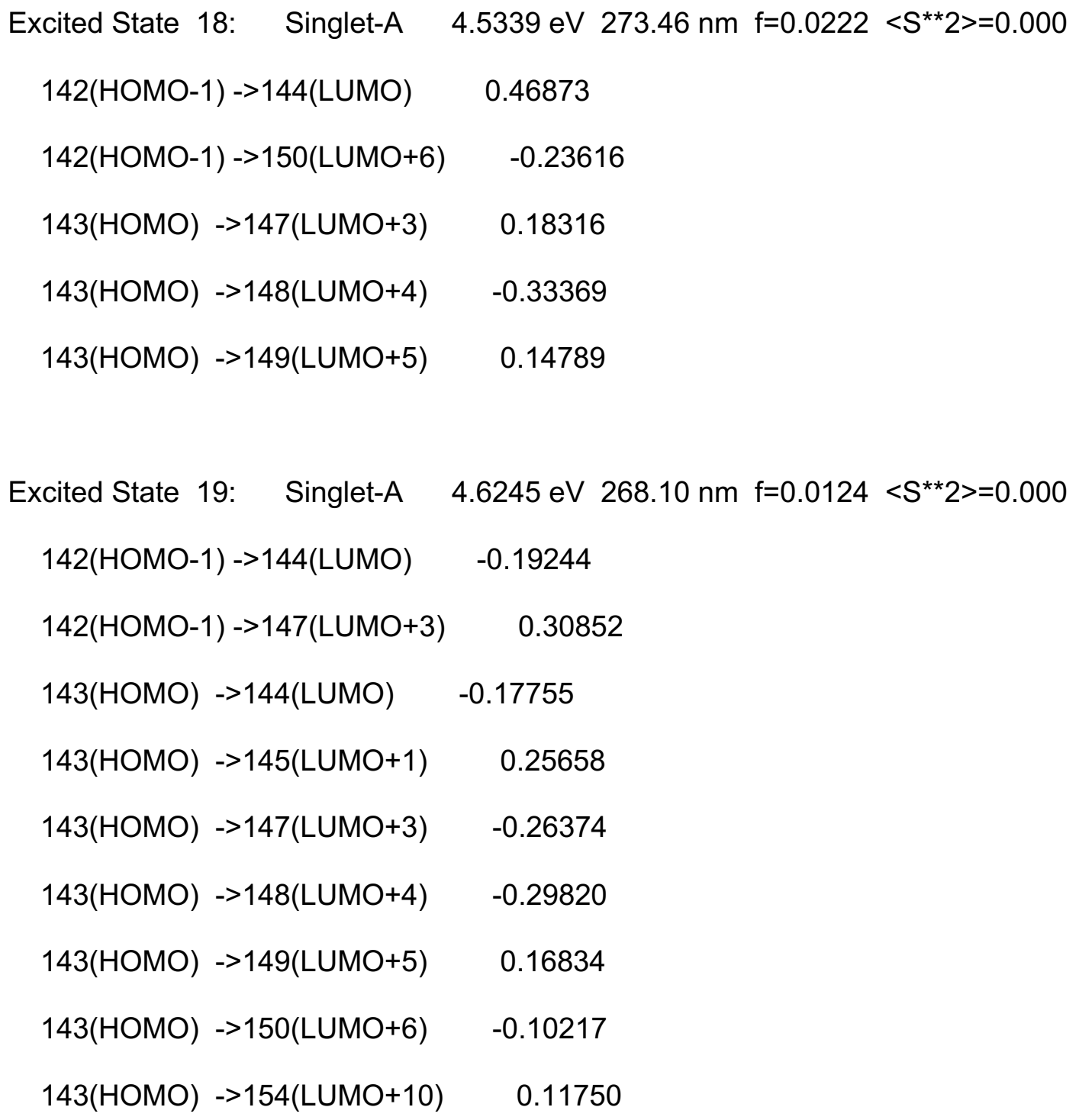

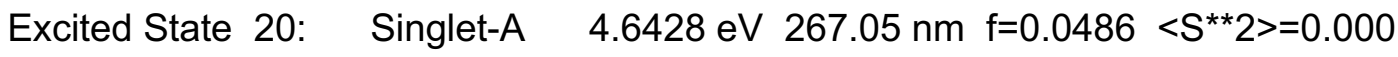
$\begin{array}{ll}\text { 142(HOMO-1) ->144(LUMO) } & 0.22136 \\ \text { 142(HOMO-1) ->145(LUMO+1) } & 0.51172 \\ \text { 142(HOMO-1) ->147(LUMO+3) } & -0.12027 \\ \text { 142(HOMO-1) ->148(LUMO+4) } & -0.14911\end{array}$ 
142(HOMO-1) ->149(LUMO+5) $\quad-0.16372$

143(HOMO) ->147(LUMO+3) - -0.23304 


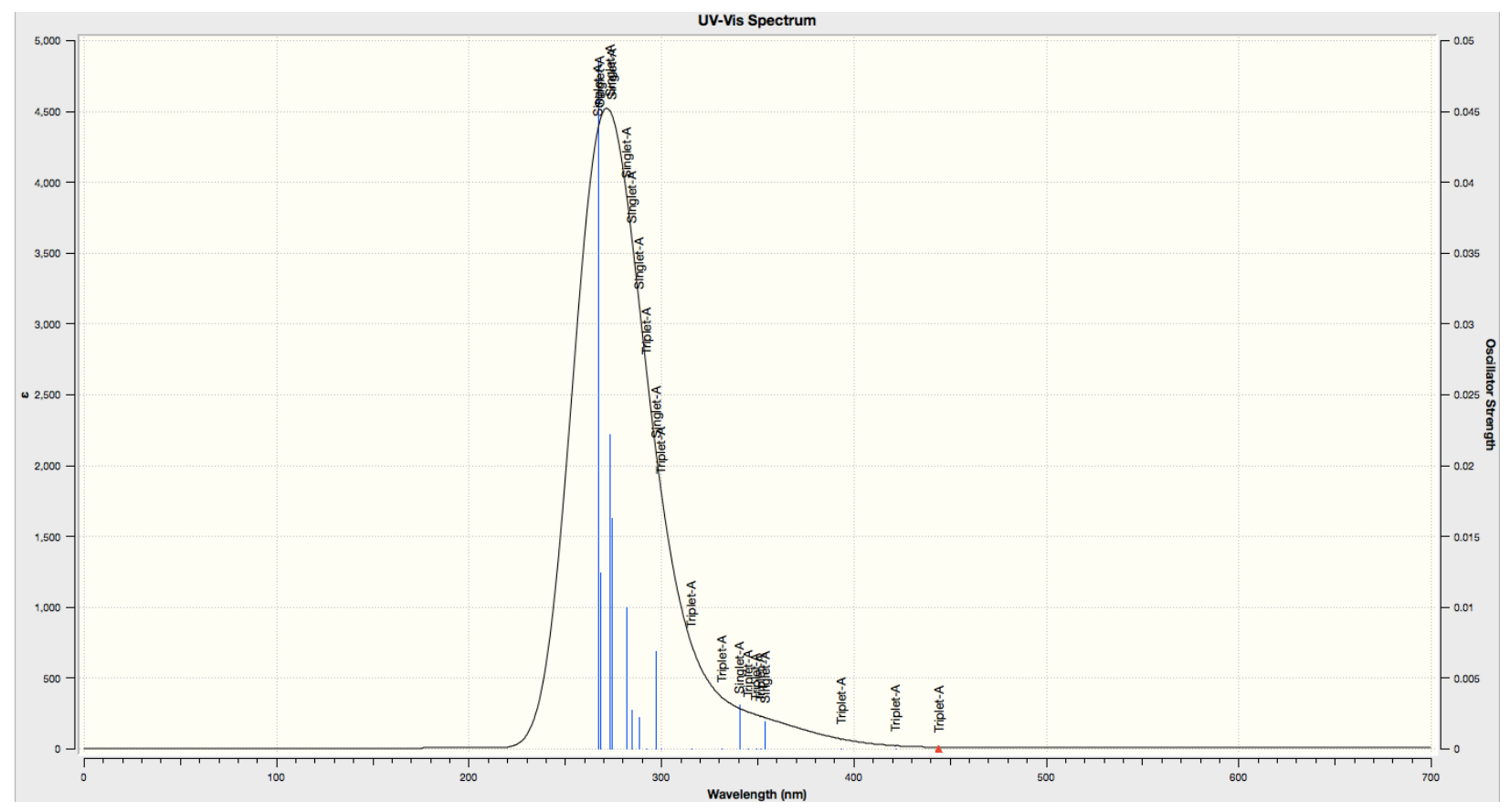

Figure S14. TD-DFT computed UV/vis spectrum of 1 with associated transitions (wB97XD/\{ccpVTZ, def2-TZVP (Co, P)\}). 


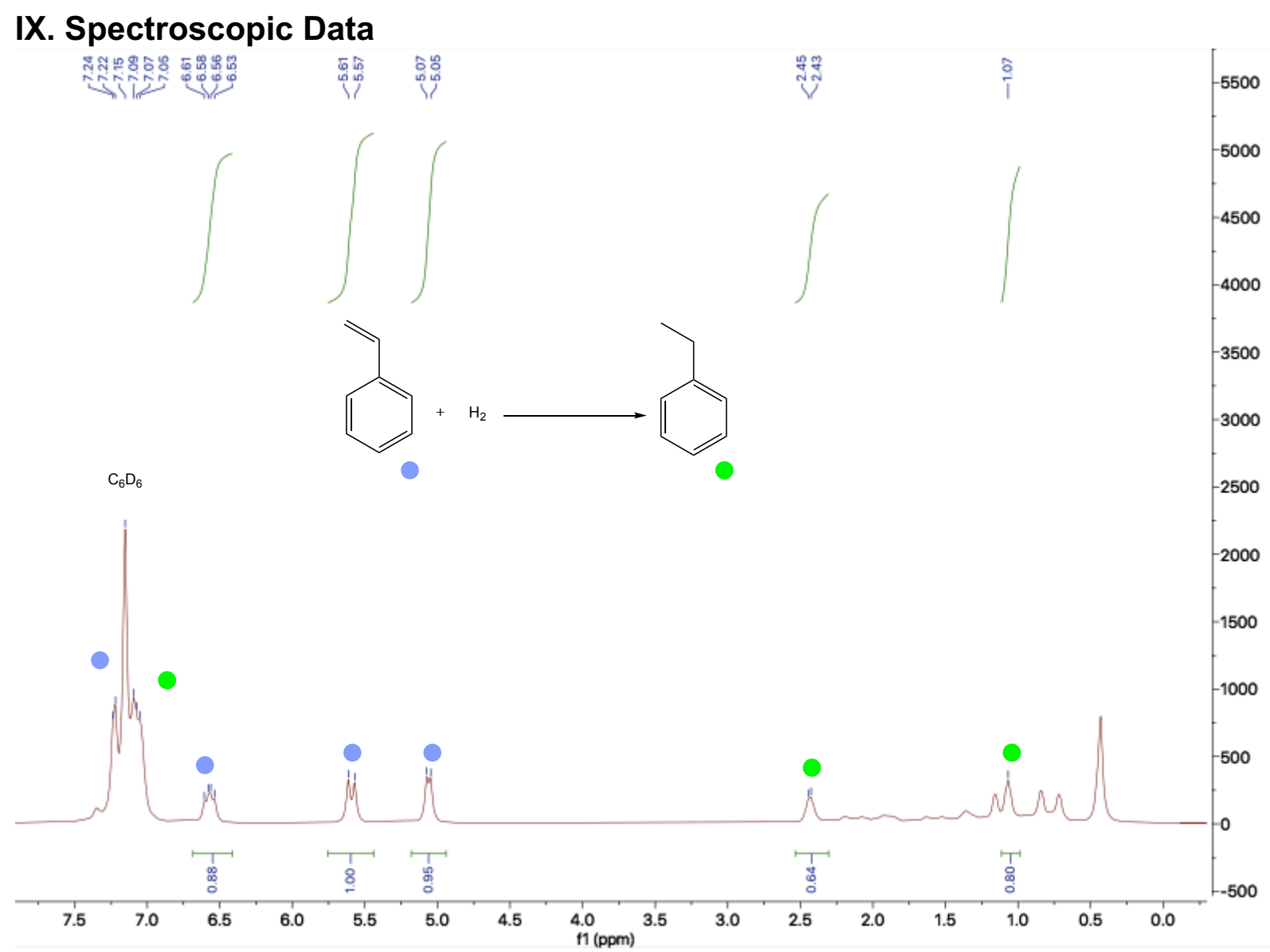

Figure S15. ${ }^{1} \mathrm{H}$ NMR (benzene- $d_{6}$, rt) spectrum of crude product formed from the hydrogenation of styrene by 1 under dark conditions. 


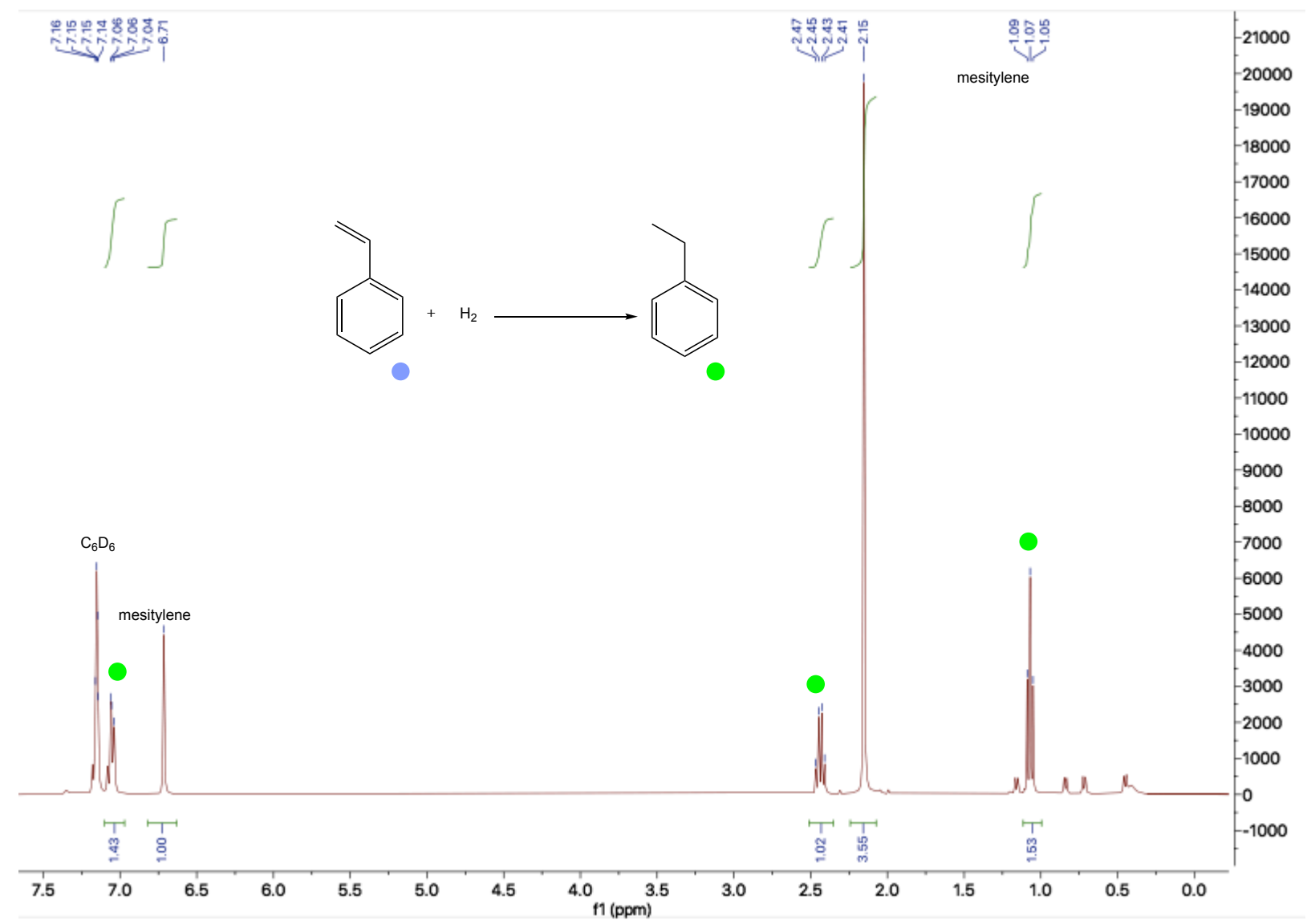

Figure S16. ${ }^{1} \mathrm{H}$ NMR (benzene- $d_{6}$, rt) spectrum of crude product formed from the hydrogenation of styrene by $\mathbf{1}$ under thermal conditions. 


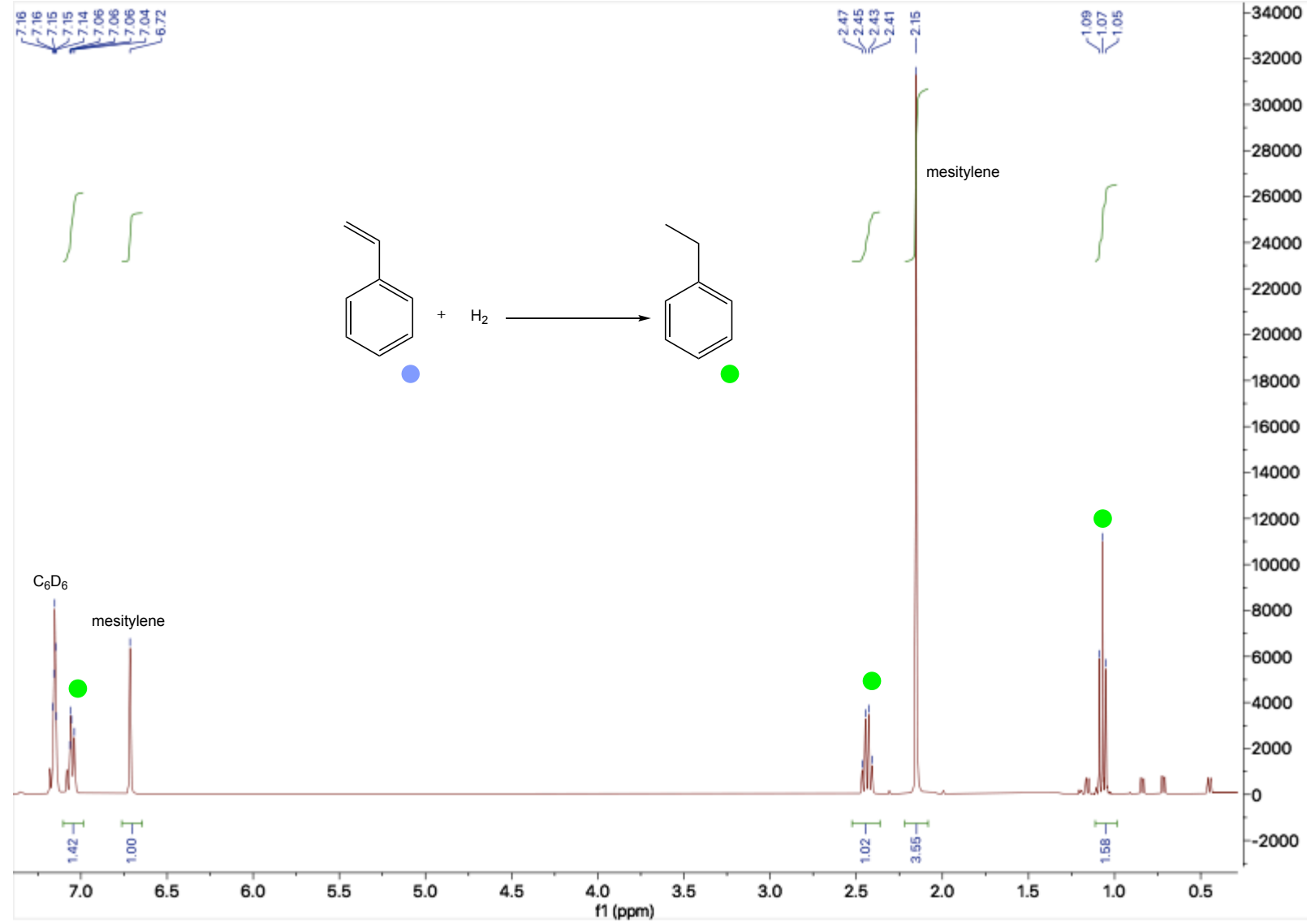

Figure S17. ${ }^{1} \mathrm{H}$ NMR (benzene- $d_{6}$, rt) spectrum of crude product formed from the hydrogenation of styrene by 1 under irradiation conditions. 


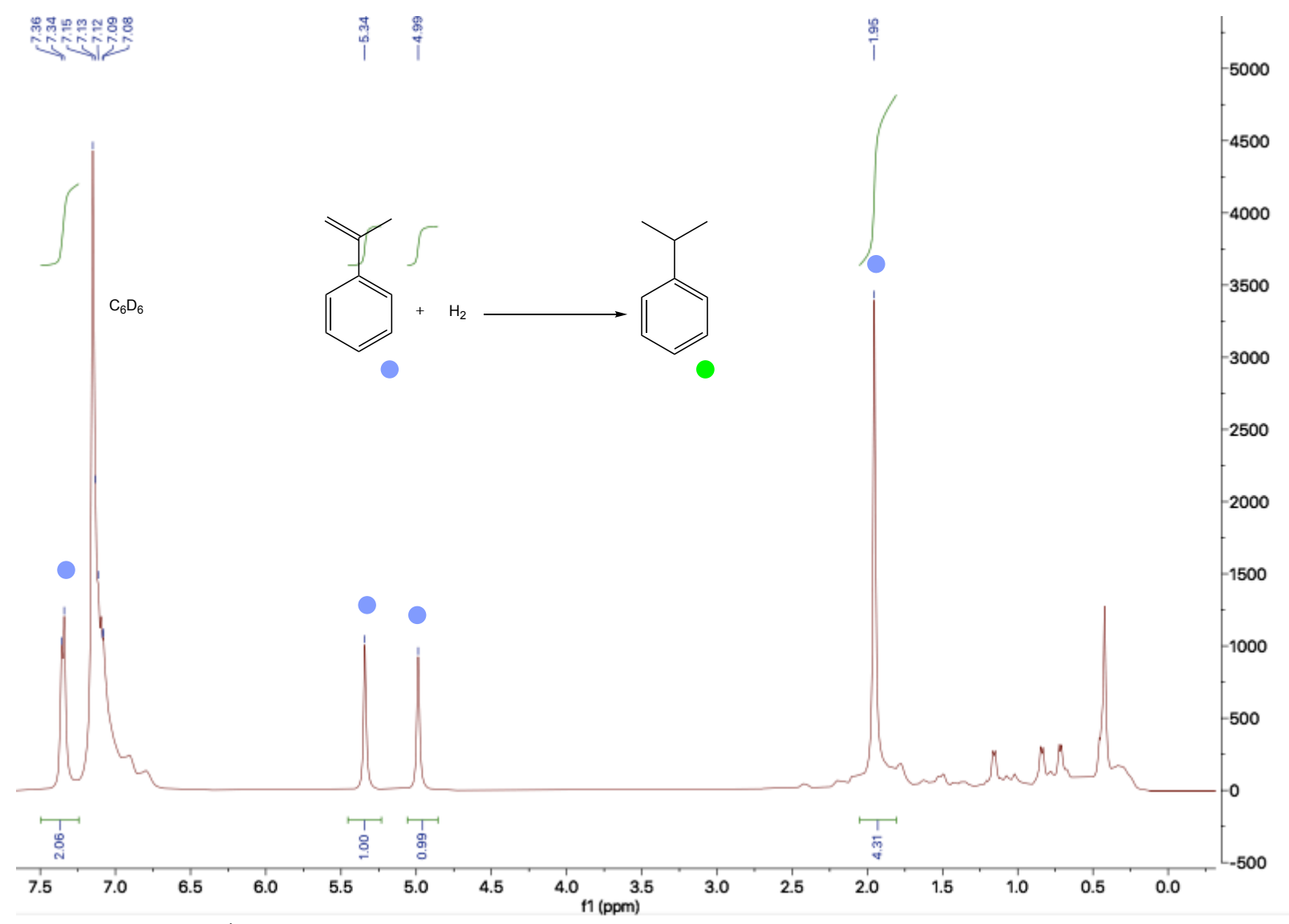

Figure S18. ${ }^{1} \mathrm{H}$ NMR (benzene- $d_{6}$, rt) spectrum of crude product formed from the hydrogenation of $\alpha$-methyl styrene by 1 under dark conditions. 


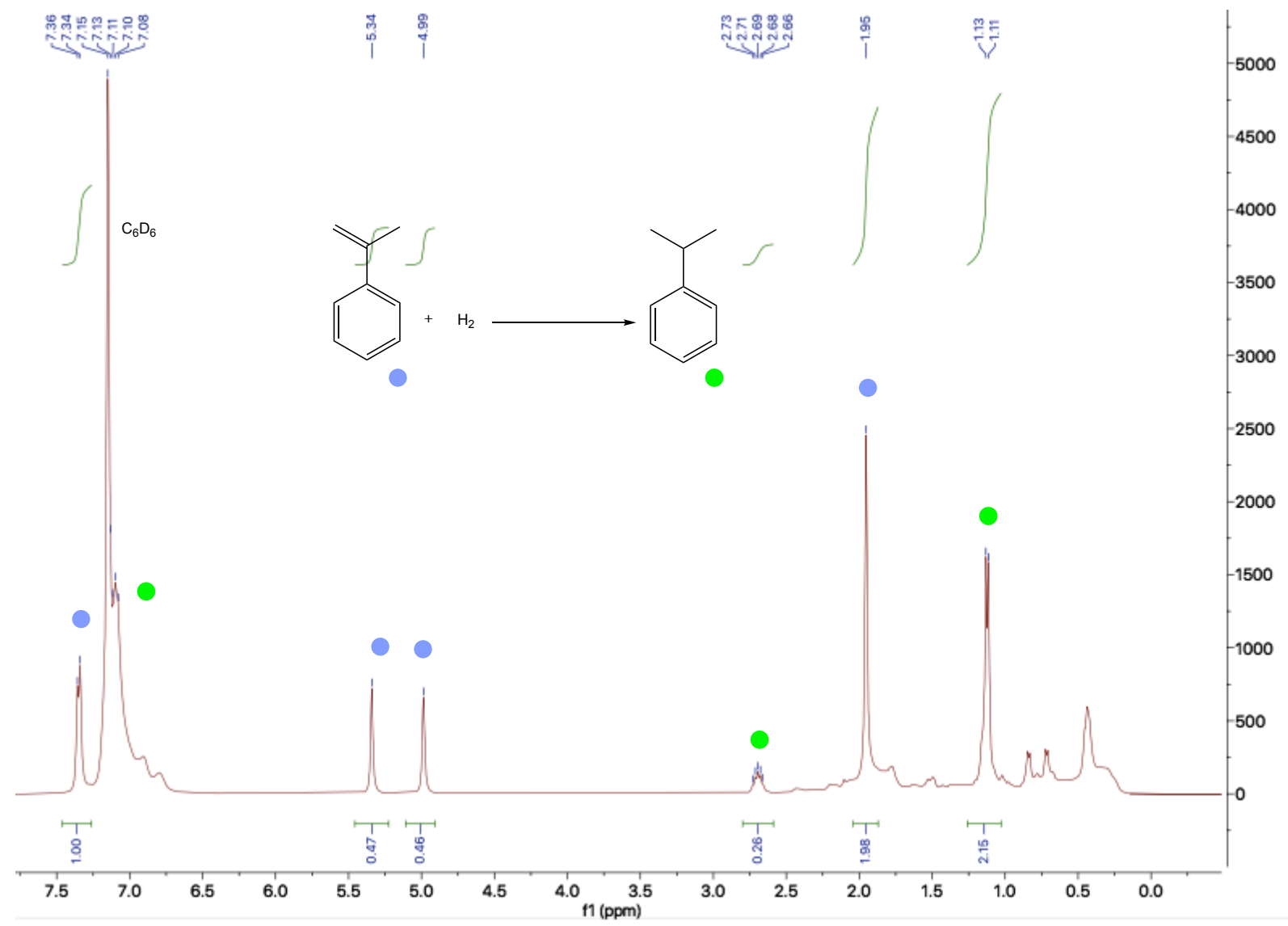

Figure S19. ${ }^{1} \mathrm{H}$ NMR (benzene- $d_{6}$, rt) spectrum of crude product formed from the hydrogenation of $\alpha$-methyl styrene by 1 under thermal conditions. 


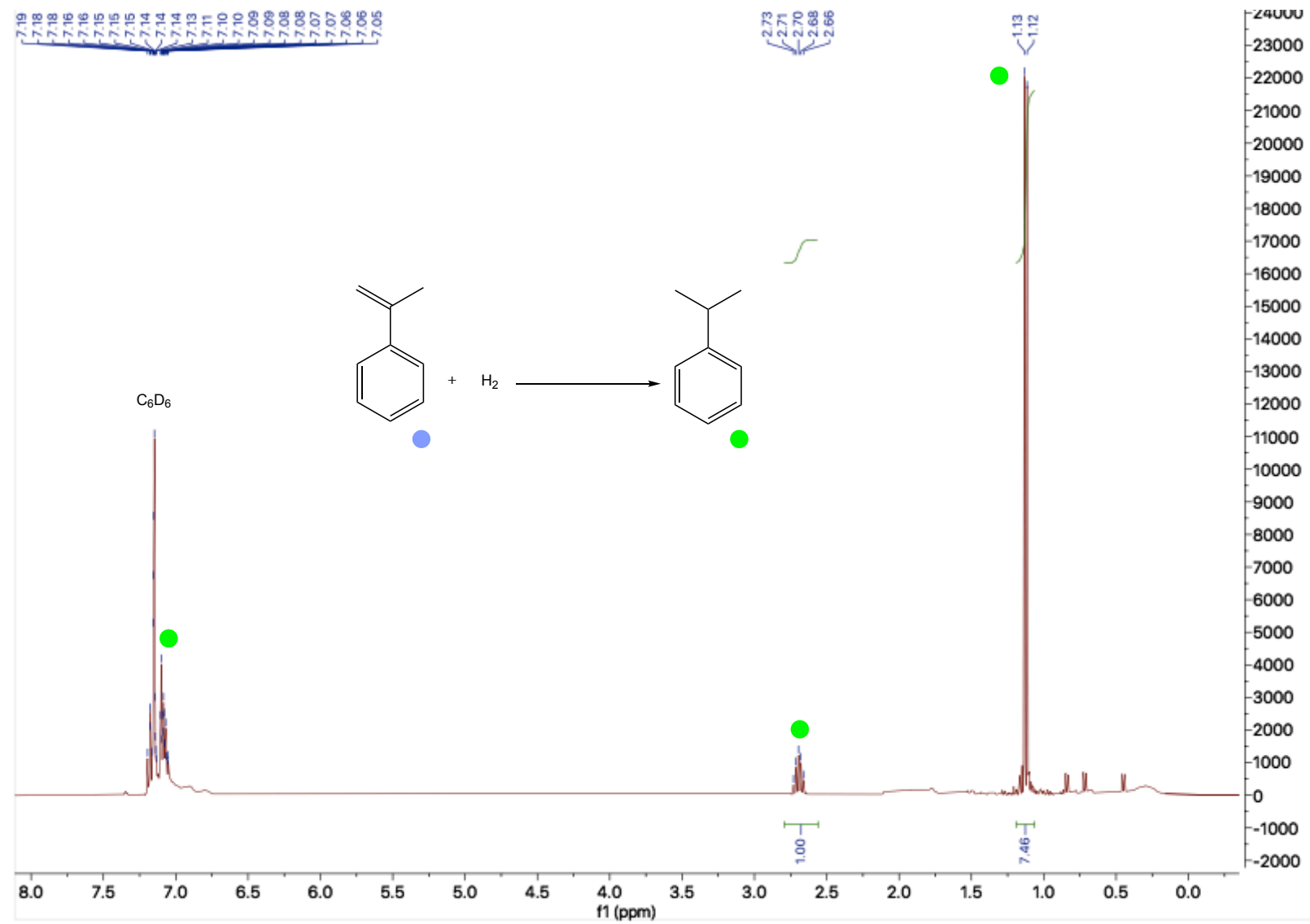

Figure S20. ${ }^{1} \mathrm{H}$ NMR (benzene- $d_{6}$, rt) spectrum of crude product formed from the hydrogenation of $\alpha$-methyl styrene by 1 under irradiation conditions. 


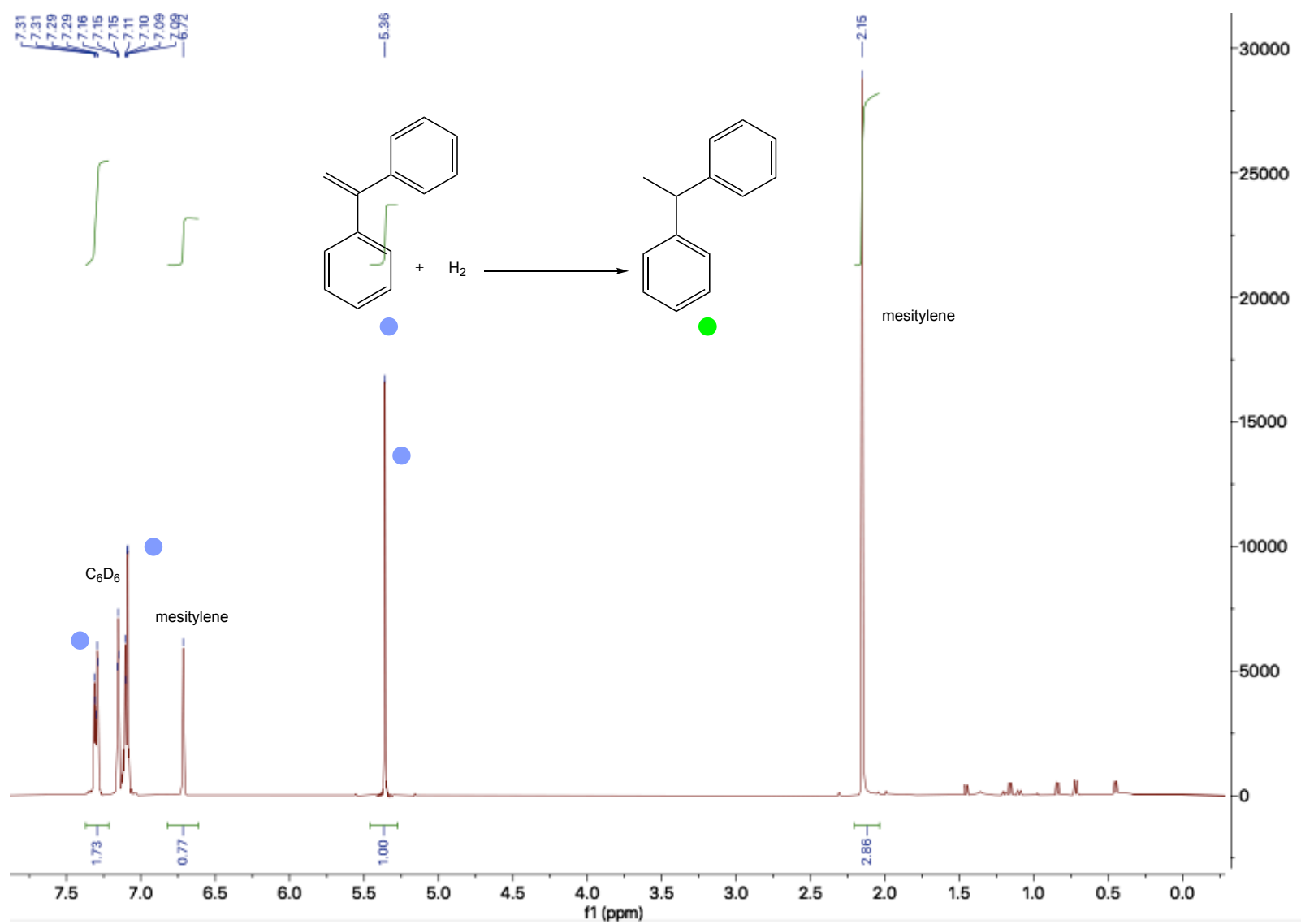

Figure S21. ${ }^{1} \mathrm{H}$ NMR (benzene- $d_{6}$, rt) spectrum of crude product formed from the hydrogenation of 1,1-diphenyl ethylene by 1 under dark conditions. 


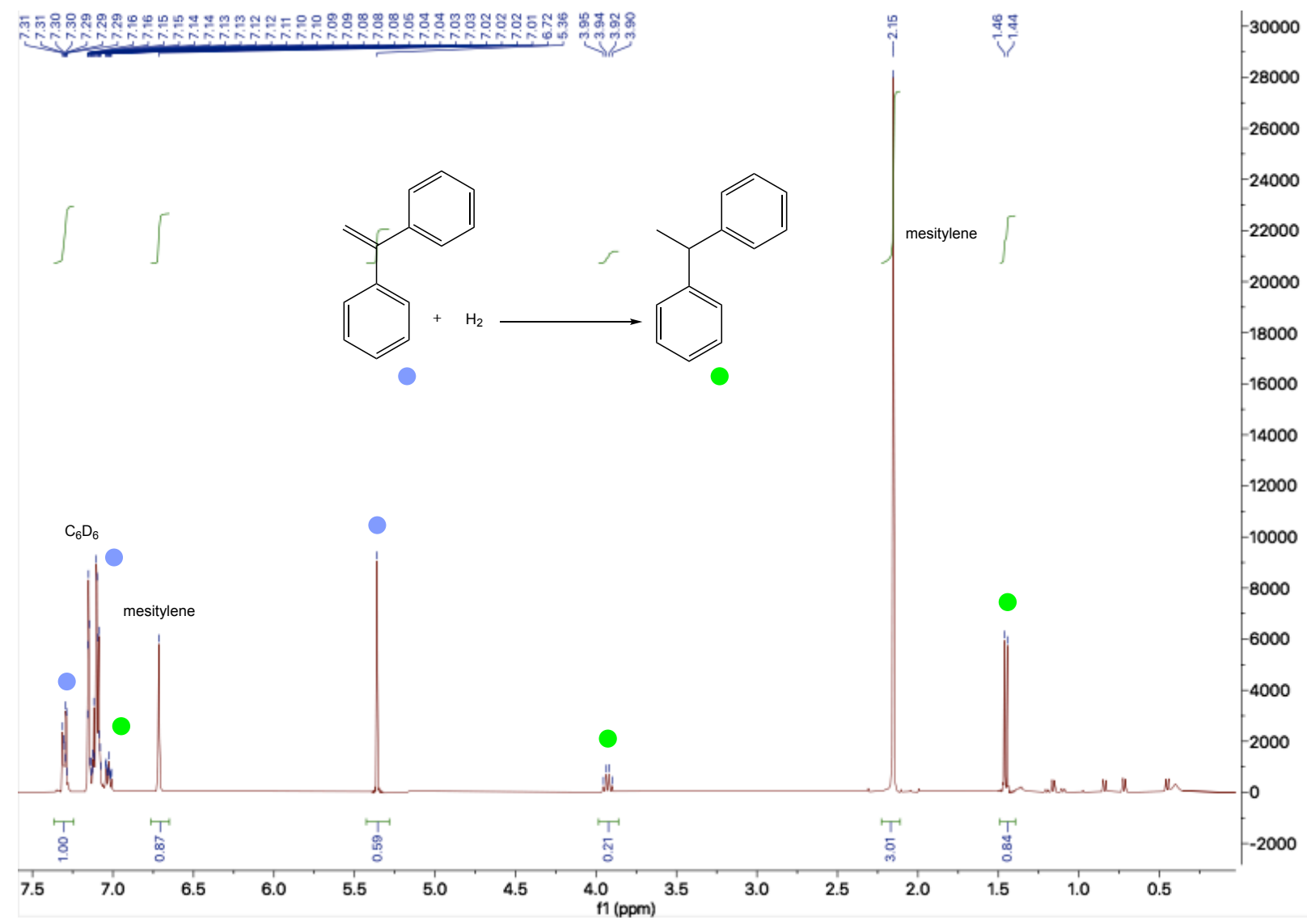

Figure S22. ${ }^{1} \mathrm{H}$ NMR (benzene- $d_{6}$, rt) spectrum of crude product formed from the hydrogenation of 1,1-diphenyl ethylene by 1 under thermal conditions. 


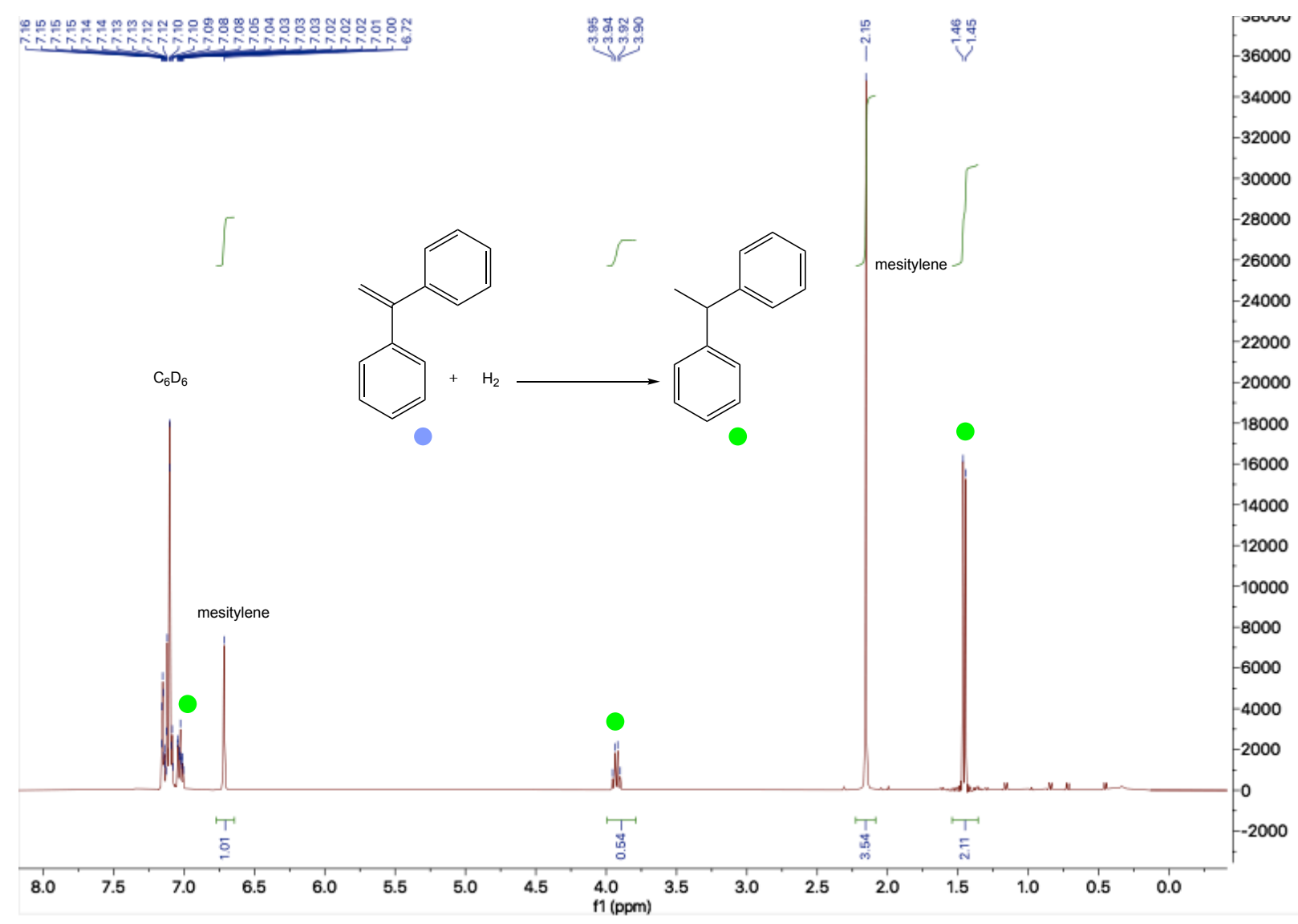

Figure S23. ${ }^{1} \mathrm{H}$ NMR (benzene- $d_{6}$, rt) spectrum of crude product formed from the hydrogenation of 1,1-diphenyl ethylene by 1 under irradiation conditions. 


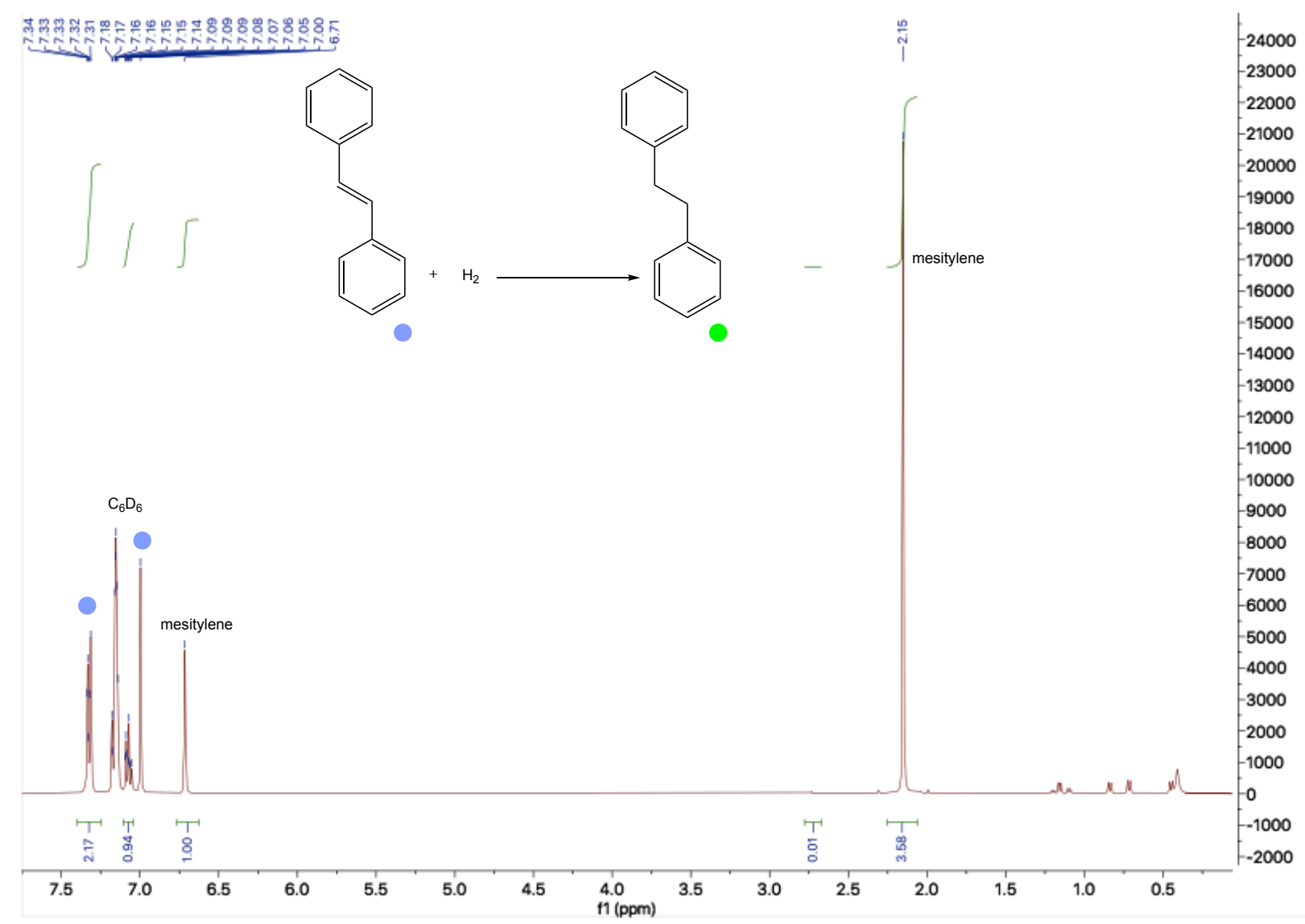

Figure S24. ${ }^{1} \mathrm{H}$ NMR (benzene- $d_{6}$, rt) spectrum of crude product formed from the hydrogenation of trans-stilbene by 1 under dark conditions. 


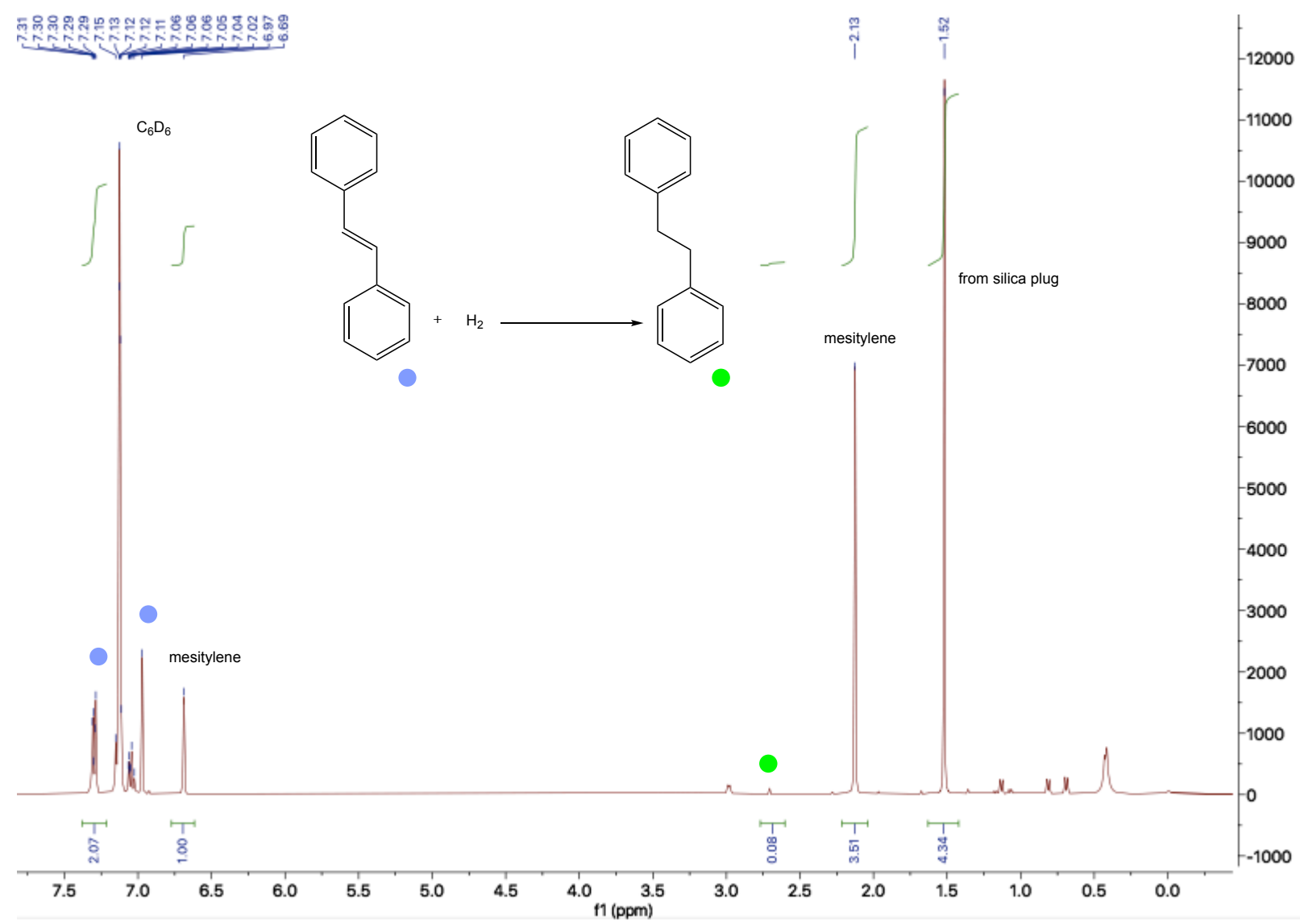

Figure S25. ${ }^{1} \mathrm{H}$ NMR (benzene- $d_{6}$, rt) spectrum of crude product formed from the hydrogenation of trans-stilbene by 1 under thermal conditions. 


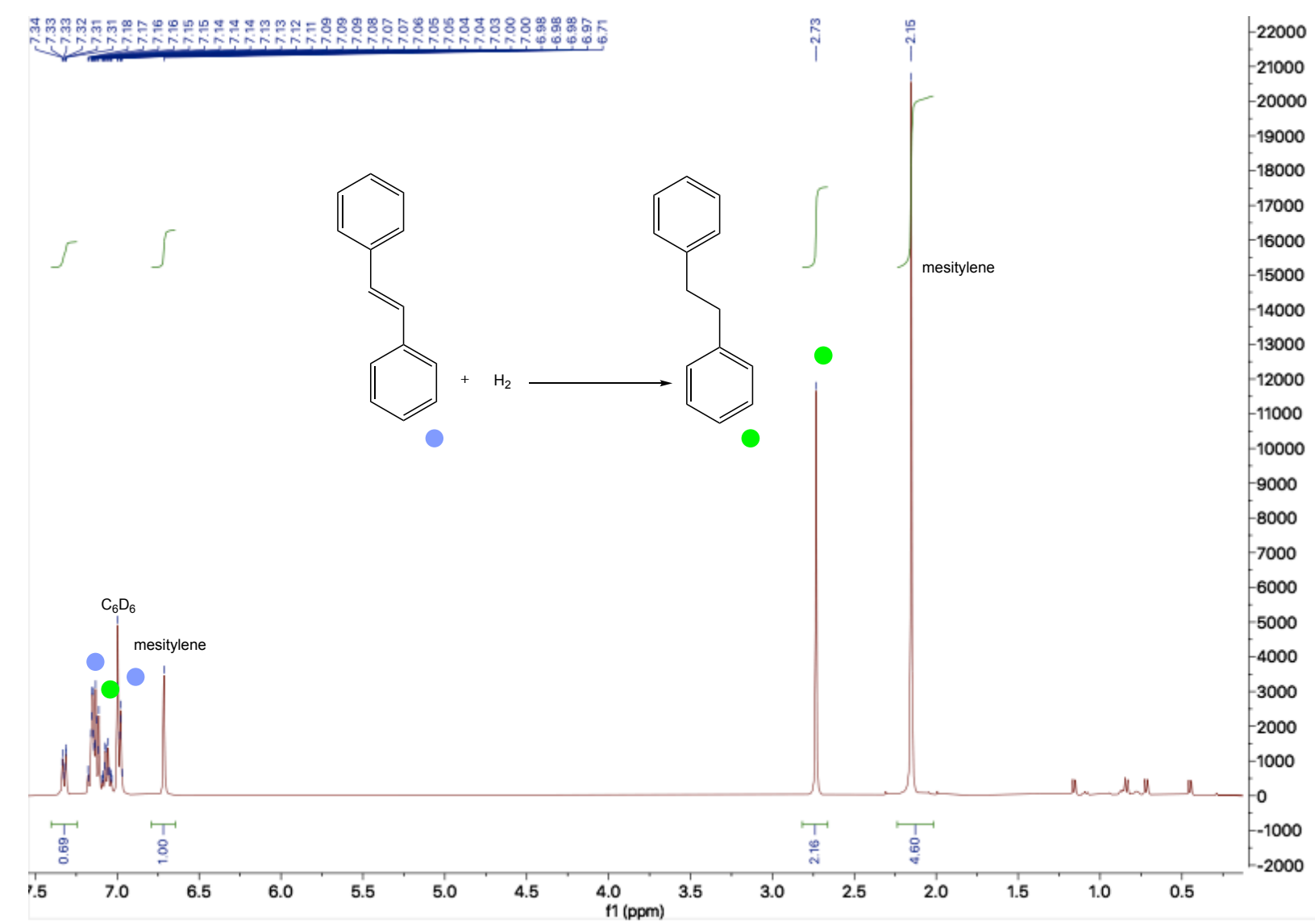

Figure S26. ${ }^{1} H$ NMR (benzene- $d_{6}$, rt) spectrum of crude product formed from the hydrogenation of trans-stilbene by 1 under irradiation conditions. 


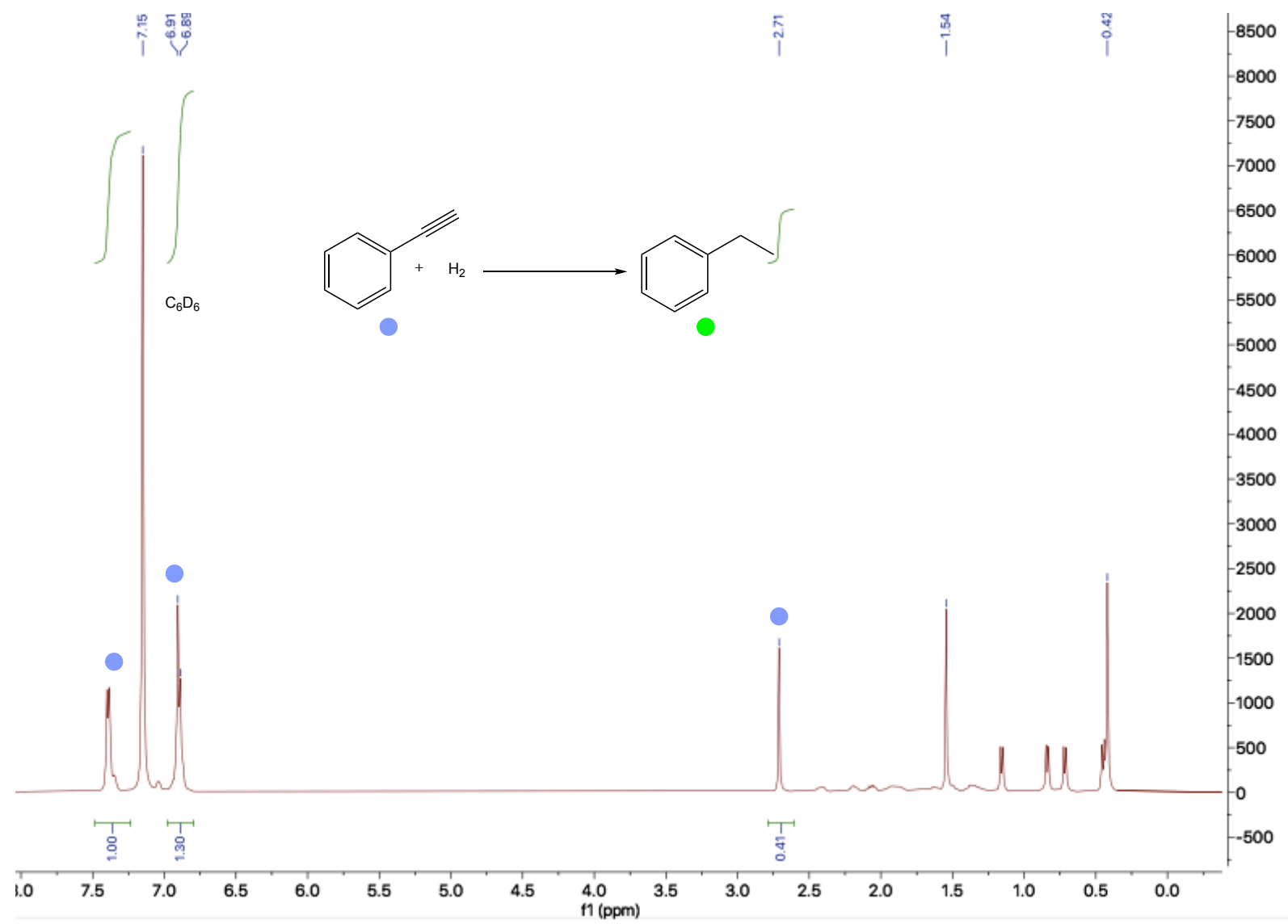

Figure S27. ${ }^{1} \mathrm{H}$ NMR (benzene- $d_{6}$, rt) spectrum of crude product formed from the hydrogenation of phenyl acetylene by 1 under dark conditions. 


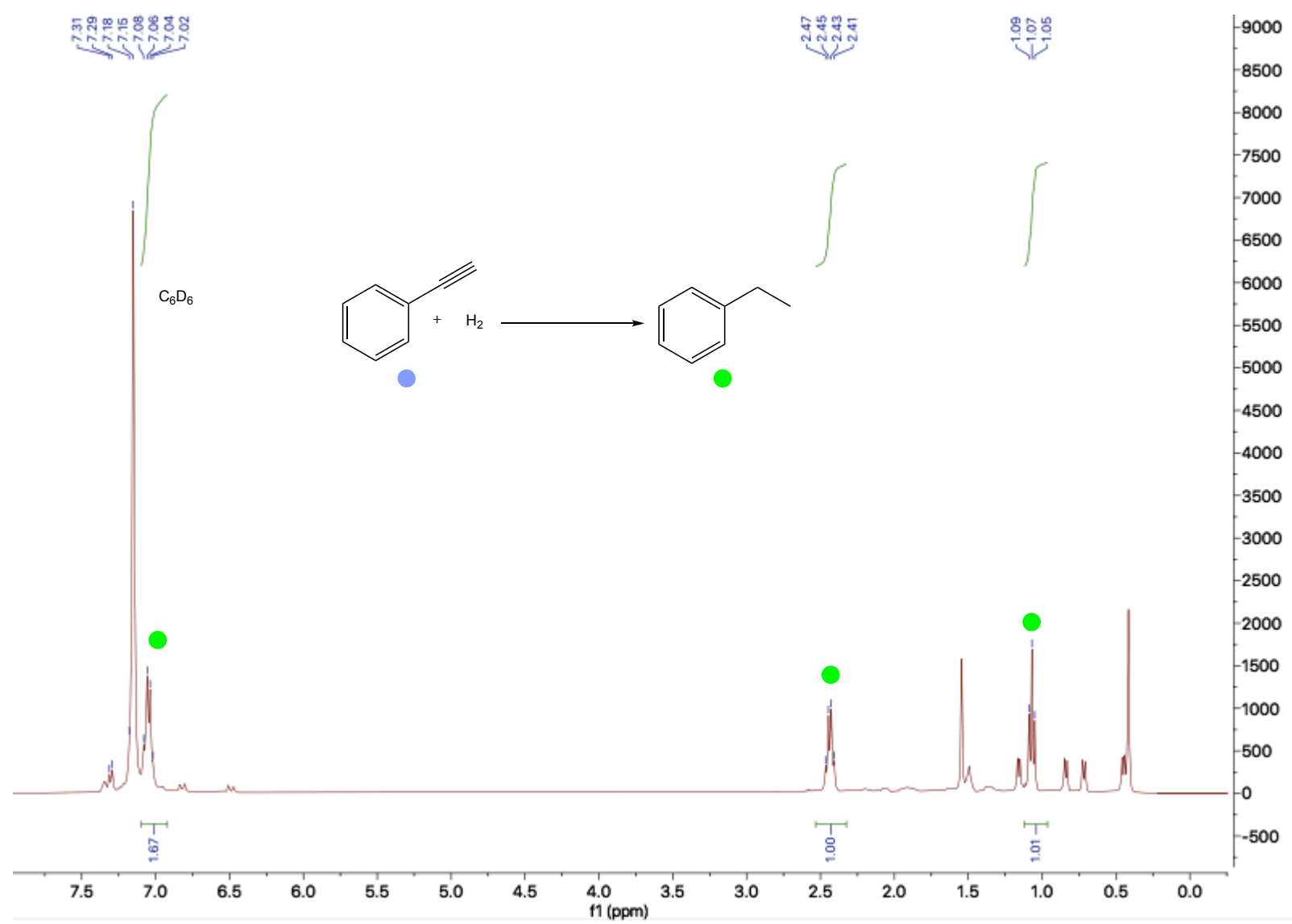

Figure S28. ${ }^{1} \mathrm{H}$ NMR (benzene- $d_{6}$, rt) spectrum of crude product formed from the hydrogenation of phenyl acetylene by 1 under thermal conditions. 


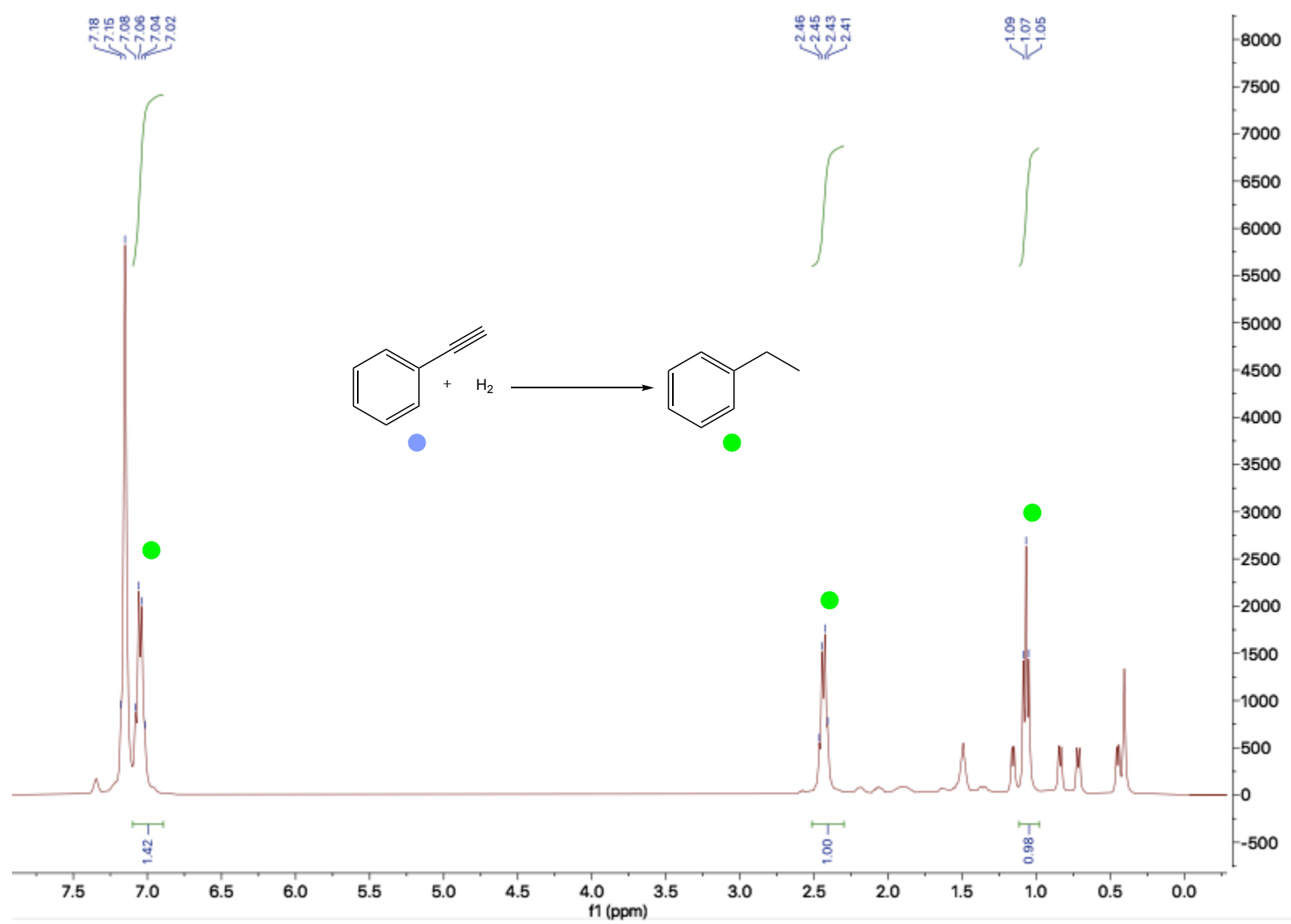

Figure S29. ${ }^{1} \mathrm{H}$ NMR (benzene- $d_{6}$, rt) spectrum of crude product formed from the hydrogenation of phenyl acetylene by 1 under irradiation conditions. 


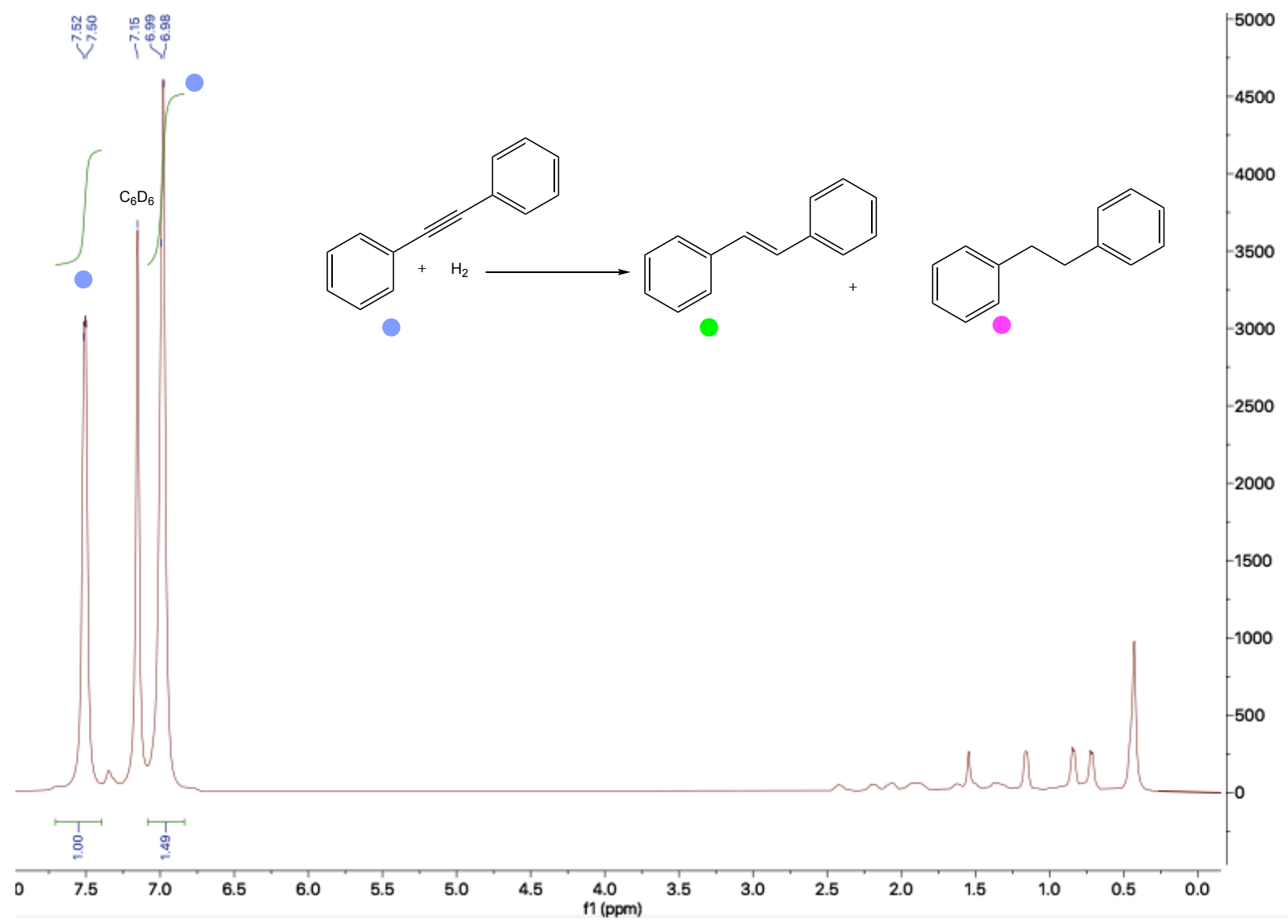

Figure S30. ${ }^{1} \mathrm{H}$ NMR (benzene- $d_{6}$, rt) spectrum of crude product formed from the hydrogenation of diphenyl acetylene by 1 under dark conditions. 


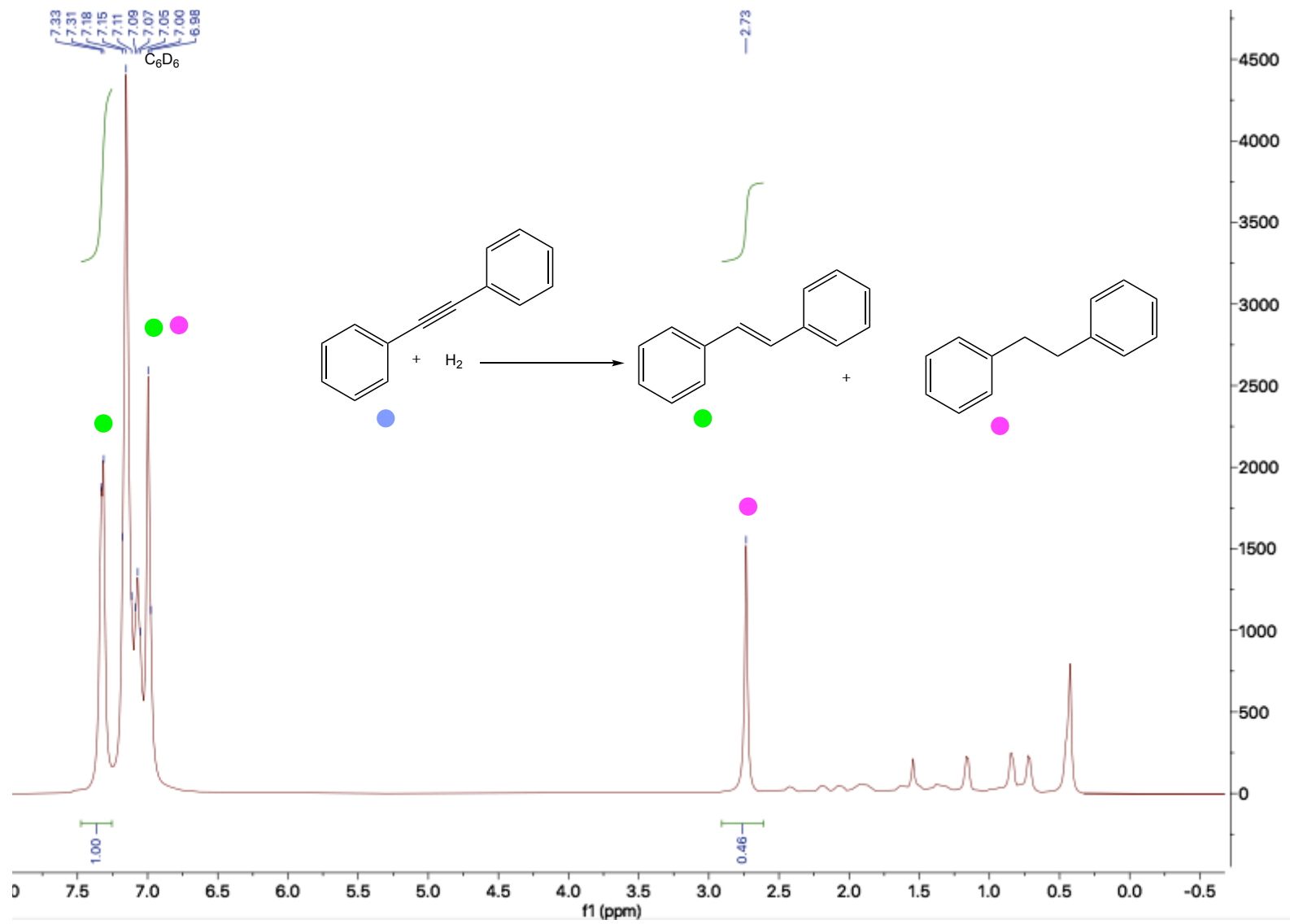

Figure S31. ${ }^{1} \mathrm{H}$ NMR (benzene- $d_{6}$, rt) spectrum of crude product formed from the hydrogenation of diphenyl acetylene by 1 under thermal conditions. 


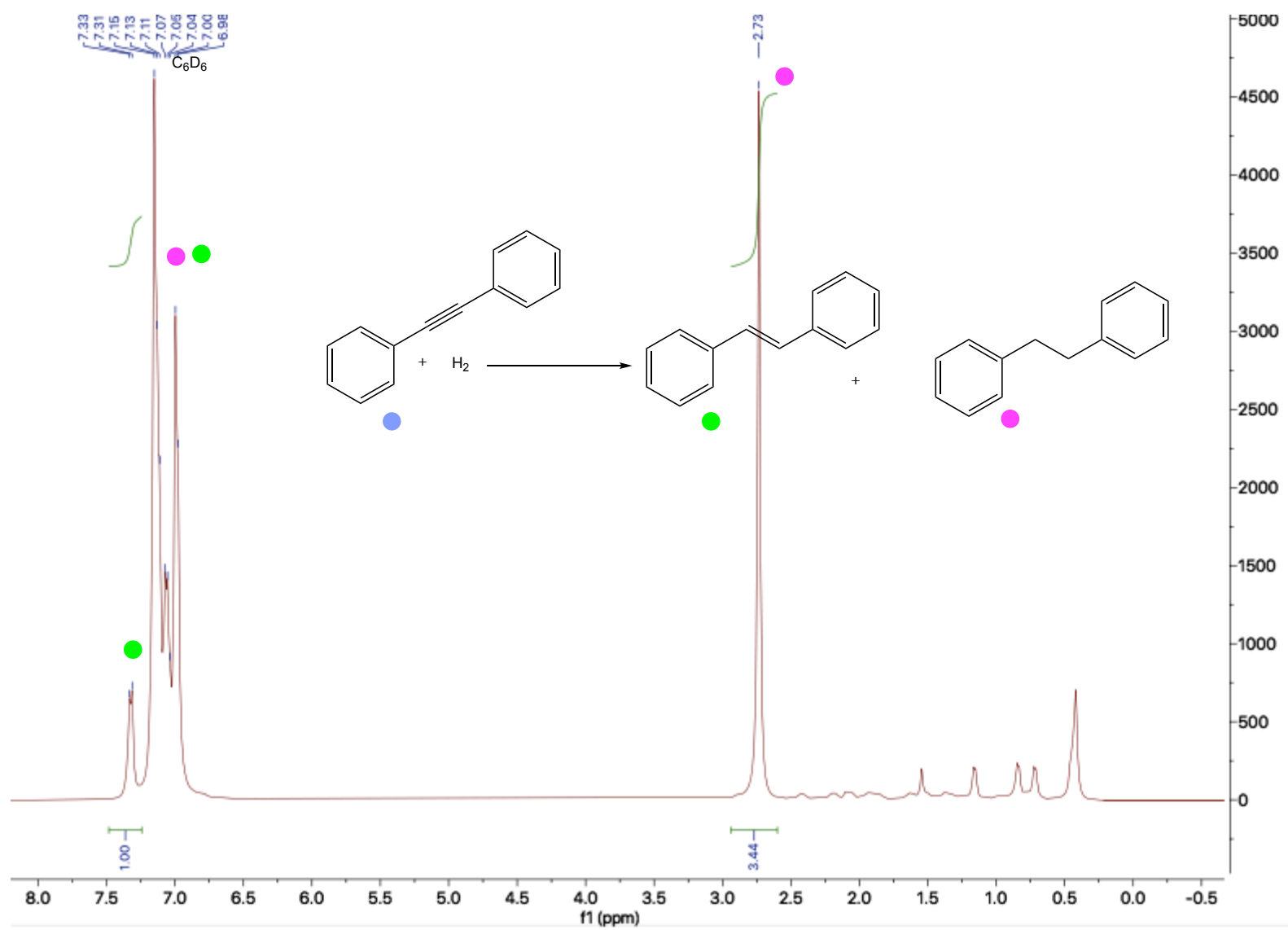

Figure S32. ${ }^{1} \mathrm{H}$ NMR (benzene- $d_{6}$, rt) spectrum of crude product formed from the hydrogenation of diphenyl acetylene by 1 under irradiation conditions. 


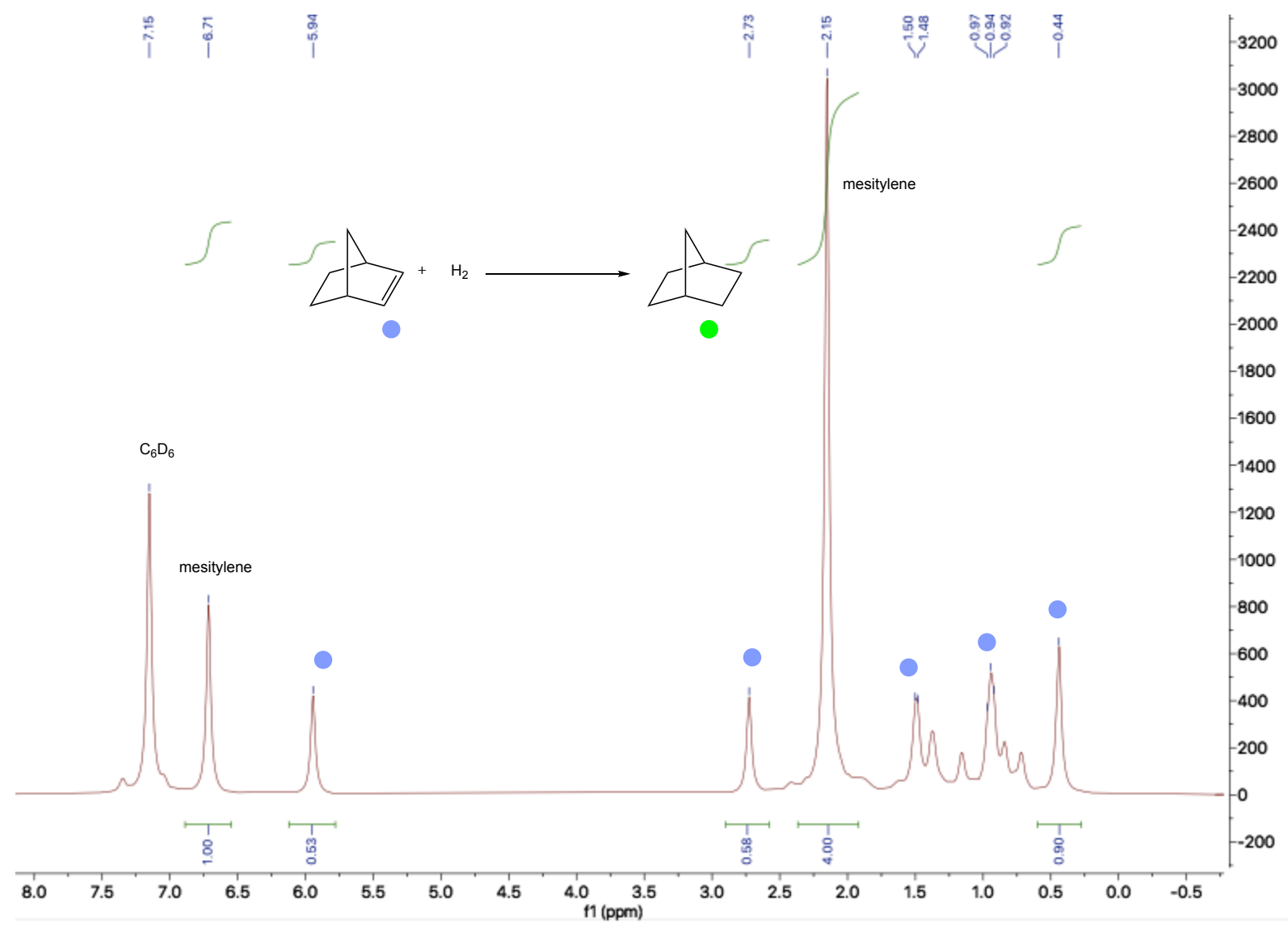

Figure S33. ${ }^{1} \mathrm{H}$ NMR (benzene- $d_{6}$, rt) spectrum of crude product formed from the hydrogenation of norbornene by 1 under dark conditions. 


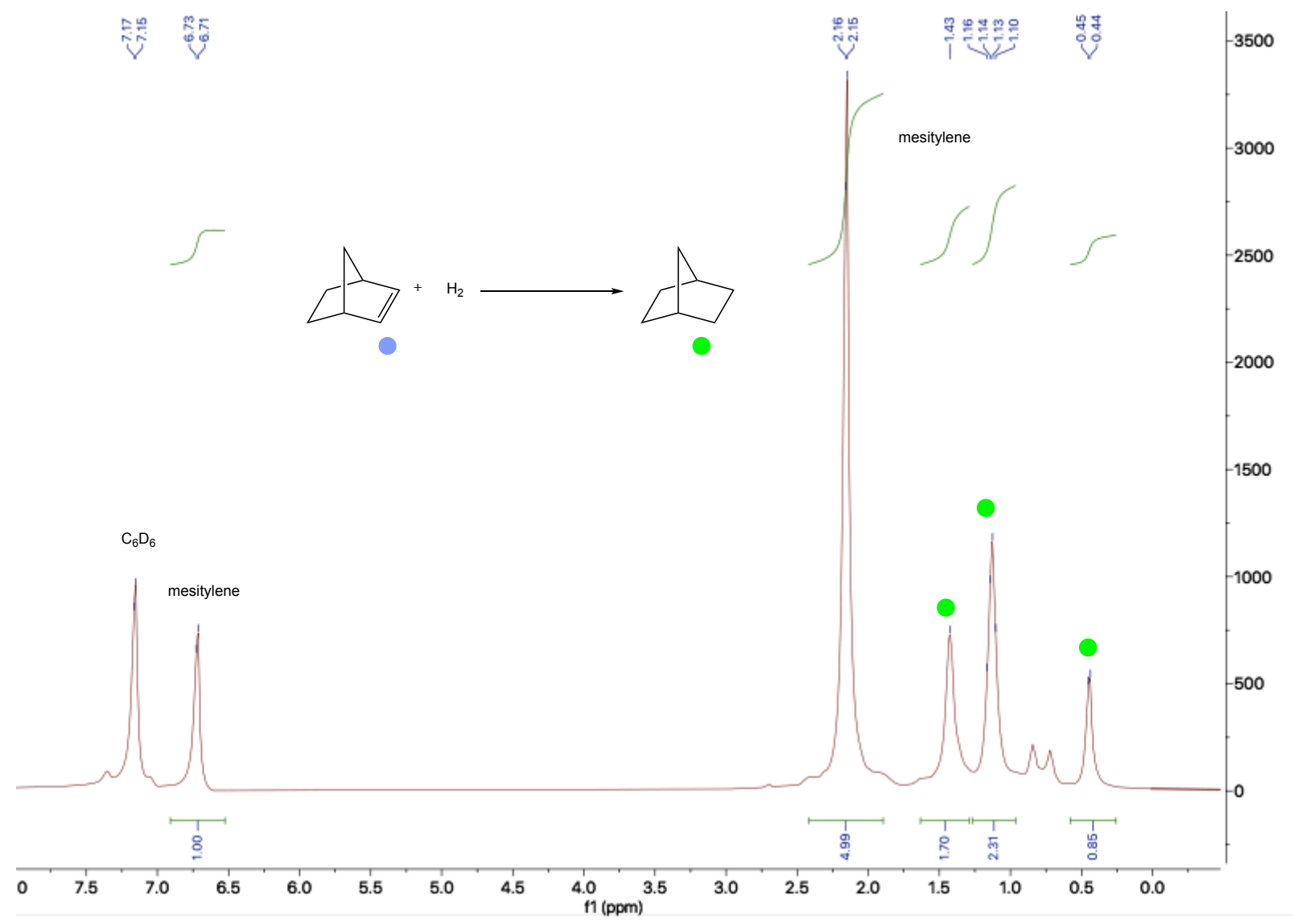

Figure S34. ${ }^{1} \mathrm{H}$ NMR (benzene- $d_{6}$, rt) spectrum of crude product formed from the hydrogenation of norbornene by 1 under thermal conditions. 


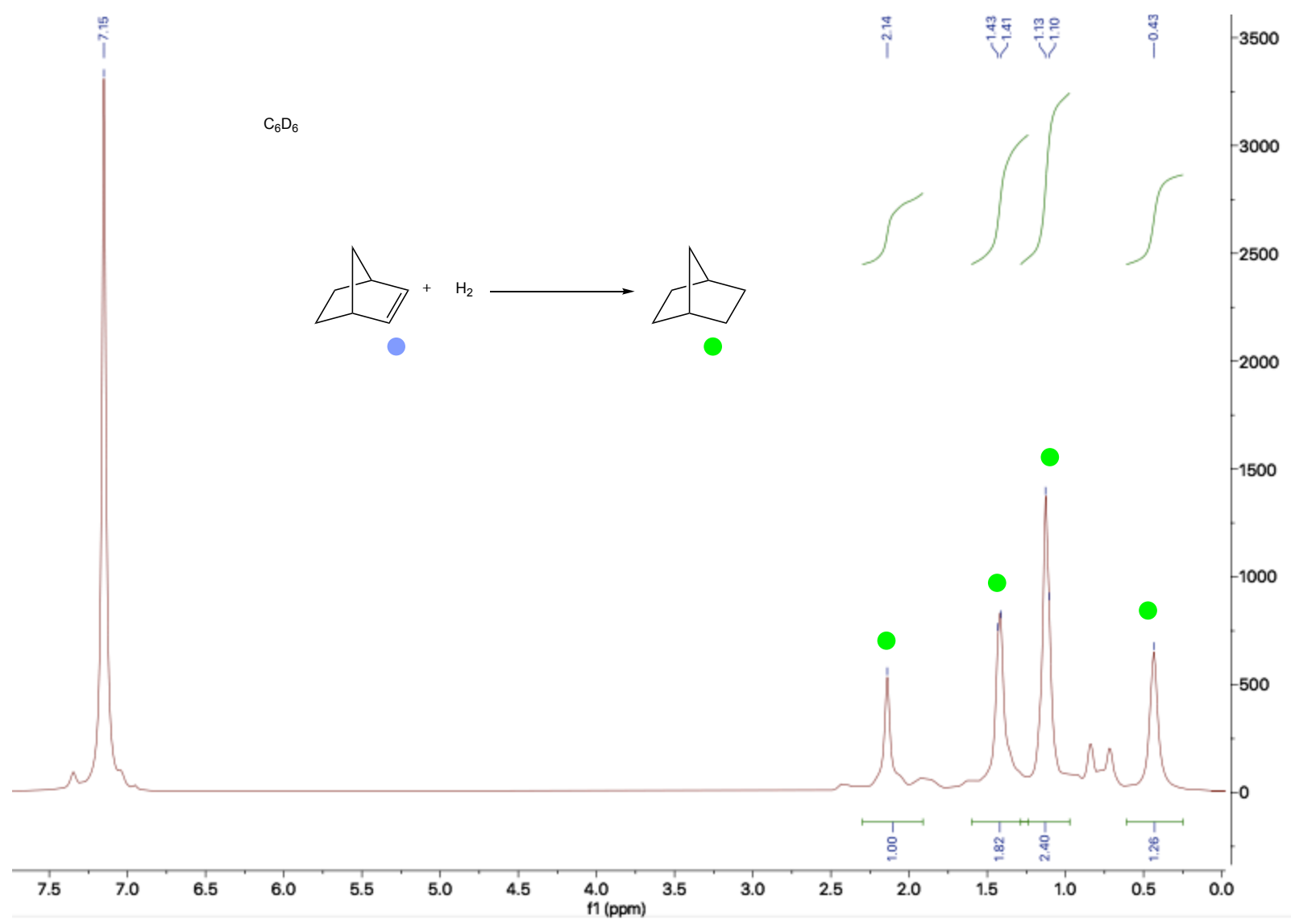

Figure S35. ${ }^{1} \mathrm{H}$ NMR (benzene- $d_{6}$, rt) spectrum of crude product formed from the hydrogenation of norbornene by 1 under irradiation conditions. 


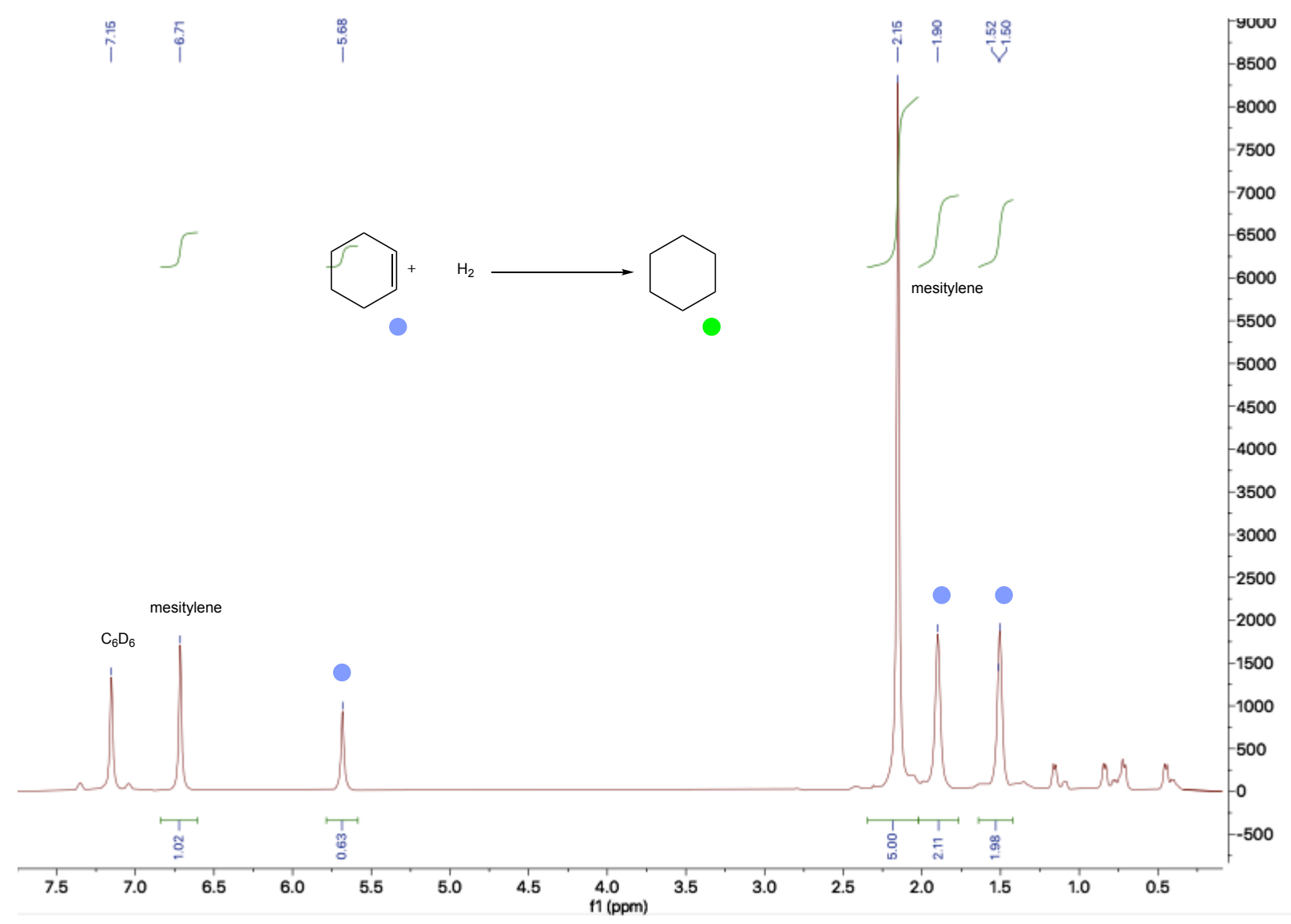

Figure S36. ${ }^{1} \mathrm{H}$ NMR (benzene- $d_{6}$, rt) spectrum of crude product formed from the hydrogenation of cyclohexene by 1 under dark conditions. 


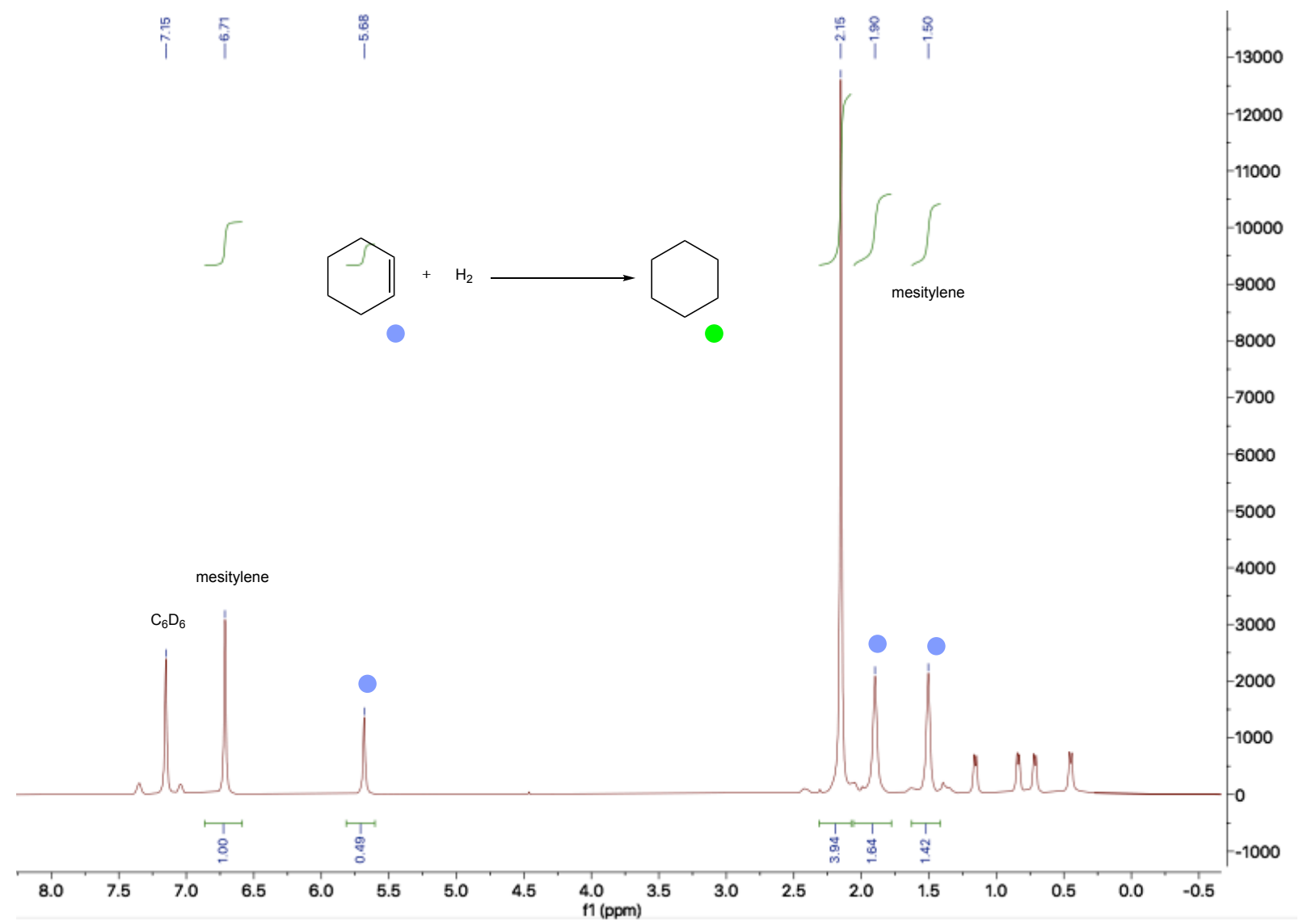

Figure S37. ${ }^{1} \mathrm{H}$ NMR (benzene- $d_{6}$, rt) spectrum of crude product formed from the hydrogenation of cyclohexene by 1 under thermal conditions. 


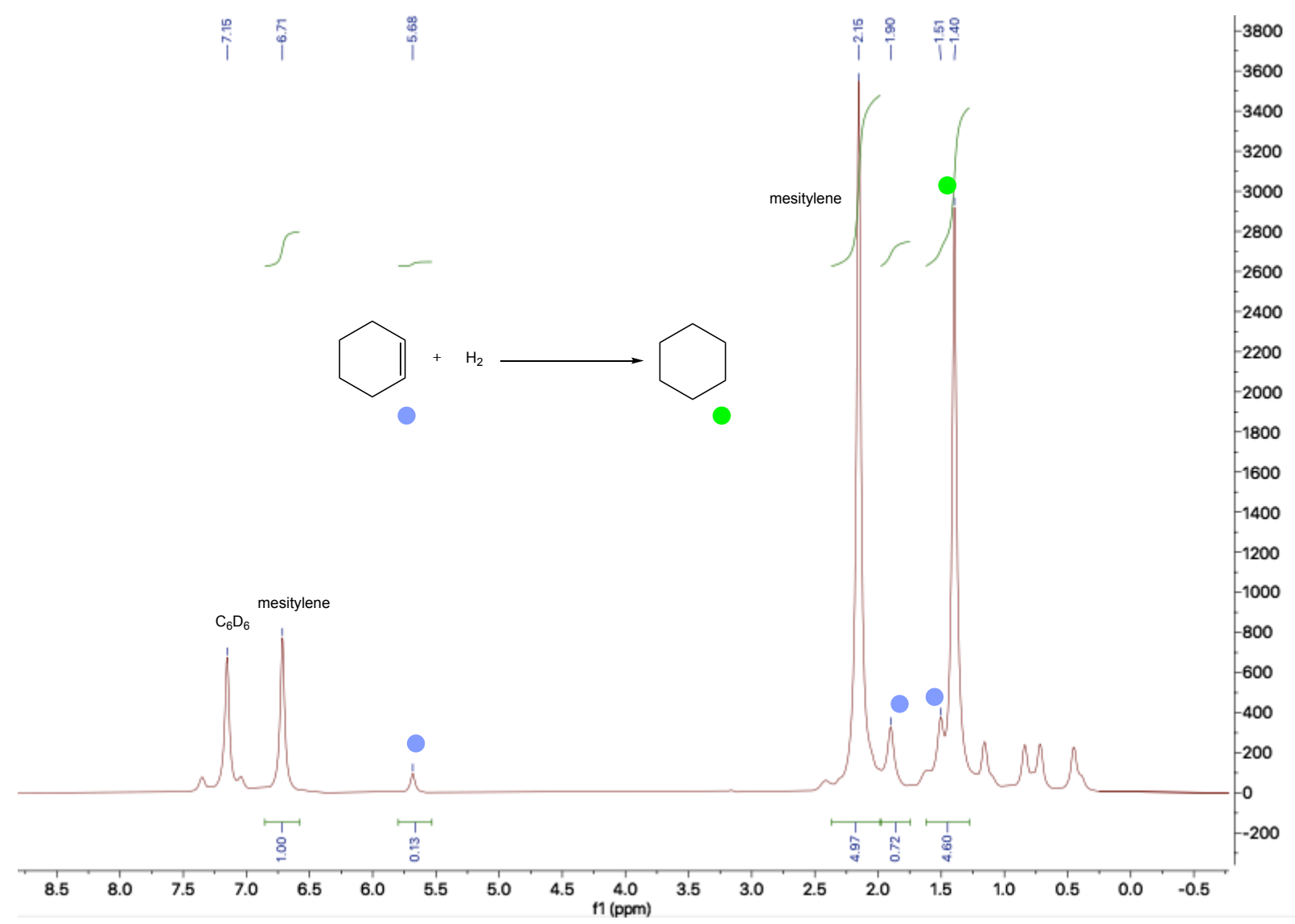

Figure S38. ${ }^{1} \mathrm{H}$ NMR (benzene- $d_{6}$, rt) spectrum of crude product formed from the hydrogenation of cyclohexene by 1 under irradiation conditions. 


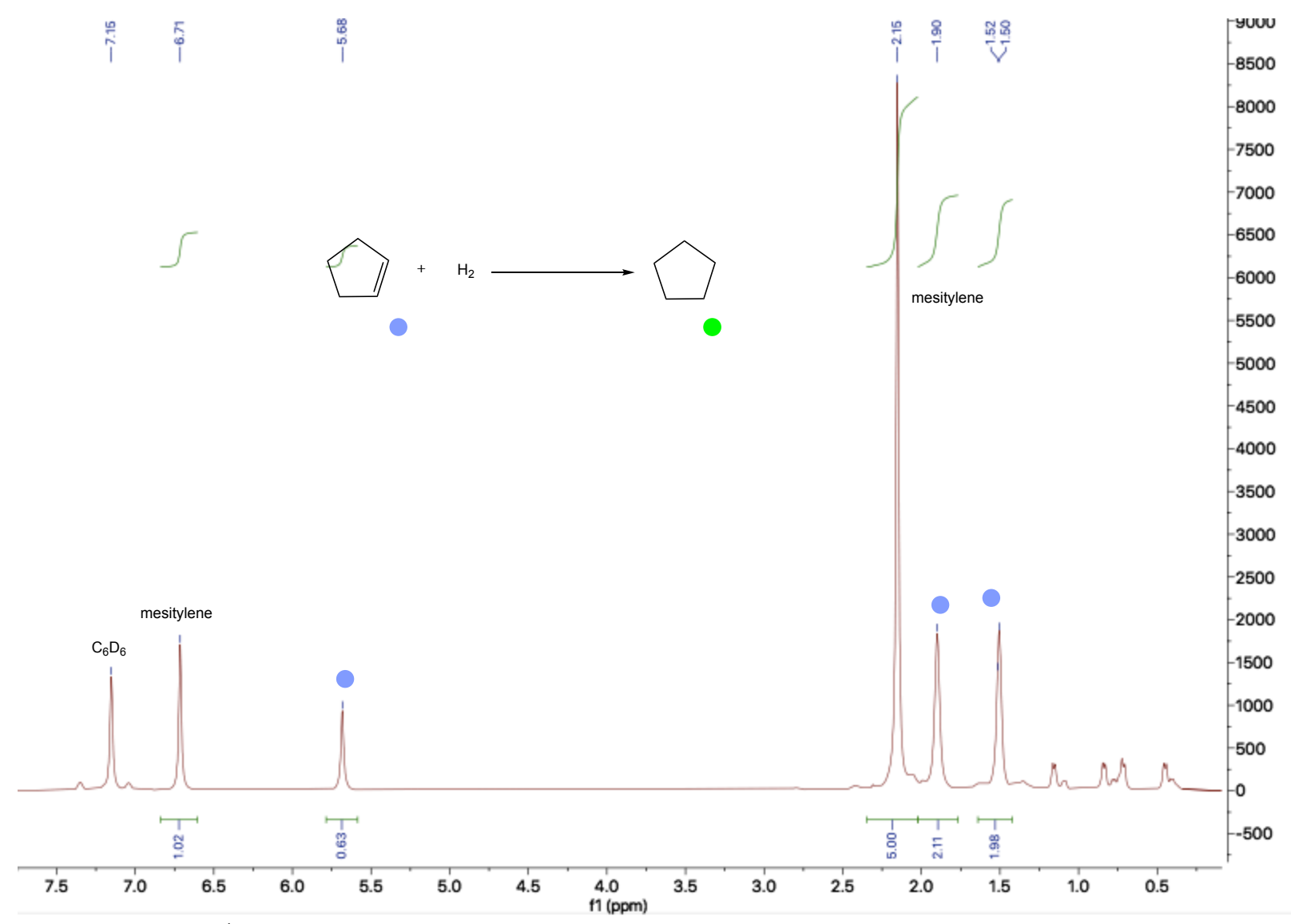

Figure S39. ${ }^{1} \mathrm{H}$ NMR (benzene- $d_{6}$, rt) spectrum of crude product formed from the hydrogenation of cyclopentene by 1 under dark conditions. 


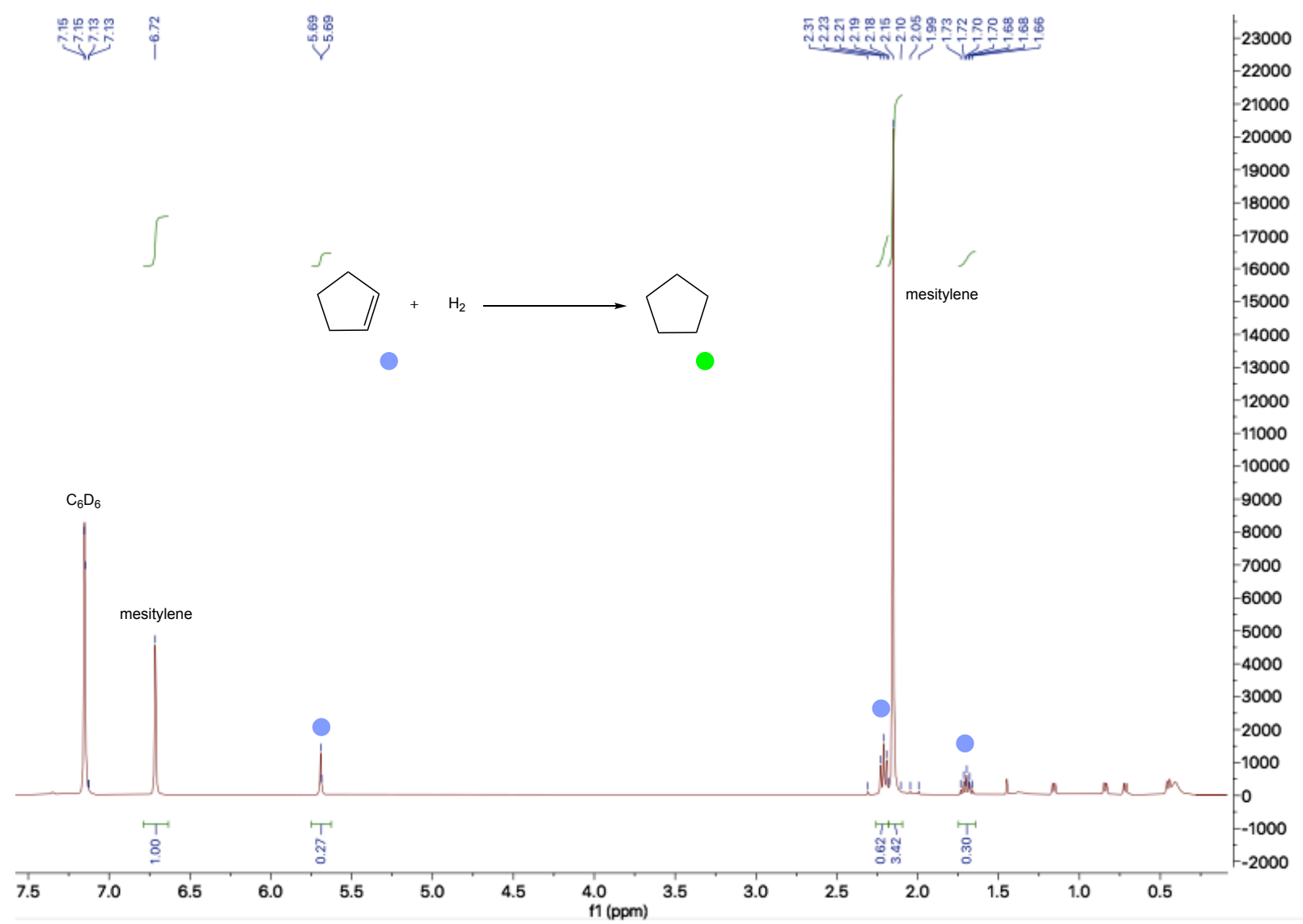

Figure S40. ${ }^{1} \mathrm{H}$ NMR (benzene- $d_{6}$, rt) spectrum of crude product formed from the hydrogenation of cyclopentene by 1 under thermal conditions. 


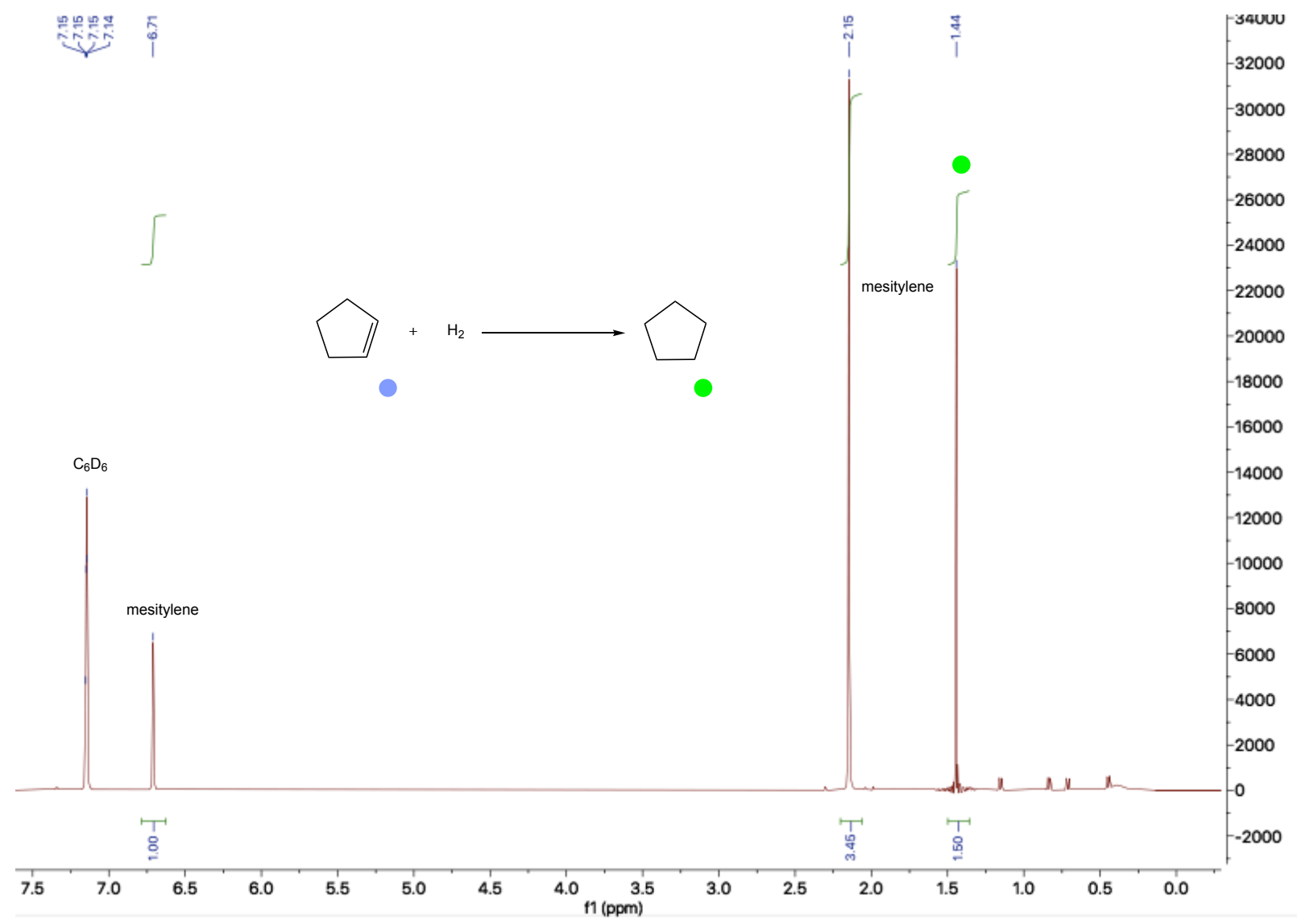

Figure S41. ${ }^{1} \mathrm{H}$ NMR (benzene- $d_{6}$, rt) spectrum of crude product formed from the hydrogenation of cyclopentene by 1 under irradiation conditions. 


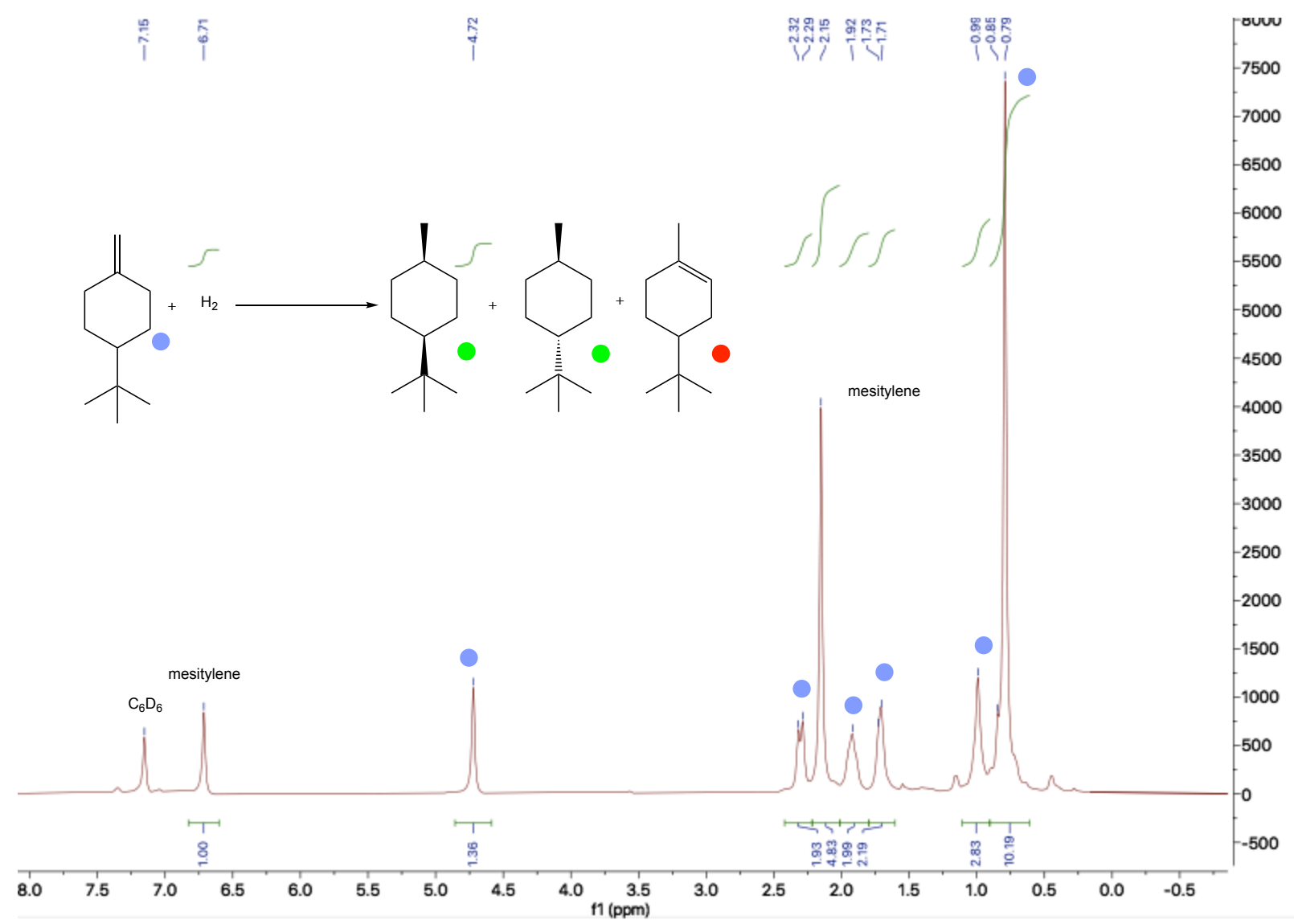

Figure S42. ${ }^{1} \mathrm{H}$ NMR (benzene- $d_{6}$, rt) spectrum of crude product formed from the hydrogenation of 4-tert-butyl-4-methylenecyclohexane by 1 under dark conditions. 


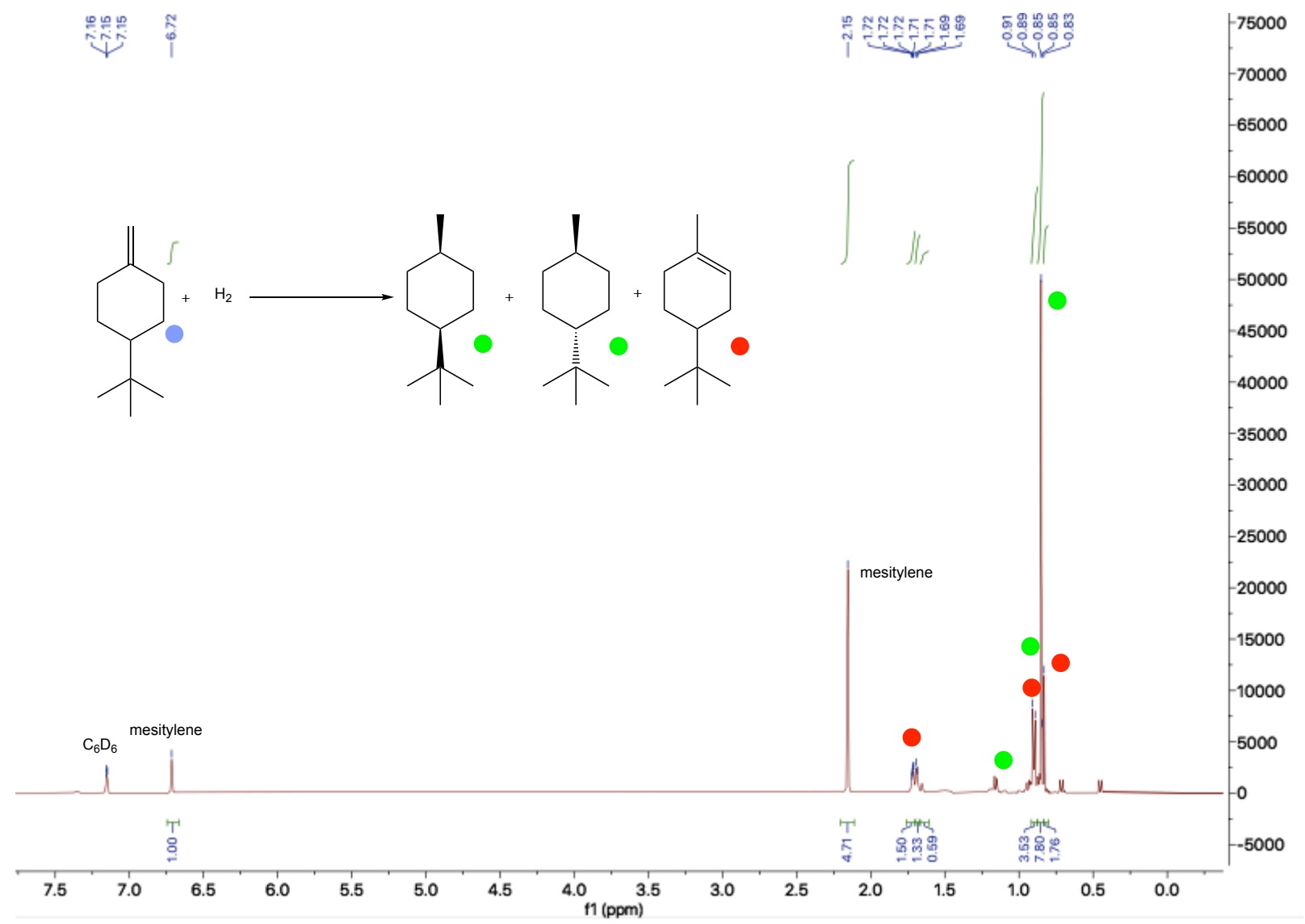

Figure S43. ${ }^{1} \mathrm{H}$ NMR (benzene- $d_{6}$, rt) spectrum of crude product formed from the hydrogenation of 4-tert-butyl-4-methylenecyclohexane by 1 under thermal conditions. 


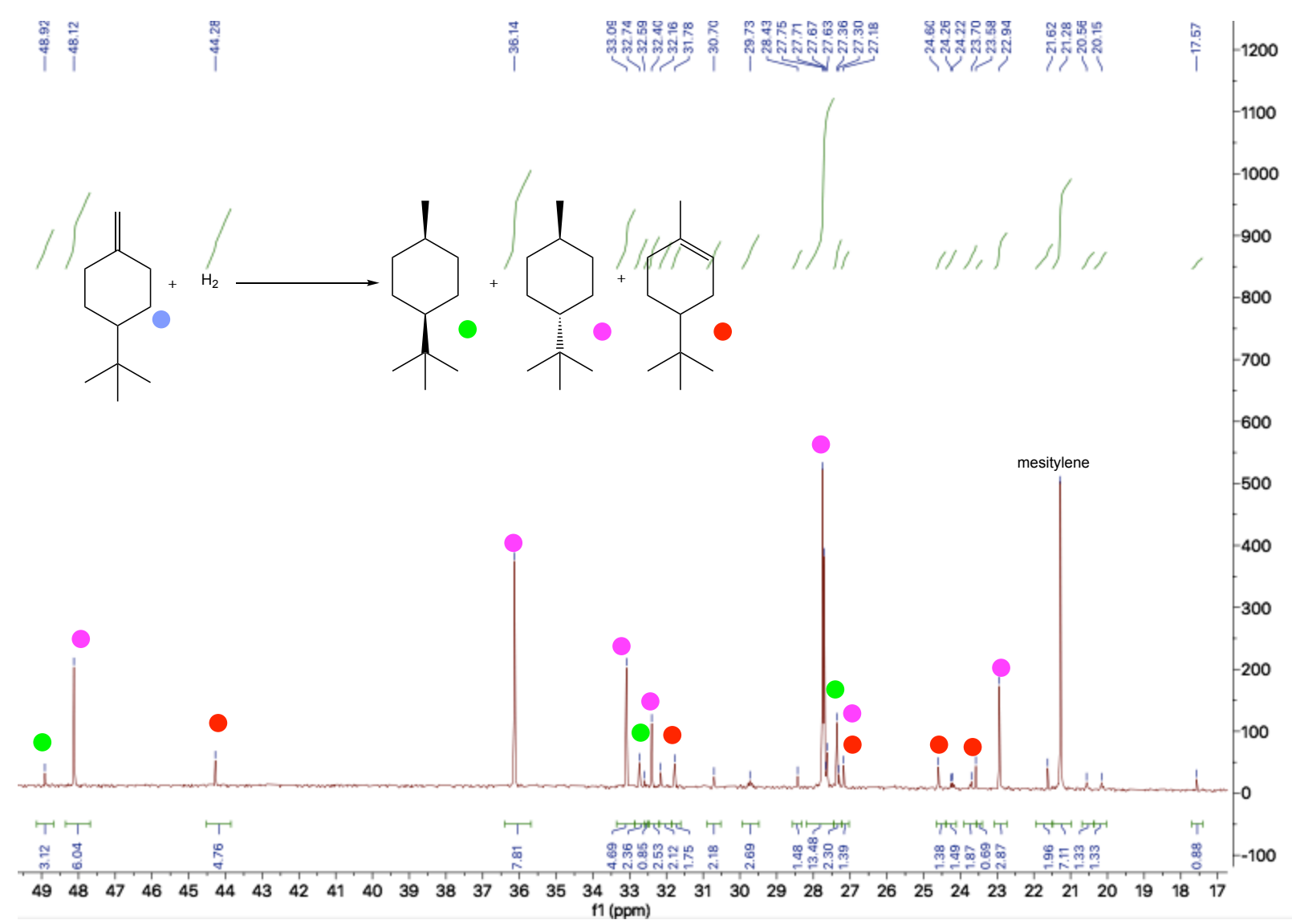

Figure S44. Quantitative ${ }^{13} \mathrm{C}$ NMR (benzene- $d_{6}$, rt) spectrum of crude product formed from the hydrogenation of 4-tert-butyl-4-methylenecyclohexane by 1 under thermal conditions. 


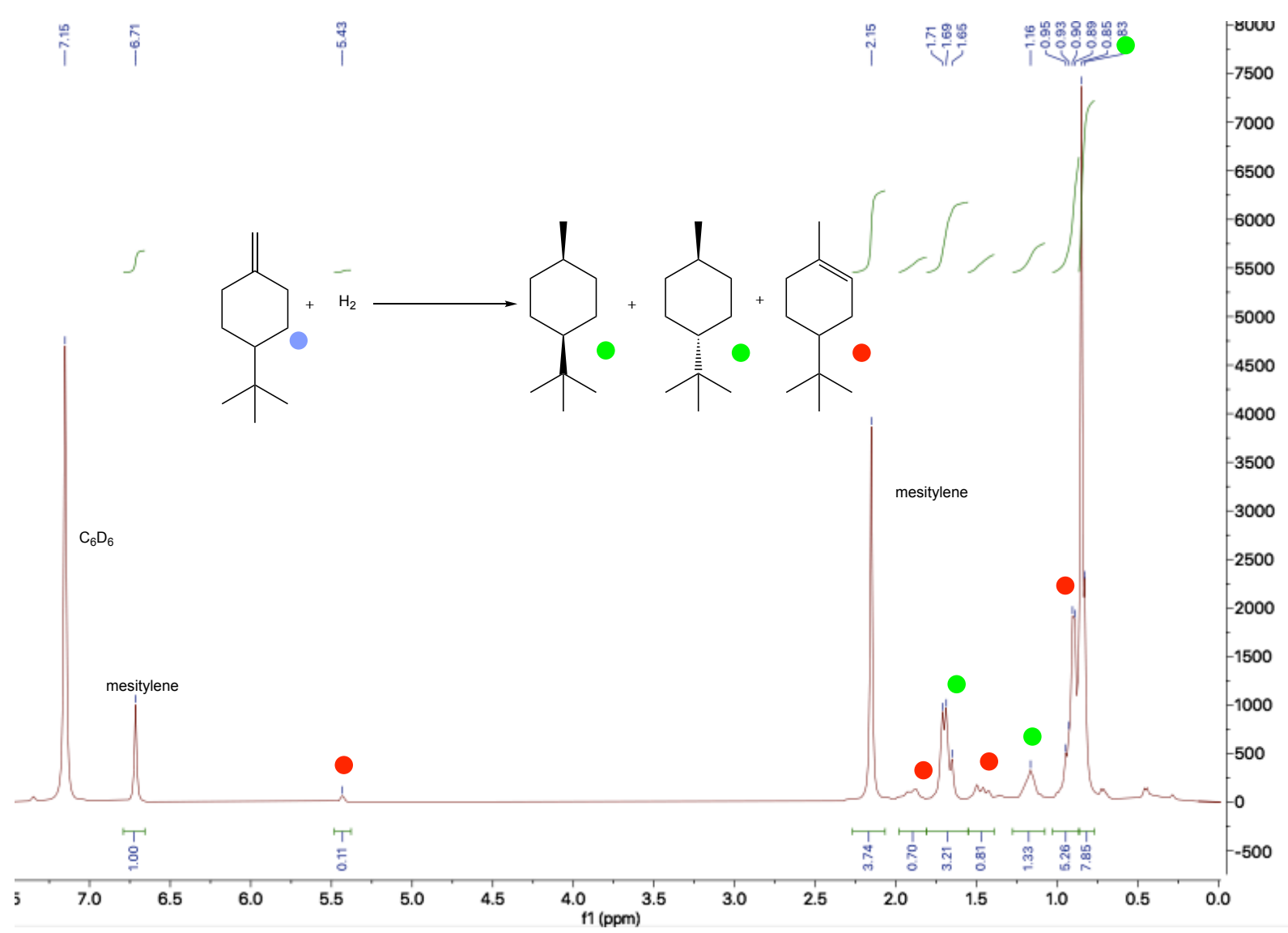

Figure S45. ${ }^{1} \mathrm{H}$ NMR (benzene- $d_{6}$, rt) spectrum of crude product formed from the hydrogenation of 4-tert-butyl-4-methylenecyclohexane by 1 under irradiation conditions. 


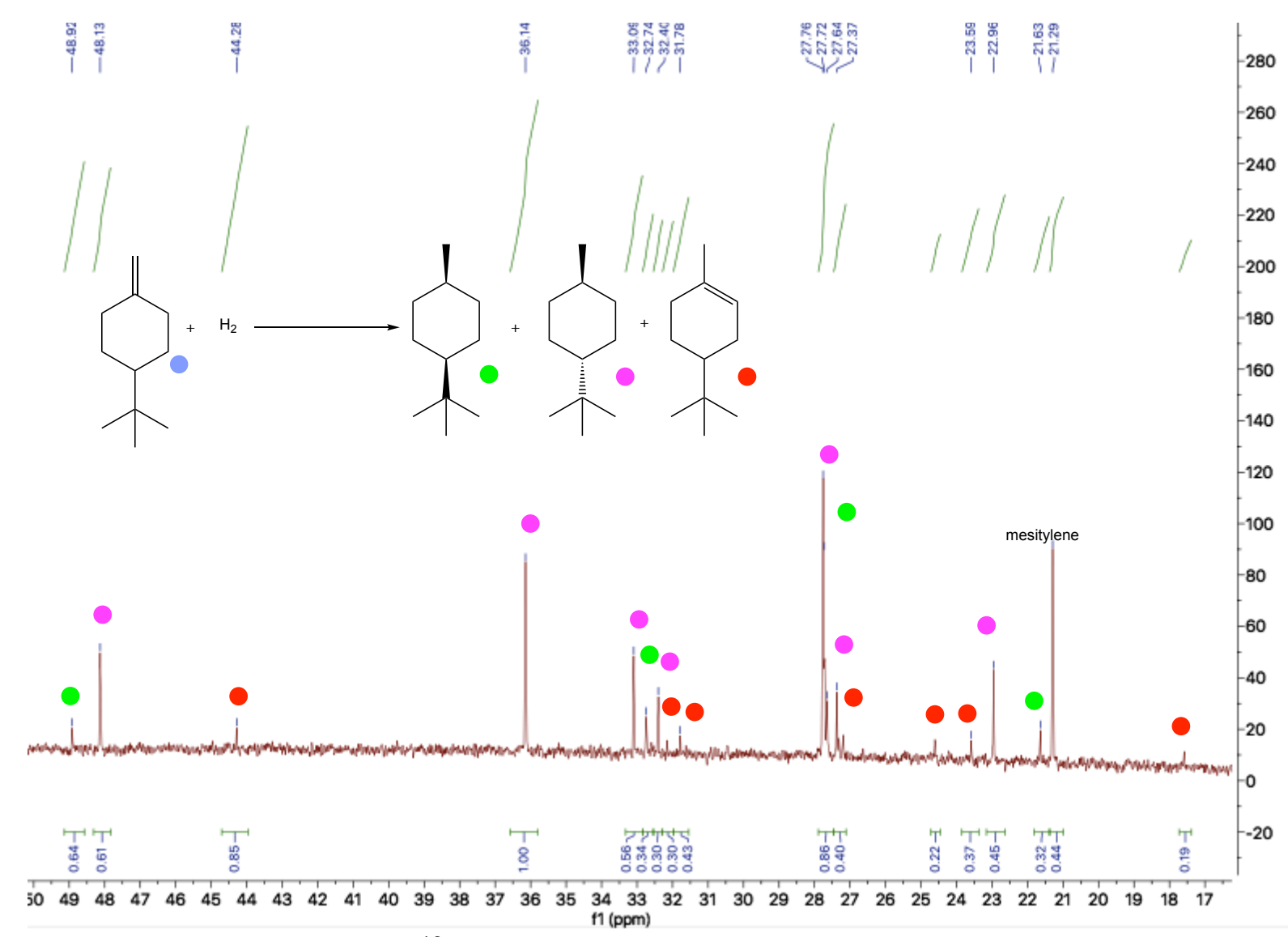

Figure S46. Quantitative ${ }^{13} \mathrm{C}$ NMR (benzene- $d_{6}$, rt) spectrum of crude product formed from the hydrogenation of 4-tert-butyl-4-methylenecyclohexane by 1 under irradiation conditions. 


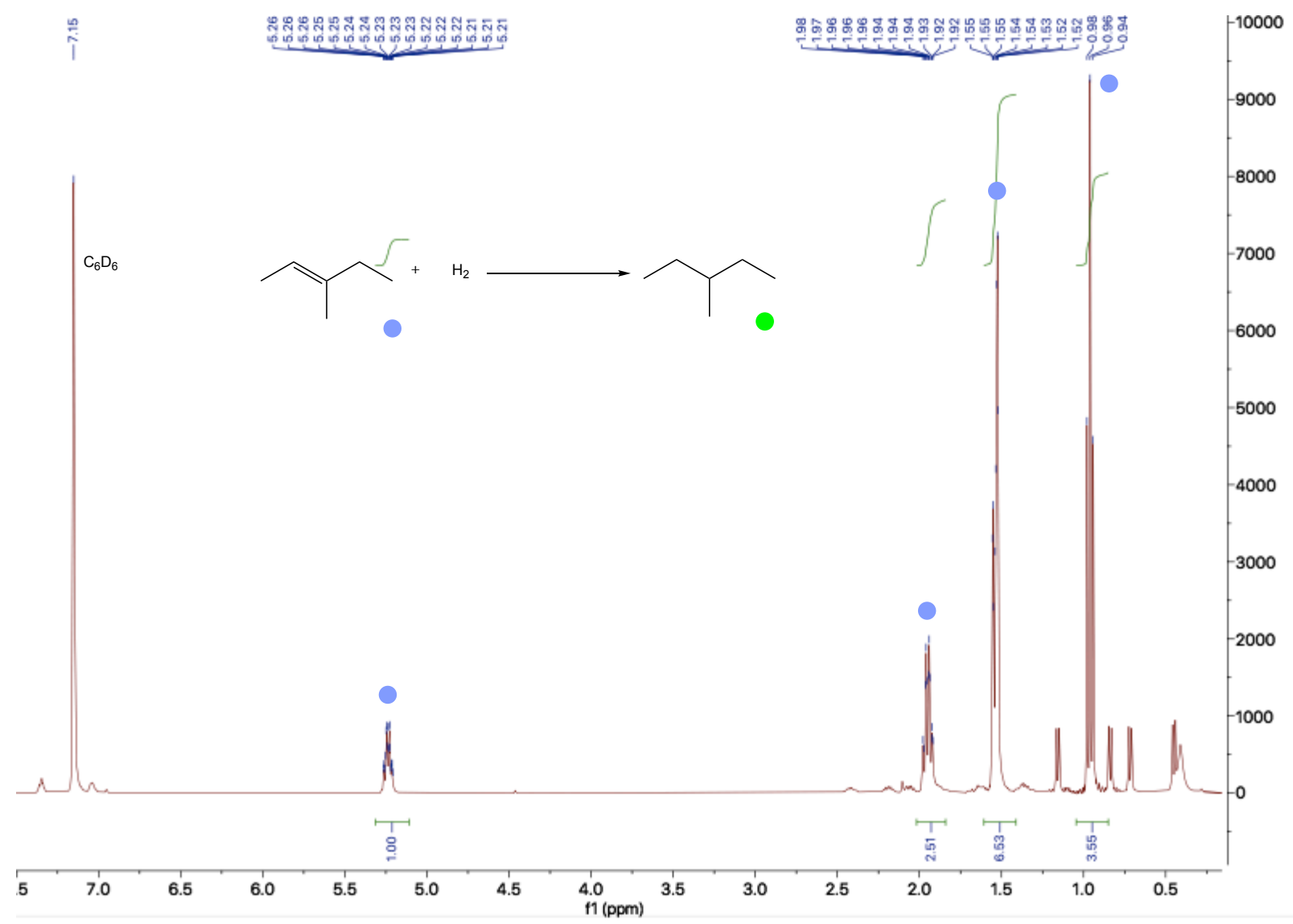

Figure S47. ${ }^{1} \mathrm{H}$ NMR (benzene- $d_{6}$, rt) spectrum of crude product formed from the hydrogenation of 3-methylpent-2-ene by 1 under dark conditions. 


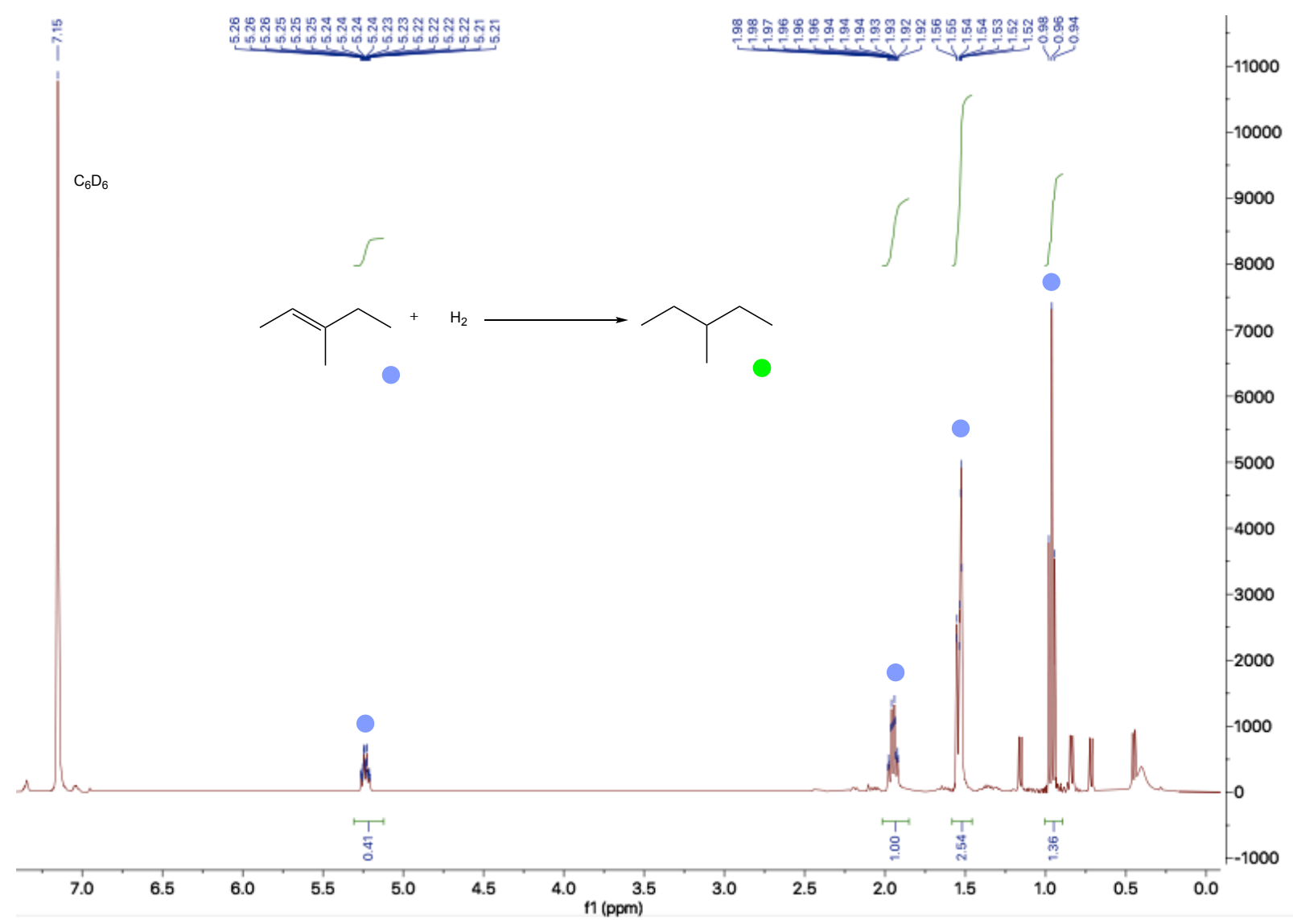

Figure S48. ${ }^{1} \mathrm{H}$ NMR (benzene- $d_{6}$, rt) spectrum of crude product formed from the hydrogenation of 3-methylpent-2-ene by 1 under thermal conditions. 


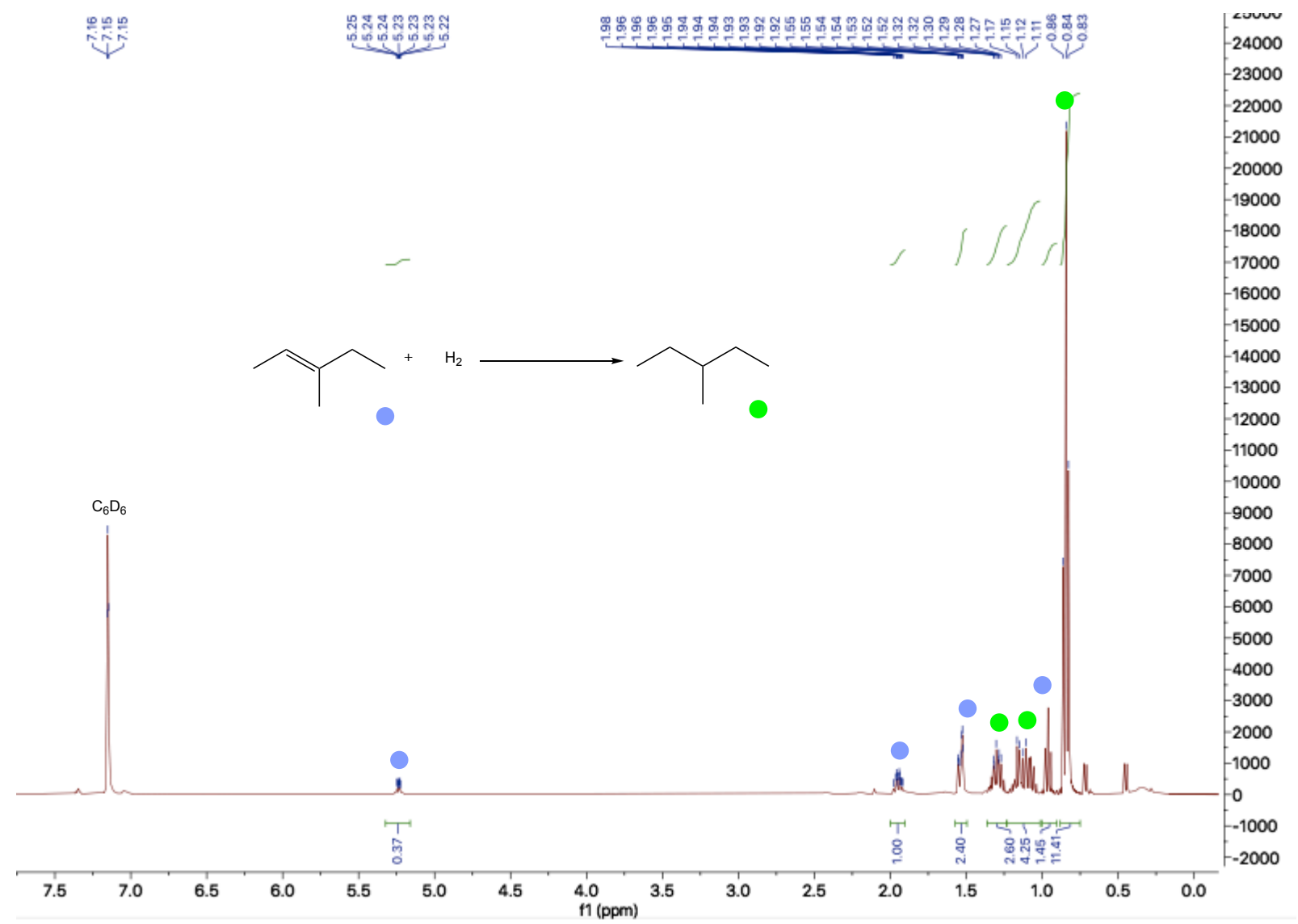

Figure S49. ${ }^{1} \mathrm{H}$ NMR (benzene- $d_{6}$, rt) spectrum of crude product formed from the hydrogenation of 3-methylpent-2-ene by 1 under irradiation conditions. 


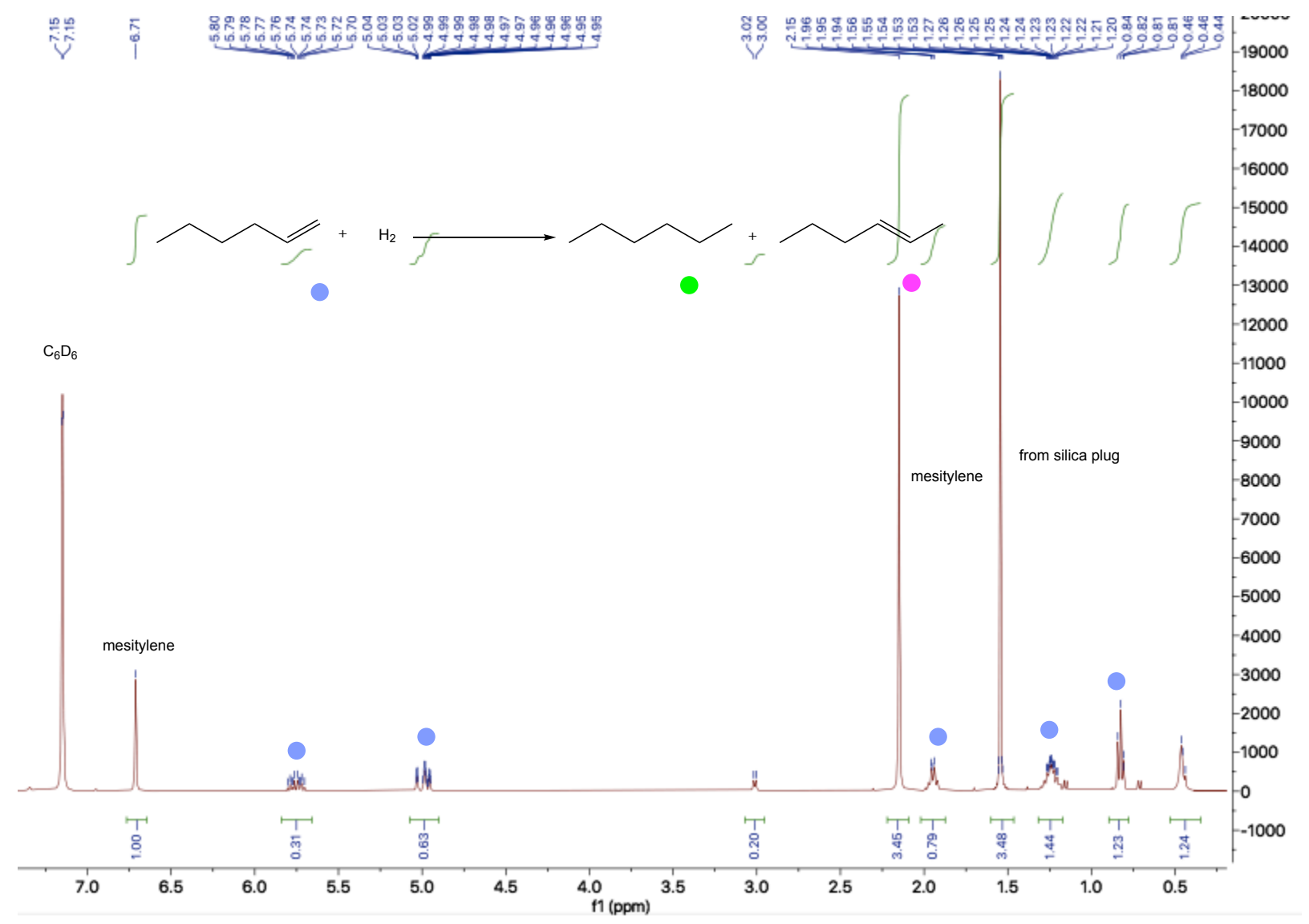

Figure S50. ${ }^{1} \mathrm{H}$ NMR (benzene- $d_{6}$, rt) spectrum of crude product formed from the hydrogenation of 1 -hexene by 1 under dark conditions. 


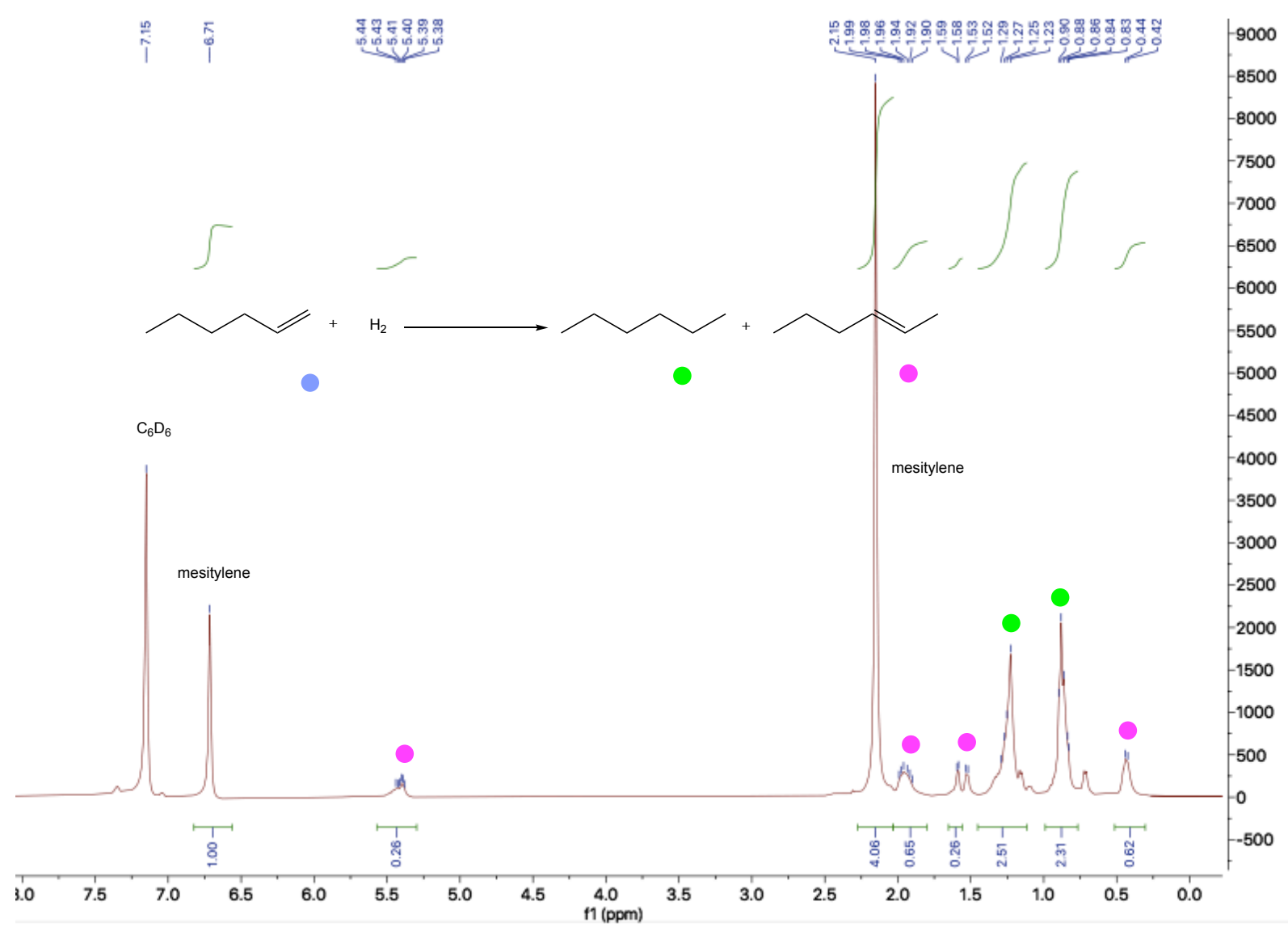

Figure S51. ${ }^{1} \mathrm{H}$ NMR (benzene- $d_{6}$, rt) spectrum of crude product formed from the hydrogenation of 1-hexene by 1 under thermal conditions. 


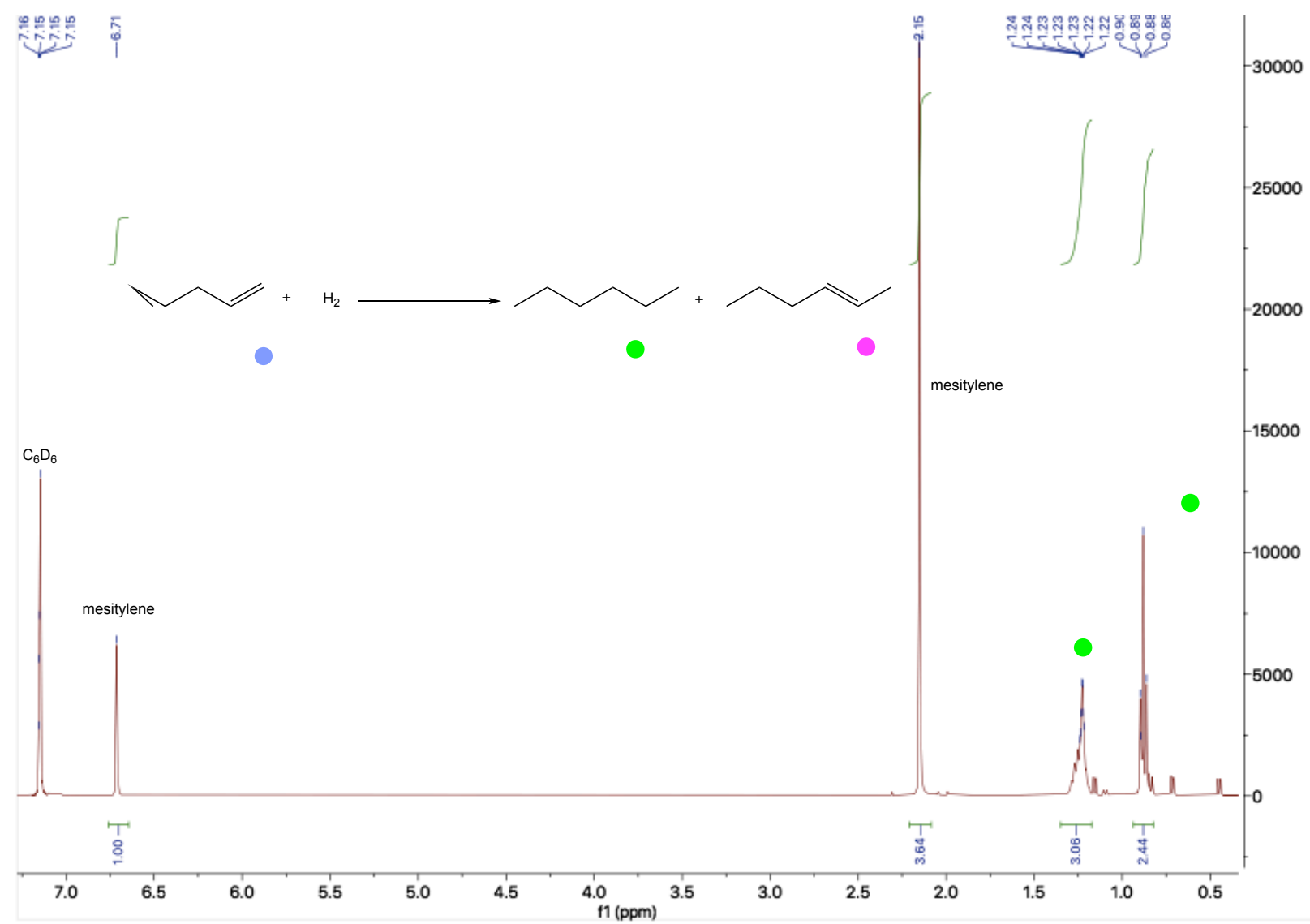

Figure S52. ${ }^{1} \mathrm{H}$ NMR (benzene- $d_{6}$, rt) spectrum of crude product formed from the hydrogenation of 1-hexene by 1 under irradiation conditions. 


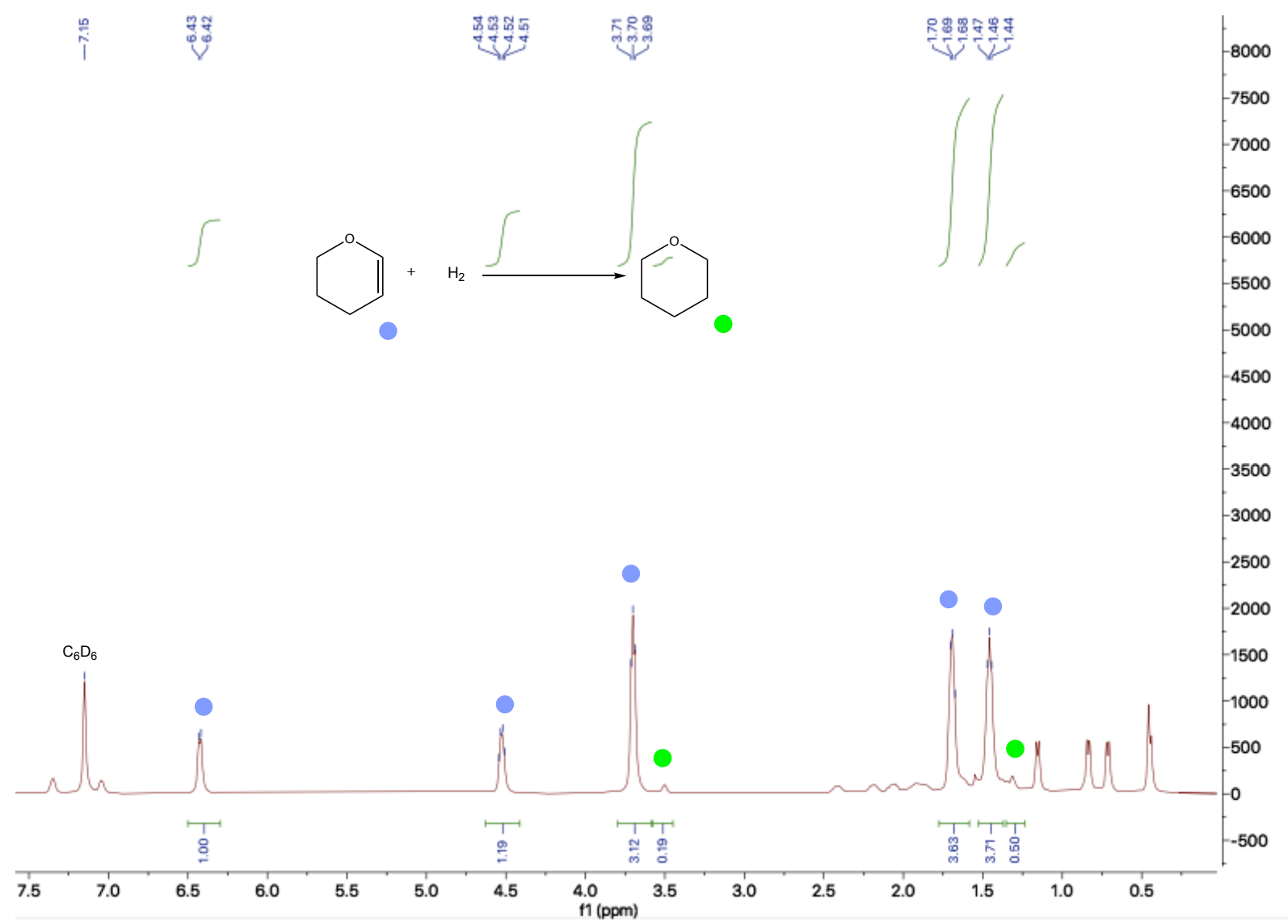

Figure S53. ${ }^{1} \mathrm{H}$ NMR (benzene- $d_{6}$, rt) spectrum of crude product formed from the hydrogenation of 3,4-dihydropyran by 1 under dark conditions. 


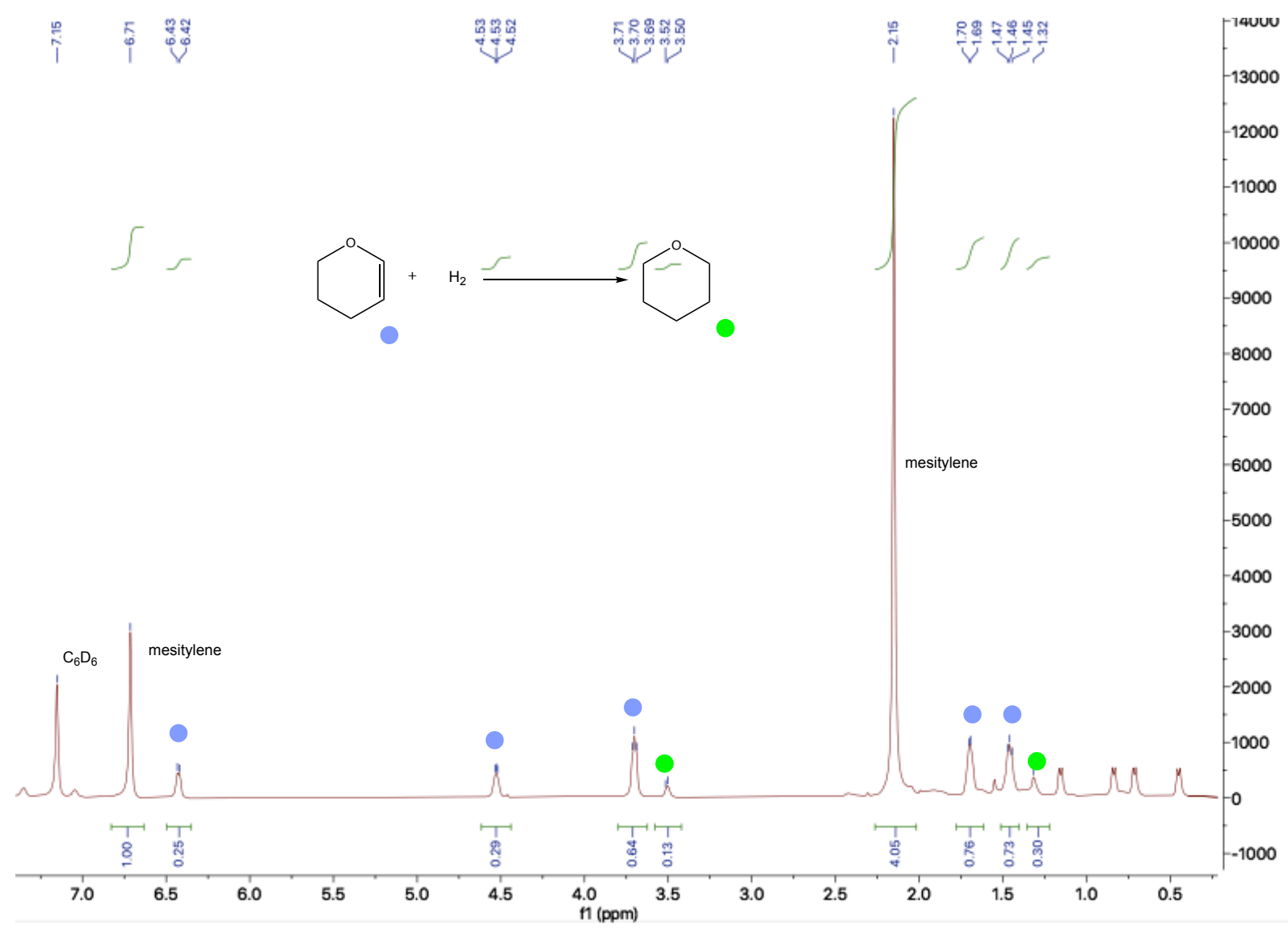

Figure S54. ${ }^{1} \mathrm{H}$ NMR (benzene- $d_{6}$, rt) spectrum of crude product formed from the hydrogenation of 3,4-dihydropyran by 1 under thermal conditions. 


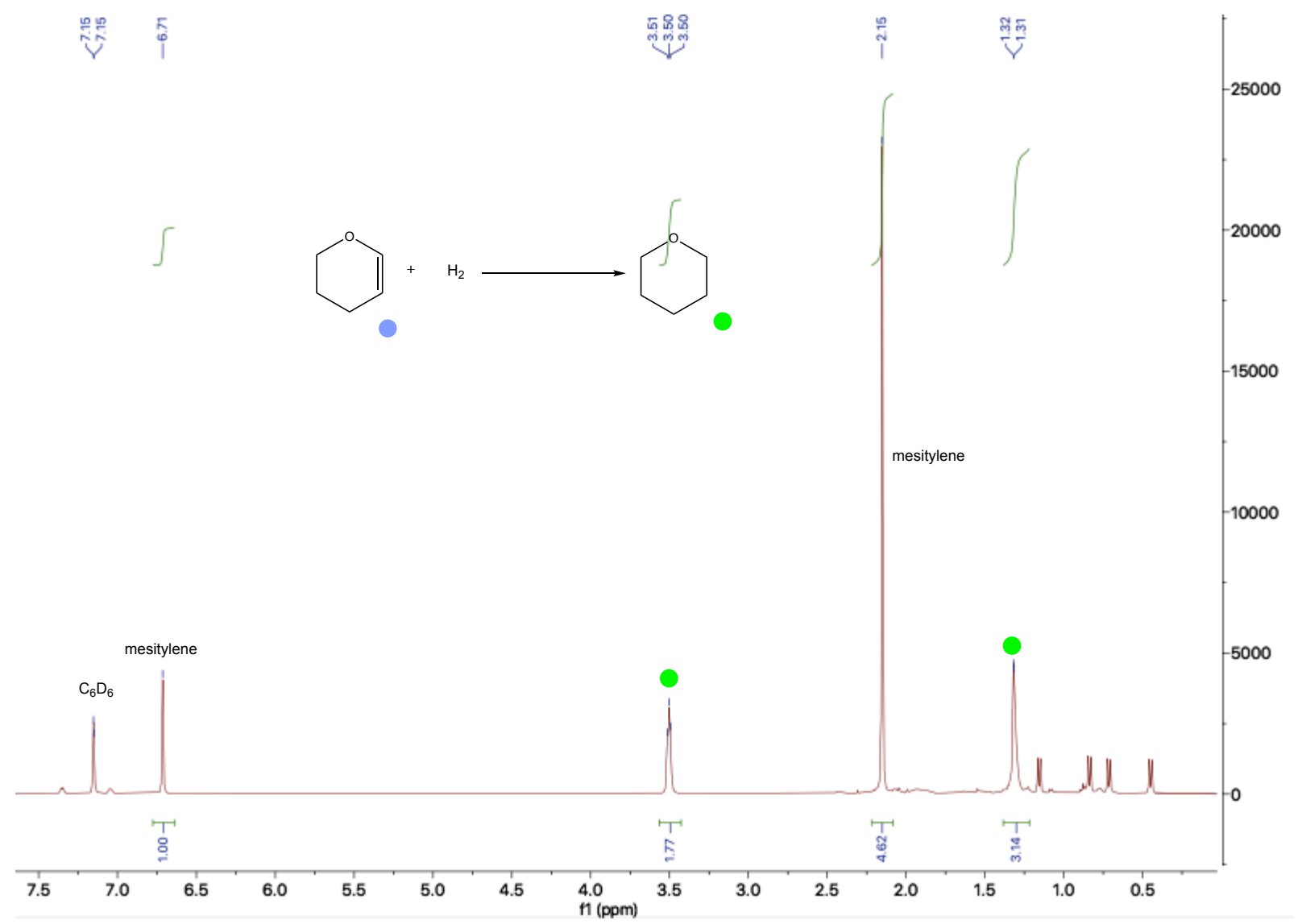

Figure S55. ${ }^{1} \mathrm{H}$ NMR (benzene- $d_{6}$, rt) spectrum of crude product formed from the hydrogenation of 3,4-dihydropyran by 1 under irradiation conditions. 


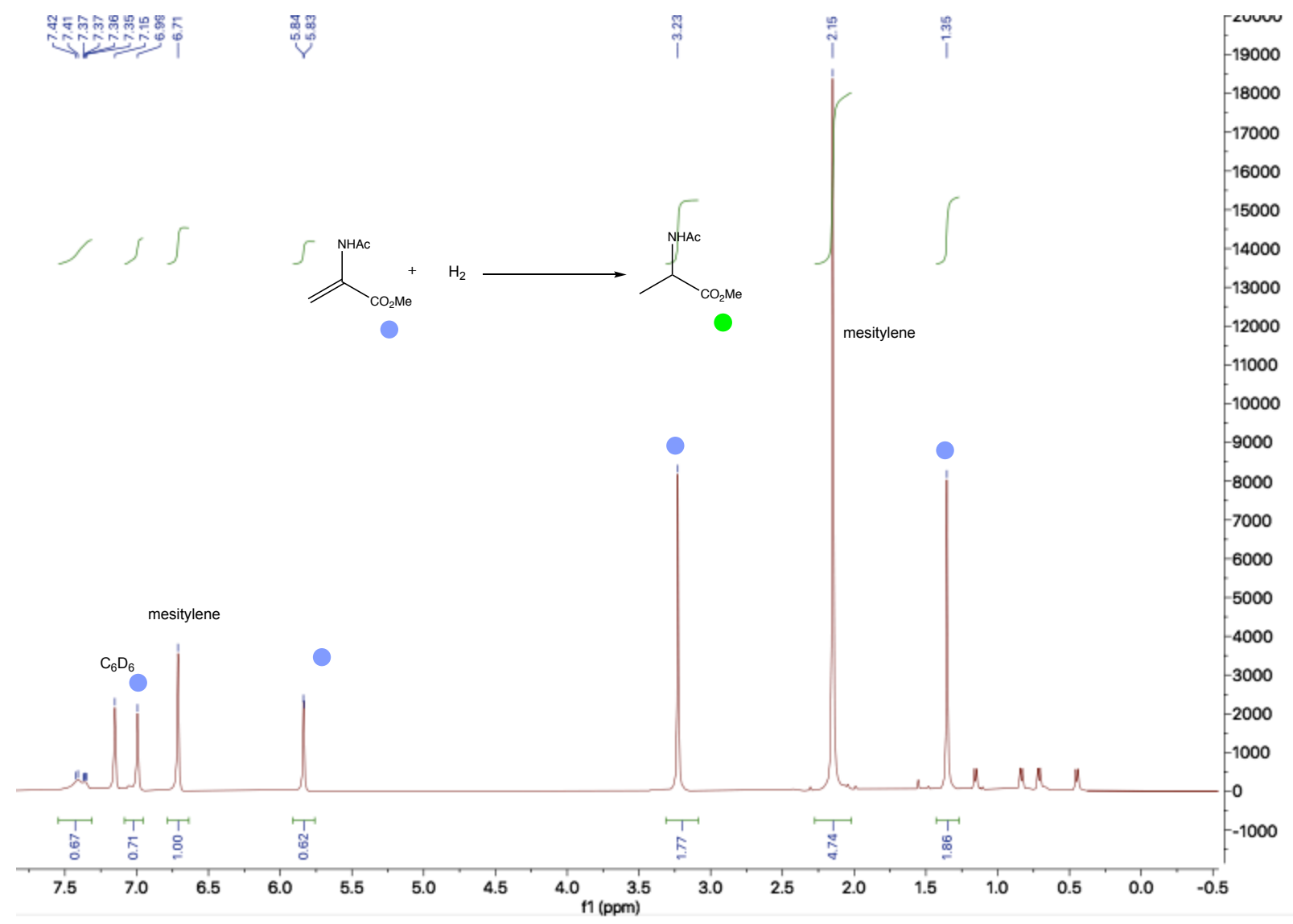

Figure S56. ${ }^{1} \mathrm{H}$ NMR (benzene- $d_{6}$, rt) spectrum of crude product formed from the hydrogenation of methyl 2-acetamidoacrylate by 1 under dark conditions. 


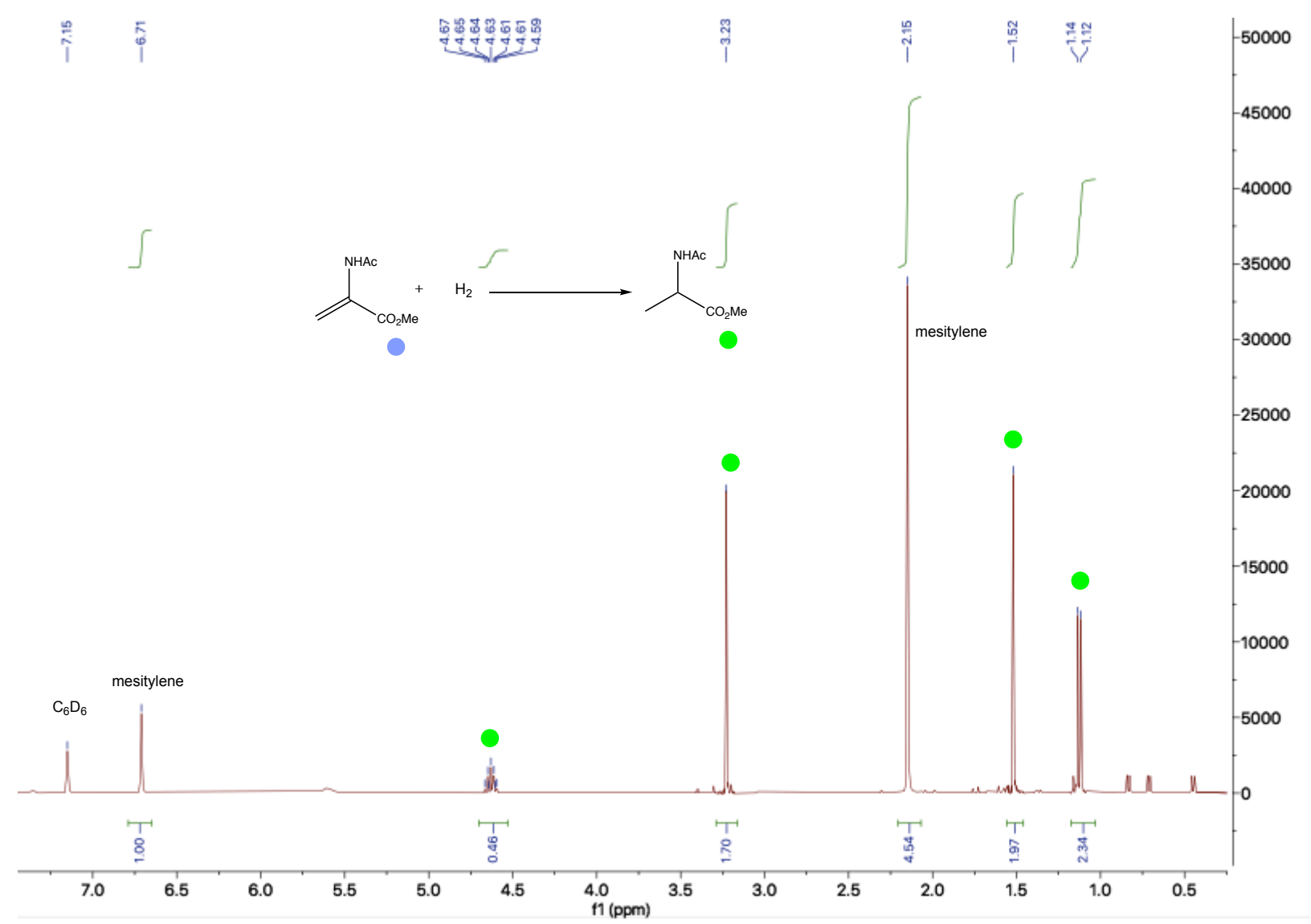

Figure S57. ${ }^{1} \mathrm{H}$ NMR (benzene- $d_{6}$, rt) spectrum of crude product formed from the hydrogenation of methyl 2-acetamidoacrylate by 1 under thermal conditions. 


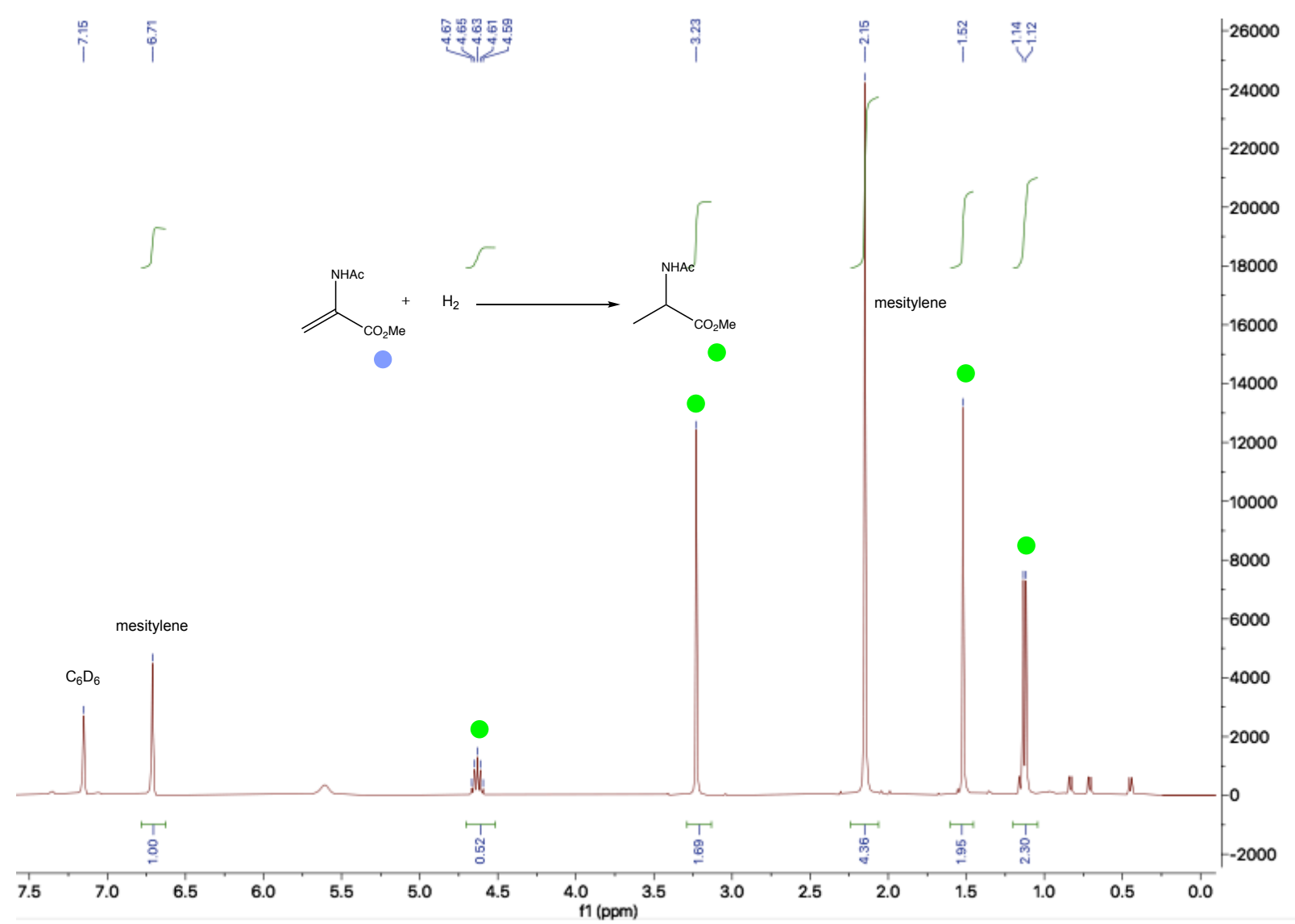

Figure S58. ${ }^{1} \mathrm{H}$ NMR (benzene- $d_{6}$, rt) spectrum of crude product formed from the hydrogenation of methyl 2-acetamidoacrylate by 1 under irradiation conditions. 


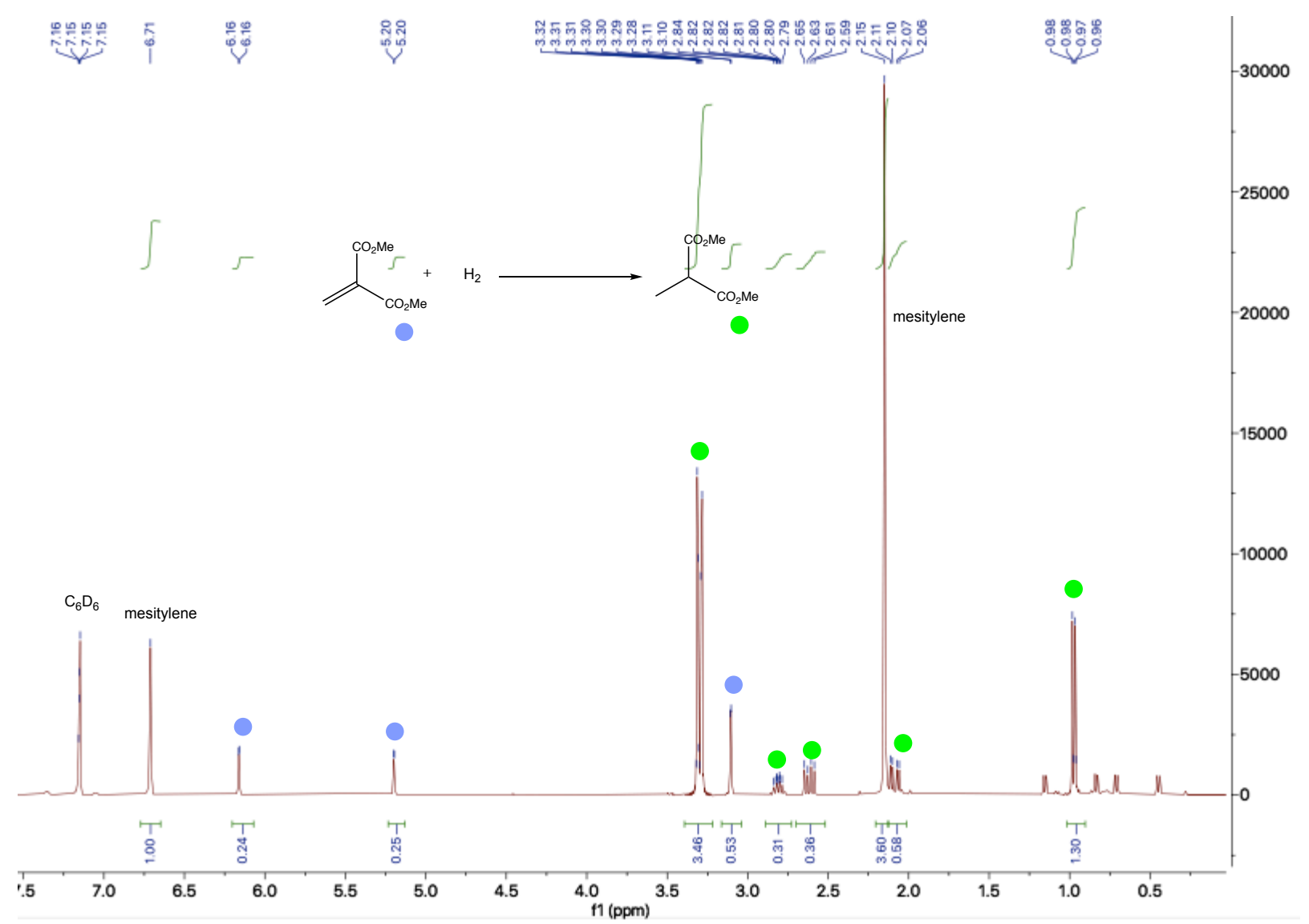

Figure S59. ${ }^{1} \mathrm{H}$ NMR (benzene- $d_{6}$, rt) spectrum of crude product formed from the hydrogenation of dimethyl 2-methylenemalonate by 1 under dark conditions. 


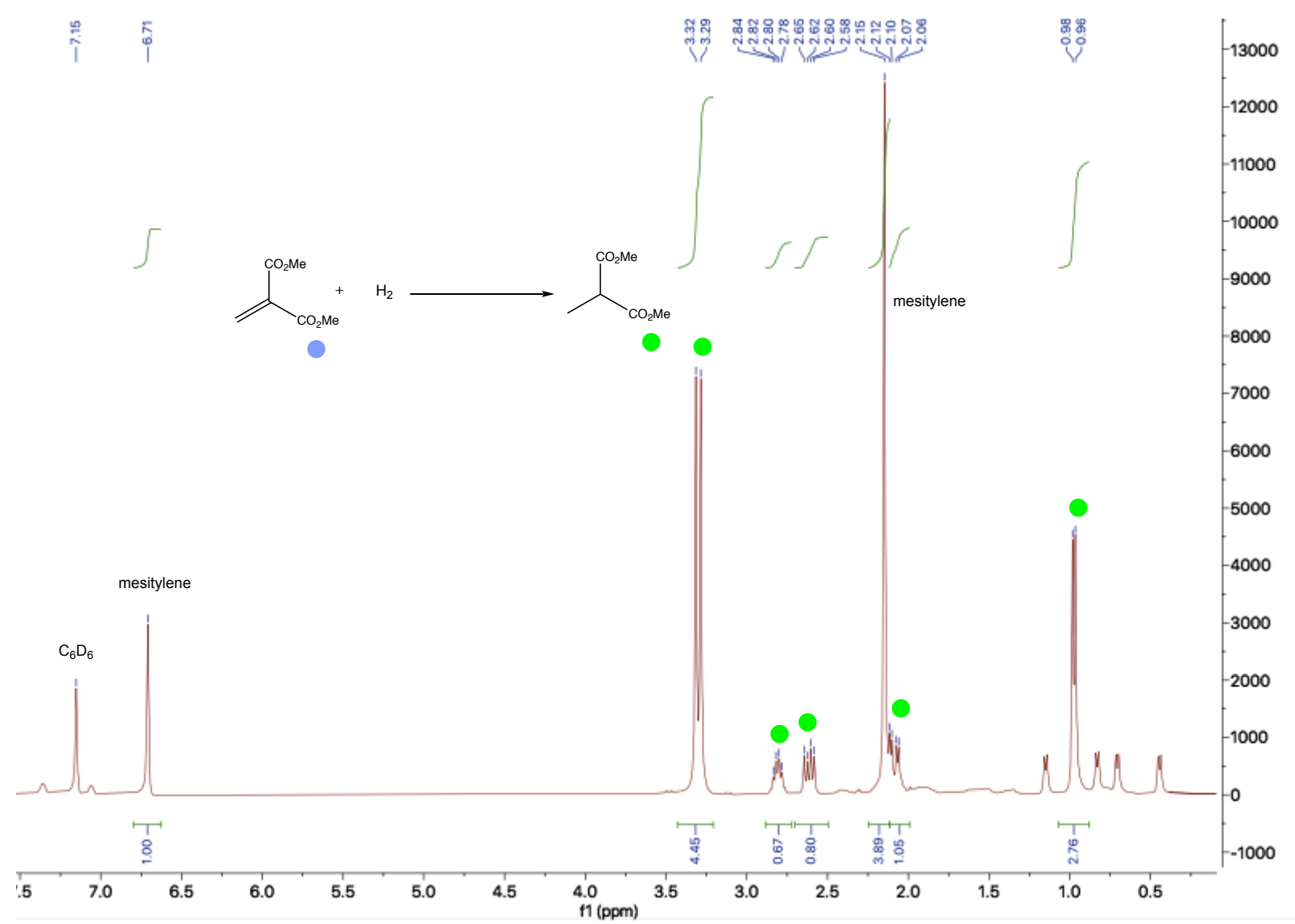

Figure S60. ${ }^{1} \mathrm{H}$ NMR (benzene- $d_{6}$, rt) spectrum of crude product formed from the hydrogenation of dimethyl 2-methylenemalonate by 1 under thermal conditions. 


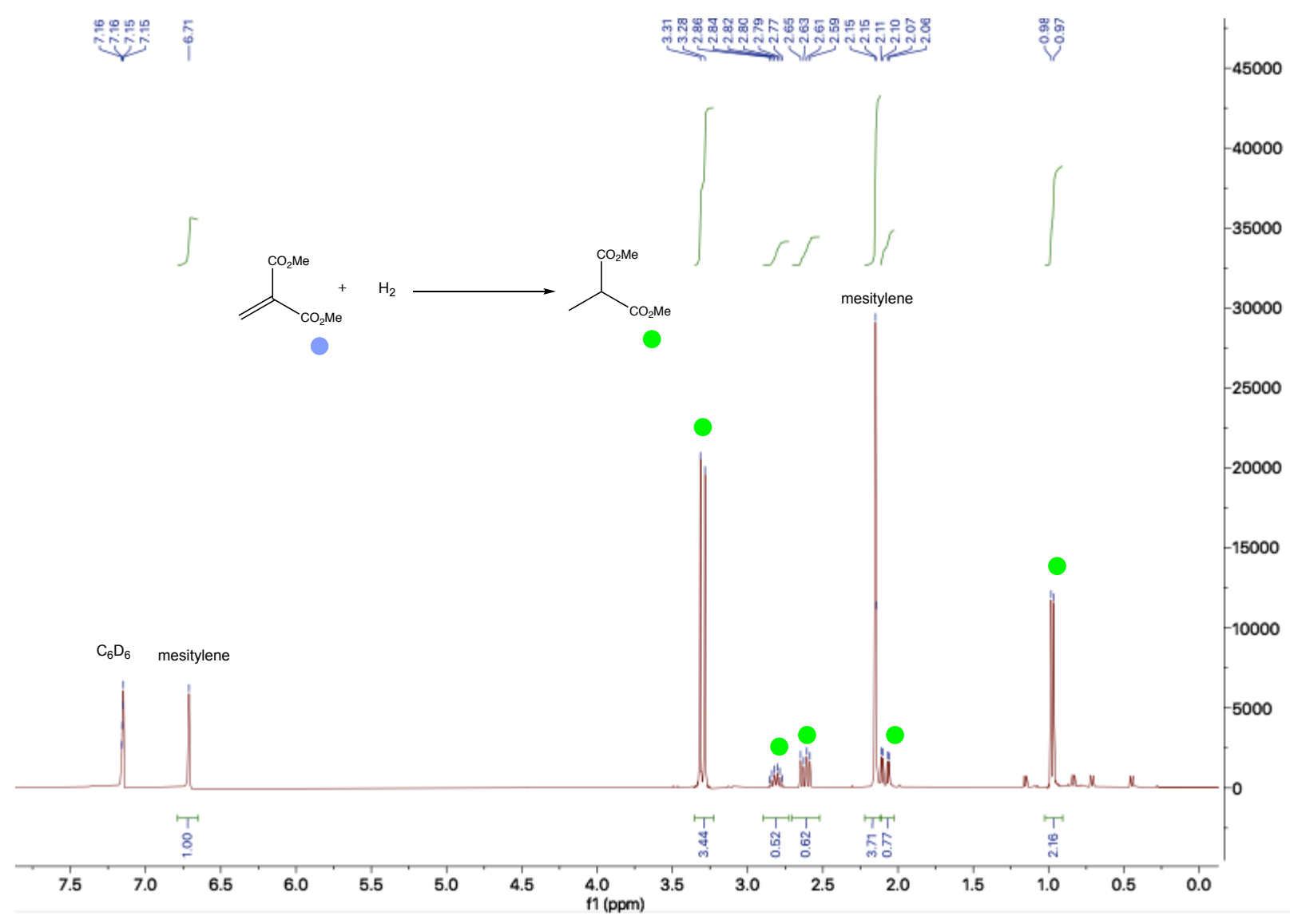

Figure S61. ${ }^{1} \mathrm{H}$ NMR (benzene- $d_{6}$, rt) spectrum of crude product formed from the hydrogenation of dimethyl 2-methylenemalonate by 1 under irradiation conditions. 


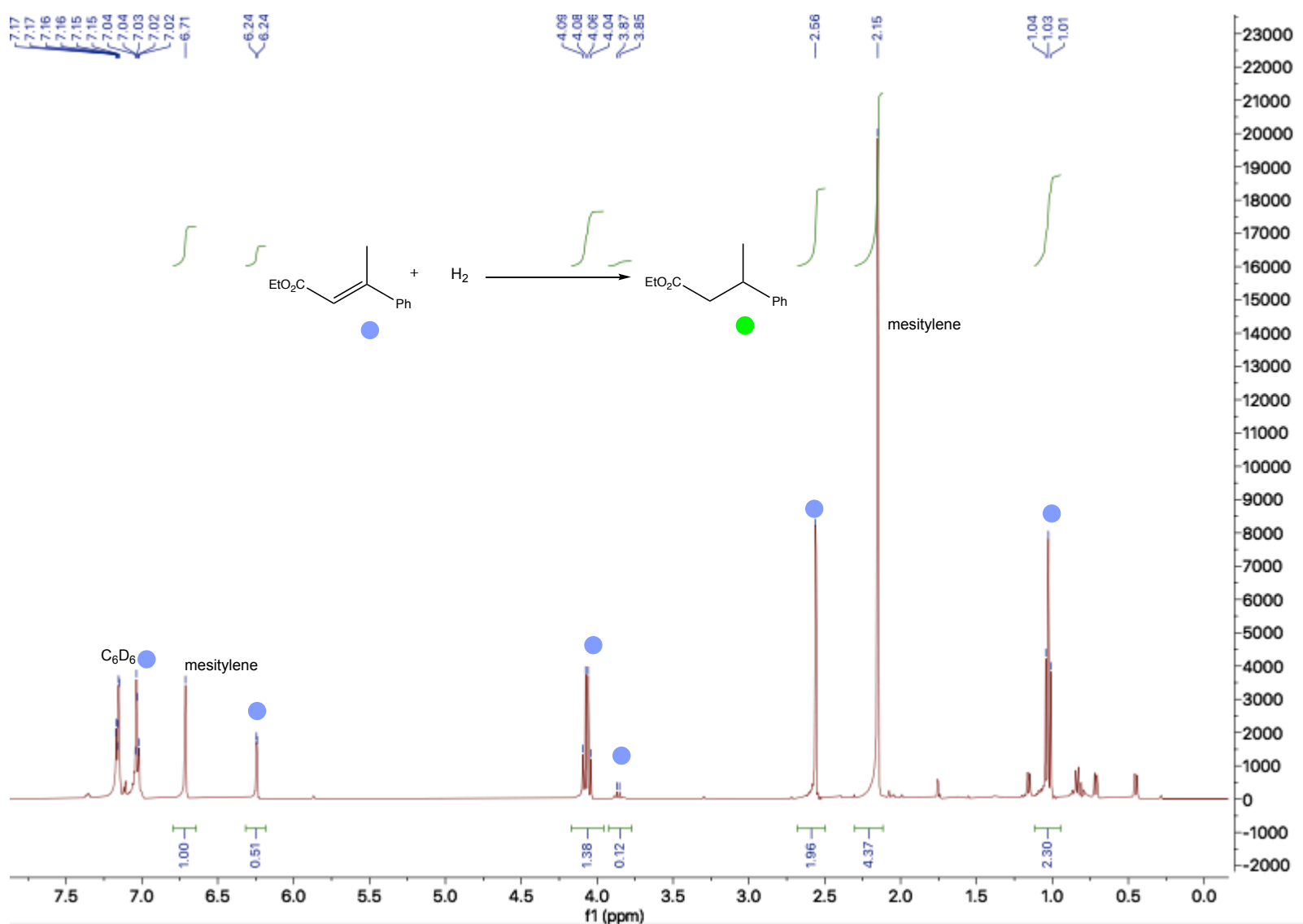

Figure S62. ${ }^{1} \mathrm{H}$ NMR (benzene- $d_{6}$, rt) spectrum of crude product formed from the hydrogenation of ethyl $(E)$-3-phenylbut-2-enoate by 1 under dark conditions. 


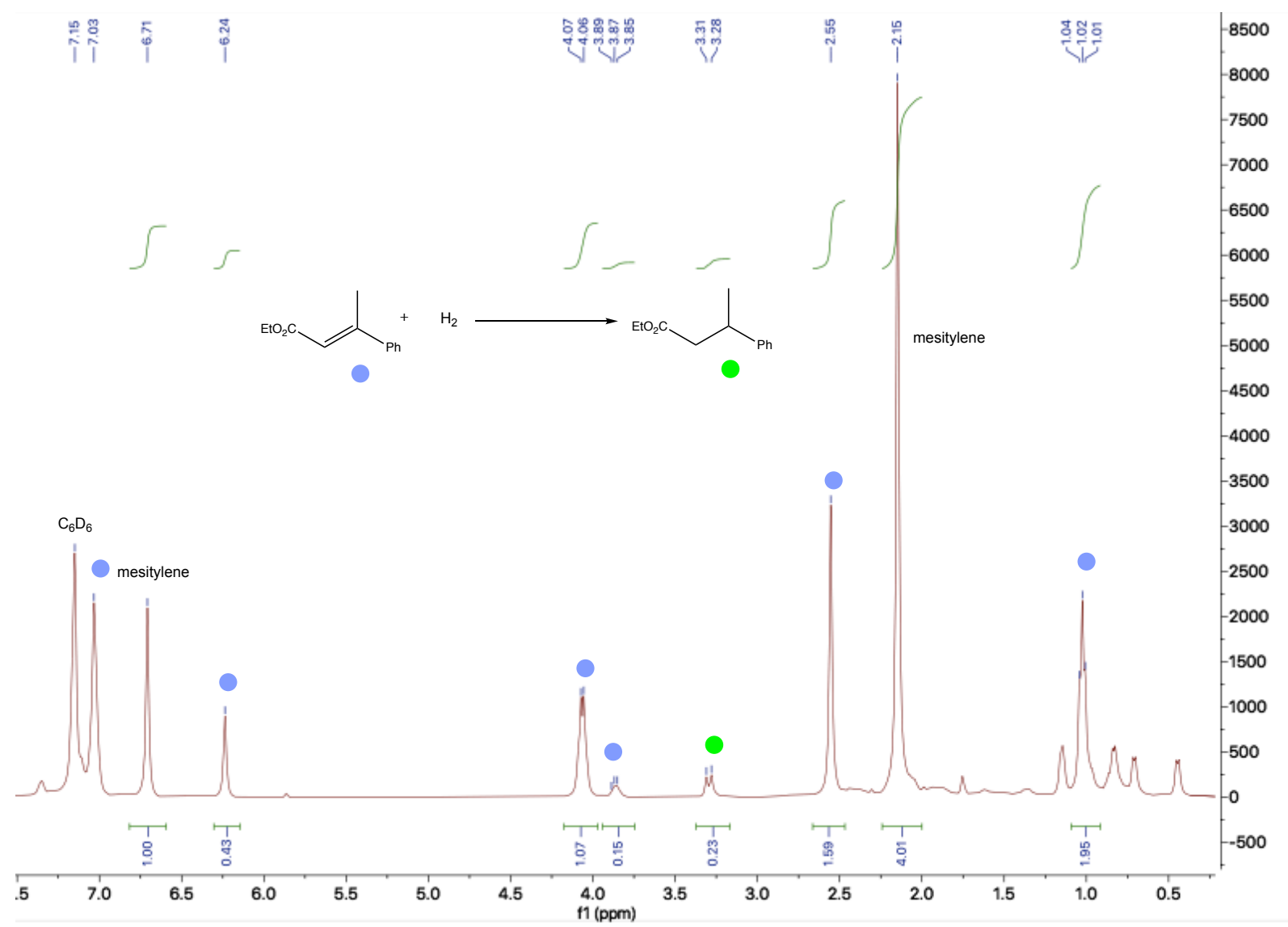

Figure S63. ${ }^{1} \mathrm{H}$ NMR (benzene- $d_{6}$, rt) spectrum of crude product formed from the

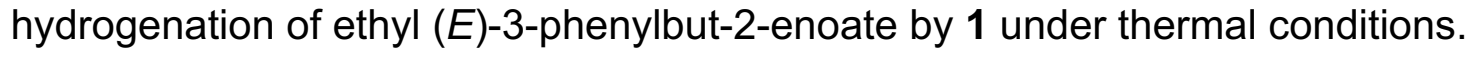




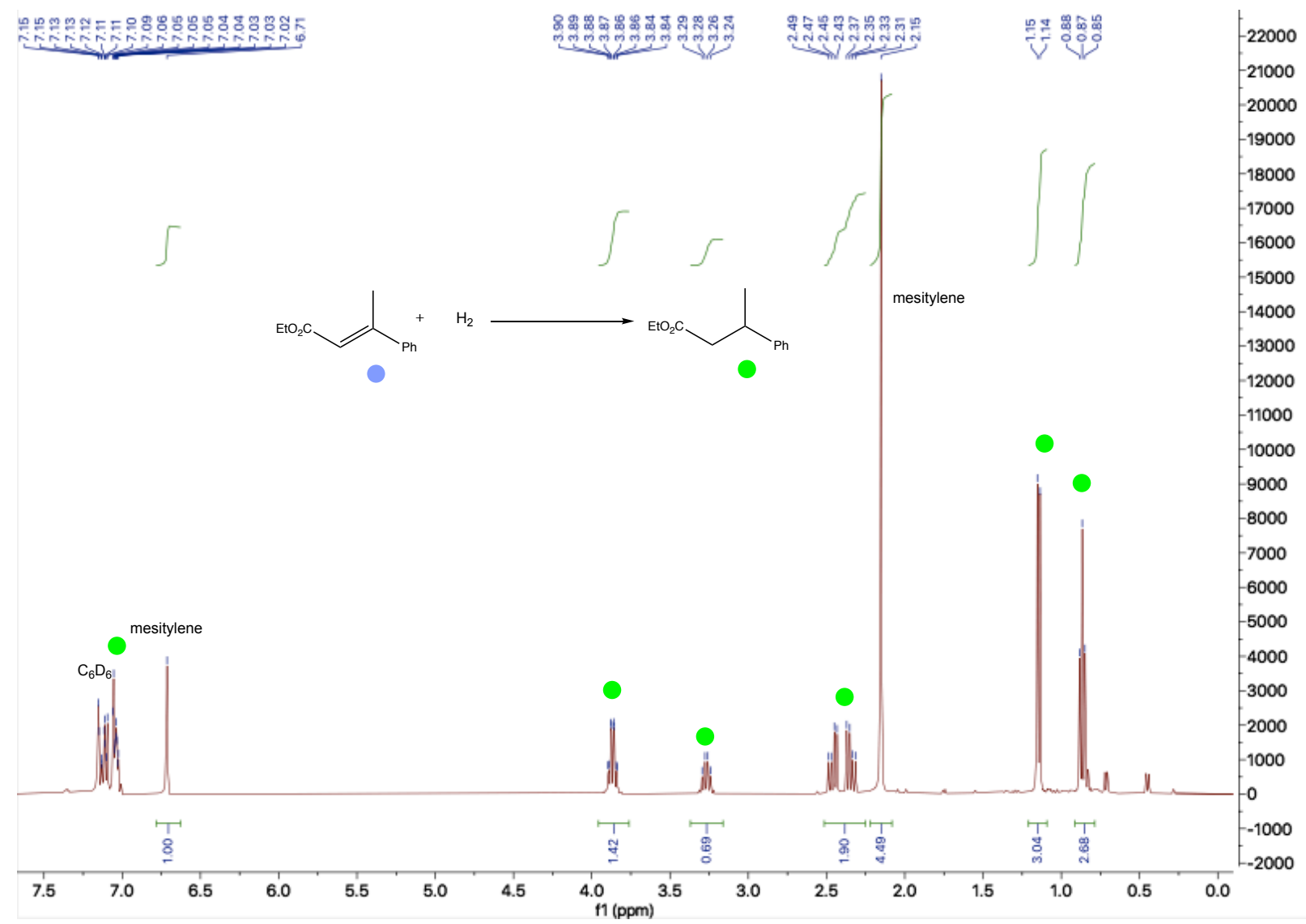

Figure S64. ${ }^{1} H$ NMR (benzene- $d_{6}$, rt) spectrum of crude product formed from the hydrogenation of ethyl (E)-3-phenylbut-2-enoate by 1 under irradiation conditions. 


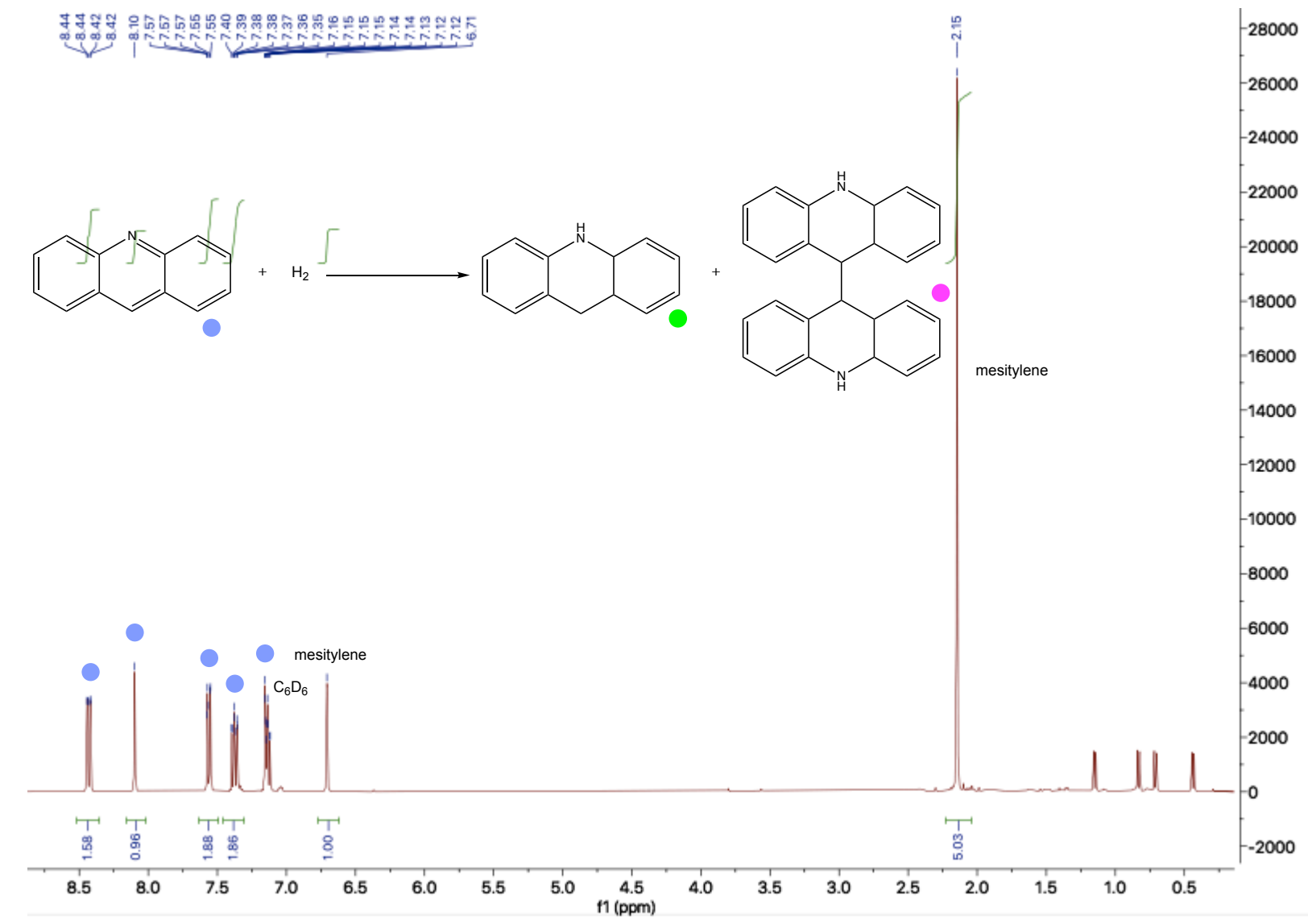

Figure S65. ${ }^{1} \mathrm{H}$ NMR (benzene- $d_{6}$, rt) spectrum of crude product formed from the hydrogenation of acridine by 1 under dark conditions. 


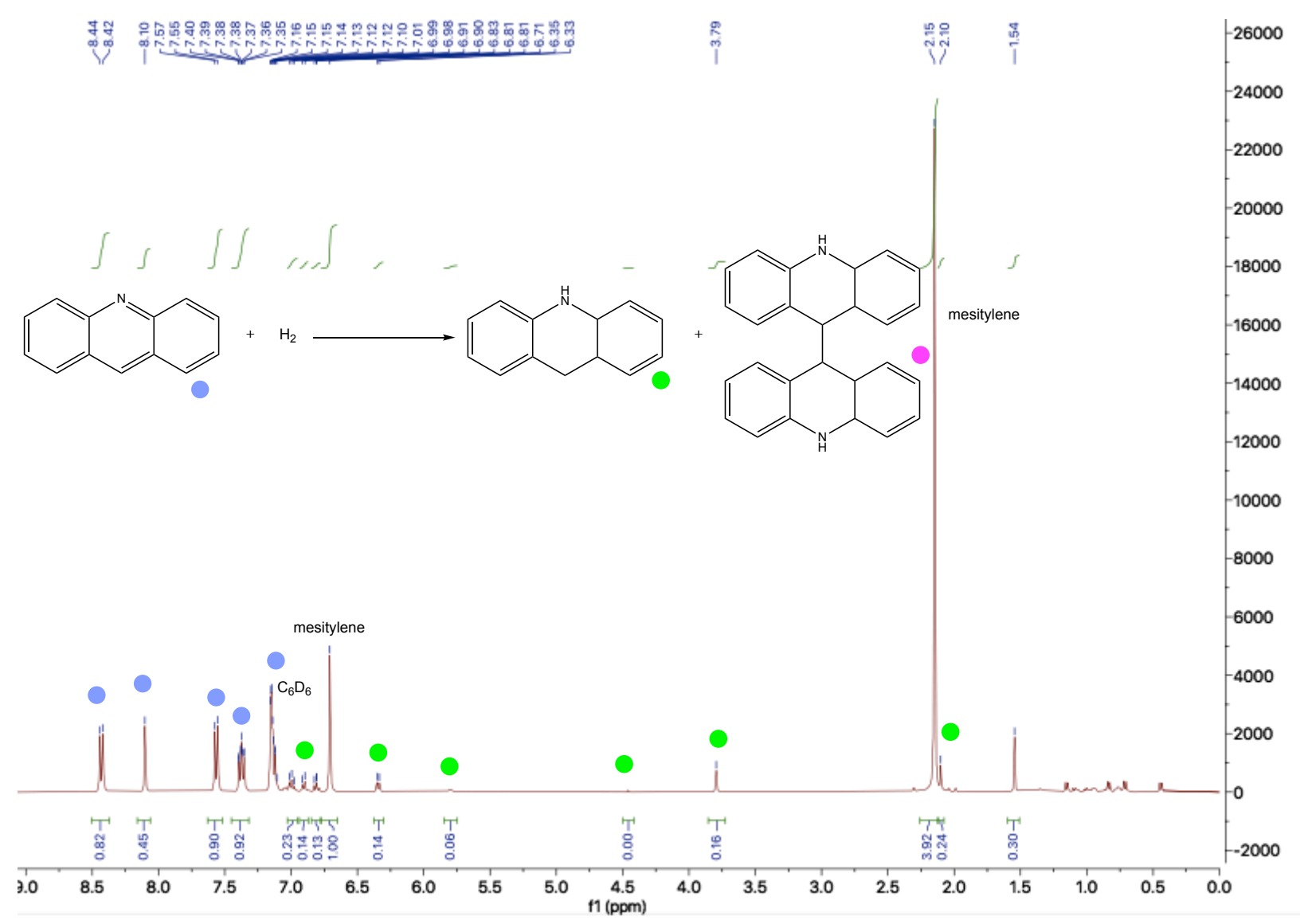

Figure S66. ${ }^{1} \mathrm{H}$ NMR (benzene- $d_{6}$, rt) spectrum of crude product formed from the hydrogenation of acridine by 1 under thermal conditions. 


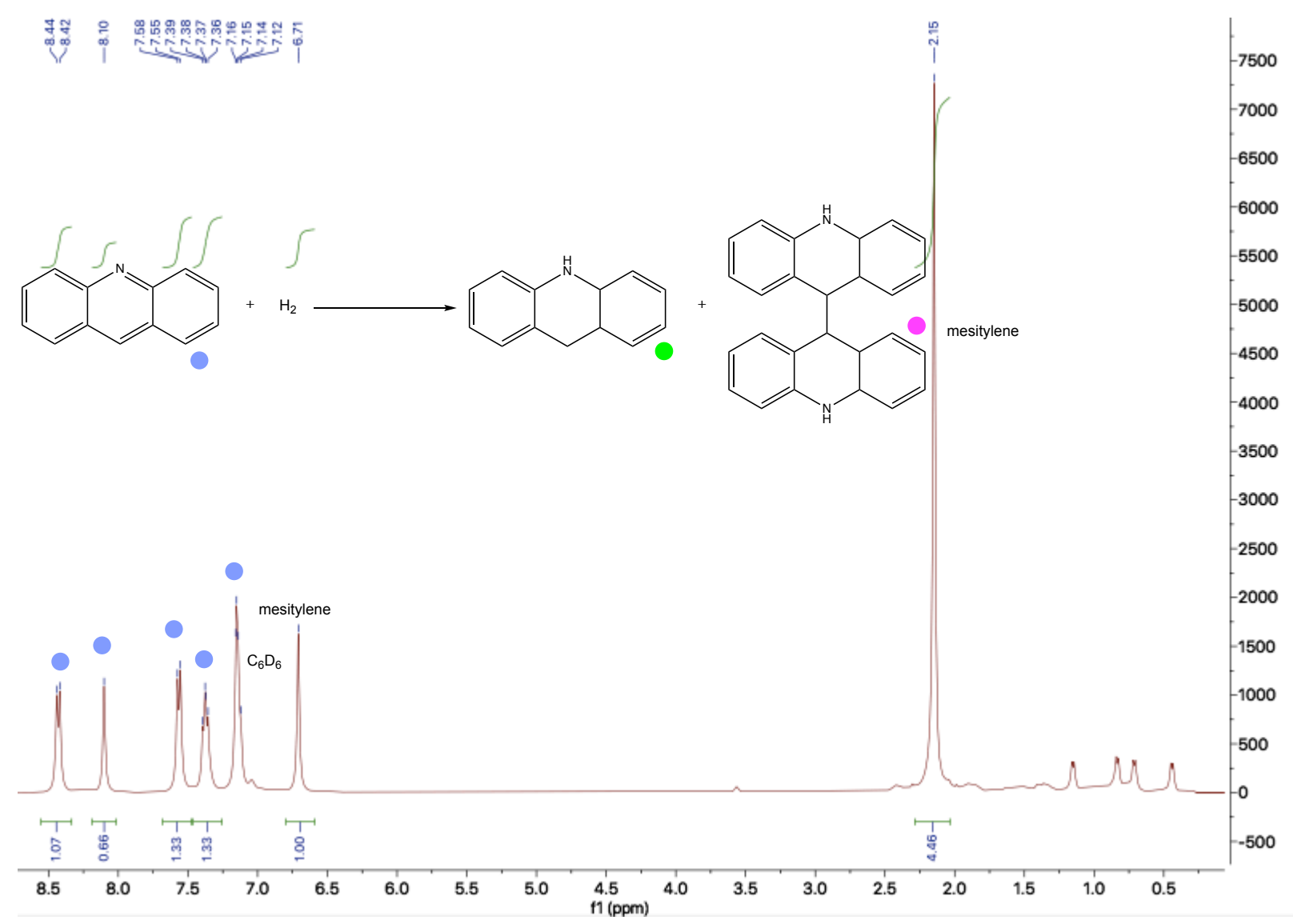

Figure S67. ${ }^{1} \mathrm{H}$ NMR (benzene- $d_{6}$, rt) spectrum of crude product formed from the hydrogenation of acridine by 1 under light conditions. 


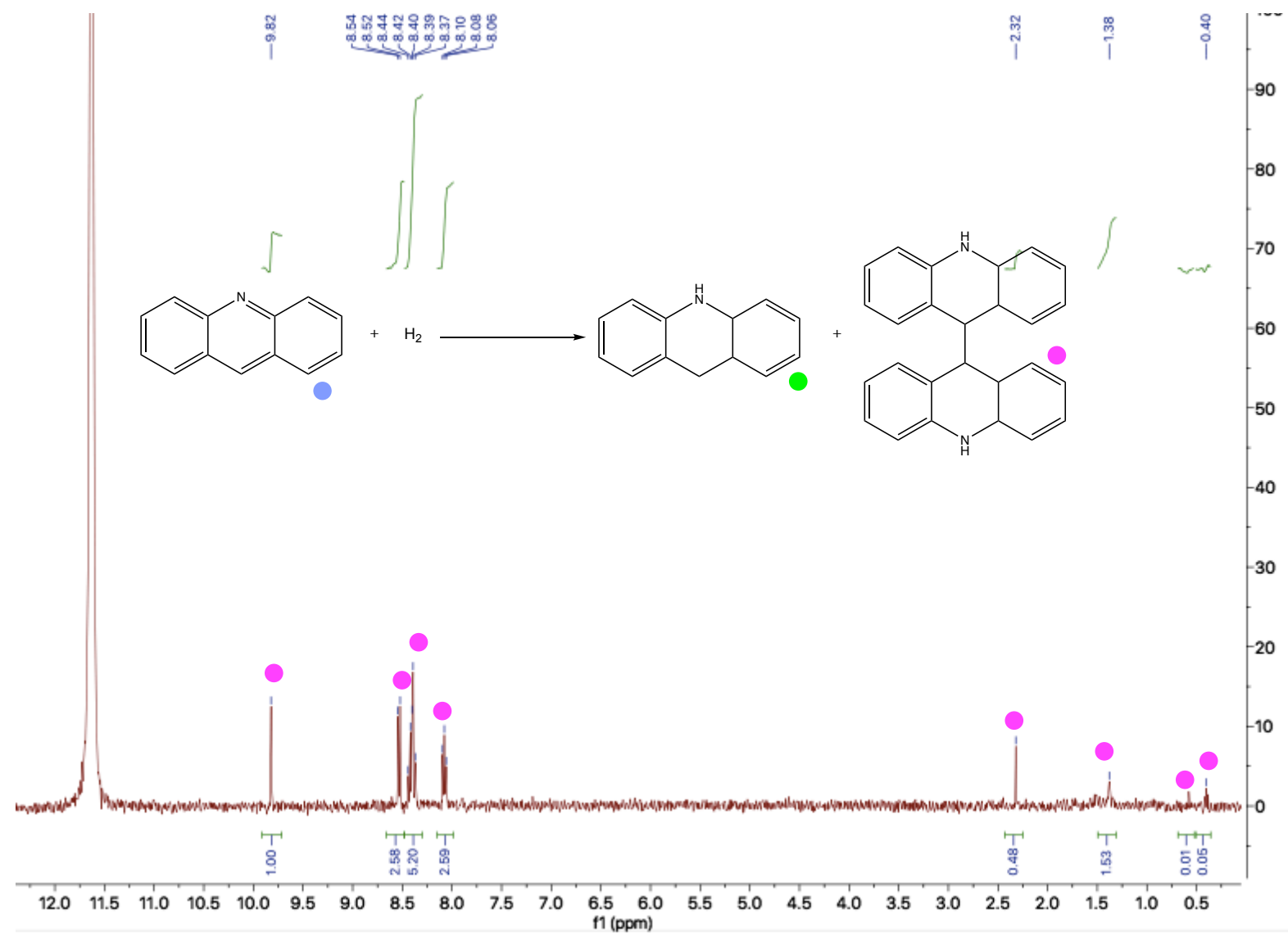

Figure S68. ${ }^{1} \mathrm{H}$ NMR (TFA- $d_{1}$, rt) spectrum of precipitate formed from the hydrogenation of acridine by 1 under light and thermal conditions. 


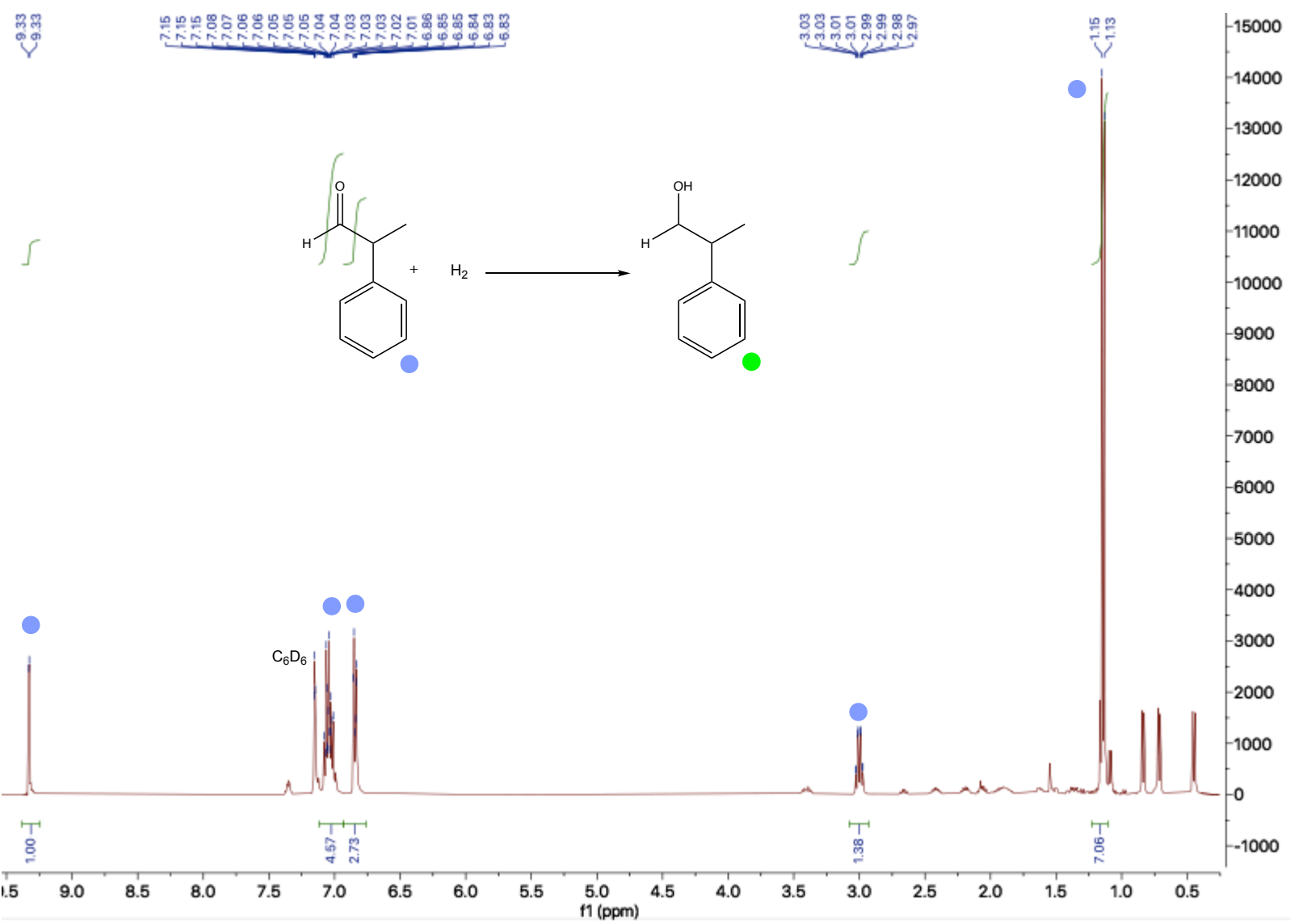

Figure S69. ${ }^{1} \mathrm{H}$ NMR (benzene- $d_{6}$, rt) spectrum of crude product formed from the hydrogenation of 2-phenylpropanal by 1 under thermal conditions. 


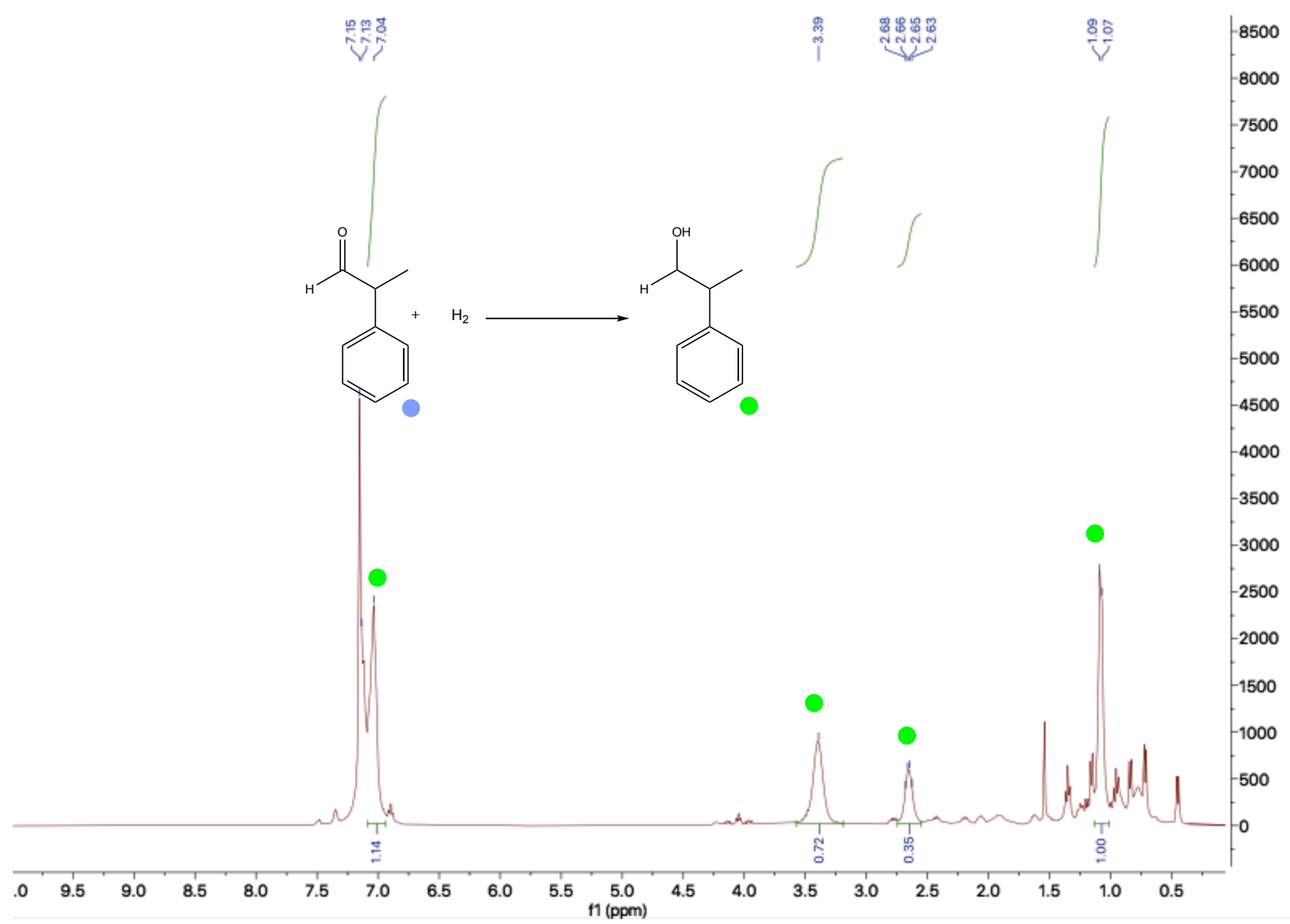

Figure S70. ${ }^{1} \mathrm{H}$ NMR (benzene- $d_{6}$, rt) spectrum of crude product formed from the hydrogenation of 2-phenylpropanal by 1 under light conditions. 


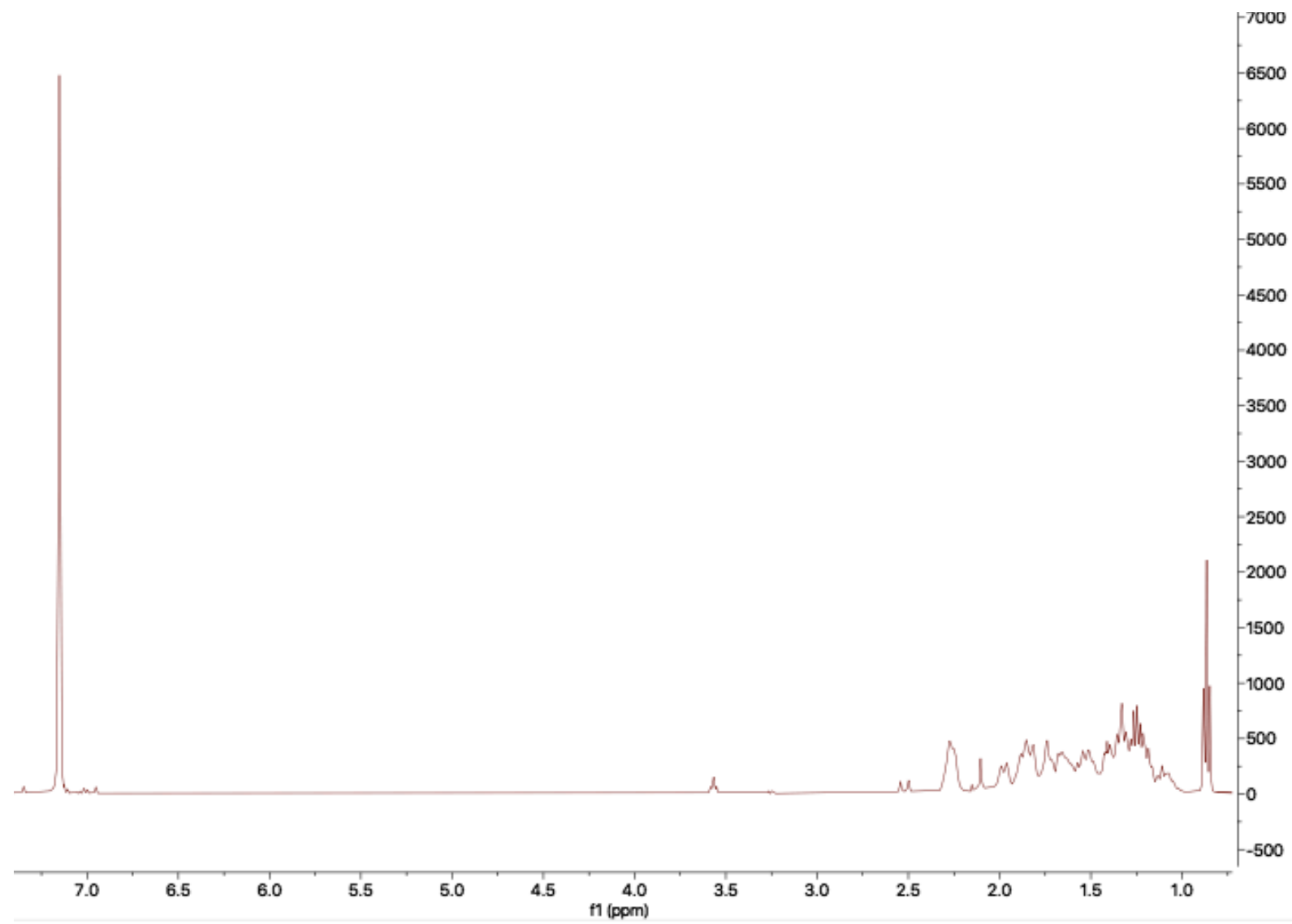

Figure S71. ${ }^{1} \mathrm{H}$ NMR (benzene- $d_{6}$, rt) spectrum of crude product formed from the reaction of $\mathrm{Co}_{2}(\mathrm{CO})_{8}$ with dcpe. 


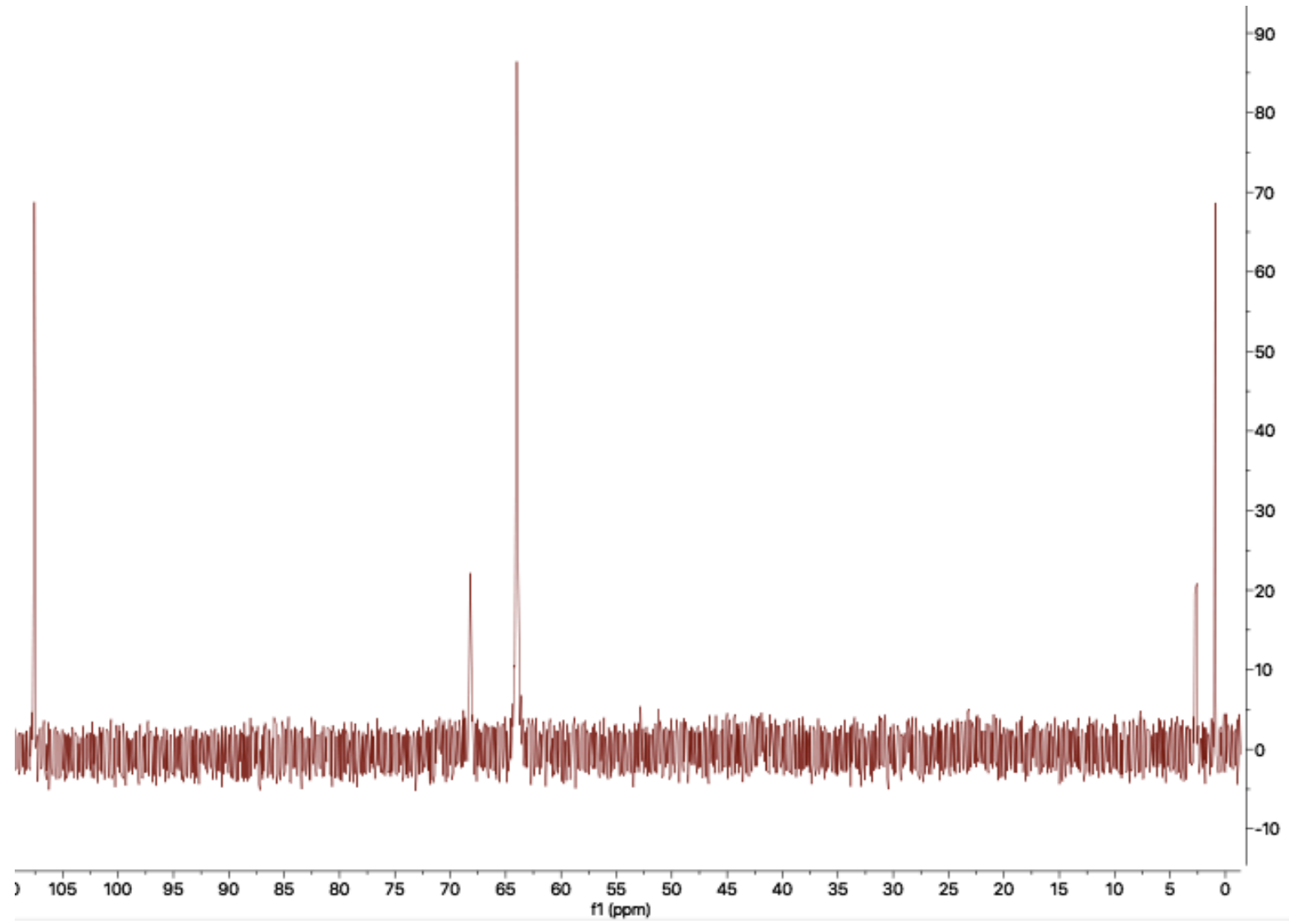

Figure S72. ${ }^{31} \mathrm{P}$ NMR (benzene- $d_{6}, \mathrm{rt}$ ) spectrum of crude product formed from the reaction of $\mathrm{CO}_{2}(\mathrm{CO})_{8}$ with dcpe. 


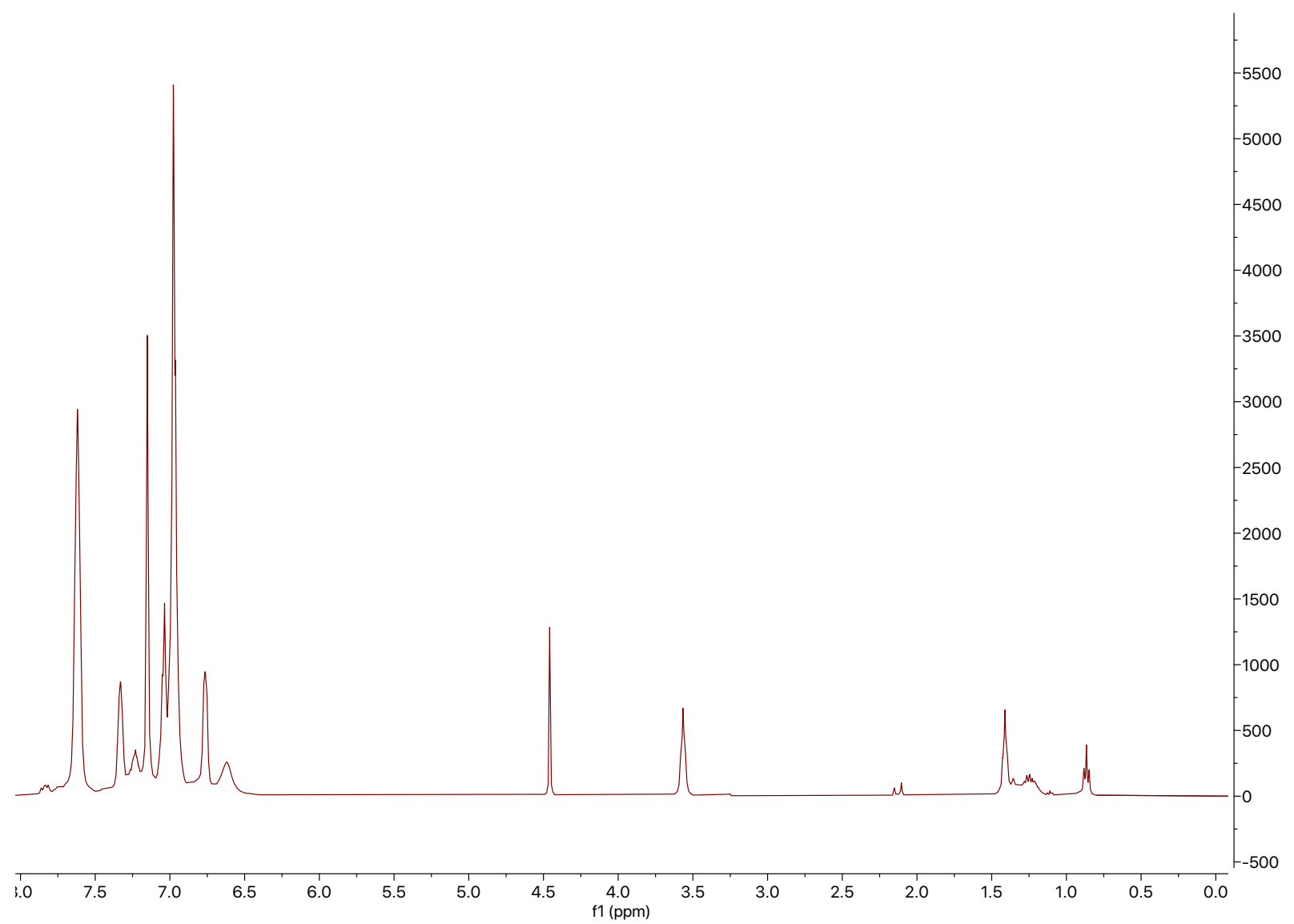

Figure S73. ${ }^{1} \mathrm{H}$ NMR (benzene- $d_{6}$, rt) spectrum of crude product formed from the reaction of $\mathrm{Co}_{2}(\mathrm{CO})_{8}$ with dppbenz. 


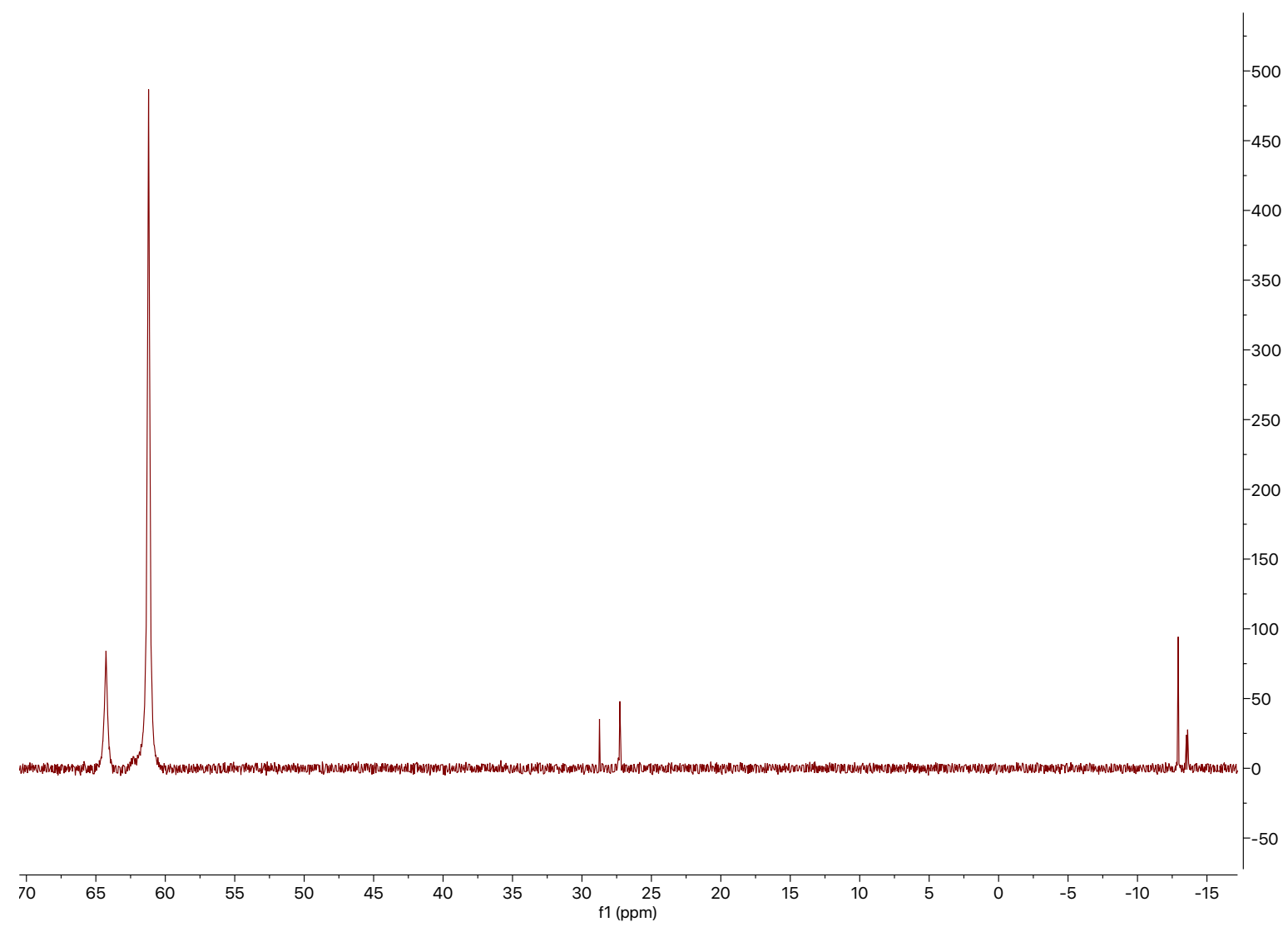

Figure S74. ${ }^{31} \mathrm{P}$ NMR (benzene- $d_{6}$, rt) spectrum of crude product formed from the reaction of $\mathrm{Co}_{2}(\mathrm{CO})_{8}$ with dppbenz. 


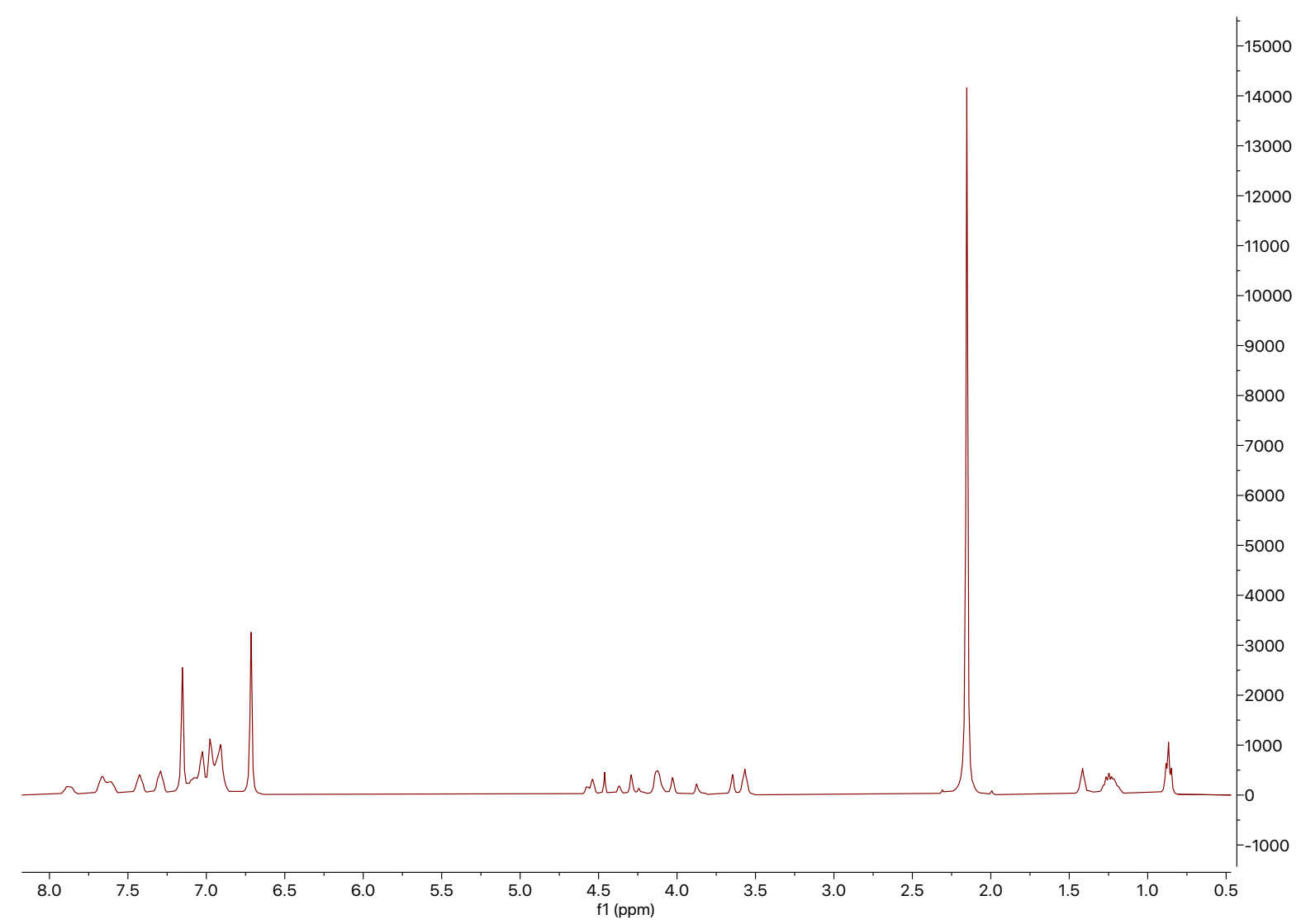

Figure S75. ${ }^{1} \mathrm{H}$ NMR (benzene- $d_{6}$, rt) spectrum of crude product formed from the reaction of $\mathrm{Co}_{2}(\mathrm{CO})_{8}$ with dppf. 


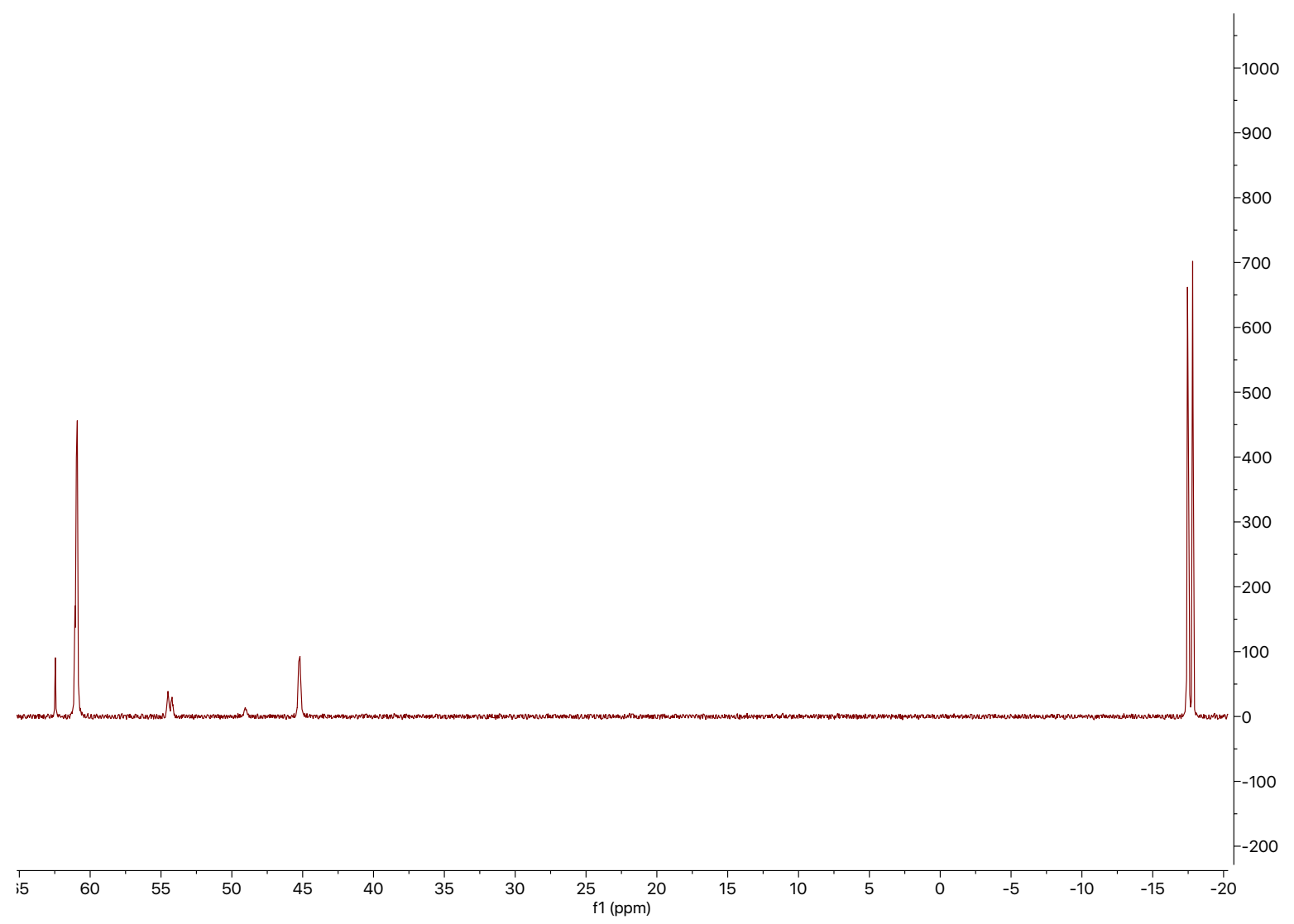

Figure S76. ${ }^{31} \mathrm{P}$ NMR (benzene- $d_{6}$, rt) spectrum of crude product formed from the reaction of $\mathrm{Co}_{2}(\mathrm{CO})_{8}$ with dppf. 


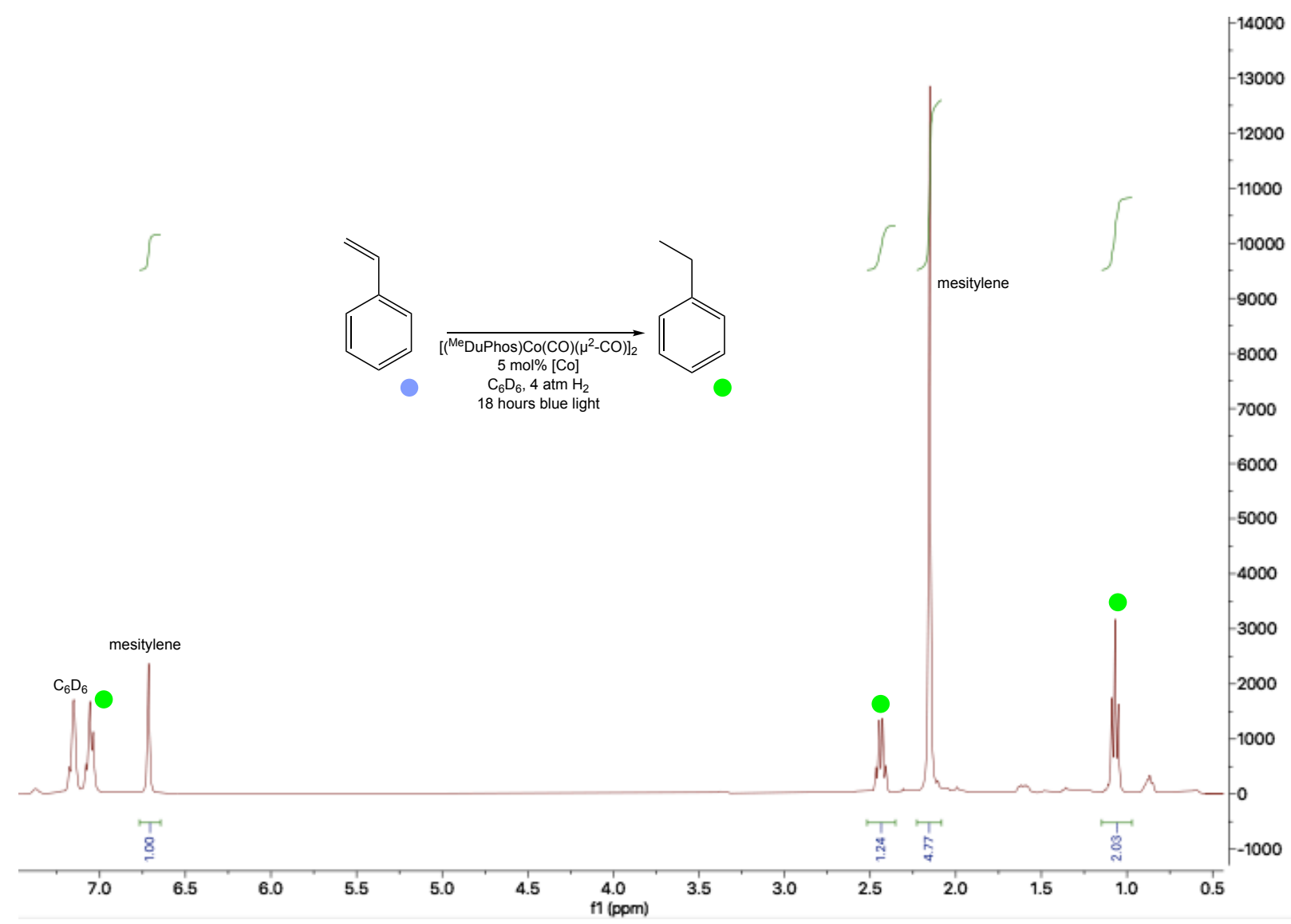

Figure S77. ${ }^{1} \mathrm{H}$ NMR (benzene- $d_{6}$, rt) spectrum of crude product formed from the hydrogenation of styrene by $\left[\left({ }^{\mathrm{Me}} \mathrm{DuPhos}\right) \mathrm{Co}(\mathrm{CO})\left(\mu^{2}-\mathrm{CO}\right)\right]_{2}$ under light conditions. 


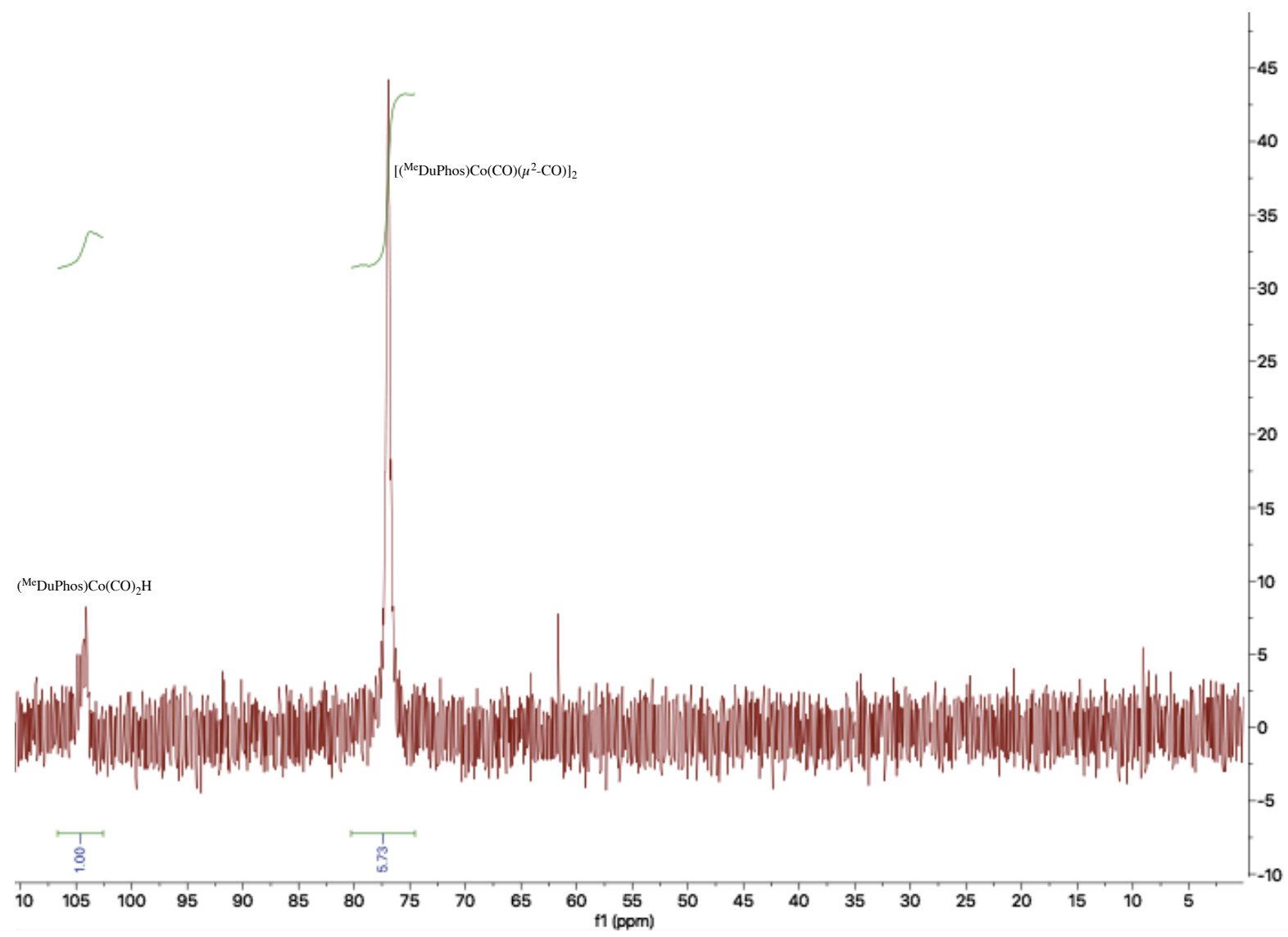

Figure S78. ${ }^{31} \mathrm{P}$ NMR (benzene- $d_{6}$, rt) spectrum of crude complexes formed from the hydrogenation of styrene by $\left[\left({ }^{\mathrm{Me}} \mathrm{DuPhos}\right) \mathrm{Co}(\mathrm{CO})\left(\mu^{2}-\mathrm{CO}\right)\right]_{2}$ under light conditions. 


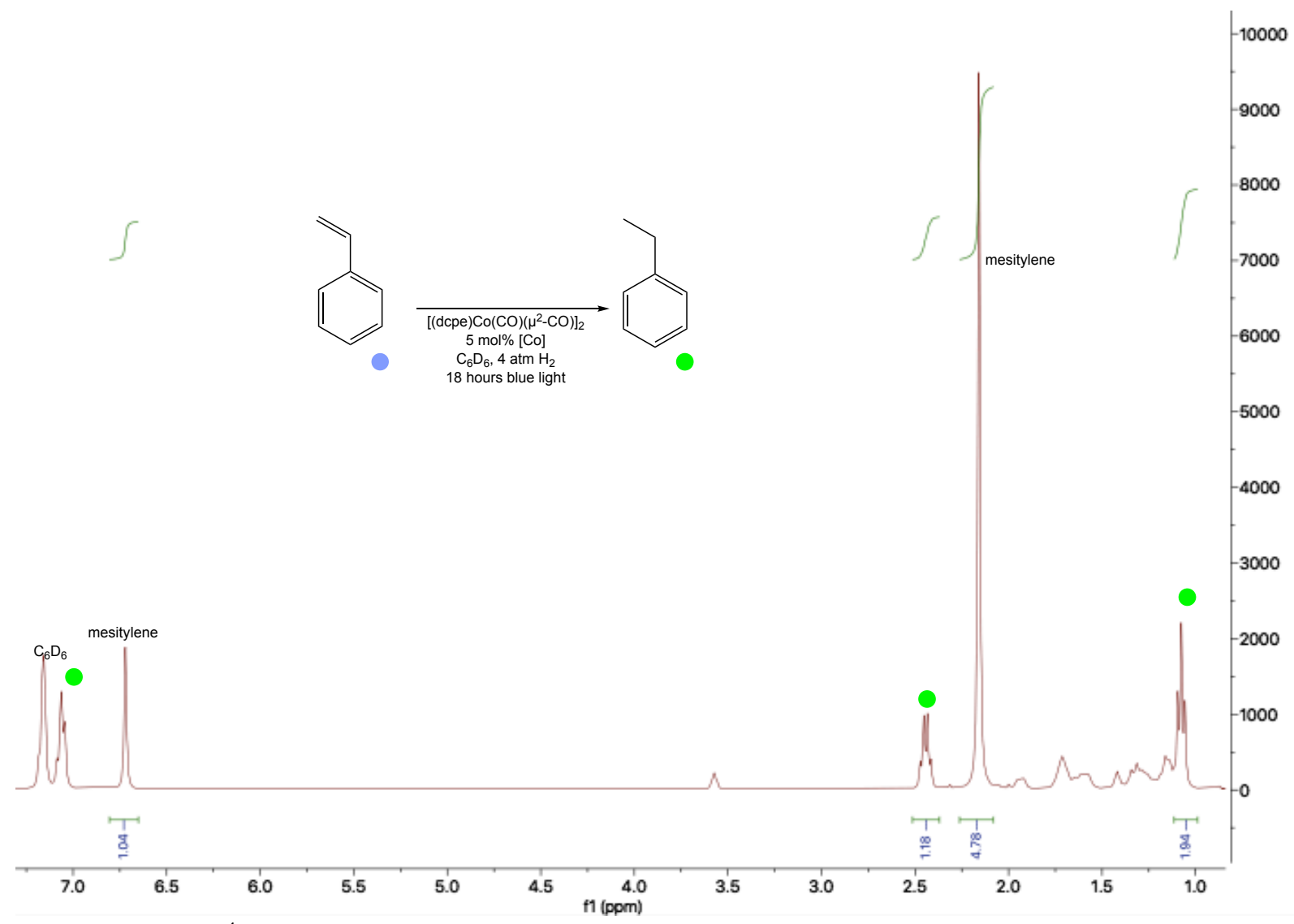

Figure S79. ${ }^{1} \mathrm{H}$ NMR (benzene- $d_{6}$, rt) spectrum of crude product formed from the hydrogenation of styrene by crude $\left[(\mathrm{dcpe}) \mathrm{Co}(\mathrm{CO})\left(\mu^{2}-\mathrm{CO}\right)\right]_{2}$ under light conditions. 


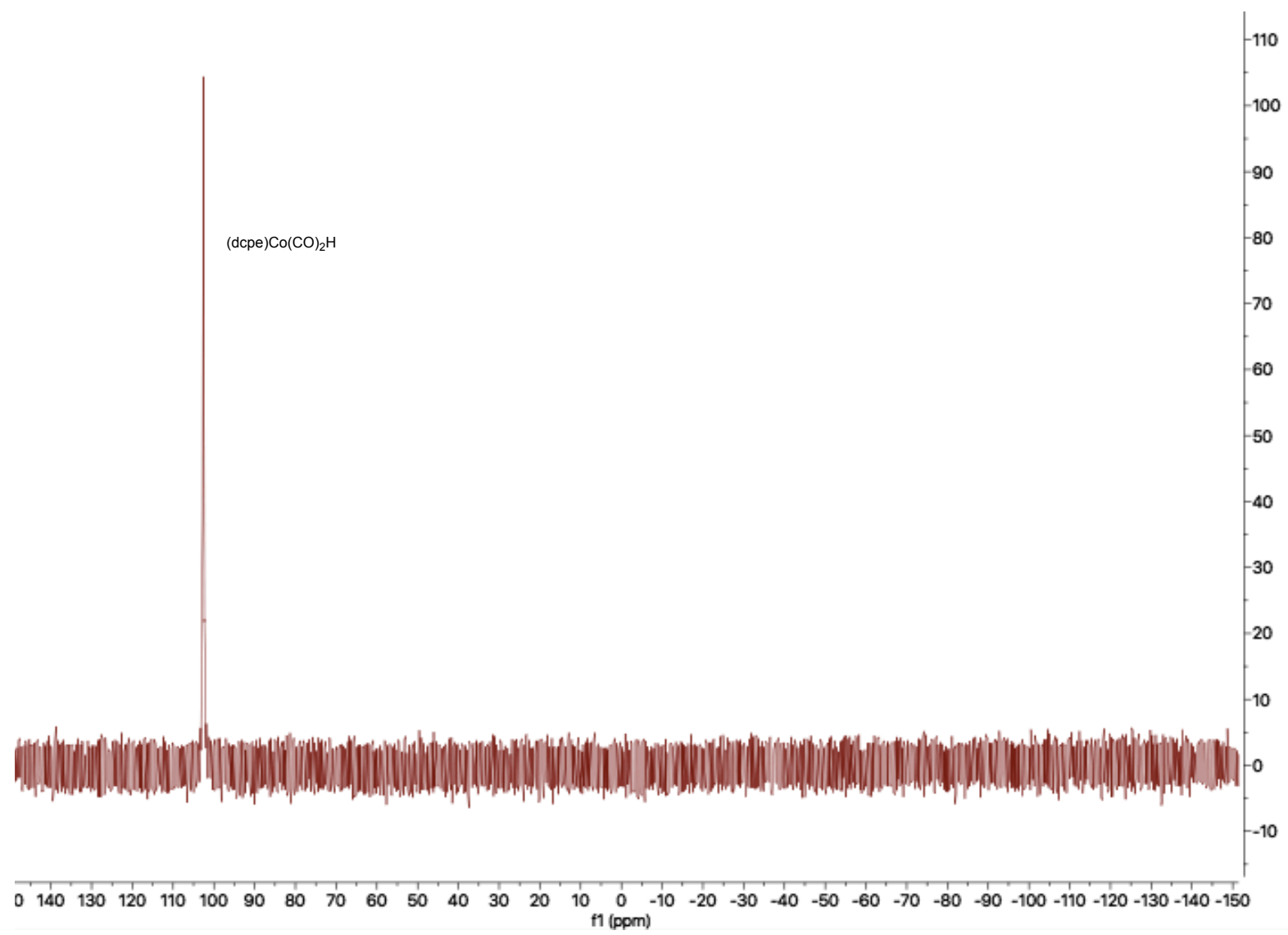

Figure S80. ${ }^{31} \mathrm{P}$ NMR (benzene- $d_{6}$, rt) spectrum of crude complexes formed from the hydrogenation of styrene by crude $\left[(\mathrm{dcpe}) \mathrm{Co}(\mathrm{CO})\left(\mu^{2}-\mathrm{CO}\right)\right]_{2}$ under light conditions. 


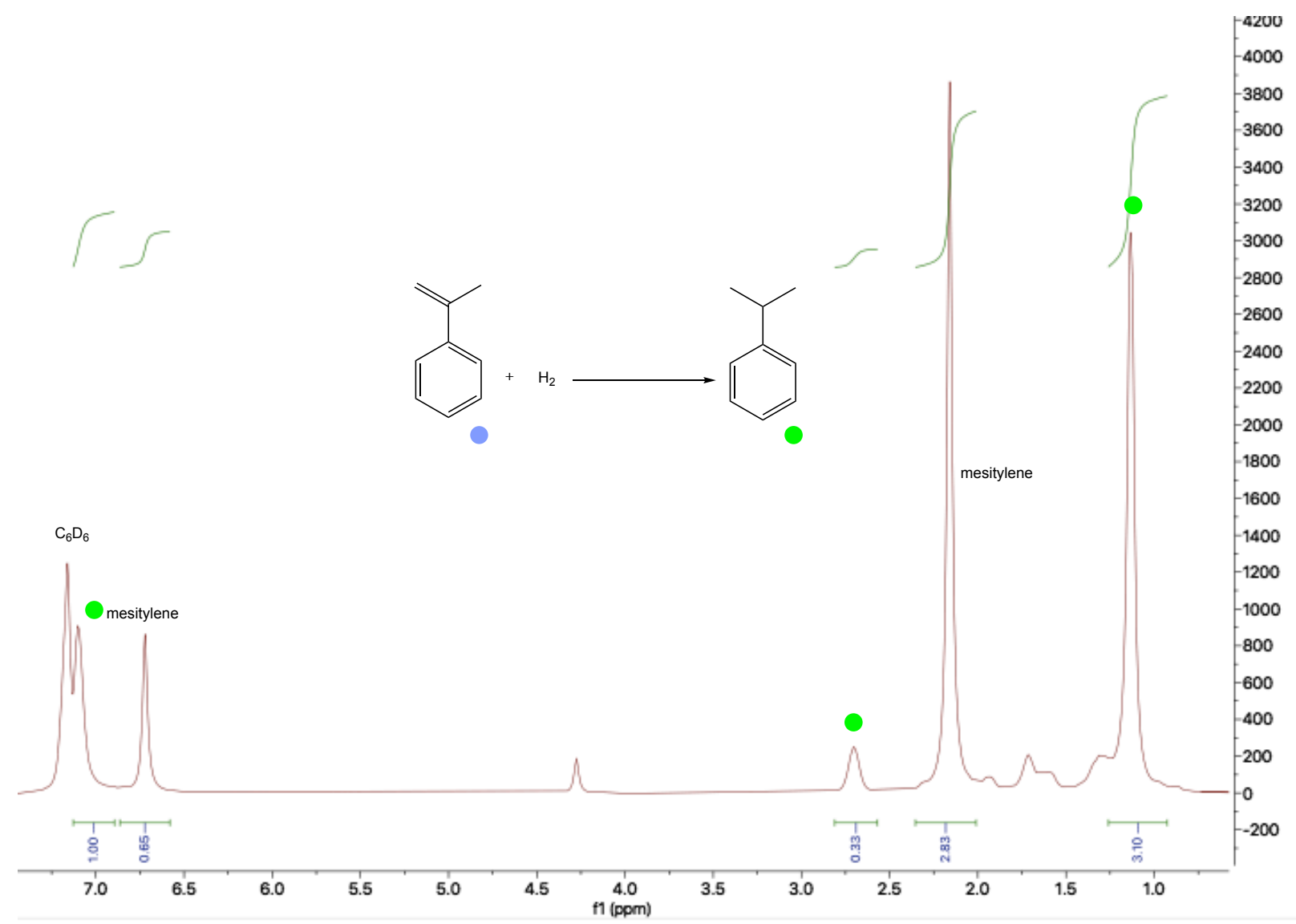

Figure S81. ${ }^{1} \mathrm{H}$ NMR (benzene- $d_{6}$, rt) spectrum of crude complexes formed from the hydrogenation of $\alpha$-methyl styrene by crude $\left[(\mathrm{dcpe}) \mathrm{Co}(\mathrm{CO})\left(\mu^{2}-\mathrm{CO}\right)\right]_{2}$ under light conditions. 


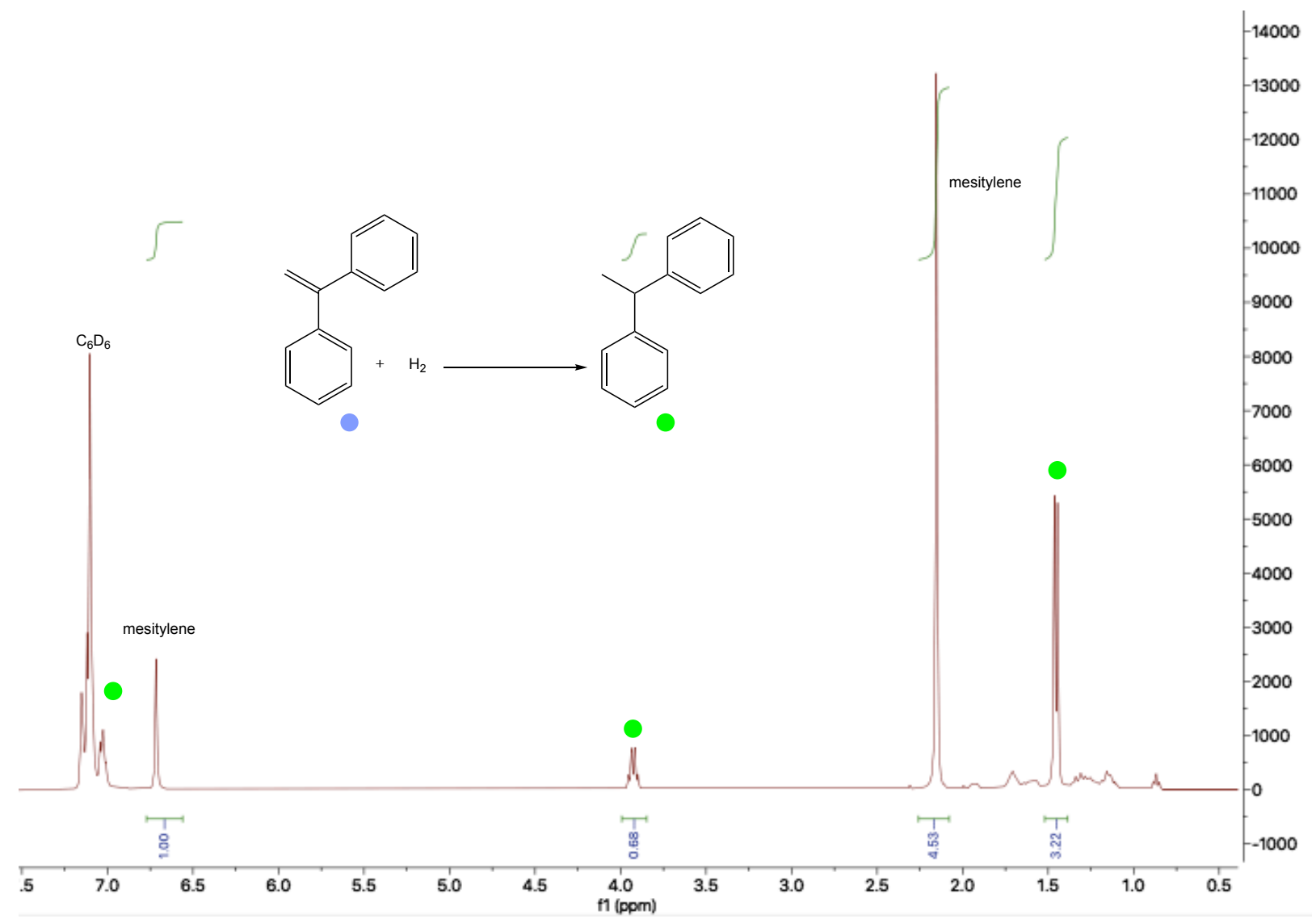

Figure S82. ${ }^{1} \mathrm{H}$ NMR (benzene- $d_{6}$, rt) spectrum of crude complexes formed from the hydrogenation of 1,1-diphenyl ethylene by crude $\left[(\mathrm{dcpe}) \mathrm{Co}(\mathrm{CO})\left(\mu^{2}-\mathrm{CO}\right)\right]_{2}$ under light conditions. 


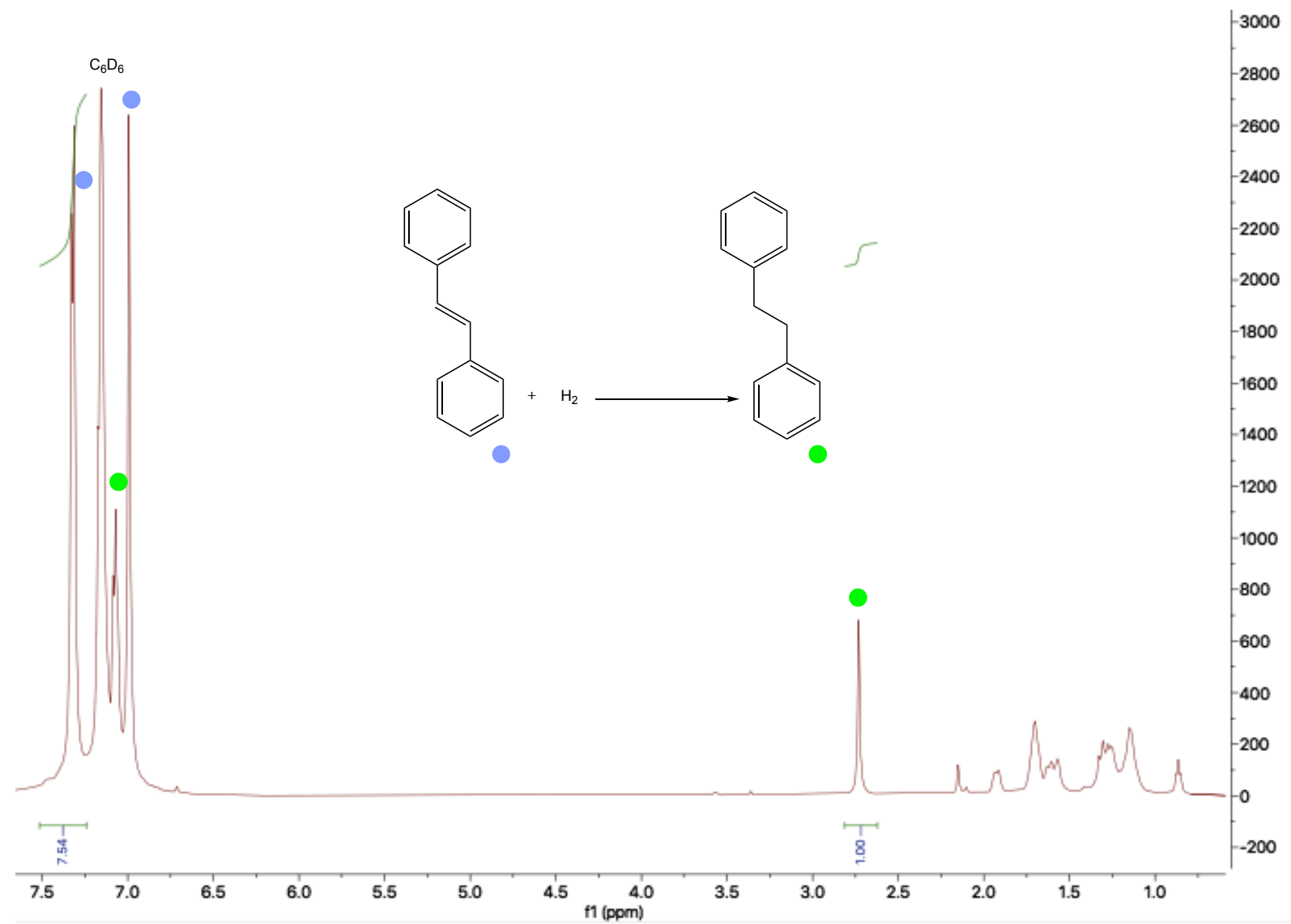

Figure S83. ${ }^{1} \mathrm{H}$ NMR (benzene- $d_{6}$, rt) spectrum of crude complexes formed from the hydrogenation of trans-stilbene by crude $\left[(\mathrm{dcpe}) \mathrm{Co}(\mathrm{CO})\left(\mu^{2}-\mathrm{CO}\right)\right]_{2}$ under light conditions. 


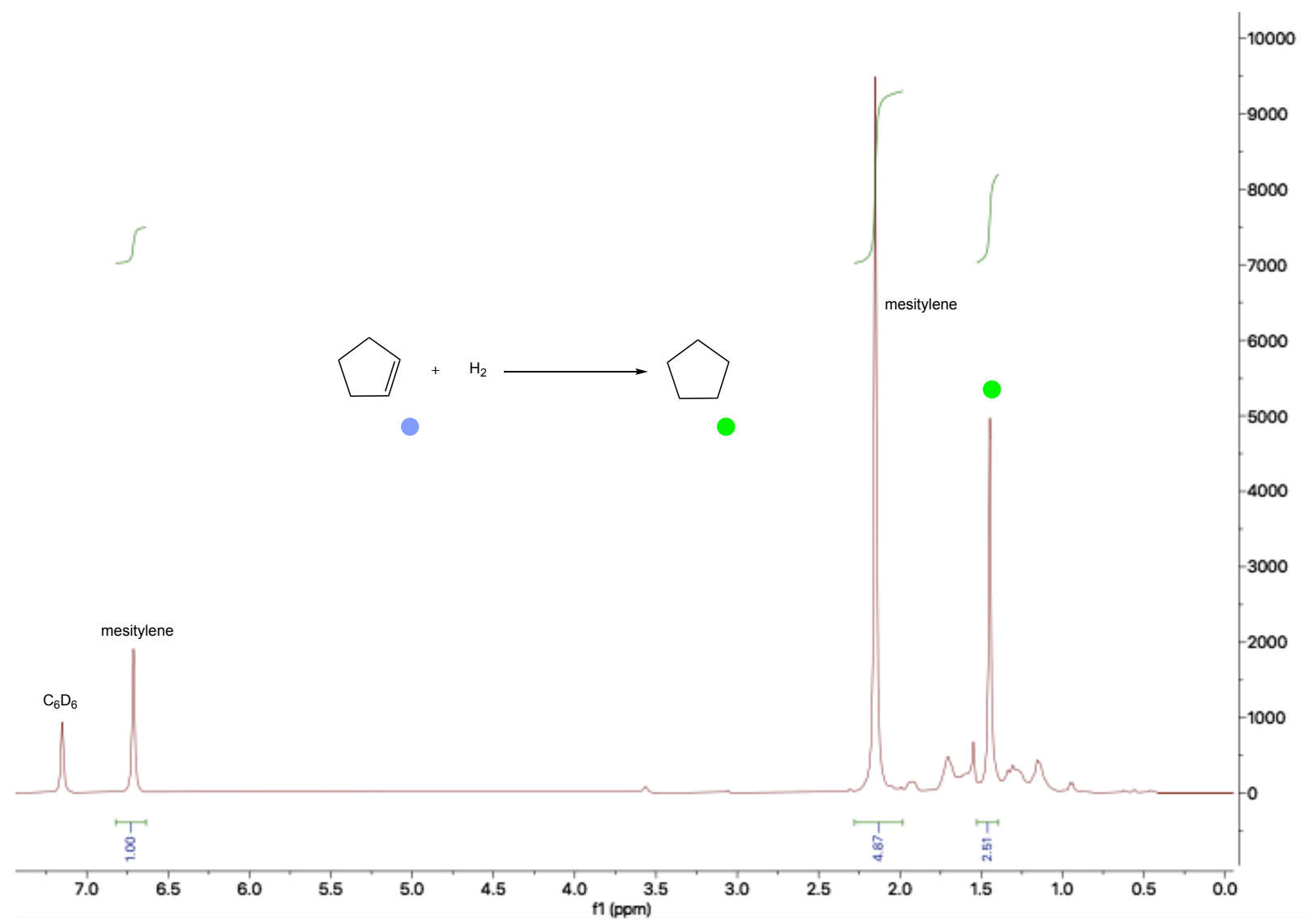

Figure S84. ${ }^{1} \mathrm{H}$ NMR (benzene- $d_{6}$, rt) spectrum of crude complexes formed from the hydrogenation of cyclopentene by crude $\left[(\mathrm{dcpe}) \mathrm{Co}(\mathrm{CO})\left(\mu^{2}-\mathrm{CO}\right)\right]_{2}$ under light conditions. 


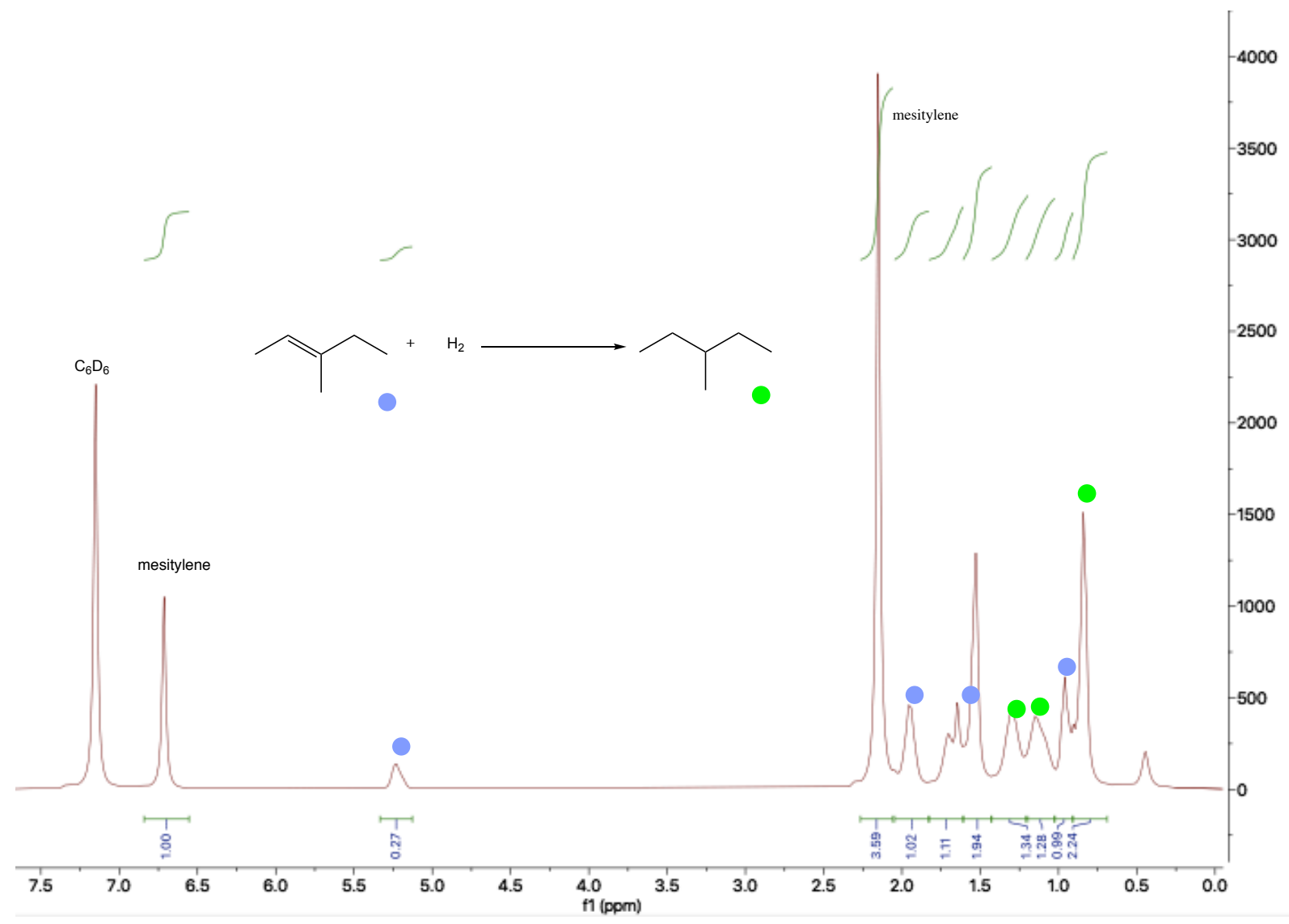

Figure S85. ${ }^{1} \mathrm{H}$ NMR (benzene- $d_{6}$, rt) spectrum of crude complexes formed from the hydrogenation of 3 -methyl pent-2-ene by crude $\left[(\mathrm{dcpe}) \mathrm{Co}(\mathrm{CO})\left(\mu^{2}-\mathrm{CO}\right)\right]_{2}$ under light conditions. 


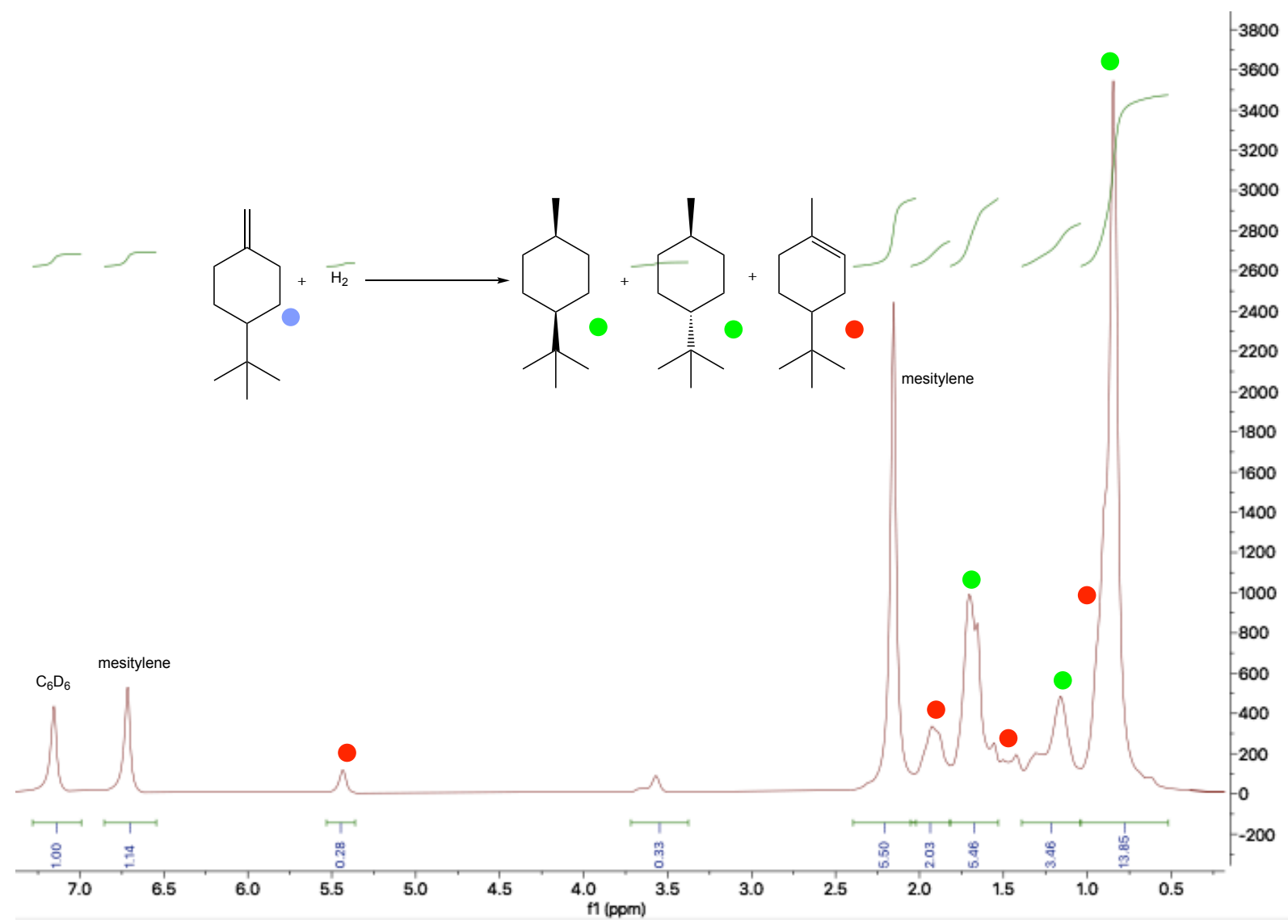

Figure S86. ${ }^{1} \mathrm{H}$ NMR (benzene- $d_{6}$, rt) spectrum of crude complexes formed from the hydrogenation of 4-tert-butyl-4-methylenecyclohexane by crude $\left[(\mathrm{dcpe}) \mathrm{Co}(\mathrm{CO})\left(\mu^{2}-\mathrm{CO}\right)\right]_{2}$ under light conditions. 


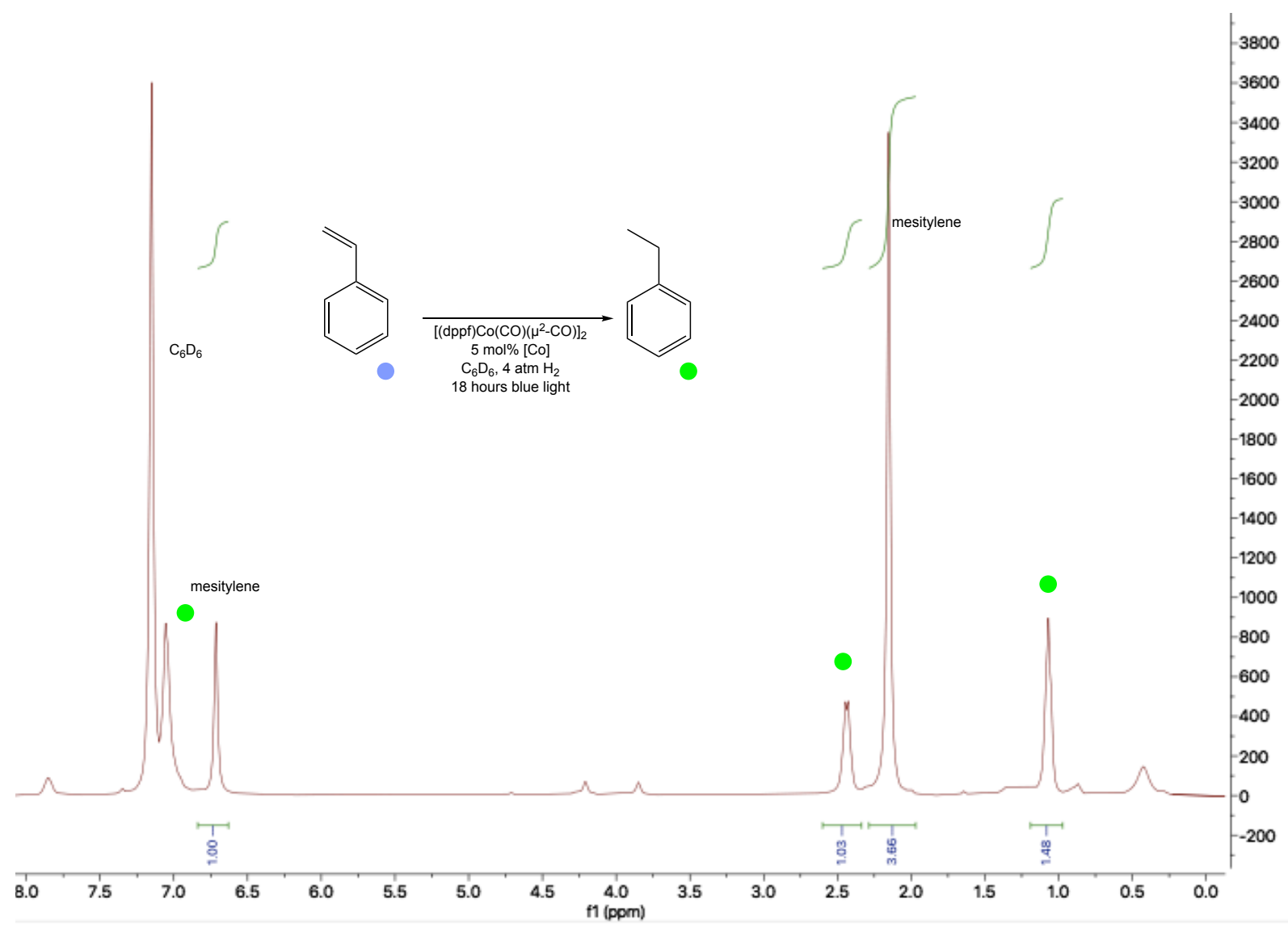

Figure S87. ${ }^{1} \mathrm{H}$ NMR (benzene- $d_{6}$, rt) spectrum of crude product formed from the hydrogenation of styrene by crude $\left[(\mathrm{dppf}) \mathrm{Co}(\mathrm{CO})\left(\mu^{2}-\mathrm{CO}\right)\right]_{2}$ under light conditions. 


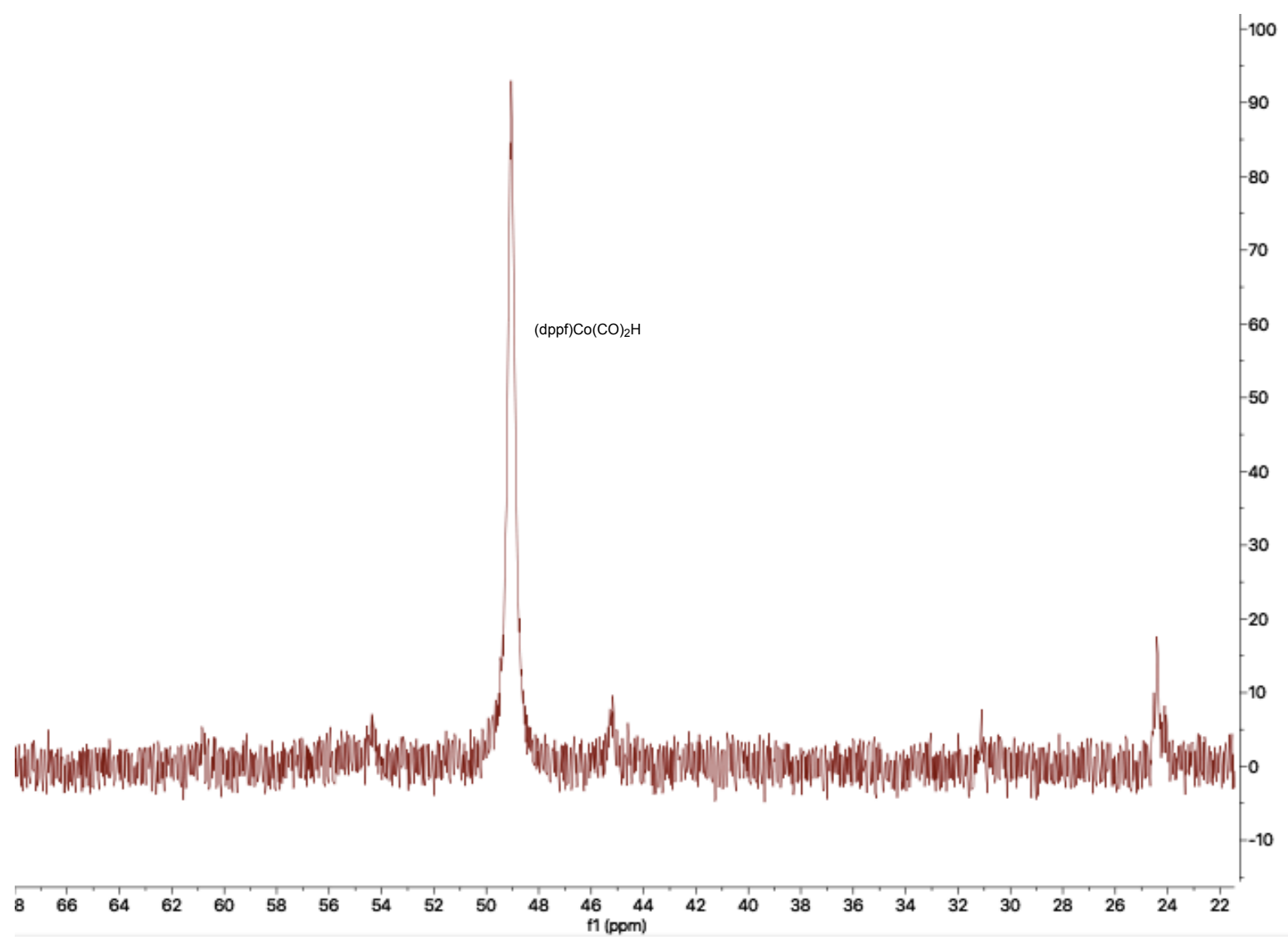

Figure S88. ${ }^{31} \mathrm{P}$ NMR (benzene- $d_{6}, \mathrm{rt}$ ) spectrum of crude complexes formed from the hydrogenation of styrene by crude $\left[(\mathrm{dppf}) \mathrm{Co}(\mathrm{CO})\left(\mu^{2}-\mathrm{CO}\right)\right]_{2}$ under light conditions. 


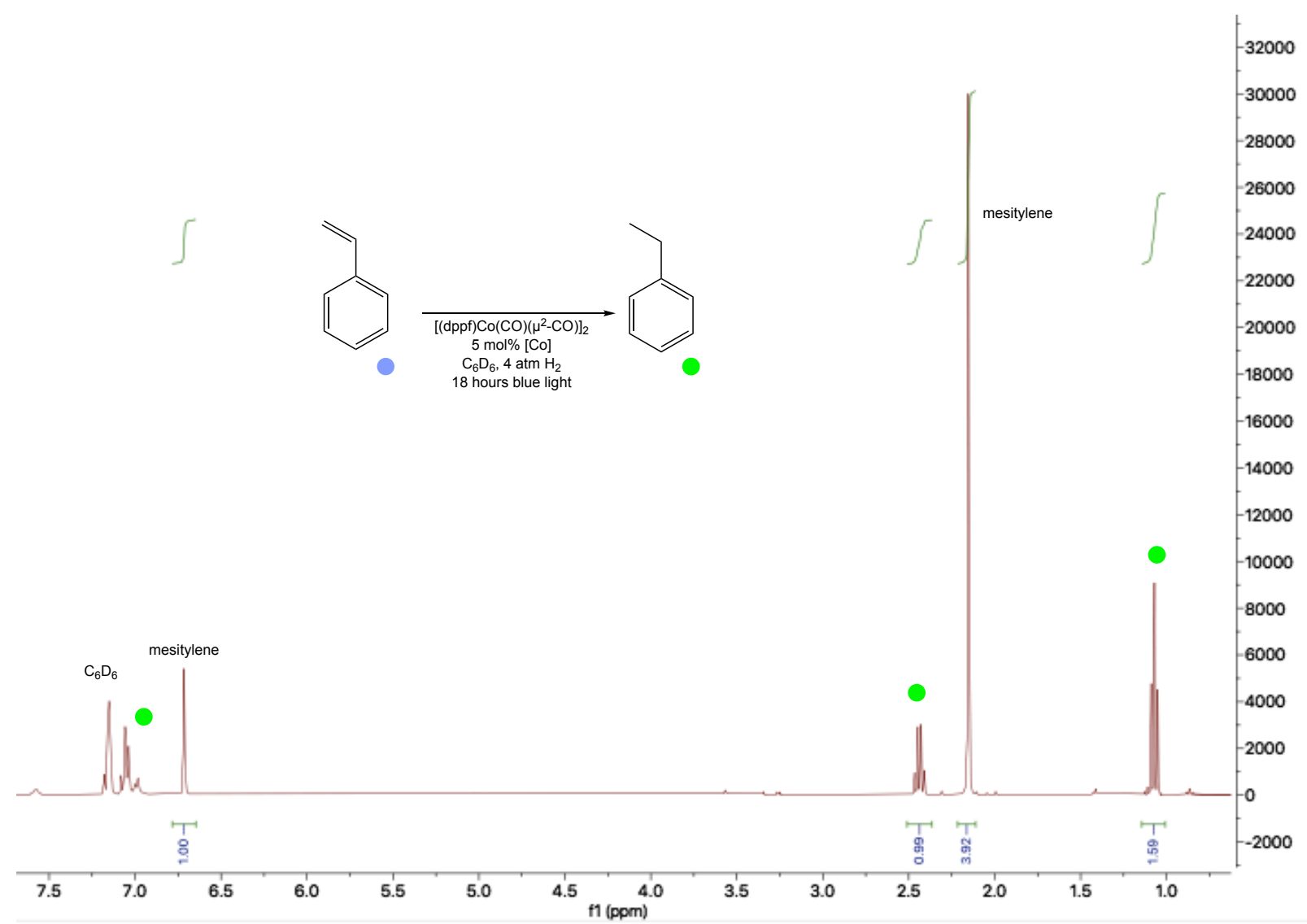

Figure S89. ${ }^{1} \mathrm{H}$ NMR (benzene- $d_{6}$, rt) spectrum of crude product formed from the hydrogenation of styrene by crude $\left[(\text { dppbenz }) \mathrm{Co}(\mathrm{CO})\left(\mu^{2}-\mathrm{CO}\right)\right]_{2}$ under light conditions. 


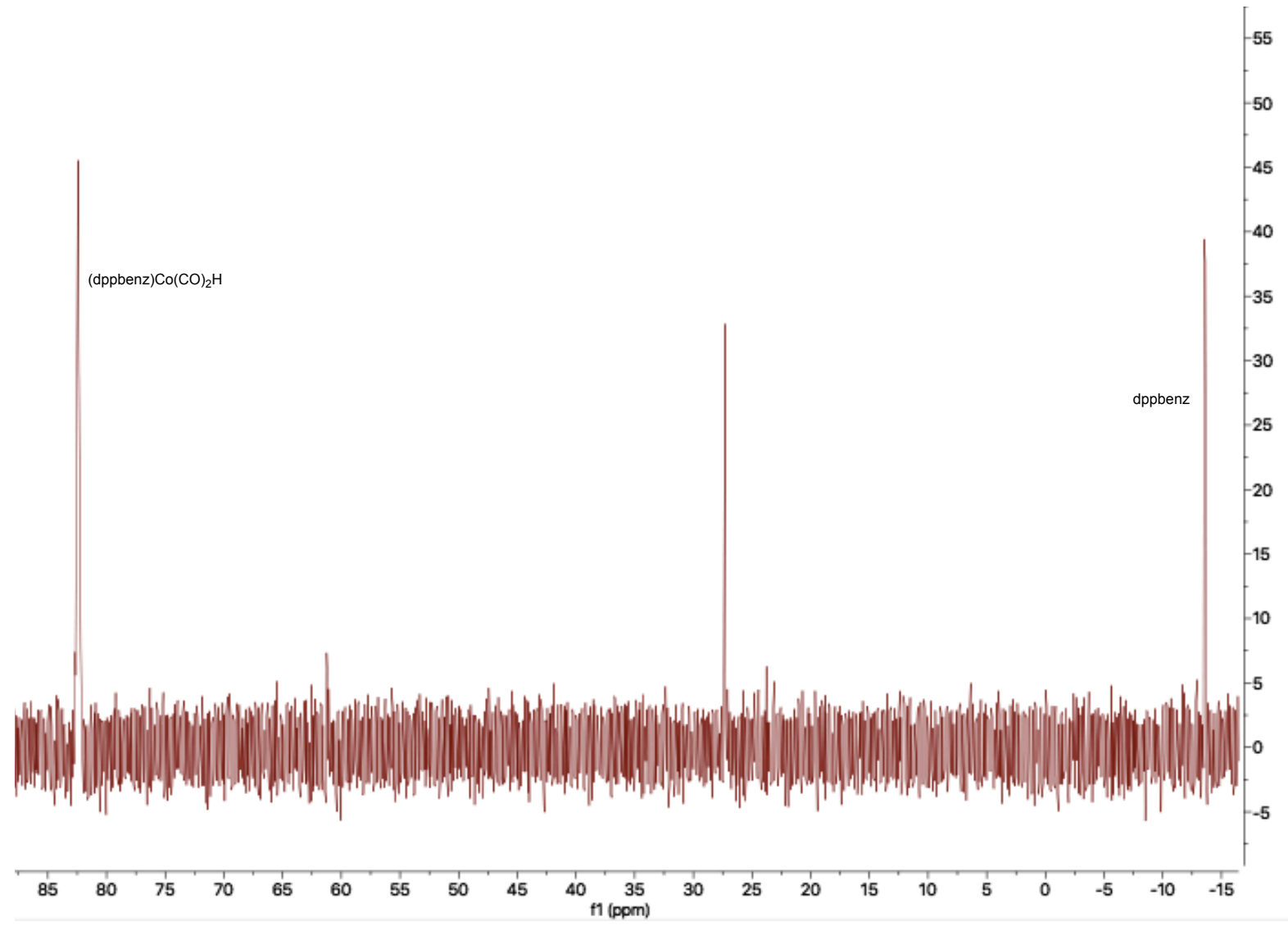

Figure S90. ${ }^{31} \mathrm{P}$ NMR (benzene- $d_{6}$, rt) spectrum of crude complexes formed from the hydrogenation of styrene by crude $\left[(\mathrm{dppbenz}) \mathrm{Co}(\mathrm{CO})\left(\mu^{2}-\mathrm{CO}\right)\right]_{2}$ under light conditions. 


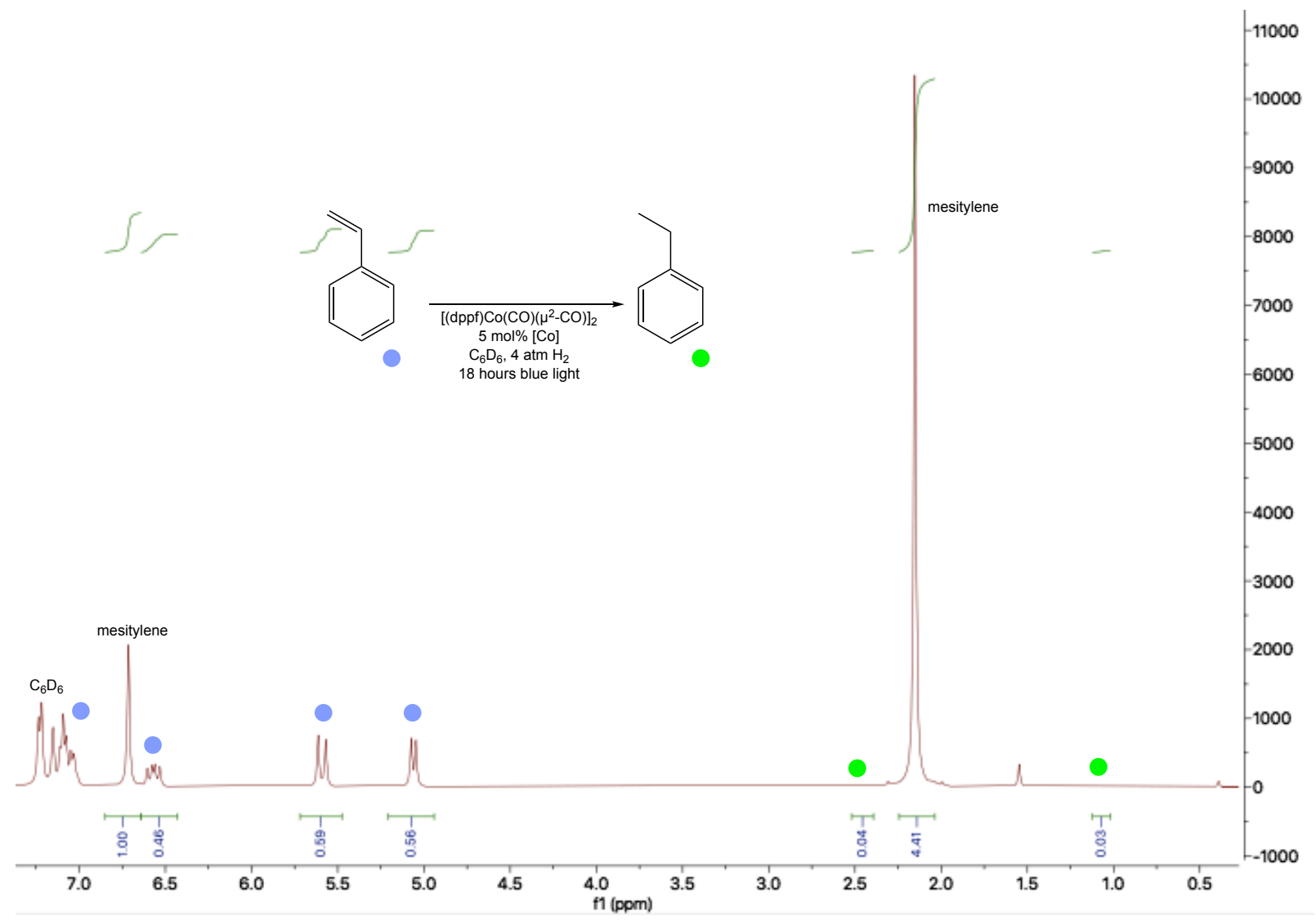

Figure S91. ${ }^{1} \mathrm{H}$ NMR (benzene- $d_{6}$, rt) spectrum of crude product formed from the hydrogenation of styrene by $\mathrm{Co}_{2}(\mathrm{CO})_{8}$ under light conditions. 


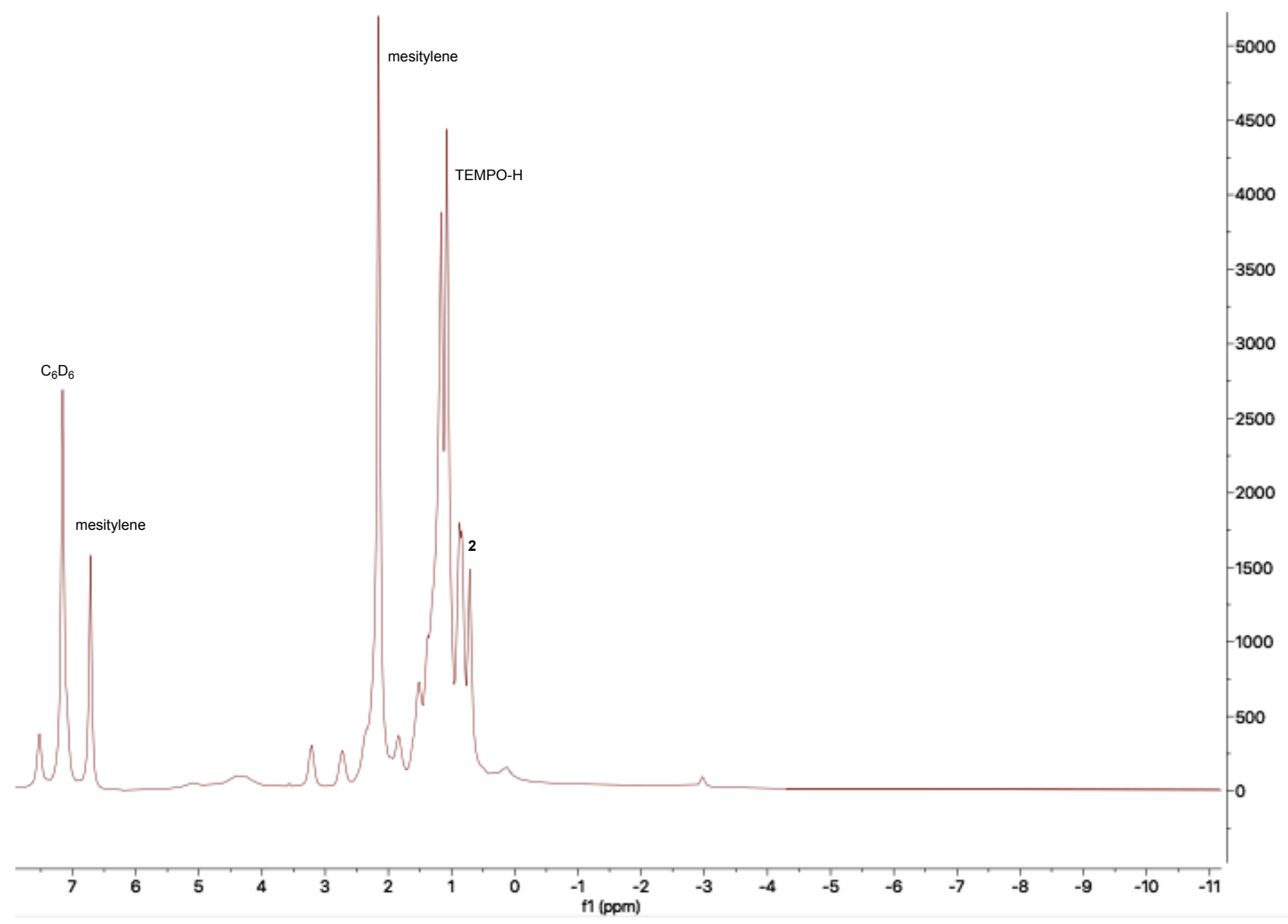

Figure S92. ${ }^{1} \mathrm{H}$ NMR (benzene- $d_{6}, \mathrm{rt}$ ) spectrum of reaction of TEMPO radical with 1. 


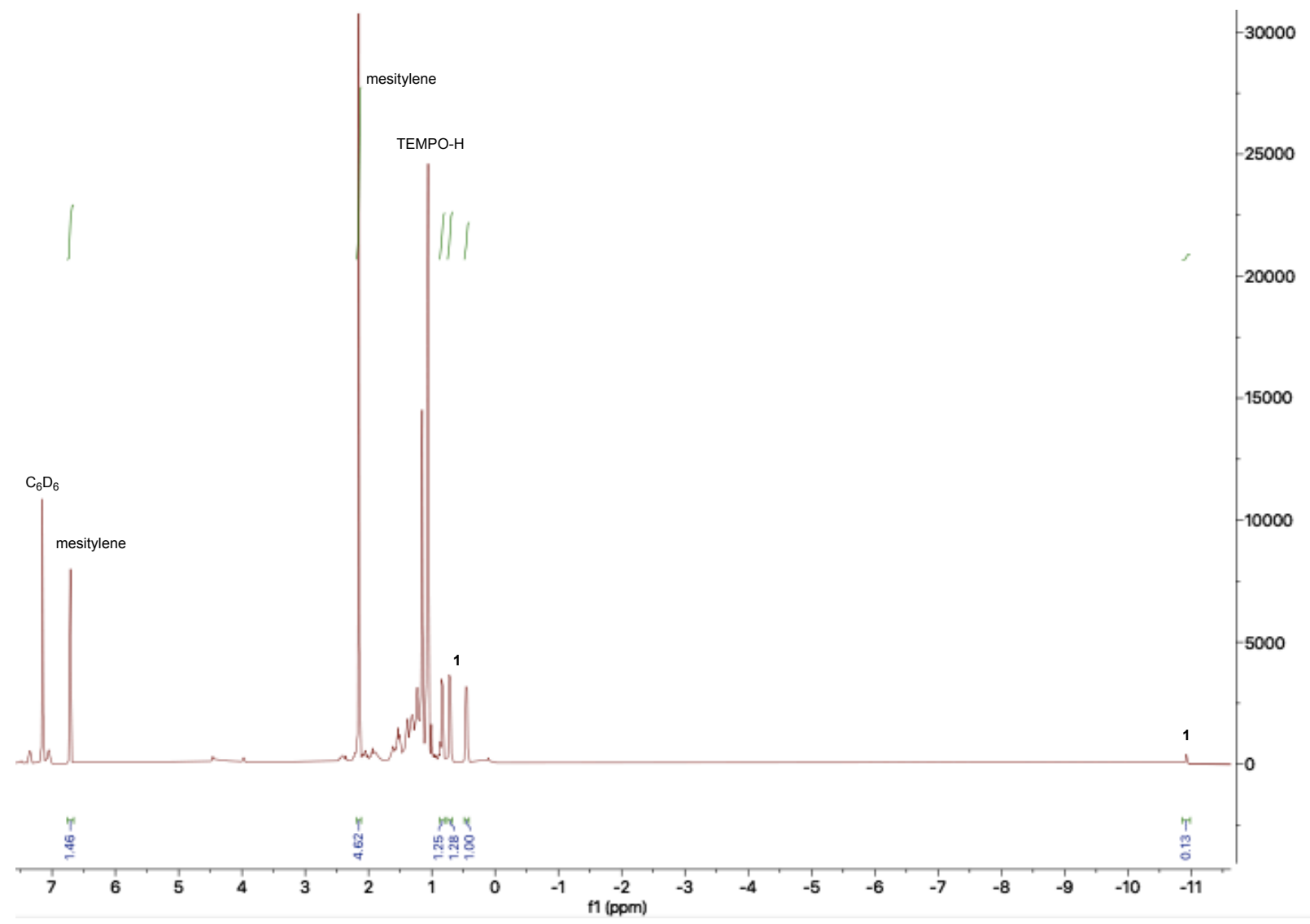

Figure S93. ${ }^{1} \mathrm{H}$ NMR (benzene- $d_{6}$, rt) spectrum of reaction of TEMPO radical with 1 , followed by exposure to $4 \mathrm{~atm}$ of $\mathrm{H}_{2}$. 


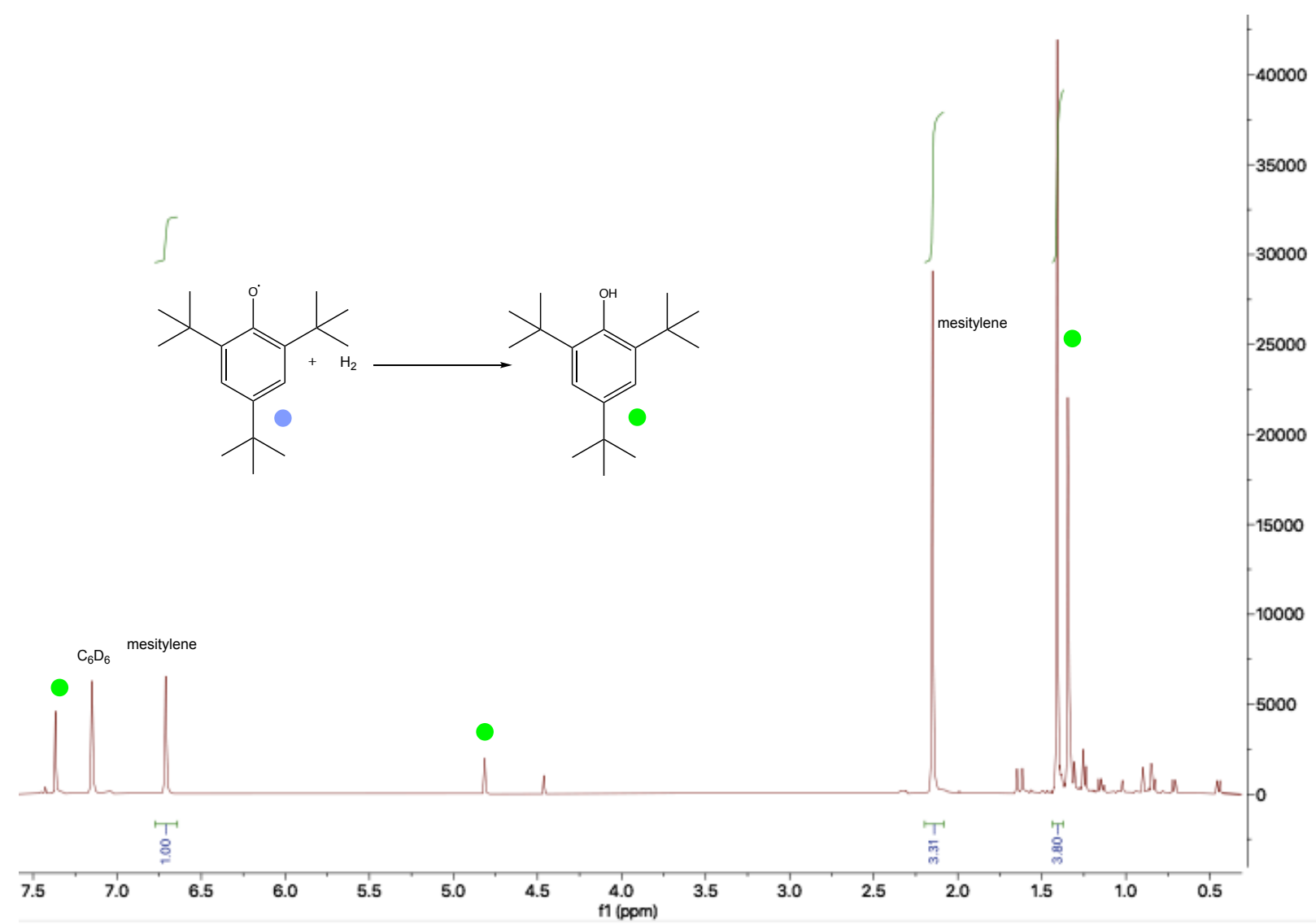

Figure S94. ${ }^{1} \mathrm{H}$ NMR (benzene- $d_{6}$, rt) spectrum of crude product formed from the hydrogenation of 2,4,6-tert-butyl-phenoxy radical by 1 under 4 atm of $\mathrm{H}_{2}$. 


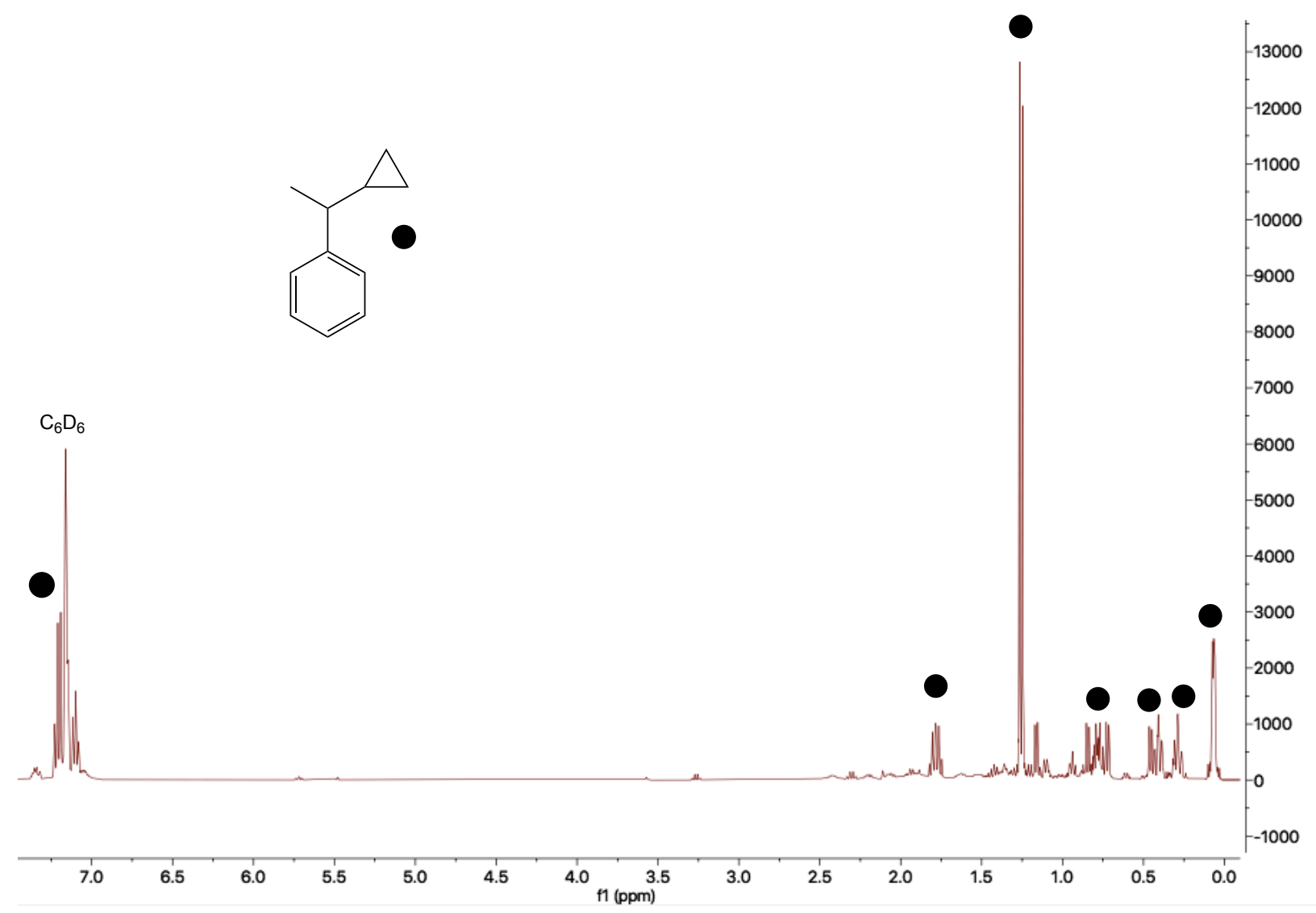

Figure S95. ${ }^{1} \mathrm{H}$ NMR (benzene- $d_{6}$, rt) spectrum of crude product formed from the hydrogenation of $\alpha$-cyclopropyl styrene by 1 under irradiation conditions.

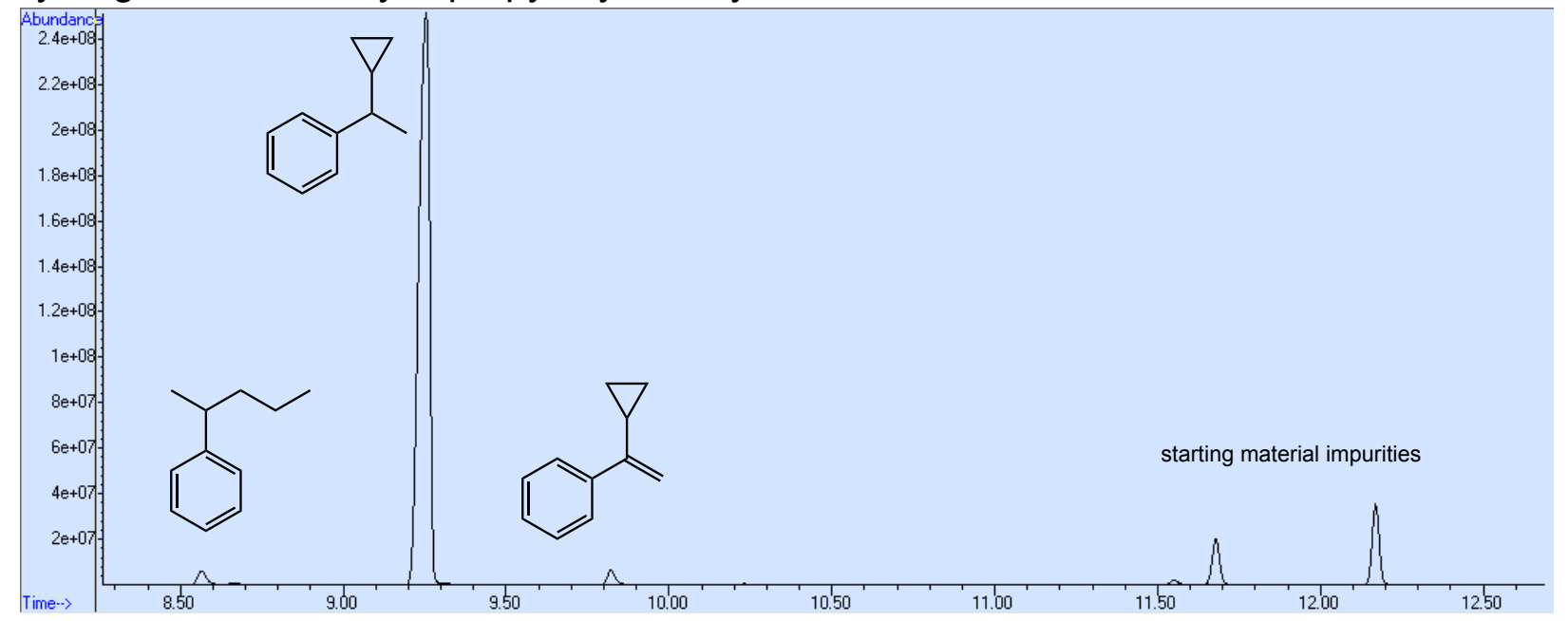

Figure S96. GC-MS trace of crude product formed from the hydrogenation of $\alpha$ cyclopropyl styrene by 1 under irradiation conditions. Trace amounts of 2-phenyl pentane and starting material were observed. 


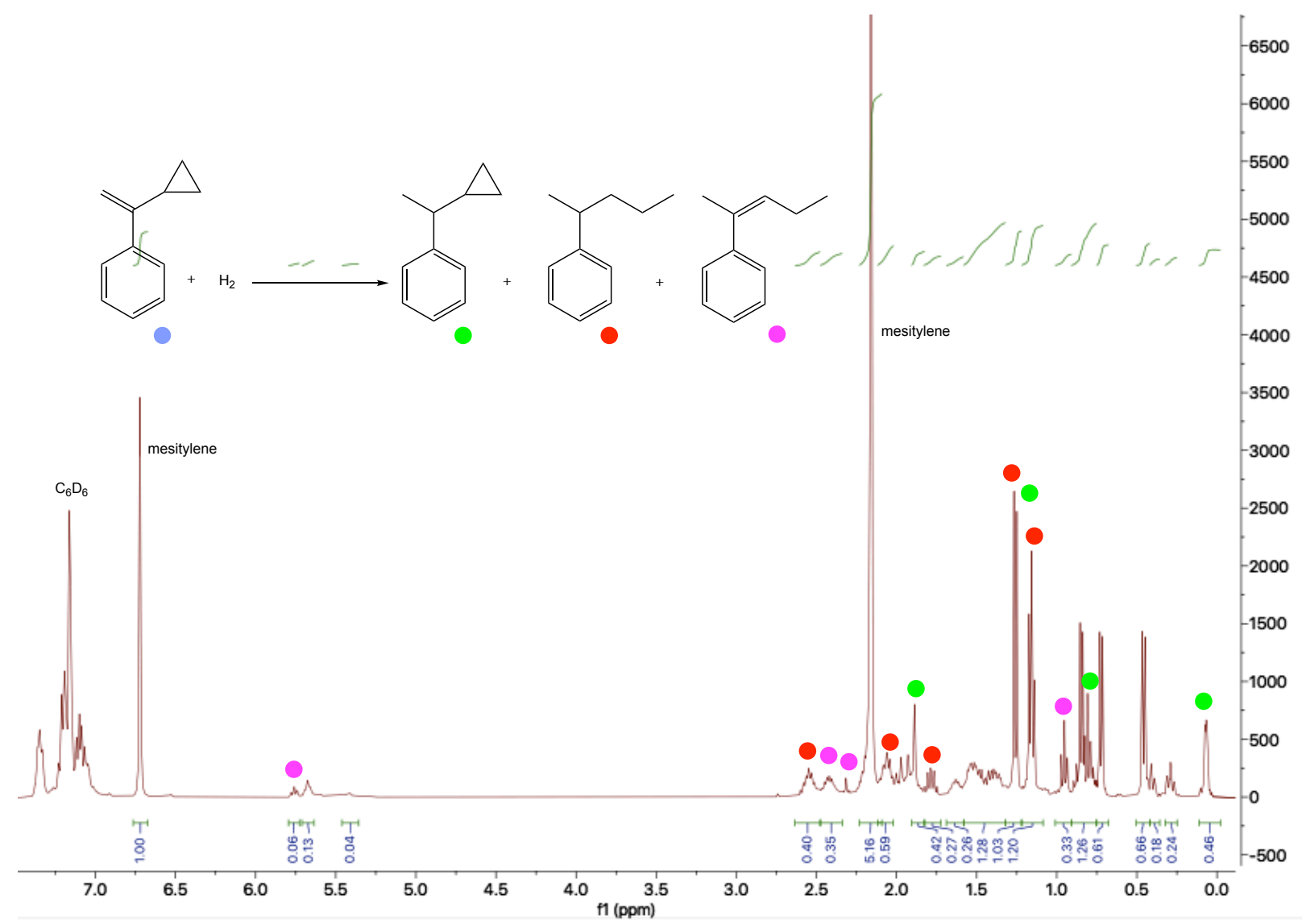

Figure S97. ${ }^{1} \mathrm{H}$ NMR (benzene- $d_{6}$, rt) spectrum of crude product formed from the hydrogenation of $\alpha$-cyclopropyl styrene by 1 under thermal conditions. 


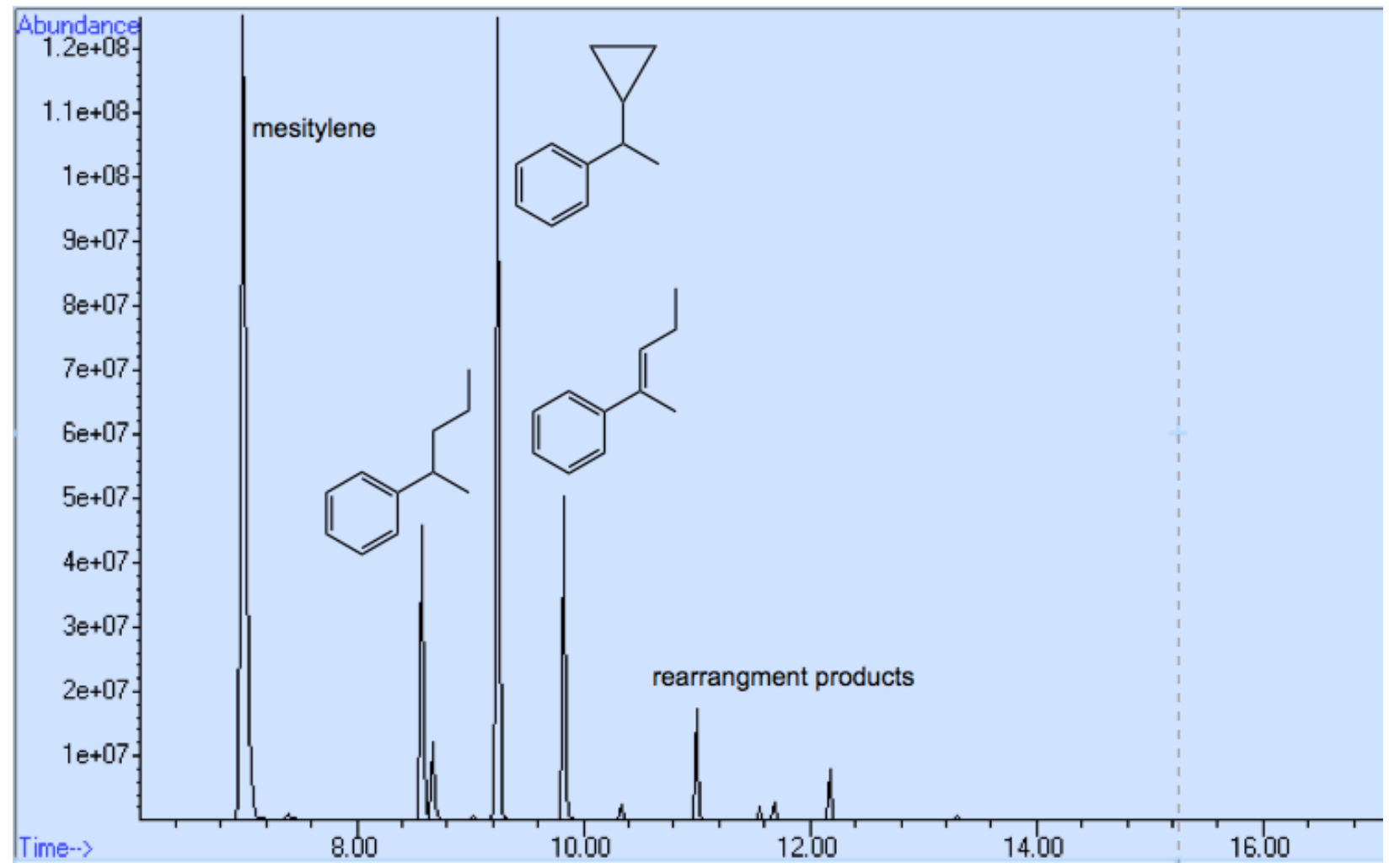

Figure S98. GC-MS trace of crude product formed from the hydrogenation of $\alpha$ cyclopropyl styrene by 1 under thermal conditions.

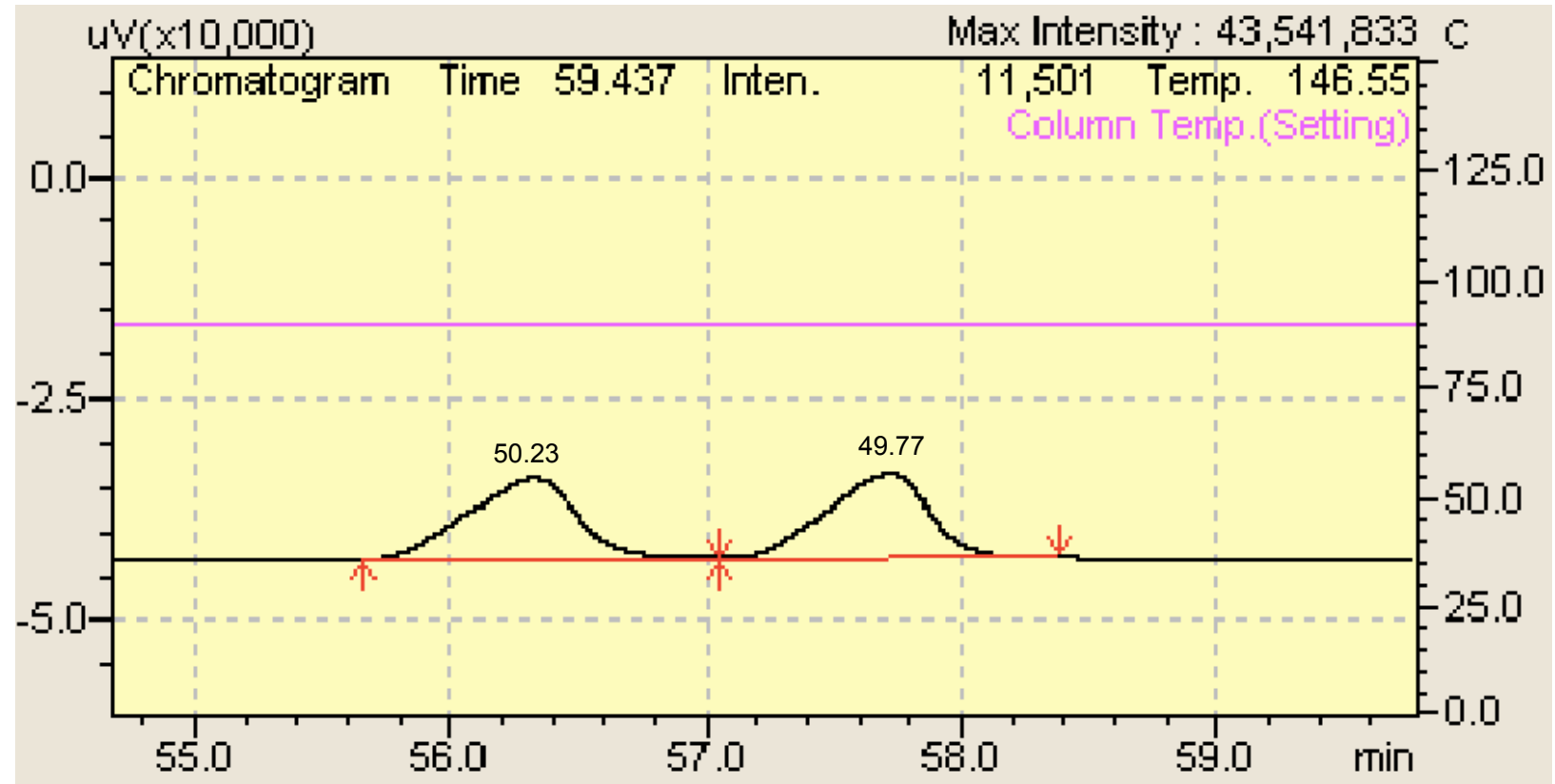

Figure S99. Selected Chiral GC trace for the crude product formed from the hydrogenation of MAA in benzene- $d_{6} / \mathrm{DCM}$ mixture under blue light conditions. 


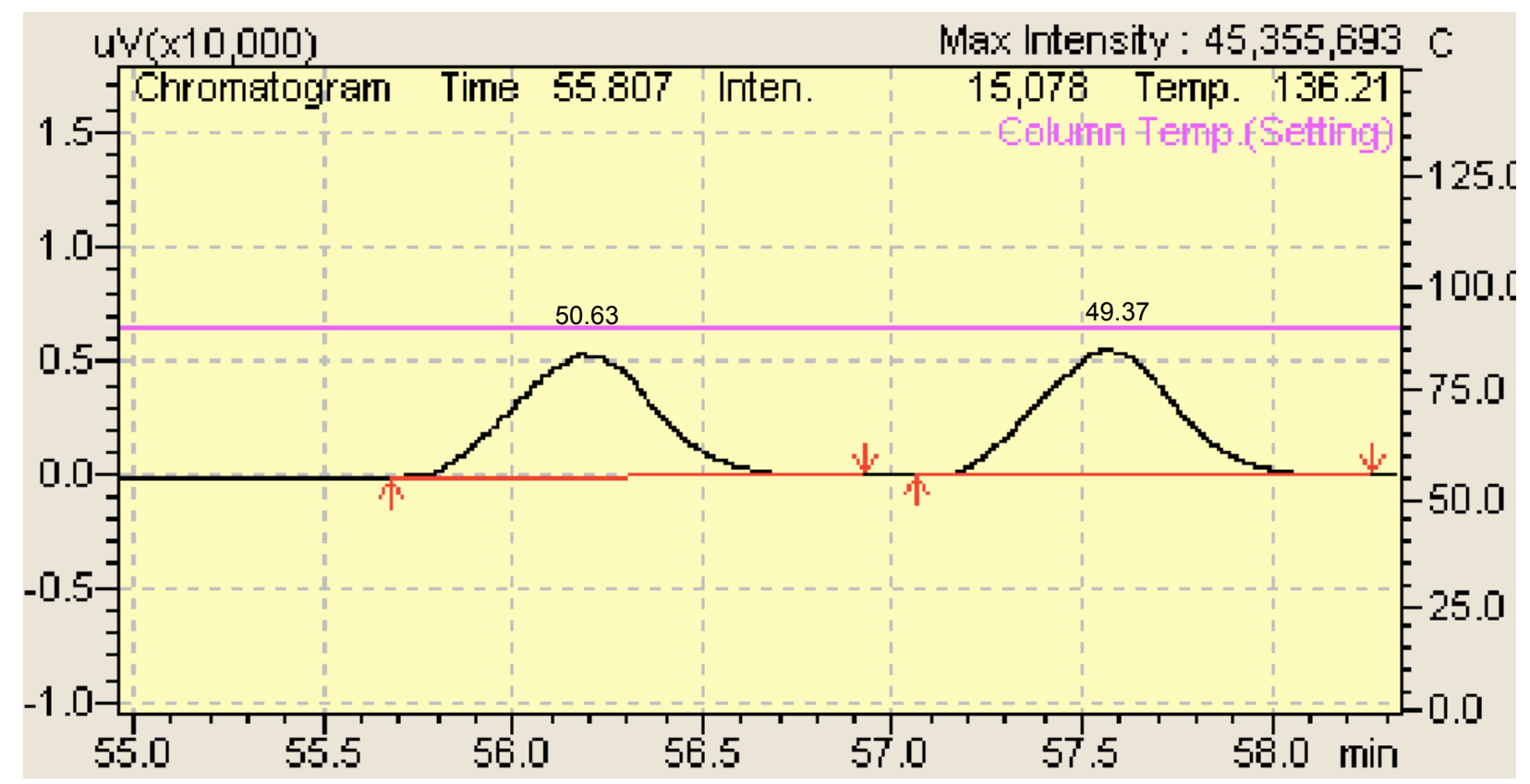

Figure S100. Selected Chiral GC trace for the crude product formed from the hydrogenation of MAA in benzene- $d_{6} / \mathrm{DCM}$ mixture under thermal conditions.

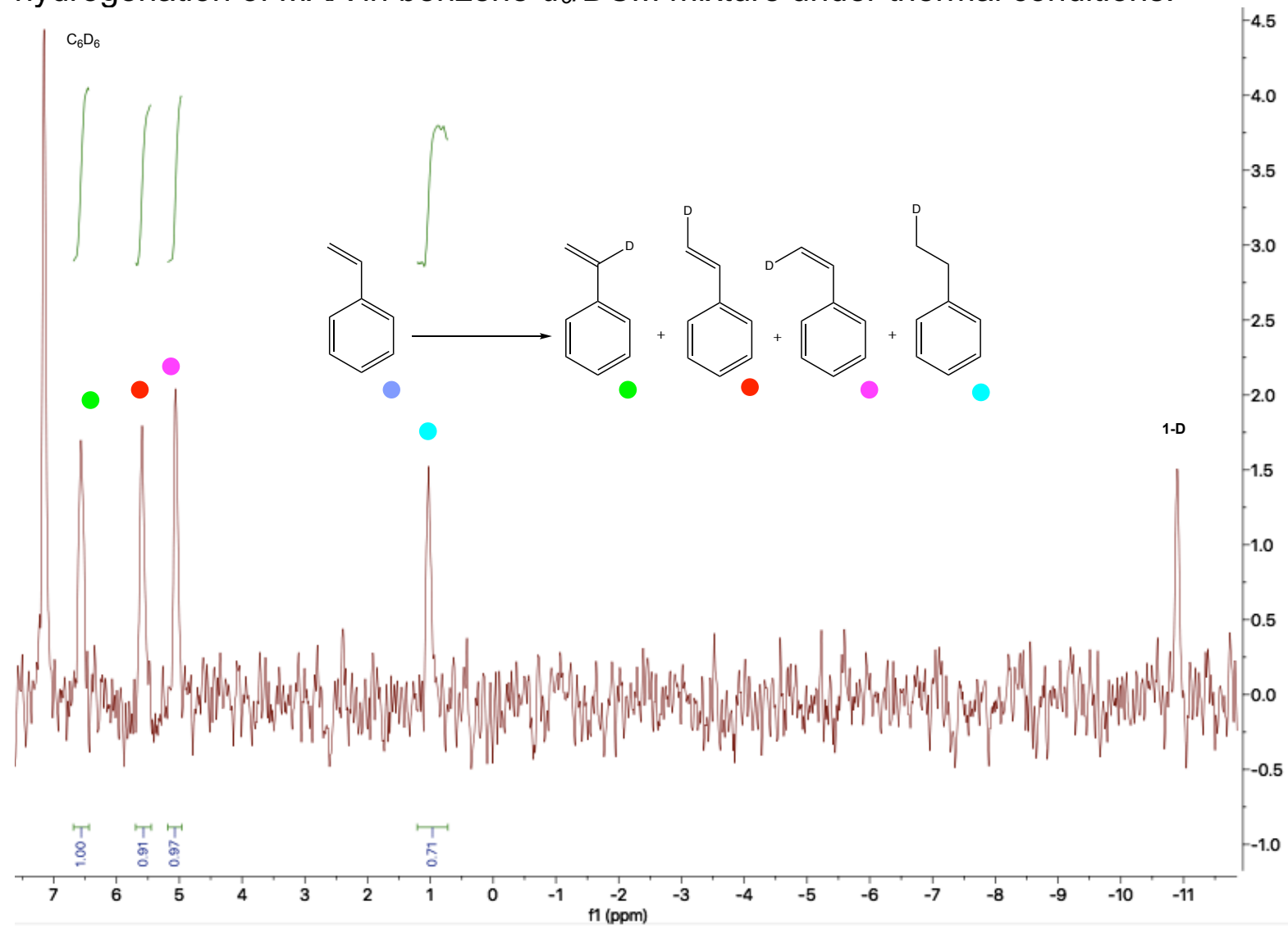

Figure S101. ${ }^{2} \mathrm{H}$ NMR $\left(\mathrm{C}_{6} \mathrm{H}_{6}\right.$, rt $)$ spectrum of crude product formed from the stoichiometric reaction of 1-D with 5 equivalents of styrene under blue light at $35^{\circ} \mathrm{C}$. 


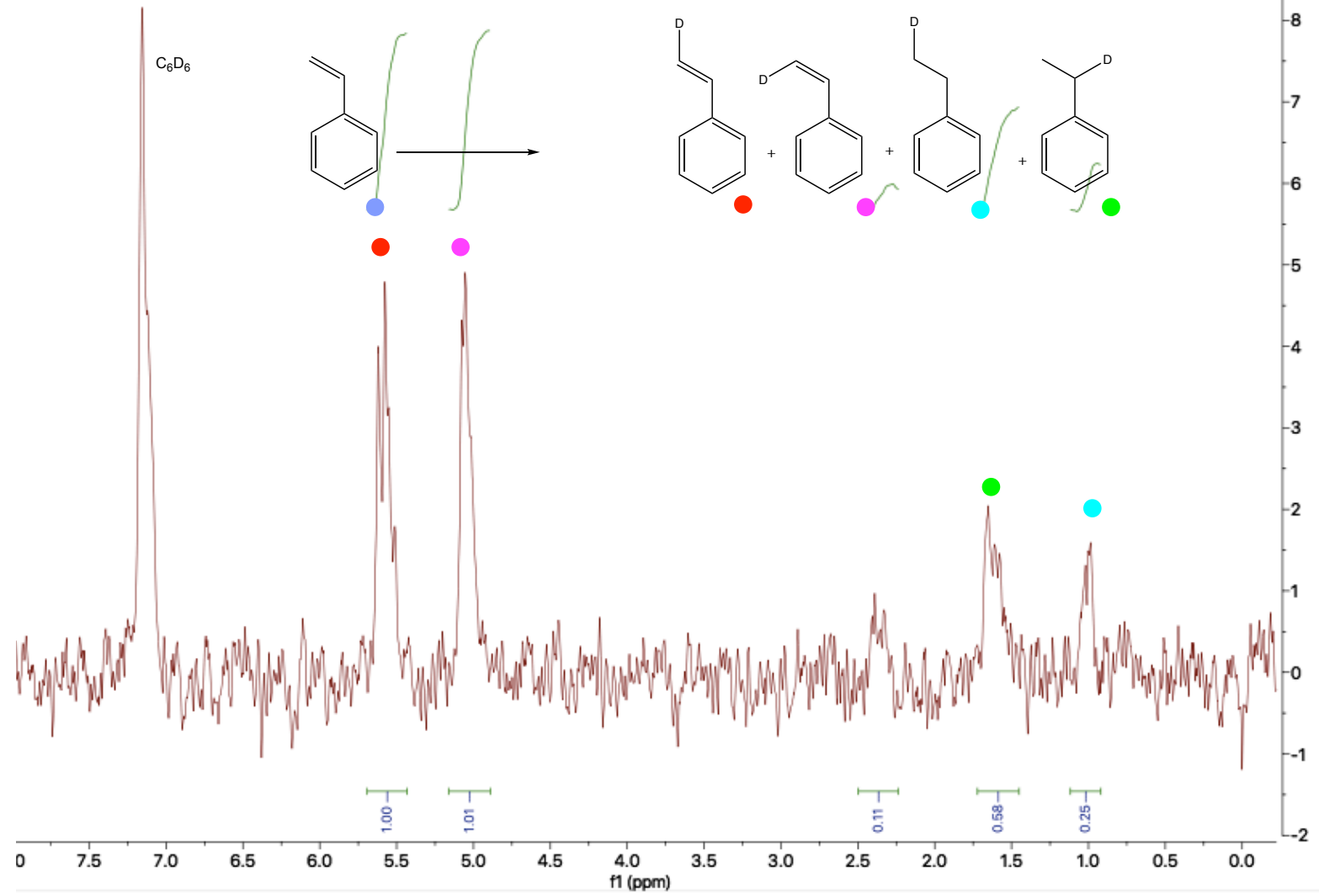

Figure S102. ${ }^{2} \mathrm{H}$ NMR $\left(\mathrm{C}_{6} \mathrm{H}_{6}\right.$, rt $)$ spectrum of crude product formed from the stoichiometric reaction of $1-\mathrm{D}$ with 5 equivalents of styrene under $\mathrm{CO}$ at $75^{\circ} \mathrm{C}$. 


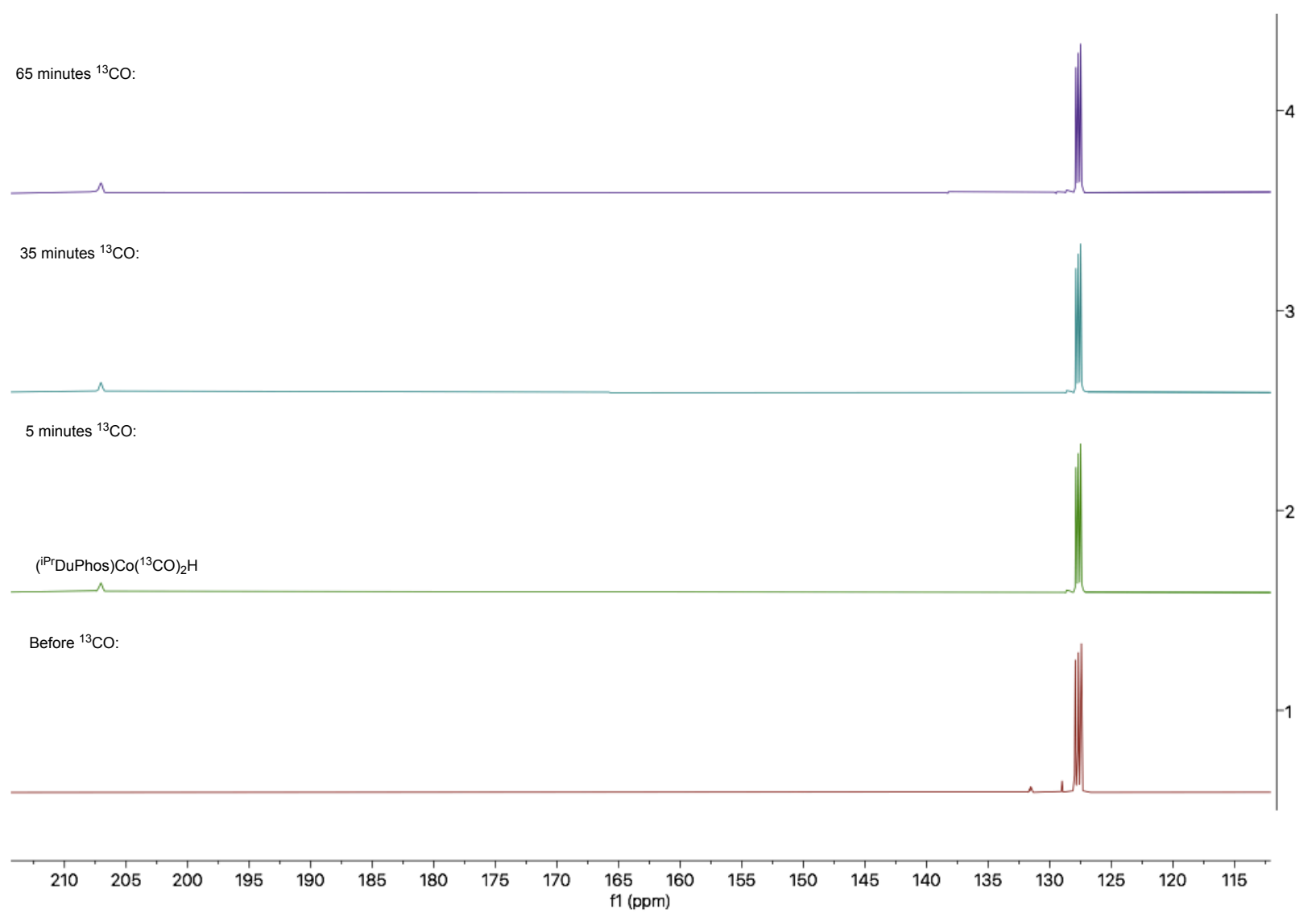

Figure S103. ${ }^{13} \mathrm{C}$ NMR (benzene- $d_{6}$, rt) spectrum of crude product formed from the exposure of 1 to ${ }^{13} \mathrm{CO}$ monitored over several timepoints. 

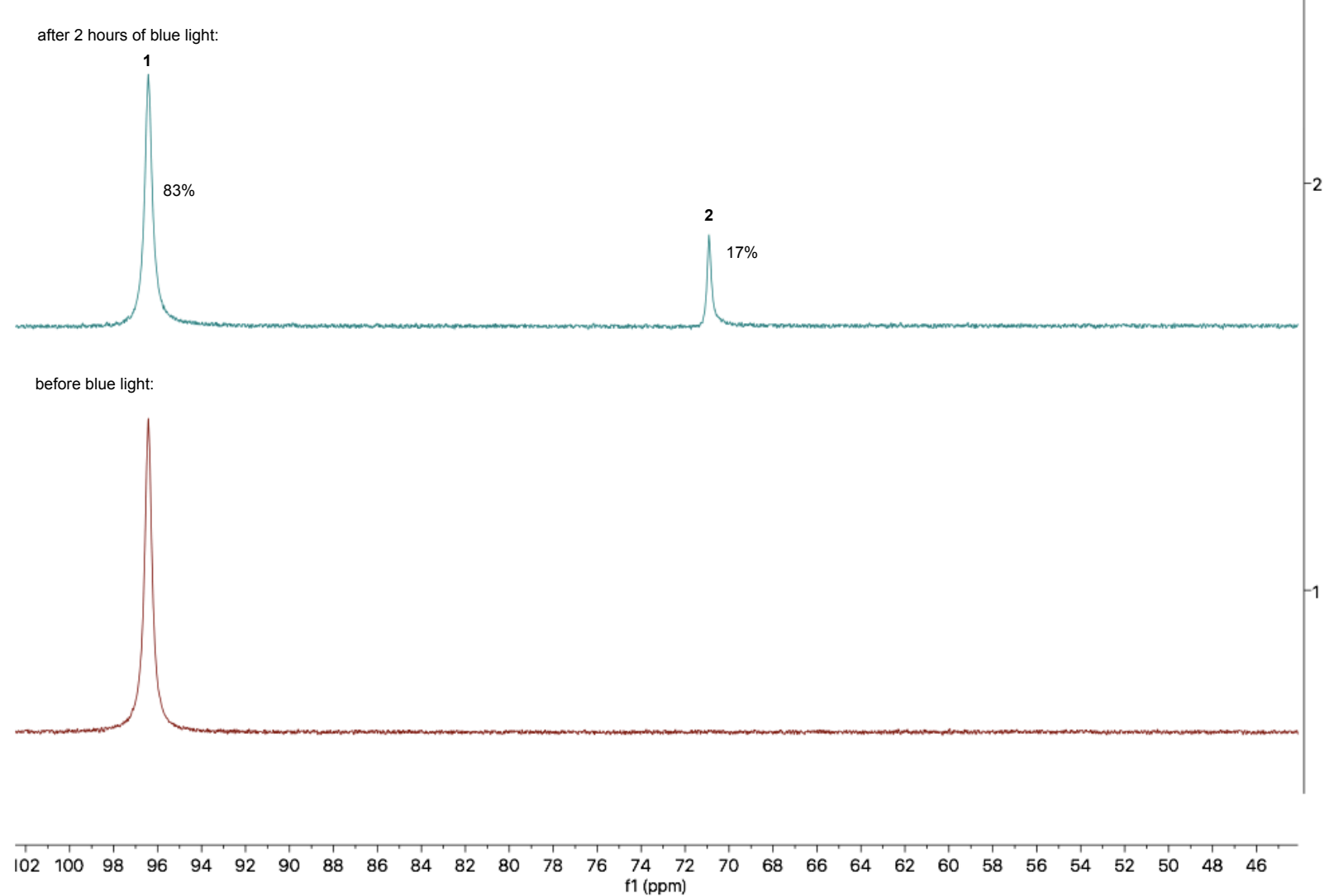

Figure S104. ${ }^{31} \mathrm{P}$ NMR (benzene- $d_{6}, \mathrm{rt}$ ) spectrum of exposure of 1 to blue light in solution. 


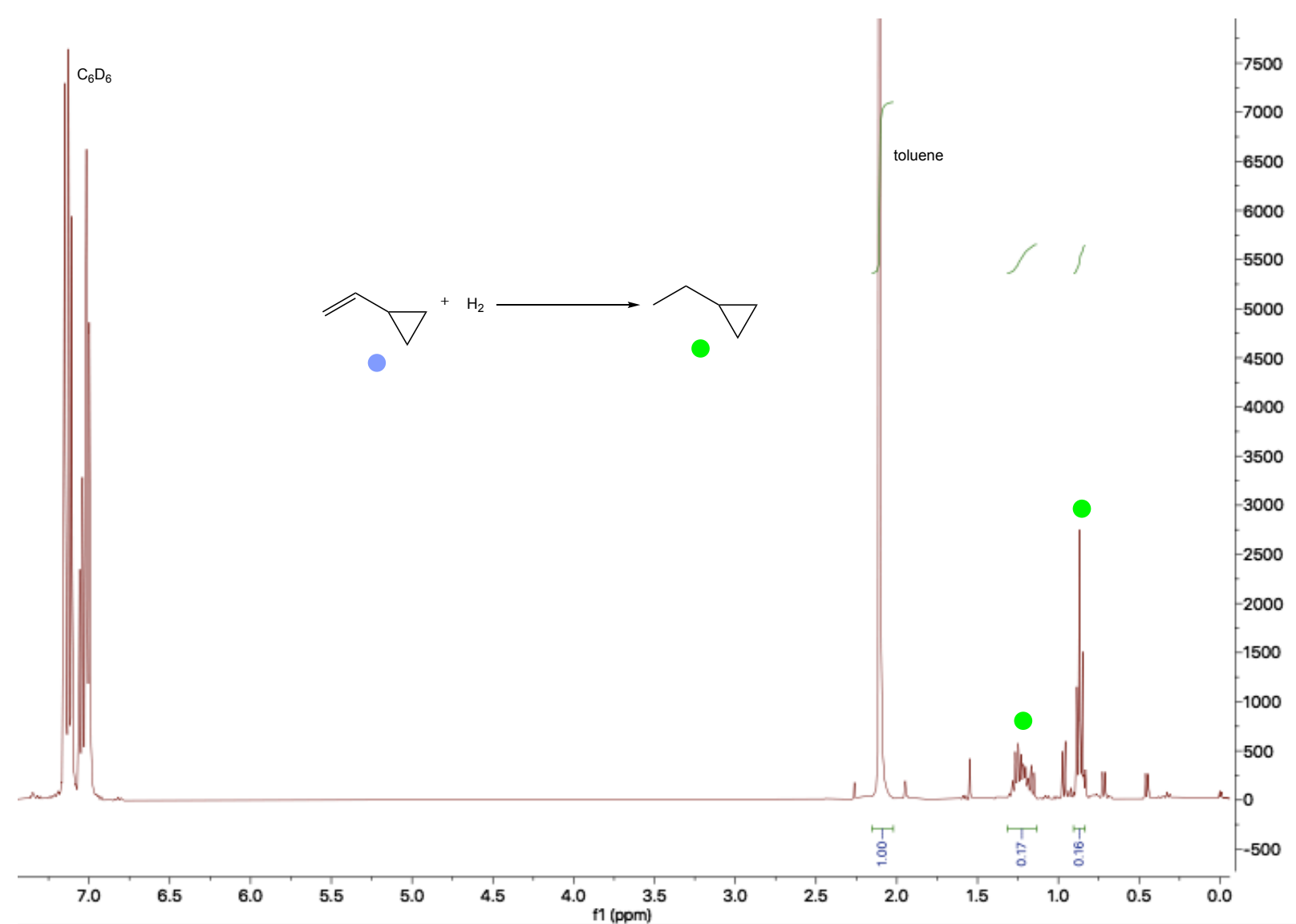

Figure S105. ${ }^{1} \mathrm{H}$ NMR (benzene- $d_{6}$, rt) spectrum of crude product formed from the hydrogenation of vinyl cyclopropane by 1 under blue light conditions. 


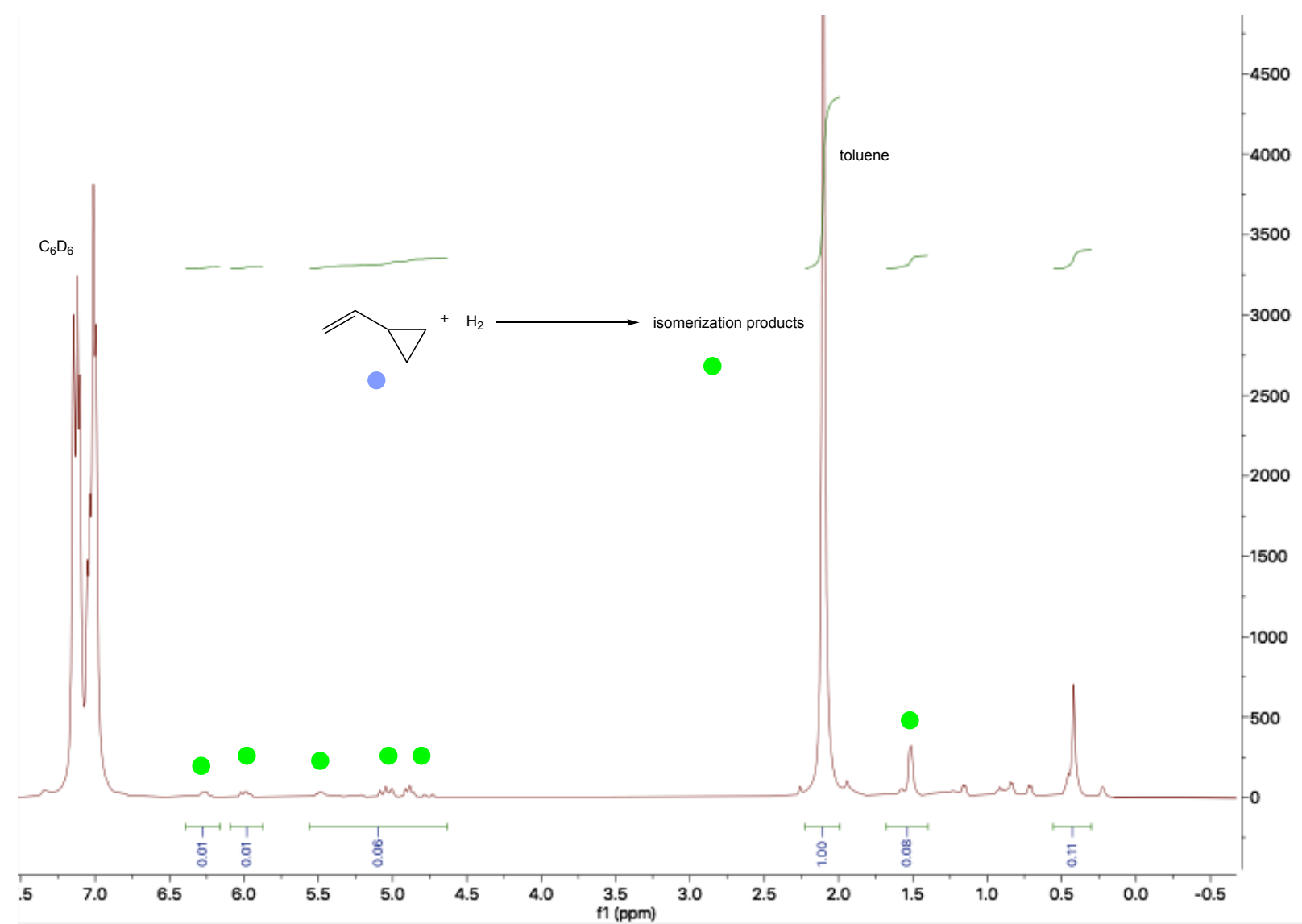

Figure S106. ${ }^{1} \mathrm{H}$ NMR (benzene- $d_{6}$, rt) spectrum of crude product formed from the hydrogenation of vinyl cyclopropane by 1 under thermal conditions. 


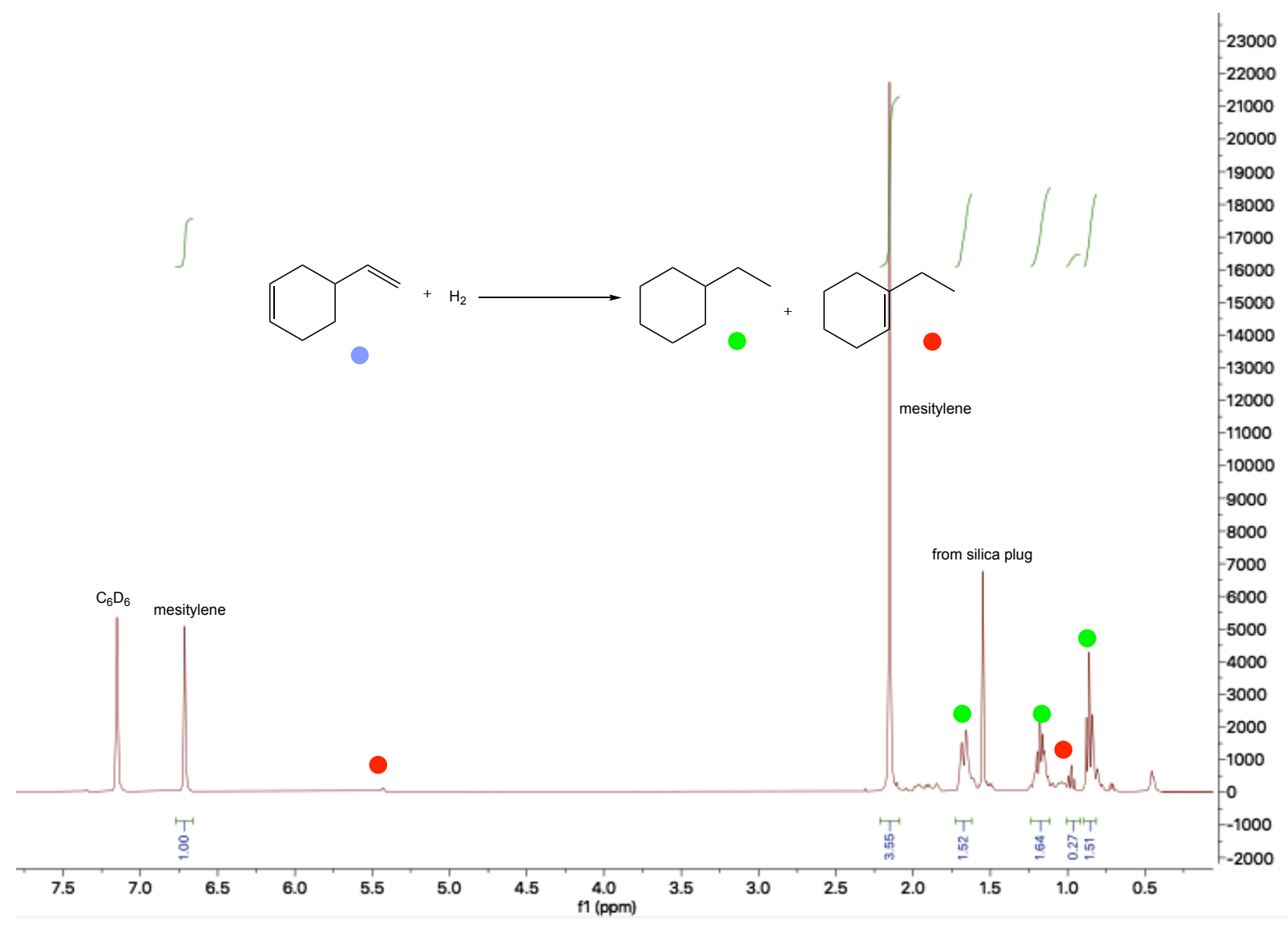

Figure S107. ${ }^{1} \mathrm{H}$ NMR (benzene- $d_{6}$, rt) spectrum of crude product formed from the hydrogenation of 4-vinylcyclohex-1-ene by 1 under blue light conditions.

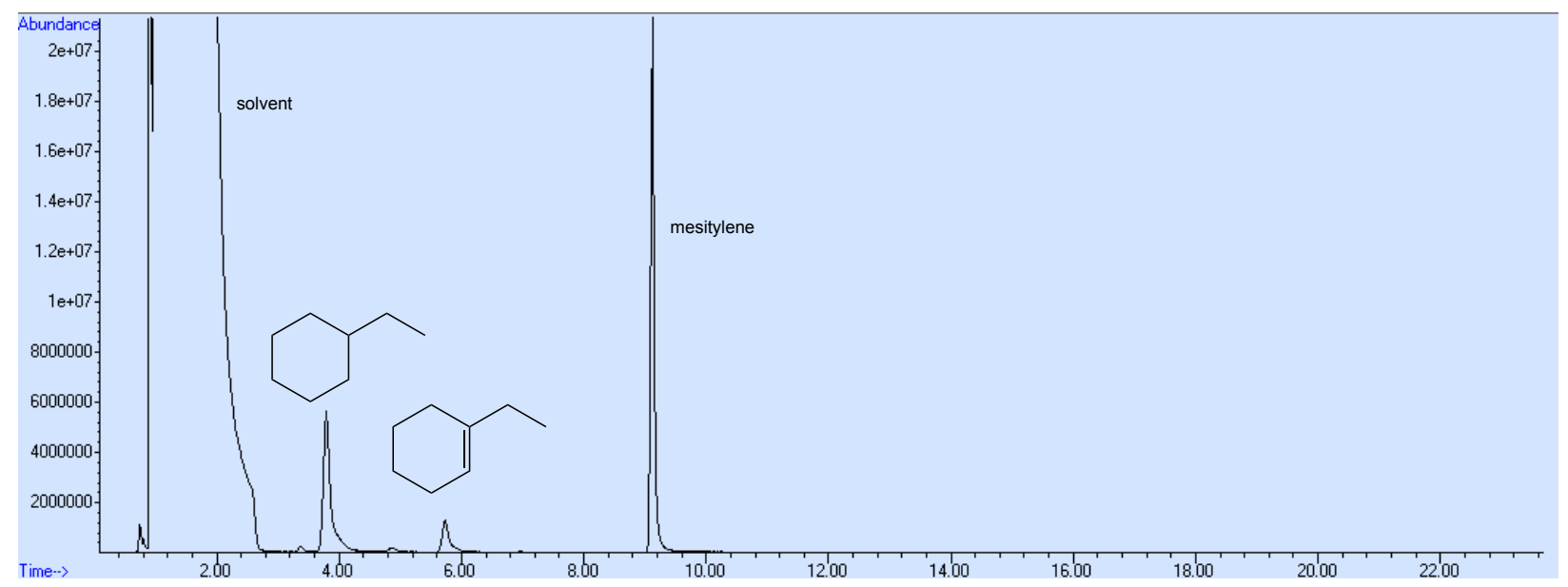

Figure S108. GC-MS trace of crude product formed from the hydrogenation of 4vinylcyclohex-1-ene by 1 under blue light conditions. 


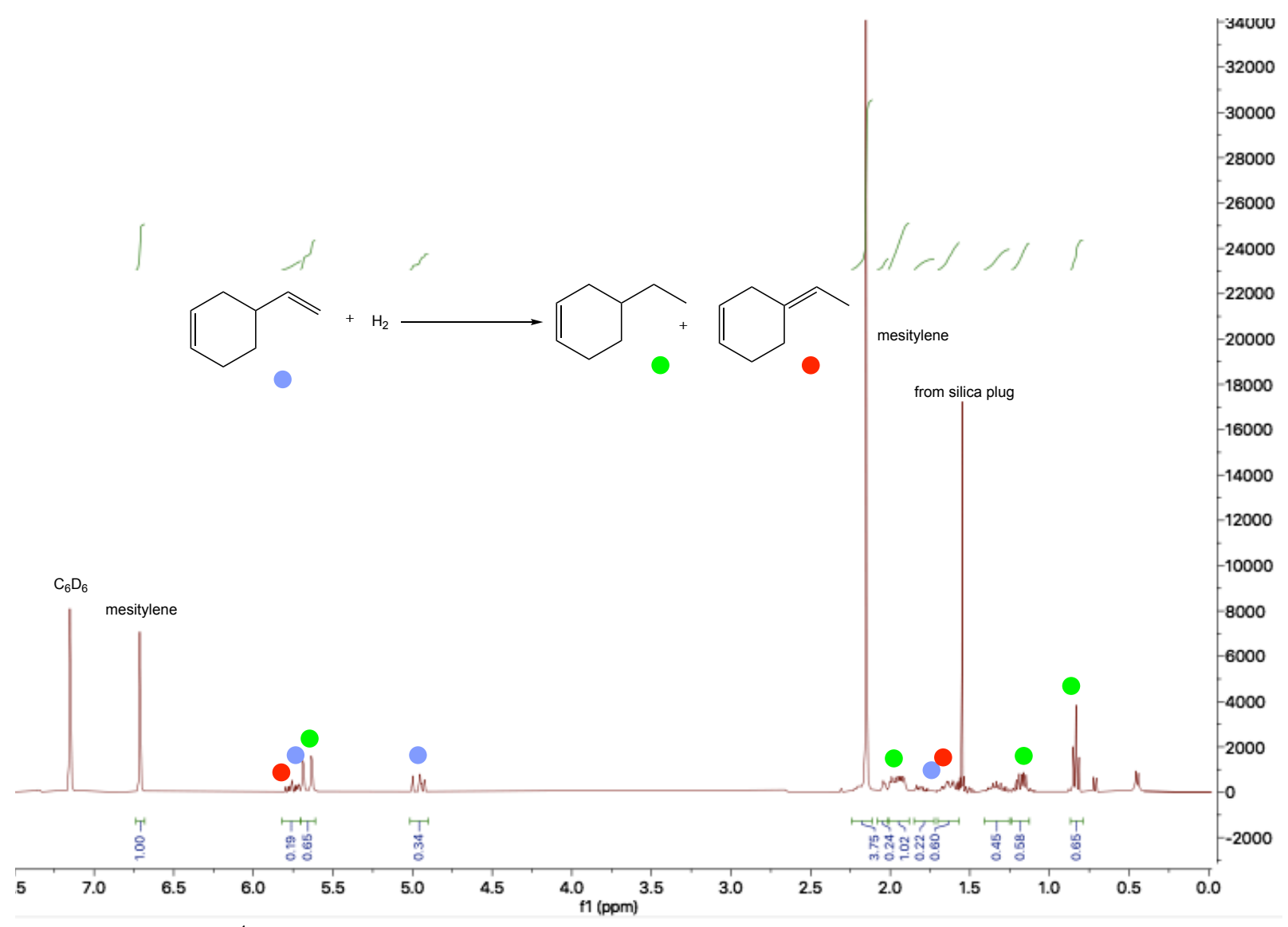

Figure S109. ${ }^{1} \mathrm{H}$ NMR (benzene- $d_{6}$, rt) spectrum of crude product formed from the hydrogenation of 4-vinylcyclohex-1-ene by 1 under thermal conditions.

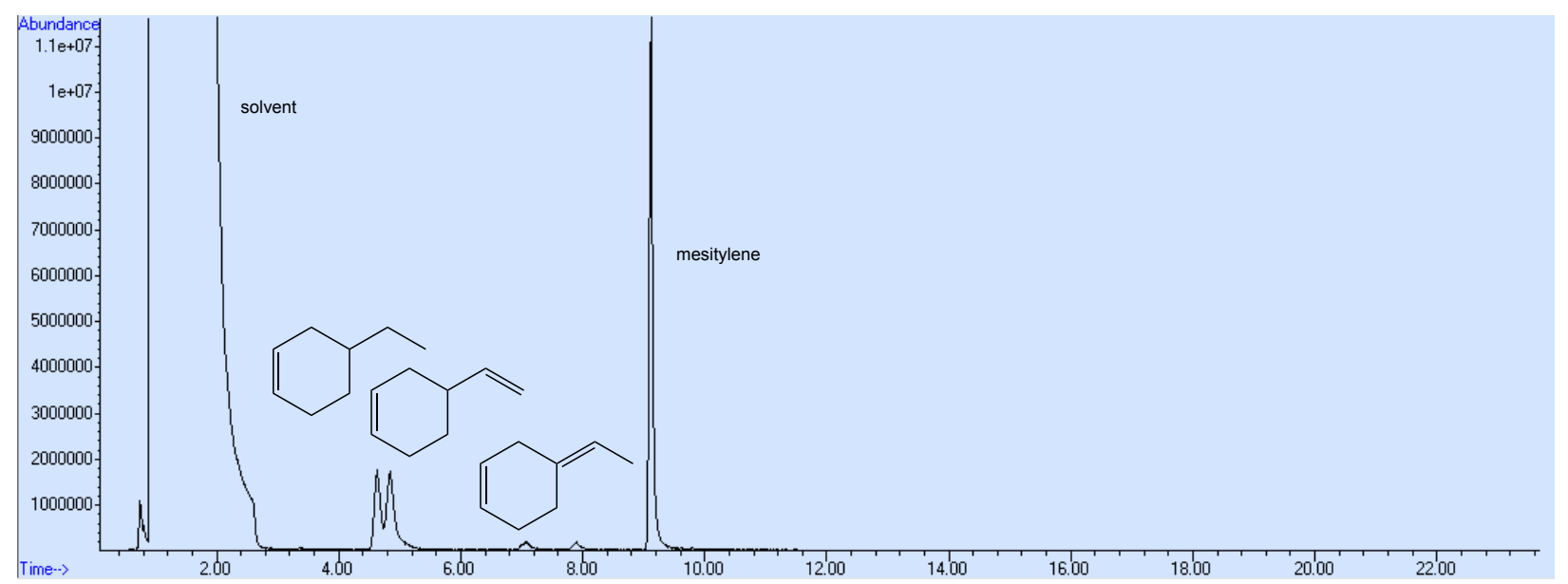

Figure S110. GC-MS trace of crude product formed from the hydrogenation of 4vinylcyclohex-1-ene by 1 under thermal conditions. 

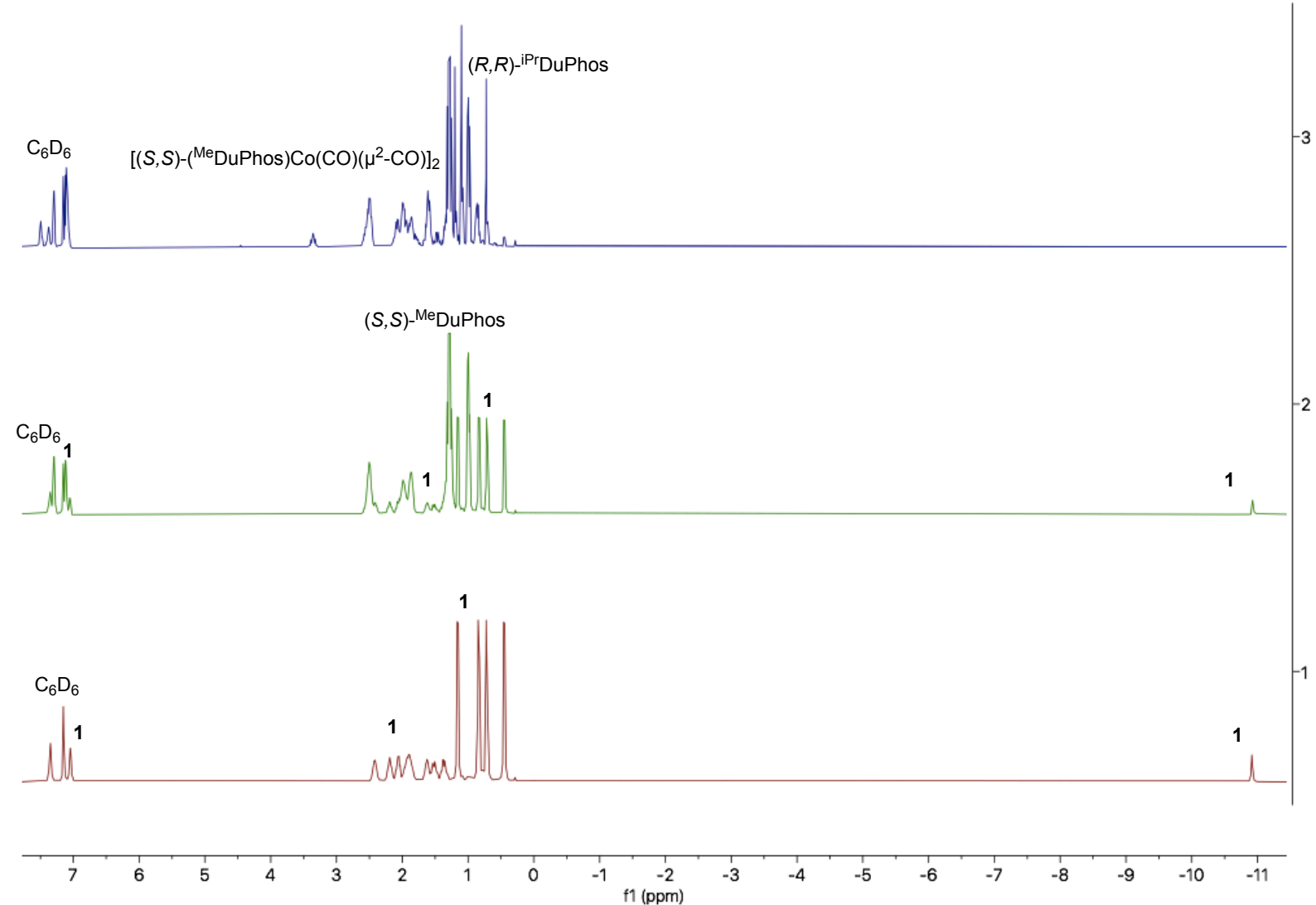

Figure S111. ${ }^{1} \mathrm{H}$ NMR (benzene- $d_{6}$, rt) spectrum of 1 (red); a mixture of $(S, S)$ - ${ }^{\text {MeDuPhos }}$ and 1 under dark, room temperature conditions (green); and a mixture of $[(S, S)$ (Me DuPhos) $\left.\mathrm{Co}(\mathrm{CO})\left(\mu^{2}-\mathrm{CO}\right)\right]_{2}$ and $(R, R)^{-}{ }^{\text {PrrDuPhos }}$ generated after blue light irradiation (blue). 
Figure S112. ${ }^{31} \mathrm{P}$ NMR (benzene- $d_{6}$, rt) spectrum of 1 (red); a mixture of $(S, S)$ MeDuPhos and 1 under dark, room temperature conditions (green); and a mixture of

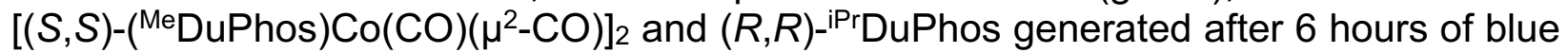
light irradiation under $\mathrm{N}_{2}$ (blue). 


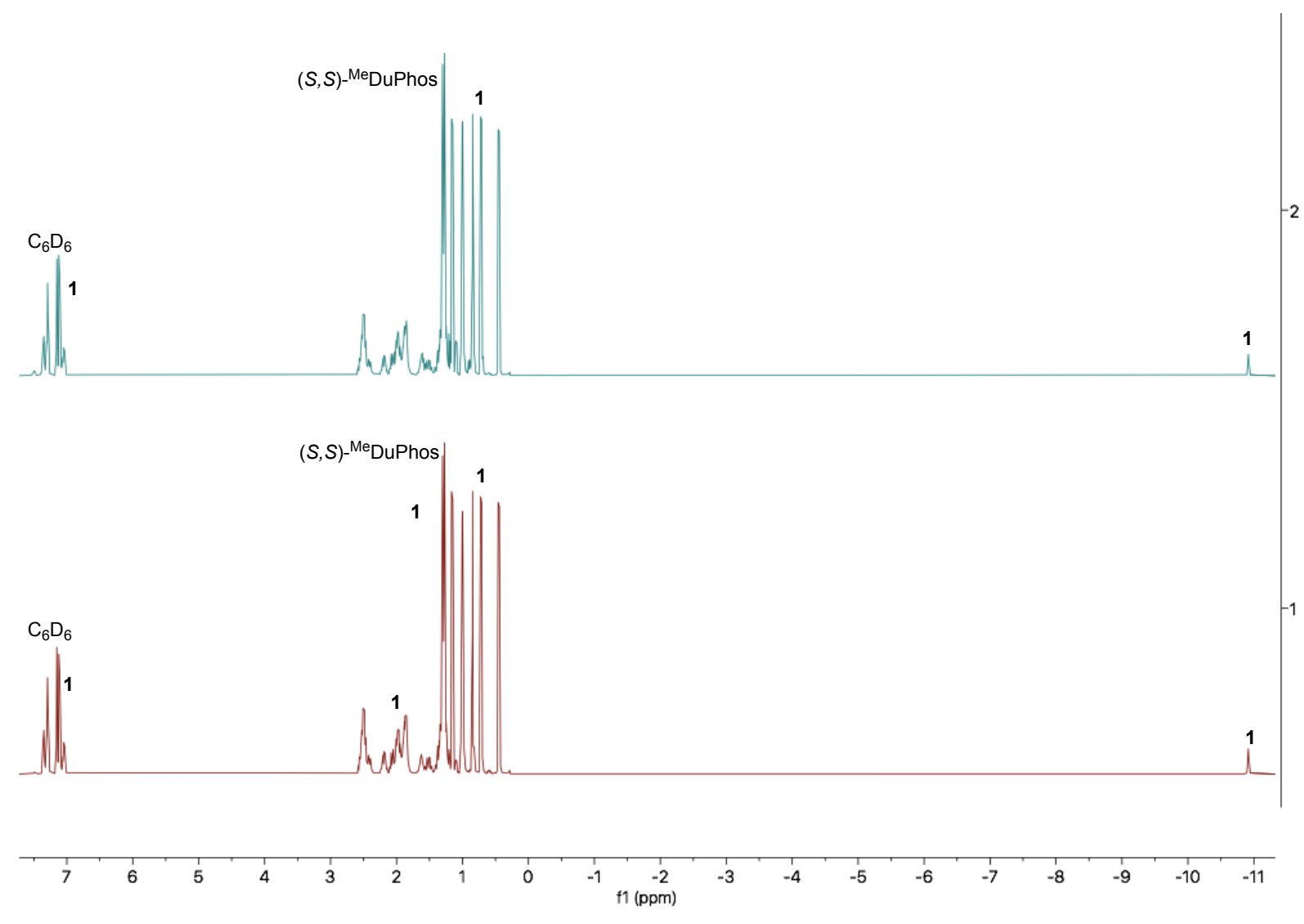

Figure S113. ${ }^{1} \mathrm{H}$ NMR (benzene- $d_{6}$, rt) spectrum of a mixture of $(S, S)-{ }^{M e}$ DuPhos and 1 under dark, room temperature conditions (red); and a mixture of $(S, S)$-MeDuPhos and 1 with only trace conversion to $\left[(S, S)-\left({ }^{\mathrm{Me}} \mathrm{DuPhos}\right) \mathrm{Co}(\mathrm{CO})\left(\mu^{2}-\mathrm{CO}\right)\right]_{2}$ and $(R, R)^{-{ }^{\mathrm{iPr}} \mathrm{DuPhos}}$ after 6 hours of irradiation by blue light under $1 \mathrm{~atm}$ of $\mathrm{CO}$ (turquoise). 


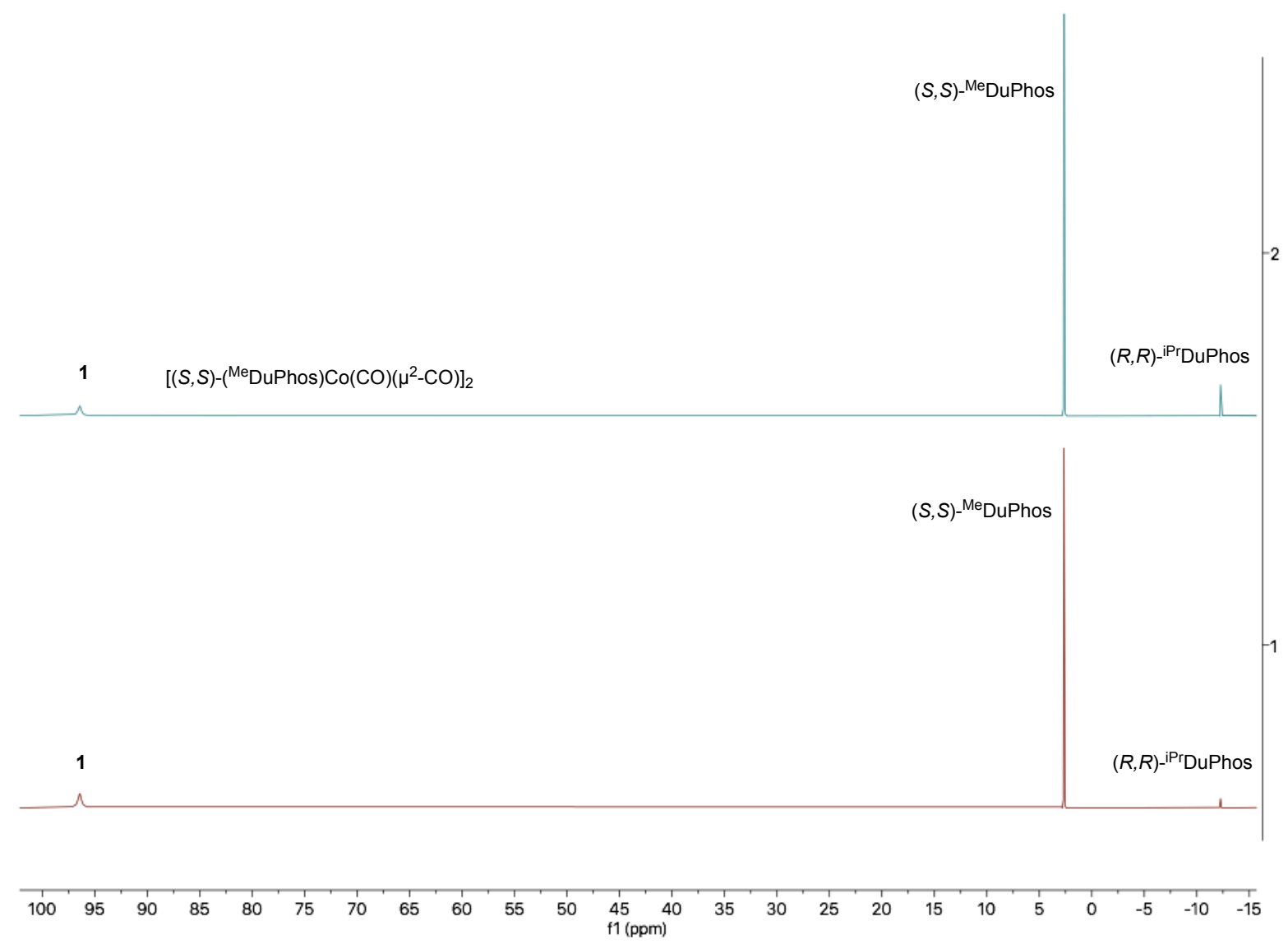

Figure S114. ${ }^{31} \mathrm{P}$ NMR (benzene- $d_{6}$, rt) spectrum of a mixture of $(S, S)$-MeDuPhos and 1 under dark, room temperature conditions (red); and a mixture of $(S, S)$-MeDuPhos and 1 with only trace conversion to $\left[(S, S)-\left({ }^{\mathrm{Me}} \mathrm{DuPhos}\right) \mathrm{Co}(\mathrm{CO})\left(\mu^{2}-\mathrm{CO}\right)\right]_{2}$ and $(R, R)^{-{ }^{\mathrm{iPr}} \mathrm{DuPhos}}$ after 6 hours of irradiation by blue light under $1 \mathrm{~atm}$ of $\mathrm{CO}$ (turquoise). 

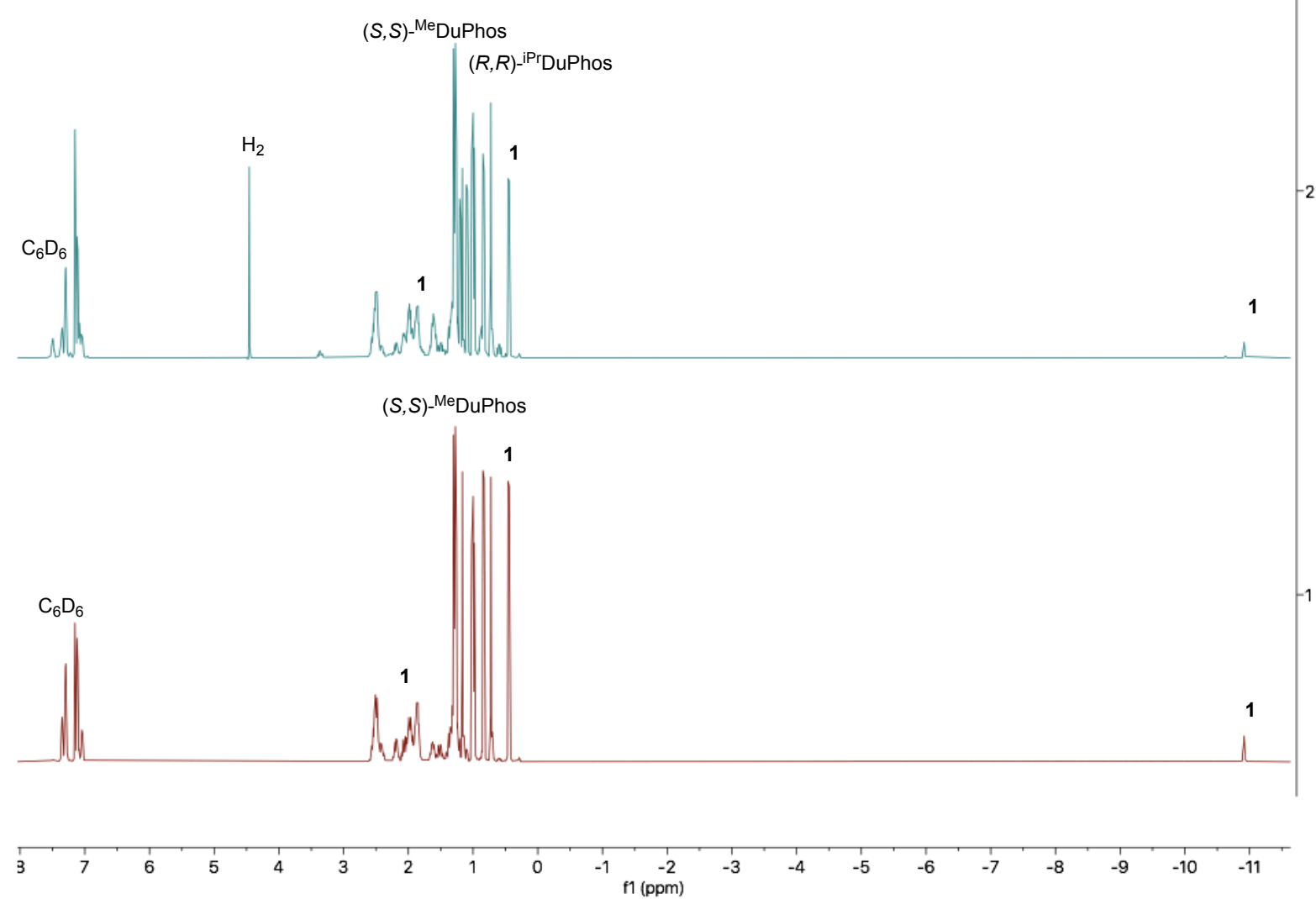

Figure S115. ${ }^{1} \mathrm{H}$ NMR (benzene- $d_{6}$, rt) spectrum of a mixture of $(S, S)-{ }^{M e}$ DuPhos and 1 under dark, room temperature conditions (red); and a mixture of $(S, S){ }^{-M e D u P h o s, ~} 1$, $\left[(S, S)-\left({ }^{M e} \text { DuPhos }\right) \mathrm{Co}(\mathrm{CO})\left(\mu^{2}-\mathrm{CO}\right)\right]_{2}$ and $(R, R)^{\text {iPr }}$ DuPhos after 6 hours of irradiation by blue light under 4 atm of $\mathrm{H}_{2}$ (turquoise). 


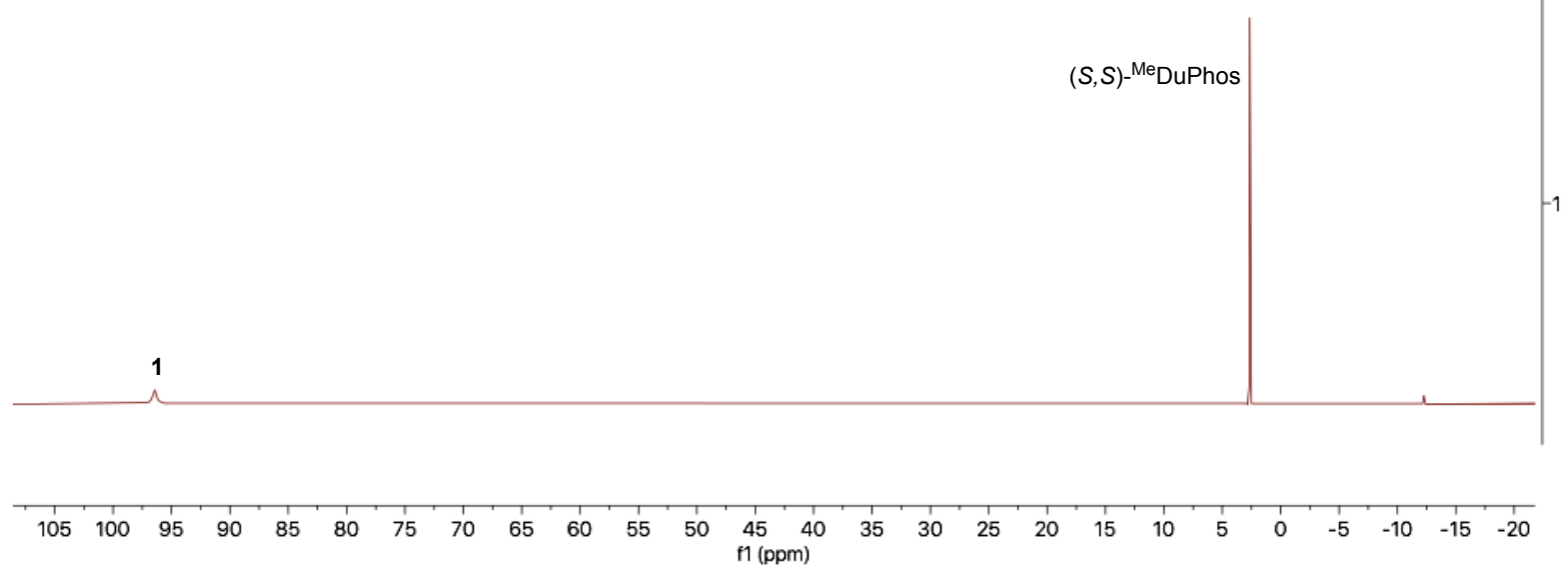

Figure S116. ${ }^{31} \mathrm{P}$ NMR (benzene- $d_{6}$, rt) spectrum of a mixture of $(S, S)-{ }^{-M e}$ DuPhos and 1 under dark, room temperature conditions (red); and a mixture of $(S, S)^{-{ }^{M e} D u P h o s, 1}$,

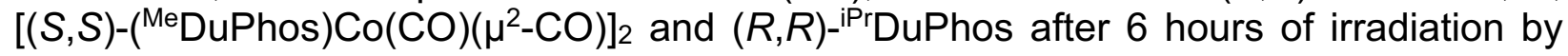
blue light under $4 \mathrm{~atm}$ of $\mathrm{H}_{2}$ (turquoise). 

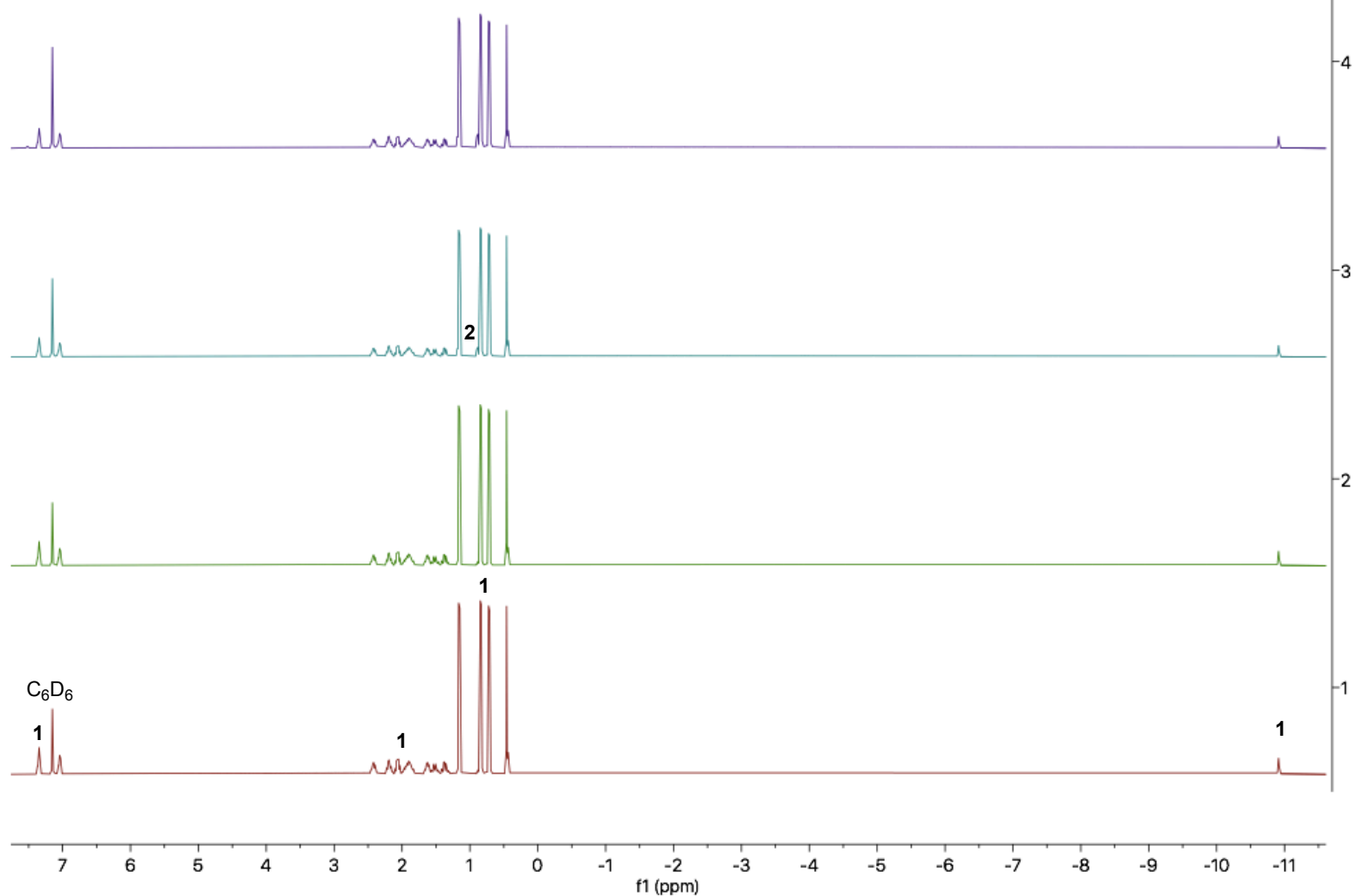

Figure S117. ${ }^{1} \mathrm{H}$ NMR (benzene- $d_{6}, \mathrm{rt}$ ) spectrum of a sample of 1 after exposure to green LED (red,1), blue LED with $475 \mathrm{~nm}$ bandpass filter (green,2), blue LED with 420 $\mathrm{nm}$ bandpass filter (turquoise,3), and blue LED (purple,4) for one hour each. 


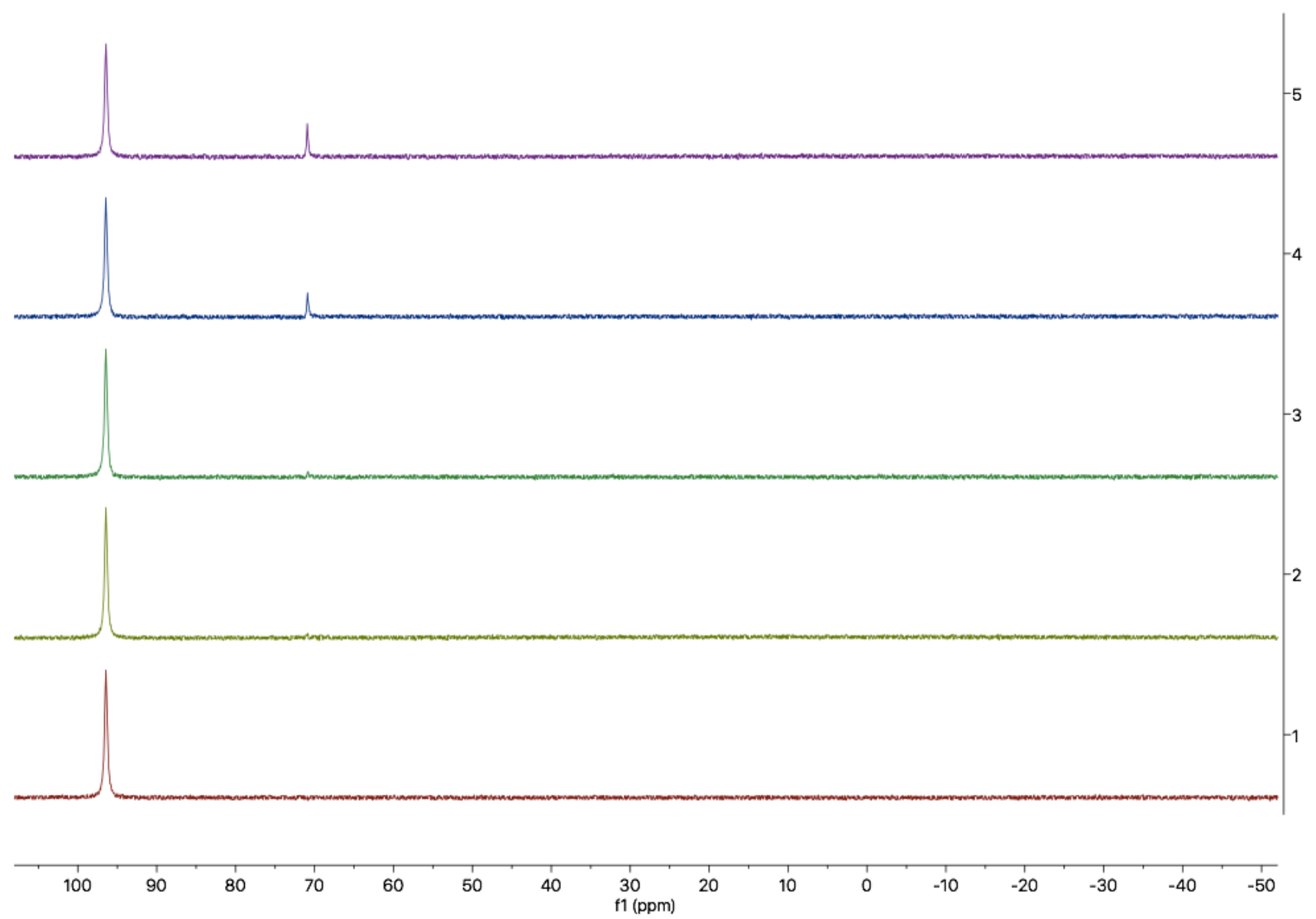

Figure S118. ${ }^{31} \mathrm{P}$ NMR (benzene- $d_{6}$, rt) spectrum of a sample of 1 in the dark (red,1) and after exposure to green LED (green,2), blue LED with $475 \mathrm{~nm}$ bandpass filter (turquoise,3), blue LED with $420 \mathrm{~nm}$ bandpass filter (blue,4), and blue LED (purple,5) for one hour each. 

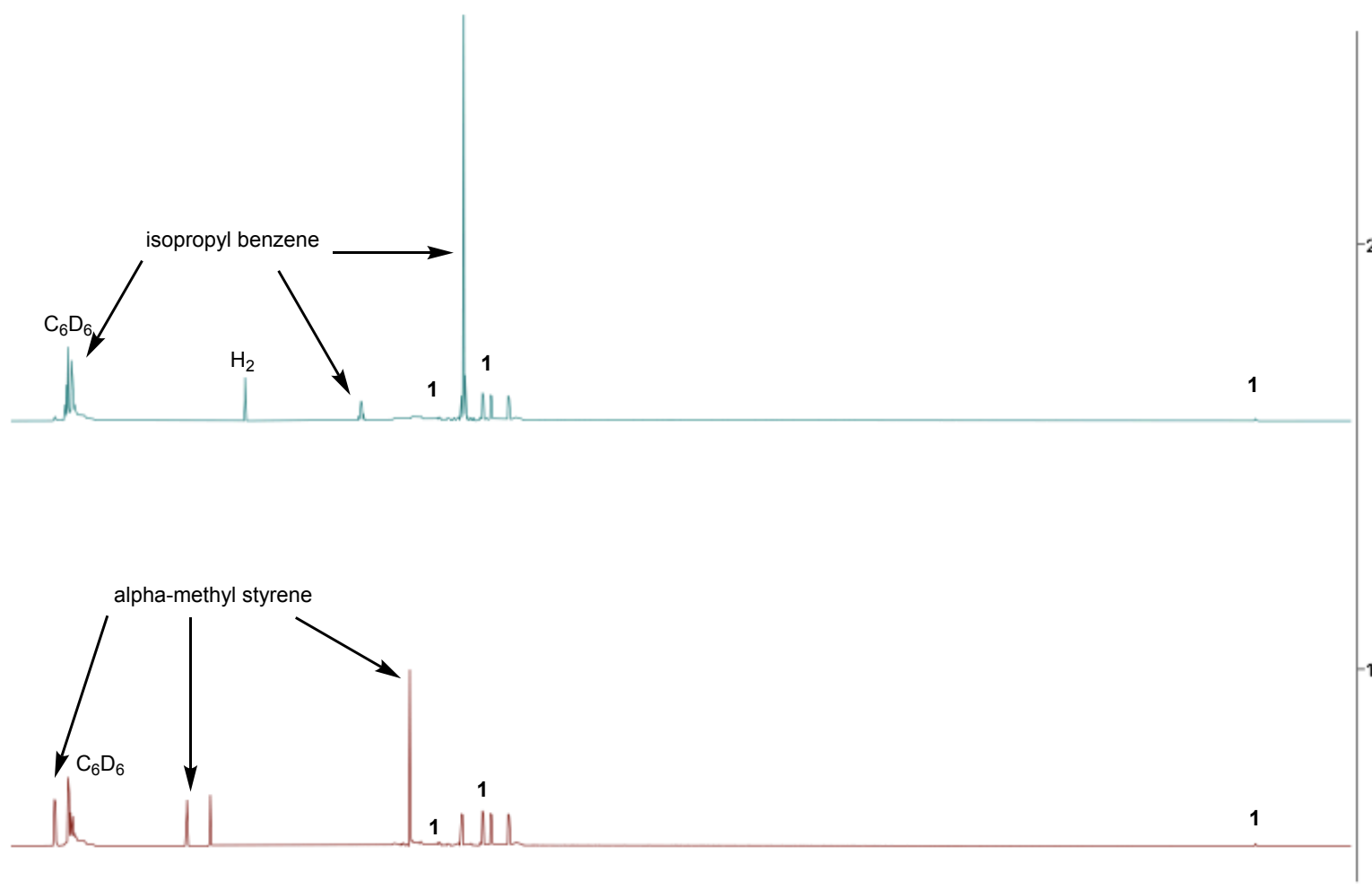

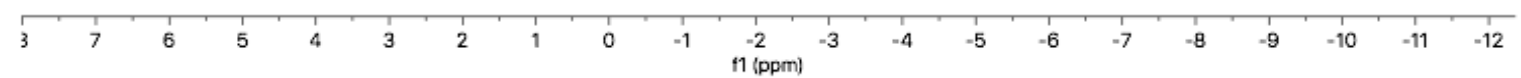

Figure S119. ${ }^{1} \mathrm{H}$ NMR (benzene- $d_{6}$, rt) spectra of 1 and $\alpha$-methyl styrene before $(r e d, 1)$ and hydrogenation under blue light irradiation (turquoise,2). 

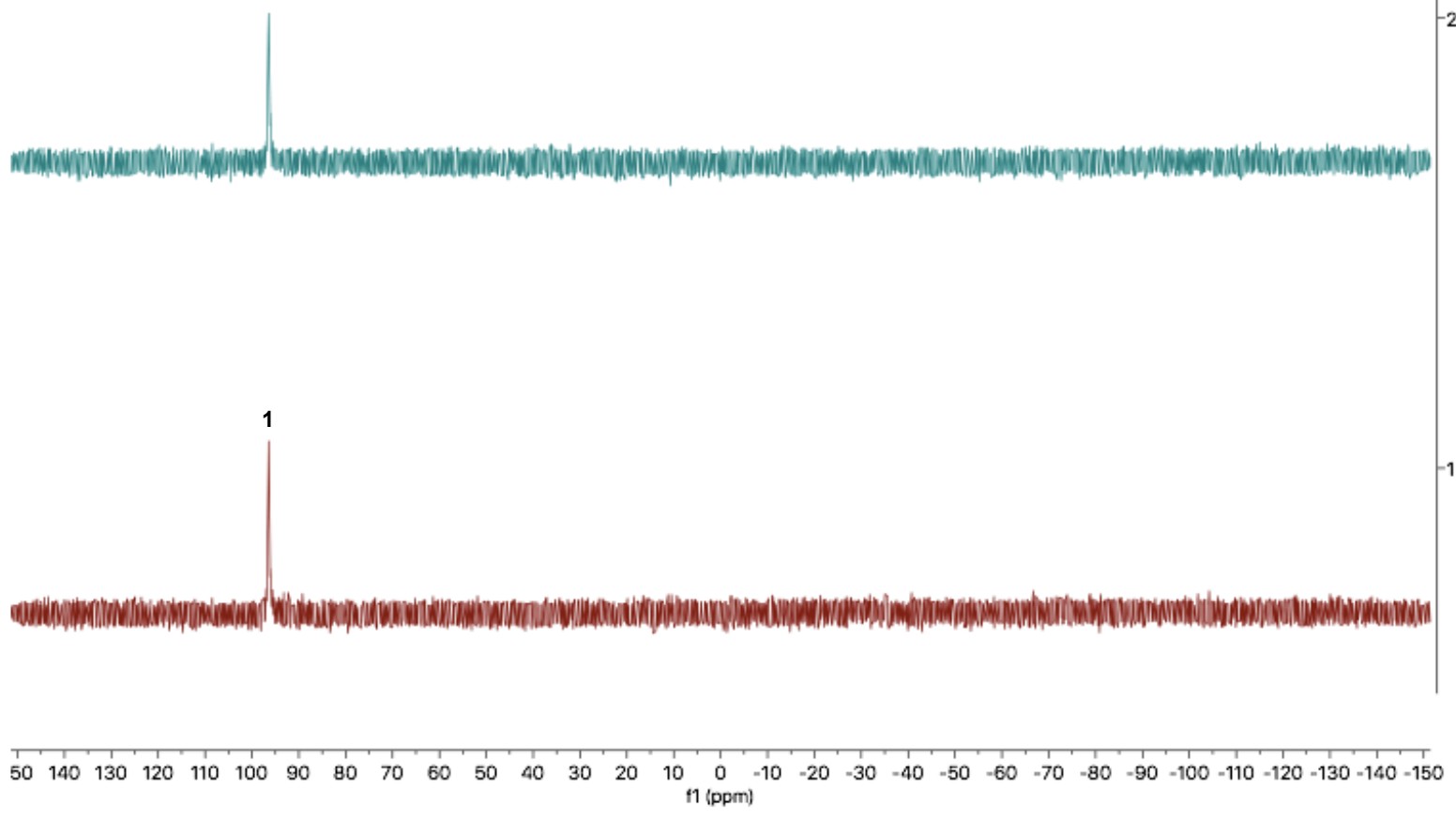

Figure S120. ${ }^{31} \mathrm{P}$ NMR (benzene- $d_{6}$, rt) spectra of 1 and $\alpha$-methyl styrene before $(\mathrm{red}, 1)$ and hydrogenation under blue light irradiation (turquoise,2). 


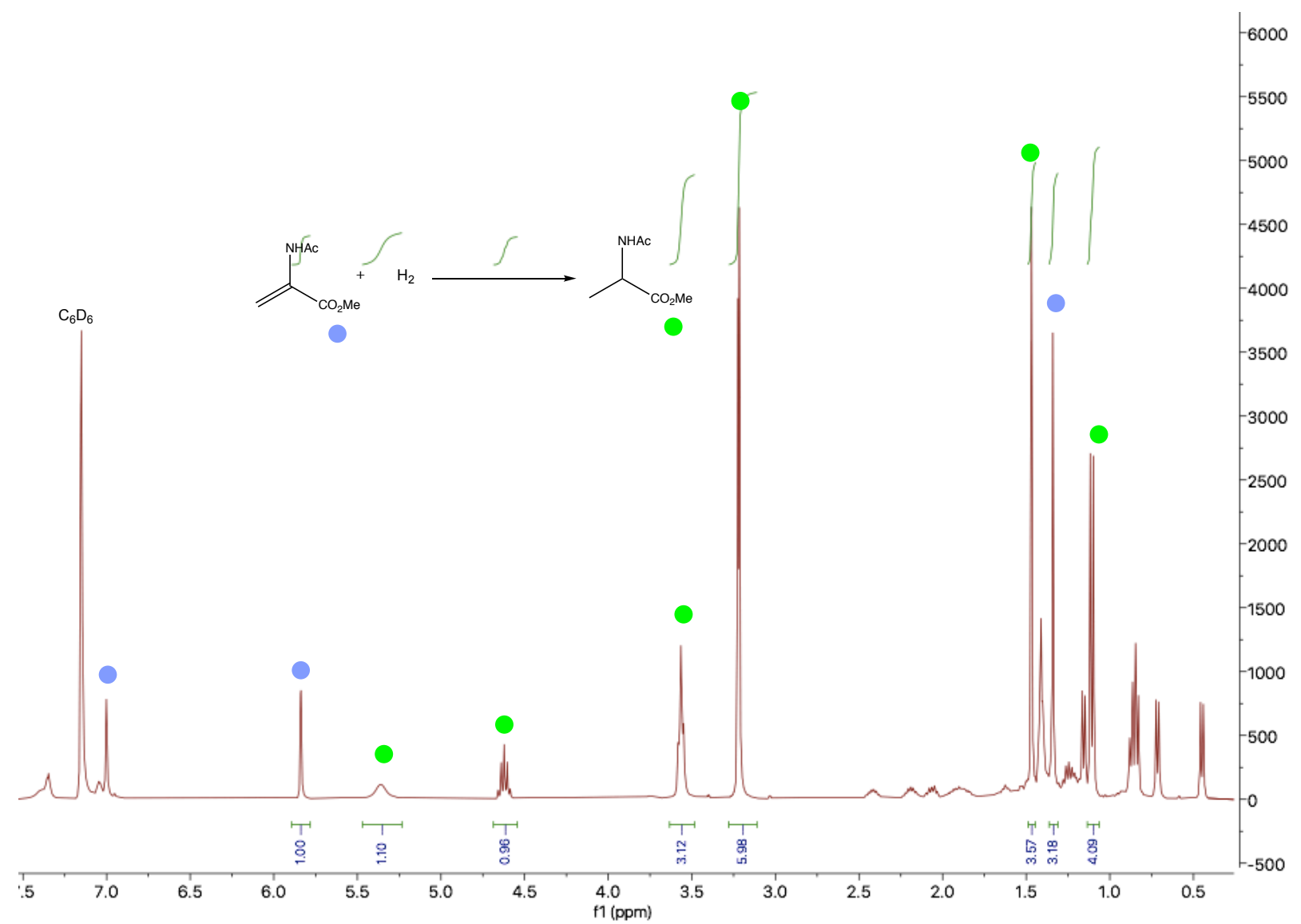

Figure S121. ${ }^{1} \mathrm{H}$ NMR (benzene- $d_{6}$, rt) spectrum of crude product formed from the hydrogenation of MAA in a pentane/THF (2:1) mixture by 1 using a UV irradiation box (Rayonet) cooled with water. 


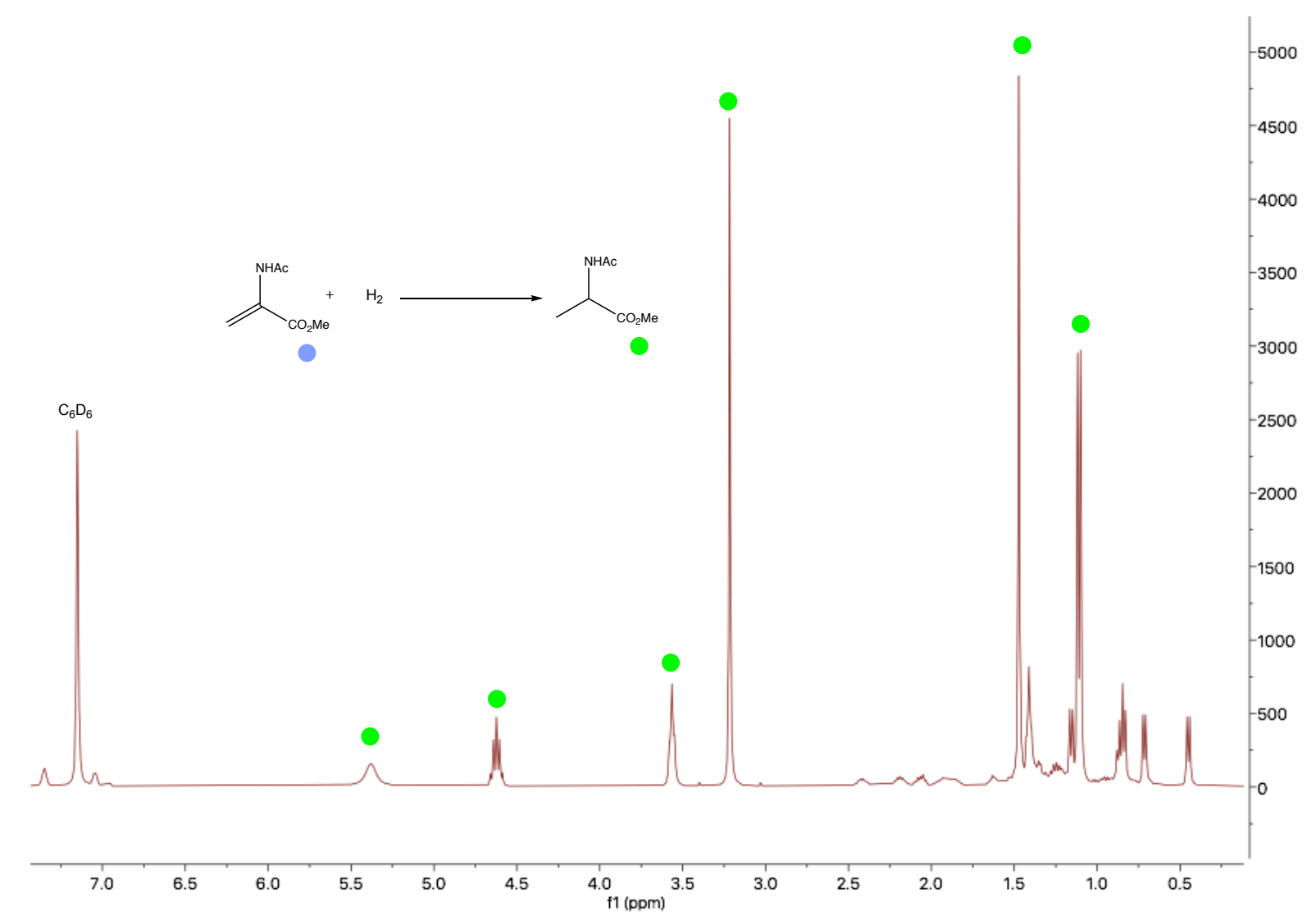

Figure S122. ${ }^{1} \mathrm{H}$ NMR (benzene- $d_{6}$, rt) spectrum of crude product formed from the hydrogenation of MAA in a pentane/THF (2:1) by 1 under blue light conditions. 


\section{References}

(1) Pangborn, A. B.; Giardello, M. A.; Grubbs, R. H.; Rosen, R. K.; Timmers, F. J. Safe and Convenient Procedure for Solvent Purification. Organometallics 1996, 15.

(2) Zhong, H.; Friedfeld, M. R.; Camacho-Bunquin, J.; Sohn, H.; Yang, C.; Delferro, M.; Chirik, P. J. Exploring the Alcohol Stability of Bis(Phosphine) Cobalt Dialkyl Precatalysts in Asymmetric Alkene Hydrogenation. Organometallics 2019, 38 (1), 149-156.

(3) Chirik, P. J.; MacNeil, C.; Zhong, H.; Pabst, T.; Mendelsohn, L. Synthesis and Reactivity of Organometallic Intermediates Relevant to Cobalt-Catalyzed Hydroformylation. Angew. Chem., Int. Ed. 2020, 59, 8912-8916.

(4) Shields, B. J.; Kudisch, B.; Scholes, G. D.; Doyle, A. G. Long-Lived ChargeTransfer States of Nickel(II) Aryl Halide Complexes Facilitate Bimolecular Photoinduced Electron Transfer. J. Am. Chem. Soc. 2018, 140(8), 3035-3039.

(5) Bydder, M.; Rahal, A.; Fullerton, G. D.; Bydder, G. M. The Magic Angle Effect: A Source of Artifact, Determinant of Image Contrast, and Technique for Imaging. J. Magn. Reson. Imaging 2007, 25 (2), 290-300.

(6) Frisch, M. J. et al. Gaussian 09, Revision D.01. Gaussian, Inc.: Wallingford, CT 2013.

(7) Perdew, J. P. Density-Functional Approximation for the Correlation Energy of the Inhomogeneous Electron Gas. Phys. Rev. B 1986, 33, 8822-8824.

(8) Perdew, J. P. Erratum: Density-Functional Approximation for the Correlation Energy of the Inhomogeneous Electron Gas. Phys. Rev. B 1986, 34, 7406.

(9) Lee, C. T.; Yang, W. T.; Parr, R. G. Development of the Colle-Salvetti CorrelationEnergy Formula into a Functional of the Electron Density. Phys. Rev. B 1988, 37, 785-789.

(10) Schäfer, A.; Horn, H.; Ahlrichs, R. Fully Optimized Contracted Gaussian Basis Sets for Atoms Li to Kr. J. Chem. Phys. 1992, 97, 2571-2577.

(11) Schäfer, A.; Huber, C.; Ahlrichs, R. Fully Optimized Contracted Gaussian Basis Sets of Triple Zeta Valence Quality for Atoms Li to Kr. J. Chem. Phys. 1994, 100, 5829-5835.

(12) Weigend, F.; Ahlrichs, R. Balanced Basis Sets of Split Valence, Triple Zeta Valence and Quadruple Zeta Valence Quality for $H$ to Rn: Design and Assessment of Accuracy. Phys. Chem. Chem. Phys. 2005, 7, 3297-3305. 
(13) Barone, V.; Cossi, M. Quantum Calculation of Molecular Energies and Energy Gradients in Solution by a Conductor Solvent Model. J. Phys. Chem. A 1998, 102 (11), 1995-2001.

(14) Cossi, M.; Rega, N.; Scalmani, G.; Barone, V. Energies, Structures, and Electronic Properties of Molecules in Solution with the C-PCM Solvation Model. J. Comput. Chem. 2003, 24 (6), 669-681.

(15) Wang, D.; Loose, F.; Chirik, P. J.; Knowles, R. R. N-H Bond Formation in a Manganese(V) Nitride Yields Ammonia by Light-Driven Proton-Coupled Electron Transfer. J. Am. Chem. Soc. 2019, 141 (12), 4795-4799.

(16) Hatchard, C. G.; Parker, C. A. A New Sensitive Chemical Actinometer II . Potassium Ferrioxalate as a Standard Chemical Actinometer. Proceedings of the Royal Society of London. Series A, Mathematical and Physical Sciences. 1956, $235,518-536$.

(17) Cismesia, M. A.; Yoon, T. P. Characterizing Chain Processes in Visible Light Photoredox Catalysis. Chem. Sci. 2015, 6, 5426-5434.

(18) Morris Bullock, R.; Samsel, E. G. Hydrogen Atom Transfer Reactions of Transition-Metal Hydrides. Kinetics and Mechanism of the Hydrogenation of $\alpha-$ Cyclopropylstyrene by Metal Carbonyl Hydrides. J. Am. Chem. Soc. 1990, 112 (19), 6886-6898.

(19) Tsunoda, T.; Hudlicky, T. Practical Synthesis of Vinylcyclopropane. Synlett 1990, 322.

(20) Wiedner, E. S.; Chambers, M. B.; Pitman, C. L.; Bullock, R. M.; Miller, A. J. M.; Appel, A. M. Thermodynamic Hydricity of Transition Metal Hydrides. Chem. Rev. 2016, 116 (15), 8655-8692.

(21) Solis, B. H.; Hammes-Schiffer, S. Substituent Effects on Cobalt Diglyoxime Catalysts for Hydrogen Evolution. J. Am. Chem. Soc. 2011, 133 (47), 1903619039.

(22) Chen, S.; Rousseau, R.; Raugei, S.; Dupuis, M.; DuBois, D. L.; Bullock, R. M. Comprehensive Thermodynamics of Nickel Hydride Bis(Diphosphine) Complexes: A Predictive Model through Computations. Organometallics 2011, 30 (22), 61086118.

(23) Qi, X. J.; Liu, L.; Fu, Y.; Guo, Q. X. Ab Initio Calculations of PKa Values of Transition-Metal Hydrides in Acetonitrile. Organometallics 2006, 25 (25), 58795886. 
(24) Chen, S.; Ho, M. H.; Bullock, R. M.; Dubois, D. L.; Dupuis, M.; Rousseau, R.; Raugei, S. Computing Free Energy Landscapes: Application to Ni-Based Electrocatalysts with Pendant Amines for $\mathrm{H}_{2}$ Production and Oxidation. ACS Catal. 2014, 4 (1), 229-242.

(25) Heiden, Z. M.; Lathem, A. P. Establishing the Hydride Donor Abilities of Main Group Hydrides. Organometallics 2015, 34 (10), 1818-1827.

(26) Ungváry, F. Kinetics and Mechanism of the Reaction between Dicobalt Octacarbonyl and Hydrogen. J. Organomet. Chem. 1972, 36 (2), 363-370.

(27) Parker, V. D.; Tilset, M. Solution Homolytic Bond Dissociation Energies of Organotransition-Metal Hydrides. J. Am. Chem. Soc. 1989, 111 (17), 6711-6717. 